Próduchonand devationg
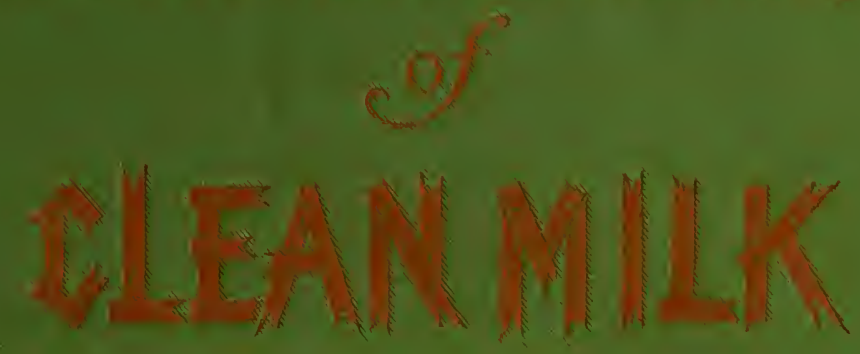

5

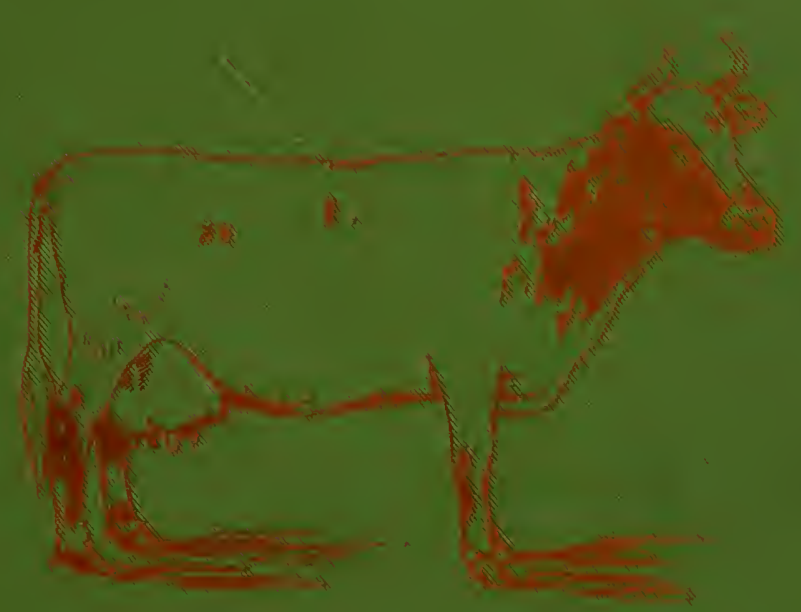

hy BENELM WMESLOW 
\% 





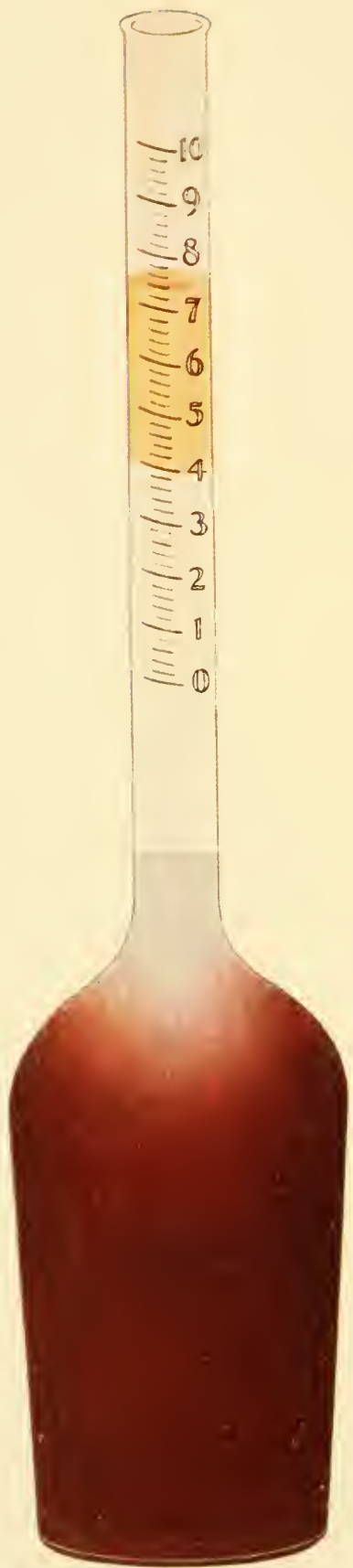

Babcock Flask, Showing Fat in Neck (after Harrington) (Frontispiece) 


\title{
THE
}

\section{PRODUCTION AND HANDLING}

\author{
$\cap F$ \\ CLEAN MILK
}

BY

KENELM IVINSLOW, M.D.; M.D.V.; B.A.S. (Harv.)

Formerly Instructor in Bussey Agriculuural Institute and Assistant Professor in the Veterinary School of Harvard University.

Author of a text book on Veterinary Materia Medica and Therapentics, Chairman of the Committee on Milk. of the Washington Slate

Medical Association, etc.

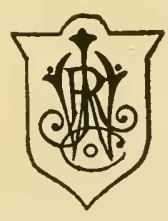

$\vdots \vdots 0$

New YORK

WILLIAM R. JENKINS CO.

PUBLISHERS

85I-853 SixTh AVEnue 


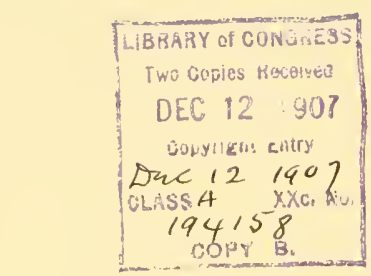

\section{Copyright, 1907 \\ By Wilitiam R. Jenkins Co. \\ All righls reserved \\ [Registered at Stationers' Hall, London] \\ Printed in the United States of America}

$$
\because \vdots \vdots
$$

PRINTED BY THE

PRESS OF W'ilitaM R. JENKINS Co.

VEW YORK 


\section{PREFACE}

The writer is a graduate in agricultural science, in veterinary and human medicine, and has been connected with a laboratory in which is examined the milk supply of a large city, and finally has had considerable practical experience in the production and distribution of clean milk.

These facts are simply mentioned to show that the book is written from various points of view.

Much blame is attached to sundry persons engaged in vending milk, but the unfortunate farmer is apt to receive an unjust share because of the commonly unclean and therefore unsanitary condition of most market milk. While city contractors and dealers may have much influence in instructing and requiring the farmer to live up to recognized standards of cleanliness, yet, after all, the chief responsibility lies with the consumer. The essential object in the clean milk crusade should be to awaken the public to the dangers of unclean milk and to emphasize the fact that it is impossible to produce and obtain clean milk except at unusual expense.

When the public is sufficiently aroused to the evils of consuming unclean milk and evinces willingness to pay_for clean milk, there will be no difficulty about its production. It is merely a question of supply and demand. 
It is not generally known that the farmer sometimes receives but one-quarter of the retail price of milk (frequently but 2 cents a quart), and he can hardly be expected to undertake a considerably increased expenditure for the production of clean milk-this being the case.

There is probably more interest being shown in this and other countries in a pure milk supply than ever before. For this reason it should be a comparatively easy task for any individual desiring to produce clean milk in any considerable community to find a sufficient patronage, particularly if the local medical profession is asked to assist, always providing that the proper standard is constantly and conscientiously maintained. The idea of financial return must be subordinated to this, and yet a reasonable profit can and must be had to sustain the required standard.

The aim of this book is to provide a working guide for those pursuing or wishing to pursue one of the most wholesome, worthy and laudable undertakings-the production of clean milk.

Most of the books at our command either touch the subject in a general manner or else describe special phases of it in detail. The attempt has here been made to cover the whole ground in as small compass as possible. That such an attempt must fall short the author is aware, as the topic of feeding cows alone (accorded but a chapter in this book) can only be fully treated in a large volume devoted wholly to this subject.

Objection may be made to the recommendation of particular apparatus of certain manufacturers. But the 
writer has been so desirous of making the book practical that it has been deemed essential to choose special appliances in order to avoid generalities and vagueness.

While endeavoring to select the best, it does not follow that other appliances are not as good, or even better than those advised; but the author can truthfully affirm that both he and his publisher are entirely free from the remotest financial interest in advertising any special dairy appliances. Such appliances are undergoing the most wonderful and rapid improvement, almost from day to day.

Kenelm Winslow. 



\section{CONTENTS}

CHAP.

PAGE

I. Germs in their General Reilation to Milk . . i

II. Composition of Milk and Creali and Their ProDUCTS . . . . . . . . . . . . 23

III. MrLK Products . . . . . . . . . . . 33

IV. FEEDING FOR MiLK . . . . . . . . . . . 46

V. Housing and Care of Cows . . . . . . 57

VI. Handling of Milk and CrFan . . . . . . 7 I

ViI. Cost of Producing and Distributing Clean Milik i io

VIII. Some Hints Concerning Milk Distribution • - I25

IX. Milk Inspection . . . . . . . . . . . I34

Appendix-Plans of Barns, Milk Houses, eitc. . . . I69

General, Outhine of a Scheme for the Control, Super-

Vision AND INSPeCtion of a City Milk Supply . . ig8

$\mathrm{INDEX}$. . . . . . . . . . . . . . 203 



\section{LIST OF ILLUSTRATIONS}

Frontispiece

Fig.

Page

I General Shape of Bacteria . . . . . . . 4

2 The Constituent Elements of Milk-Fat, Serum, Casein . 24

Sketcl A-Two methods of ventilating a Dairy Farm . . 62

Sketch B-Method of ventilating a Lean-to Stable . . 63

Sketch C-Section of the Cow Stable of the Dairy Barn at the Wisconsin Experiment Station . . . • 64

3 Iron Milking Stool . . . . . . . . 72

3A The Gurler Milk Pail . . . . . . . . 73

3B A Recent Improvement on the Gurler Milk Pail . 73

$3 \mathrm{C}$ Modification of Stewart's Milk Pail . . . . . 74

4 The Conical Cooler . . . . . . . . 79

5 Star Cooler. . . . . . . . . . . 80

6 Tubular Cooler . . . . . . . . . . . 80

7 Star Cooler. . . . . . . . . $8 \mathrm{I}$

8 Star Cooler. . . . . . . . . . . . 82

9 Star Cooler . . . . . . . . . . . 83

Io Trap Milk Strainer . . . . . . . . . . 84

I I Wash Sink . . . . . . . . . . . 86

I 2 Various Forms of Brushes . . . . . . . 87

I 3 Milk-Can Jacket . . . . . . . . . . 88

14 Star Side-Bar Filler . . . . . . . . 89

I 5 Star High-Pressure Cylinder . . . . . . . 90

16 Star Sterilizer . . . . . . . . . . 92

I7 Bottle Brush . . . . . . . . . . 93

I8 Star Metal Wash Sink . . . . . . . . 94

I9 Star Bottle-Washing Outfit . . . . . . . 95

20 Steam Heating Tee . . . . . . . . . 95 
Fig.

Page

2 I Glass Dairy Thermometer . . . . . . . 96

22 Machine for Chopping Ice used to pack about milk bottles . 97

23 Banjo Conductor for carrying milk through a wall . . 98

24 Cylinder for conveying milk through a floor . . . . 99

25 Cream Cooler connected with Separator . . . . 100

26 Creanı Bottle Filler . . . . . . . . I I I

27 Bottle Carriers . . . . . . . . . 102

28 Car for conreying Carriers and Bottles . . . . . 103

29 Car for conveying Carriers and Bottles . . . . 104

30 Wagon Box for carrying bottles on ice . . . . 105

3 I Star Milk Bottles . . . . . . . . 106

32 Hand Separator for separating cream from milk . . . 107

33 Milk Wagon . . . . . . . . . I 26

34 Milk Wragon . . . . . . . . . . I 27

35 Delivery Basket . . . . . . . . 128

36 Small Babcock Machine, with other necessary paraphernalia I 42

37 Eight-Bottle Babcock Machine . . . . . . I 43

38 Power Babcock Machine . . . . . . . . 143

39 Pipette for making the Babcock test . . . . . I 44

40 Shows method of introducing milk into Babcock bottle with pipette in making the fat test . . . . . I 45

4 I I cc. Pipettes enclosed in tubes for sterilizing . . . . I 49

42 Flasks and Vials for quantitative bacteriological analysis . I50

43 Two Burettes arranged for neutralizing culture media. . I 52

44 Petri Dishes . . . . . . . . . I53

45 Sketch showing ground plan of milk house owned by J. D. Farrell, Esq. . . . . . . . . I 79

t6 Rougl sketch of ground plan of barn for forty cows (W. H. Paulhamus, Esq.) . . . . . I 8 I

47 Rough sketch of ground plan of milk house (W. H. Paulliamus, Esq.) . . . . . . . 183 


\section{PLATES}

Page

I Yeksa Sunbeam (Guernsey) . . . . . follows I 70

II Shadybrook Gerben (Holstein) . • • . " " 170

III Pansy of Woodroffe (Ayrshire) . . . . “ “ 172

IV Loretta D. (Jersey) • • • . . . “ “ 172

V Stable (J. D. Farrell, Esq.) . . . . “ “ 178

VI Stable (J. D. Farrell, Esq.) . . . . “ “

VII Wash Room (J. D. Farrell, Esq.) . . . “ “

VIII Milk Room (J. D. Farrell, Esq.) . • . “ “ I80

IX Interior of the Paulhamus Barn . . . . " " I80

$\mathrm{X}$ Bottle-washing Machine at the Paulhamus Farm “ 182

XI Concrete and Cement Sterilizer, " " " 184

XII The Improved “Drown” Stall . • . . “ “ 186

XIII The Burrell-Lawrence-Kennedy Cow Milker . “ “ 88

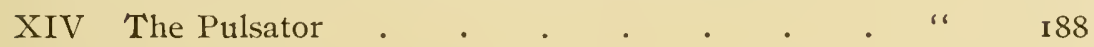

$\mathrm{XV}$ Illustrating the Hegelund method of milking . " 192

D Dipper and Siphon for removing cream and milk respectively . : . . . . . " 132

$\mathrm{T}$ Colonies or collections of germs . . . . . . 456 



\section{CHAPTER I}

\section{GERMS IN THEIR GENERAL RELATIONS TO MILH}

\section{$\mathrm{T}$}

HE object of this book is to show the importancenay, even necessity - of a clean milk production, and the practical methods by which it may be obtained. Heretofore milk has been regarded much in the same light as other articles of food, but it differs from them in many important respects. It is the only animal food which is commonly eaten in the raw state, and it forms the sole diet for human beings at an immature age, when they are least able to cope with the disorders which contaminated and dirty milk is liable to produce. Again-and this is the chief reason why milk needs especial care in its production-it always contains more or less germs, and, indeed, forms one of the most favorable foods on which germs grow.

The common idea of germs appears to be that they are chiefly important in being the cause of disease, and while some germs do produce disease-and occasionally those inhabiting milk which has not been properly cared for-yet they mainly interest the farmer on account of their powerful and enormous influence upon milk and its products. The chief aim of this book is to enforce on the farmer and dairyman this one fact, that the One Essential in producing and handling milk is Cleanliness, and cleanliness means in this connection freedom from germs, so far as this is possible. 
It would scarce be an exaggeration to say that ali the trouble which arises in the endeavor to secure good milk or milkproducts results from the contamination of milk with undesirable germs. Thus the proper taste, odor, color, consistency and keeping qualities of milk depend upon its comparative freedom from undesirable germs. Conversely, the souring of milk and faults in odor, color, consistency and taste depend almost wholly upon the presence of one or more varieties of germs.

Moreover, the prevention of contamination of milk with miscellaneous germs is just as important in order to make the best products from milk, as it is to avoid disease in man. Thus the finest cream is only produced from milk in which germs are comparatively absent. Cream laden with miscellaneous germs has bad keeping qualities and often a faulty taste or odor. Most of the so-called faults of butter arise not from improper feeding of cows or from improper making or handling of butter, but from undesirable germs which infest it. Among some of the more common faults of butter are poor flavor, tallowy or oily butter, butter having a bitter, rotten or root-taste like turnips, rancid, mottled and moldy butter, and butter of unusual colors; all of these faults have been proved to be due to the contamination of butter with germs which existed in the milk.

While germs in milk produce changes in cheese which give rise to its proper consistency and flavor, yet it is only a certain type or types of germs which are desirable, and a general pollution of milk with germs of many kinds may wholly unfit milk for cheese making.

It is essential that milk should be pure when employed for condensing, and, although germs are destroyed in the 
process, this is much more readily accomplished if the milk is clean in the beginning and the keeping qualities will be much better. Above all, when milk is sold for general consumption it must be pure-comparatively germ-free-to be wholesome, to bring a good price, to keep, and to fall within the legal requirements which will soon become general throughout this country.

Heretofore, when milk was regarded in the same light as any other food, the law required simply that it should not be adulterated and that it should contain a quantity of food-constituents equivalent to the minimum standard in force. Now, however, it has come to be realized that of the two the cleanliness of the milk is an hundredfold more important than its food value. While a milk poor in fat may mean a certain loss of nutriment to one using it, the contamination of milk with certain germs may be a matter of life and death to the consumer-particularly if an infant. The sooner the farmer and dairyman realize that the secret of success in the making of milk and milk-products is cleanliness-and by cleanliness we mean essentially methods to prevent the entrance of germs into milk-the better will it be for them and for everyone.

Germs, or, as they are more technically termed, bacteria, are the most minute forms of plant life we know. They occur in various shapes, but chiefly in the form of either rods, round cells or spirals. When seen through the microscope they present somewhat the appearance of minute pencils, billiard balls or cork-screws, according as they belong to one or the other of these three types. In masses of thousands they may be visible to the naked eye as specks like mold, but singly they can only be seen with a compound microscope magnifying more than 500 times. The 
most common of all varieties of germs in milk are those which cause it to sour-the lactic acid bacilli (the bacilli are the rod or pencil-shaped germs), and these are about 3-25,000 of an inch long and I-25,000 of an inch broad. Germs grow on vegetable and animal matter, but not in the tissues or cells of living animals or vegetables, although they are found on all parts of them exposed to the air. Germs are, in fact, everywhere--in the air, in water, in soil, on the skin and in the digestive canal of animals and on the sur. face of plants and in dust. Professor Conn has found as many as 200 different kinds of germs in milk alone. Germs

FIG. I.
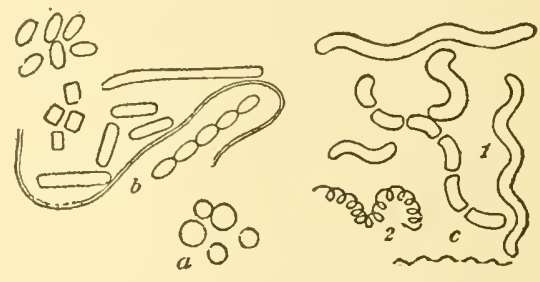

General shape of bacteria. $a$, spheres ; $b$, rods ; $c$, spirals. (After Conn.)

propagate by dividing into two equal parts-more usually -which form new individuals. The time required for a germ to mature and form a new germ may not be more than twenty minutes.

Germs also multiply by spores-that is, small, round or egg-shaped bodies appear within the mature germ and these later break loose and develop, under favorable circumstances, into full-grown germs again. Germs which increase in this manner are much more difficult to kill, for in the spore stage they often defy prolonged heat, even at the boiling temperature, and also cold at or below freezing and dryness, as dust, in $1 ! ' s$ they may exist for years. 
To show the possibilities in the way of multiplication, it has been calculated that a single germ, under favorable circumstances, may within twenty-four hours produce over sixteen millions of progeny.

Germs, however, depend upon certain conditions for their growth; otherwise they would crowd all other life off the globe. Besides organic matter to feed on, the chief circumstances limiting their existence are heat and moisture. Germs usually do not grow at a temperature below $39^{\circ}$ or above $140^{\circ} \mathrm{F}$. Freezing does not necessarily destroy germs-as, for instance, the germs of typhoid fever have remained alive in ice for a period of three months-but this temperature checks their growth and many kinds of germs are killed by it. Ice water is therefore comparatively free from germs. The most favorable temperature for the growth of disease germs is that of the animal body-from $98^{\circ} \mathrm{F}$. to $103^{\circ} \mathrm{F}$. - while most other germs multiply most readily between the temperatures of $59^{\circ} \mathrm{F}$. and $77^{\circ} \mathrm{F}$.

This knowledge is of the greatest importance in the care of milk and teaches us that the chief essential consists in cooling it immediately to a low temperature $-40^{\circ} \mathrm{F}$. to. $50^{\circ} \mathrm{F}$ - - and keeping it at this temperature thereafter till consumed. The number of germs in milk is always estimated as that number contained in a cubic centimeter of milk. A cubic centimeter represents a cube holding a quantity of liquid equivalent to about one-quarter of a teaspoonful, or sixteen drops of water. If milk is kept at below $50^{\circ} \mathrm{F}$. for 24 hours there is not only not an increase but generally a decrease in the number of germs, and the same usually holls good for milk kept 36 hours below $45^{\circ} \mathrm{F}$. After 36 hours, when milk is kept at $40^{\circ} \mathrm{F}$., there is an increase in the number of germs. Dr. Park found in a sample of milk 
containing only 3,000 germs in the cubic centimeter, that after 24 hours at $42^{\circ} \mathrm{F}$. it contained 2,600 germs; after 48 hours 3,600 germs; and after 96 hours 500,000 germs to the cubic centimeter. The number of germs in milk kept at $32^{\circ} \mathrm{F}$. lessens from day to day.

When milk is kept at higher temperatures the germs multiply rapidly and it sours and deteriorates correspondingly. It has been shown that very clean milk (containing but 3,000 germs to the cubic centimeter), if kept for 24 hours at $60^{\circ} \mathrm{F}$, held Iso,ooo germs; if kept at $86^{\circ} \mathrm{F}$. for 24 hours it contained I, 400,000 germs; and at $94^{\circ} \mathrm{F}$. the germs multiplied so tremendously that at the end of 24 hours the same milk contained 25 billion germs per cubic centimeter.

All germs require some moisture in order that they may actually grow, but they may exist in large quantities-for a longer or shorter time-in dust. Some require air for their existence, others do not.

Sunlight is one of the most powerful enemies of germs, since few will thrive in sunlight, especially in the presence of plenty of air. This explains the value of sunning dairy utensils and of permitting the sunlight to enter freely into the barn and dairy. Some germs grow more readily in substances having an alkaline or neutral reaction; others, as those which cause milk to sour, flourish in an acid medium, providing the acidity is not too great.

The most potent factors in destroying germs are intense heat and cold, sunlight and chemicals. A temperature varying from $14 \mathrm{O}^{\circ}$ to $5_{5}^{\circ} \mathrm{F}$. will kill most germs-if continued long enough or repeated at frequent intervals. Milk treated by continued, intermittent heating at $140^{\circ} \mathrm{F}$. has been kept for years without changing, owing to the destruc- 
tion of germs (and ferments) in it. As the time required for the destruction of germs at this temperature is too great for practical dairy purposes, a temperature of $165^{\circ} \mathrm{F}$. is usually applied for either killing or checking the development of germs in milk. Heating milk with this object in view is called technically pasteurization, after the great originator of the process. If properly done for twenty minutes, pasteurization kills most of the germs in milk and this is the best way to obviate the dangers of dirty milk for human consumption-more particularly in the case of infants. There are certain drawbacks to the process, however. If the milk has been kept long before heating, poisons may form in it which the heat will not destroy. Many medical authorities believe that milk thus heated is less digestible, but this is an unsettled matter at present. 'There are certain substances present in cows' milk exactly resembling those which bring about the digestion of food in the stomach and bowels of man and animals. These chemical substances in milk or in the digestive organs are called ferments. They appear to aid the digestibility of milk, particularly in infants, and are destroyed by heating milk over $179^{\circ} \mathrm{F}$., or at a lower temperature if the milk is repeatedly heated. It is generally accepted, however, that babies will not thrive so well on pasteurized milk for long periods, as on clean, unheated milk, and occasionally develop malnutrition, anemia, rickets and scurvy. The last may be prevented by feeding infants a small amount of orange juice daily. The simplest method of home pasteurization consists in pouring a quart of milk into a two-quart glass preserve jar and placing the jar with the milk in it on a flat, thin piece of wood (to prevent breaking of the jar by heat) in an open kettle. Warm water is then poured into the kettle so that it 
will rise to almost the level of the milk in the jar and the kettle is set upon a stove. When the water in the kettle begins to boil the kettle is removed to the back or side of the stove-where it will receive but little heat-for twenty minutes, and then the bottle is taken from the kettle and placed in a refrigerator. As I have observed, in pasteurization done on a large scale for market purposes in Seattle, the result has been a farce other than it enabled the milkman to keep the milk for perhaps twenty-four hours longer than it would have otherwise kept sweet. The pasteurization of the market milk was only done for three minutes, possibly because the machine-which permitted of a continuous flow of milk through it-was not competent to do the work properly, but also because thoroughly pasteurized milk has a cooked taste and cream does not rise readily from it, much of the fat remaining in the skim milk. The pasteurizers having a large chamber, in which the milk may be retained for the required time at the proper temperature, are preferable. Short pasteurization prevents milk from souring quickly because the germs which cause milk to sour are those most readily succumbing to heat. The general effect of short pasteurization is simply to check-for a longer or shorter time-the growth of germs. They are retarded in their development, not killed. Disease germs are not destroyed at all in the process. Experiments which I have conducted with the pasteurized milk of the general market showed that while containing but i 5,000 germs to the cubic centimeter, soon after emerging from the pasteurizer on the delivery wagon, in twenty-four hours the same milk contained several million germs to the cubic centimeter. Drs. Bergey and Pennington found much the same result in Philadelphia; that raw and recently pasteurized milk con- 
tained respectively $\mathrm{I}, 260$ and $\mathrm{I} 2 \mathrm{bacteria}$, but, at the end of 72 hours, the numbers were $17,000,000$ and $148,000,000$ germs. Also the harmless lactic acid germs of raw milk are killed by heat, and the more dangerous germs from dirty bottles, corks and dust contaminate the improperly pasteurized milk. I have, however, pasteurized fresh, clean milk for twenty minutes and exposed it at mild spring weather temperature for nineteen hours in a sealed bottle with the result that it was absolutely free from germs at the end of that time. If pasteurization is done thoroughly the lactic acid bacilli (sour milk germs) are destroyed and so the milk does not sour but putrefies when it ages.

Pasteurization prevents milk from being properly curdled by rennet and so unfits milk for cheese-making. Pasteurized milk or cream may be used to advantage for buttermaking when the lactic acid germs are added in the form of sour milk, known as a "starter," which will be described later. If we must have dirty milk, pasteurization is the best remedy for this unhappy state of affairs, but it may well prove undesirable to thus remove the incentive to dairymen to produce clean milk. If done at all for the market, it should be done thoroughly by heating the milk for twenty minutes to $165^{\circ} \mathrm{F}$., followed by rapid cooling.* If milk is not cooled down to a low point after pasteurization, spores will develop which have escaped destruction on account of their great resistance to heat, and these will result in germs which, while not souring milk, act on the casein to cause it to curdle and perhaps become poisonous and putrid. In Europe pasteurization of milk is much more common than in this country, since ice is in less common use. In Denmark it is required by law, so that tuberculosis may not be spread when skim milk is returned from the creameries and

* Pasteurized milk which is sold for general consumption should be always marked as such, in order that infants shall not be harmed by its use. 
fed to calves. This custom might well be imitated in the United States, since the young stock are not only protected from disease, but the keeping quality of the skim milk is so much improved. A higher temperature than $165^{\circ} \mathrm{F}$. gives the milk a boiled taste and alters its composition to some extent. Steam or boiling water are used to destroy germs in or on dairy utensils.

Chemicals find little use as germ-destroyers in a properly conducted dairy or farm. They may be employed to some extent in the barn (as lime scattered on the floor), or in case milk products become faulty through some contamination with special germs in the stable or dairy, when general disinfection is in order. The employment of the various preservatives under the trade names of Freezine, Iceline, Preservaline, Milk Sweet (all containing from two to five per cent. of formaldehyde), and others containing boric acid, as Dry Antiseptic, Preserving Salts, "A" Preservaline, Cream Albuminoid, Patent “M” Preservaline and Ozone Antiseptic Compound, are employed to keep milk from souring without the use of ice or cleanliness by killing or checking the growth of germs in milk. Their use is contrary to law and detrimental to the consumer's health, especially when employed, as they usually are, in a careless way, without regard to what the effect of a considerable amount of the chemical might be. Thus the following instance is related in the Year Book of the Department of Agriculture for 1900 of a case where a preserving fluid was first added to the milk by the farmer, then by the collector of the milk, again by the wholesale dealer, and finally the fourth dose by the retail clealer.

If it were impossible to produce clean milk or to preserve it with ice, and if preservatives could be used properly 
in a harmless dose, their employment might be permitted, but such is not the case.

\section{Significance of Germs in Milk}

The growth of large numbers of germs in milk causes it to deteriorate because they remove nutriment or alter the milk chemically and thus lessen its food-value. Ordinary market milk, which is overrun with germs, loses much of its value as food after it is twenty-four hours old. The ideal result would be reached if milk could be withdrawn from the cow absolutely free from germs. This might be possible if germs did not enter the udder in the air through the opening in the teat and find their way into the cavity or milk-cistern in the lower part of the udder. As the milking proceeds the germs in the milk-cistern and teat are washed away so that the latter part of the milk withdrawn is often absolutely free from germs until contaminated with the outside air. Occasionally germs may persist in milk throughout milking, and the strippings may contain as many as 500 germs to the cubic centimeter. If the latter part of the milk is withdrawn through an absolutely clean milking tube into an absolutely clean bottle, it will often be wholly without germs, and may keep sweet for months or years if it does not come in contact with the air. Such painstaking cleanliness as is necessary to make this experiment successful, is not of course practicable in actual dairy work, since it is not economically possible to throw away a larger part of the milk nor to withdraw milk so that it will not come in contact with air.* Therefore, under any ordinary conditions a certain number of germs must inevitably be present in the cleanest milk-perhaps 200 to 4,000 as the least number to the cubic centimeter.

* Since writing the above the use of the milking machine (see p. I 89 ) makes withdrawal of milk without exposure to air practicable. 
Then, if the milk is immediately cooled to $40^{\circ} \mathrm{F}$. and retained at this temperature, the number of germs will lessen until it is thirty-six hours old.

The presence of many thousand germs to the cubic centimeter in milk freshly withdrawn indicates filthiness of the cow, milker or surroundings.

The existence of a great variety of germs in milk several hours old signifies contamination of the milk with filth also, because in clean milk only one kind of germs (lactic acid bacilli) are found very numerous after many hours.

While the mere fact that milk contains a vast number of germs is not a sure proof of its unwholesomenessbecause the commonest germs in milk are harmless and because milk may contain but a few germs and these may be the cause of dangerous disease in man-yet the estimation of the number of germs in milk is to-day the best method we possess for determining its purity.

Ordinary market milk contains as many germs as sewage, and unusually dirty milk contains more germs than sewage was ever known to hold. This is, however, not at all a fair comparison, for while sewage is likely to contain all sorts of germs of disease, the germs in dirty milk are mostly not disease-germs.

We may consider the influence of germs in milk under two heads: 1 . The effects of germs on milk and its products. 2. The influence of germs in milk on the consumer.

I. The Effects of Germs on Milk and Its Products.All fermentation and putrefaction or rotting, anywhere and of anything, are due to germs.

Germs are the great disintegrating agencies in the world; they tend to break up complex, natural constituents 
in milk and its products into simpler bodies. The commonest germs in milk-as we have noted-are those causing souring of milk; they are invariably present and are about the only kind existing in very clean milk. They act to ferment or change the natural sugar of milk into an acid (lactic acid), and if they occur in large numbers a few hours after milking it is a sign that the milk has not been properly cooled and will sour early. Lactic acid germs, or those producing souring of milk, besides being the most common, are of most importance in their influence on milk and its products. They exist in very small numbers in milk soon after leaving the cow, but as they grow more readily than all other germs in milk at favorable temperatures (above $50^{\circ}$ and better over $70^{\circ} \mathrm{F}$.), they of ten constitute almost 50 per cent. of all the germs in twenty-four hours. While, after this time, they gradually crowd out the different varieties of competing germs until they produce so much acid that the milk or cream sours and curdles, and they have multiplied so rapidly and have made the milk so unfavorable for other germs that they form from 90 to 99 per cent. of all the germs present. This is a most favorable occurrence, because the flavor of most butter and cheese is chiefly dependent on the action of the lactic acid germs, and in their growth they protect the milk from the action of miscellaneous germs which would spoil these products.

Even to man the growth of the lactic acid germs is a favorable happening, as they are not harmful to adults in themselves and tend to check the development of other harmful germs in the digestive canal.* As we have pointed out, heating milk to $155^{\circ}$ or $165^{\circ} \mathrm{F}$. readily kills the lactic acid germs. Therefore such milk does not sour, but is changed by the action of other harmful germs so that it rots

* Indeed Metchnikoff, perhaps the most celebrated living authority on the action of germs on the body, belives that lactic acid germs in buttermilk coustitute one of the best agencies for prolonging life. 
or putrefies when old. A low temperature $\left(40^{\circ} \mathrm{F}\right.$.) also retards the development of the lactic acid germs and they are killed when the milk or cream becomes very sour by means of the lactic acid they themselves produce. The action of these lactic acid germs is taken advantage of in the ripening of cream for butter by adding them in great numbers, either by the use of sour cream or milk, or by laboratory methods by which they can be obtained in pure culture--that is, free from admixture with other varieties of germs (see page 39). Lactic acid germs are not found in milk when it leaves the udder, but enter the milk when it is exposed to air. They are thought to reside on the skin of the cow, in dust, in the air or surroundings of the barn. Ordinary market milk at $50^{\circ} \mathrm{F}$. sours in 120 hours; at $60^{\circ}$ F. it sours in 66 hours; at $98^{\circ}$ it sours in 16 to is hours.

At the Paris exposition of 1900 there was an exhibit of dairy products, under care of Major Alford of the U.S. Department of Agriculture, which consisted of fresh milk and cream shipped from Illinois, New Jersey and New York in hot weather (July). Coming some 3,000 to 4,000 miles, the cream and milk were perfectly sweet a fortnight after being bottled, while the only other competitor was the French with a local supply which did not keep a day after reaching the grounds. Cleanliness and cold were the only methods used in so wonderfully preserving this milk.

If milk is very dirty, however, it is not safe to keep it too long with ice, even if it does not sour and is unaltered in taste, as various sorts of harmful germs may develop at a low temperature. Thus, milk containing, soon after milking, some 800,000 germs to the cubic centimeter, after four days at $4 \mathrm{I}^{\circ} \mathrm{F}$. contained almost five million germs and became sour. At the end of ten days this same milk con- 
tained over 400 million germs, or over ten times the number of germs in the same milk kept the same time at $59^{\circ} \mathrm{F}$. The milk kept at a higher temperature soured more quickly and the acid destroyed many of the germs in the process.

There is a large class of germs known as putrefactive germs because they produce changes in milk which are akin to rotting of meat. If these continue to develop long enough they may impart a bad odor to milk or its products and are likely to induce diarrhœal diseases in children. These germs are more liable to arise from the contamination of milk with manure and are the germs which have escaped from the intestines of the cow.

If milk contains many of this type of germs it signifies that the milk was withdrawn under filthy conditions. There are a great number of germs in milk which apparently have no effect upon its character and also are not harmful to the consumer. It is practically impossible to discover the germs of special diseases in milk with any certainty, so that besides recognizing the chief types of germs - the lactic acid germs, the putrefactive germs, and miscellaneous germs whose action is unknown to us-the best that can be done at present is to estimate the number of germs in milk per cubic centimeter. Large numbers of miscellaneous and putrefactive germs signify that the milk is contaminated with filth and is most dangerous. Large numbers of lactic acid germs indicate that the milk has not been kept cool enough or is old. Freedom from any considerable number of germs is a pretty zertain sign that the milk has been drawn from the cow and handled in a cleanly manner; has been properly cooled and is likely to be uncontaminated

* Swithinbank \& Newman. 
with disease-germs. This is the justification of cities which require that milk shall not contain more than a specified number of germs (bacteria) to the cubic centimeter.

Thus the law in force in Boston requires that milk sold in that city shall not contain more than 500,000 germs to the cubic centimeter.

It has generally been admitted that it is difficult to obtain any large supply of milk which shall certainly contain less than 30,000 germs to the cubic centimeter. In various parts of the United States milk of such purity is now sold and is often called "Certified Milk," when certified by some responsible body who have a laboratory to daily determine that the milk comes up to the required standard. The name "Certified Milk" originated with Henry L. Coit, M.D. He established a commission of medical men in Newark, N. J., in I893, who made an agreement with a dairyman of Caldwell, N.J., to furnish milk subject to their requirements and inspection which should be known as "Certified Milk" when approved by the commission.

Any person who pretends to produce clean milk must submit to the germ standard, as this is the best means of estimating purity which we now possess. Exactly what that standard should be has, however, not been generally agreed upon.* It is perfectly possible to produce milk which shall not contain more than a few hundred, or, at most, not more than 2,000 to 4,000 germs to the cubic centimeter without great expense, if every precaution to secure cleanliness be observed in milking and handling the milk.

The usual contamination of milk with germs may be judged by the following figures with the understanding that great improvement is taking place owing to the interest

* It is not unusual to find 10,000 germs as the maximum number per cubic centineter permitted in certain localities for certified milk.

The standard of Albany for certified nilk has beenl So,ooo; for Rochester and New York City, 30,00o; for Philadelphia and Milwaukee, I0,000. 
which has been shown in the matter of obtaining a pure milk supply in recent years by physicians and others. In Boston, during the spring of 1890,57 samples of milk showed an average of $2,355,500$ germs in the better class milk, and of $4,557,000$ germs in grocery milk. In winter the growth of germs is considerably lessened by the colder temperature and this is somewhat counterbalanced by the filthier conditions of the barn floors, air and of the animals. On the whole, winter milk is, however, much freer from germs. The New York County Medical Society issue a certificate of inspection to farmers who will follow their directions for producing a second-grade, pure milk which shall not average over 100,000 germs from May to October, and not over 60,000 germs from October to May. In Seattle I found in twenty-eight examinations of different samples of milk on as many days in May and June, that sixteen samples averaged over 3,000,000 germs, and twelve samples less than $\mathrm{I}, 000,000$ germs per cubic centimeter. The examination of these milk samples was done when the milk was fifteen to thirty-six hours old, on the way to the consumer's house, being taken from the delivery wagons or on arrival of the milk train.

A great many conditions may alter the number of germs in milk if milk is not produced and handled in a proper manner. Time and temperature are the two most important factors upon which the growth of germs depends -and the greatest of these is temperature. The milk from one farm examined at the same hour on two consecutive days averaged 1, 1 50,000 germs on the first day--which was warm for May-and 48,ooo germs the following day, which was cold and rainy. The great increase of germs when milk is kept at improper temperatures, we have already noticed, 
the number of germs in such milk depending entirely upon its age. To show the effect of dust and unclean utensils on milk I may cice the following: a sample of pasteurized milk, taken from a delivery wagon and examined by the writer, contained seven million germs, while from the same wagon was also taken a sample of the same milk put into sealed milk bottles which contained but 24,000 germs to the cubic centimeter. The first sample was taken from a large can which was frequently opened to pour out small quantities for consumers and very likely the can was unclean before the milk was put into it.

Germs do not multiply at all in milk at $32^{\circ} \mathrm{F}$, no matter how long it is kept. After the milk is withdrawn from the cow the number of germs in it generally diminishes for a longer or shorter time, and after this period the number rapidly increases. Thus at fifty degrees the number of germs may not be greater in thirty or forty hours than it was when the milk was first withdrawn. At a higher temperature the germs begin to multiply in the milk as soon as the third hour after it has left the cow. Each variety of germ has a special temperature at which it flourishes to best advantage. The lactic acid germs grow more favorably at comparatively high temperatures-from $70^{\circ}$ to $90^{\circ} \mathrm{F}$, or even higher.

There are certain special germs-not all of which have been studied-which produce special faults, or, as they have been called, diseases of milk.

Thus the butyric acid germs develop that acid by the splitting up the fat in rancid butter. Yellow, red, blue, brown and green milk are rarely seen and the particular coloration is due to changes produced in the milk by special germs. So also are slimy milk, bitter, stringy and soapy 
milk, entirely owing to germ-development and its effect on milk.

This whole book is chiefly devoted to the influence of germs on milk, in one way or another, and further reference to the subject will be found under the special topics considered.

2. Action of Germs in Milk Upon the Consumer.-As we have already intimated, germs do not enter milk during its formation in the udder of the cow, in normal conditions, but only gain entrance to milk through the medium of the air when the milk flows into the receptacle or cistern which communicates with the air through the opening in the teat. We showed that if the milk cistern was washed out clean and that if then a milking tube was introduced into the teat it was possible to secure milk free from germs altogether and which would therefore remain sweet indefinitely if kept in a sealed flask. If the cow is suffering from a germ disease it is possible for the germs to get into the milk, during its formation in the udder, from the blood of the animal, if it has a general disease, or what is still more likely, if there is disease of the udder itself, the germs may find their way into the milk directly from the diseased parts. Inflammation of the udder may be caused by various germs, of which the germ of tuberculosis is one and perhaps the most dangerous. This germ is found in milk then more frequently when tuberculosis affects the udder, but possibly also when tuberculosis attacks other parts of the cow. Just how common, and how important, therefore, is tuberculosis in the cow a source of the disease in man through drinking milk of tuberculous cows, it is impossible to say. Cases of tuberculosis in 
human beings have undoubtedly arisen from this source and in consequence it is essential that all cows should be tested with tuberculin, to exclude the possibility of tuberculosis, before the milk is used for dairy purposes.

The germs of tuberculosis have been found not only in milk, but in cream and butter, although there is no certain evidence that the disease was ever produced in man by the latter two products.

The more ordinary germs which cause acute inflammation of the udder, or garget, are those which produce acute inflammation and pus in all parts of the body, and pus or "matter" is often found in the milk (see page I 59).

Milk obtained from cows with garget is highly dangerous to man and causes disease in him which in some cases resembles diphtheria and at other times has appeared identical with scarlet fever. The milk from such cows may communicate the inflammation of the udder to other cows in the same barn by means of germs carried by the milker's hands. Therefore cows with caked or inflamed udders should be kept apart and milked by one not milking the healthy cows. The milk from cows with foot-and-mouth disease has been the means of communicating this disease to man, giving rise in him to sore mouth, tender swellings under the jaw, an eruption of blisters or "cold sores" on the face, fever and disturbance of the digestion. Cow pox, milk fever, anthrax and pleuropneumonia in cows have been conveyed by the germs of these diseases, in their milk, to human beings.

It may be positively affirmed that the milk from a sick cow or one receiving drugs, is not fit for human consumption. The milk of tuberculous cows may be safely fed to swine or calves after boiling for ten or more minutes. 
The germs of typhoid fever, diphtheria and scarlet fever* (rarely of cholera, dysentery and smallpox) occasionally find their way into milk, owing to the milk coming in contact with human patients suffering from these diseases, or with their surroundings, or from contamination of milk utensils with water harboring the germs of typhoid fever. Also, by wading in filth containing the bowel and urinary discharges of human beings, cows may contaminate their udders with germs of typhoid fever and thus convey them to milk.

Other agencies by which disease germs may be carried to milk and by which many cases of typhoid fever, diphteria and scarlet fever have been communicated to man are as follows: by attendants in the sick room coming in contact with milk, by dish cloths, brushes and other articles coming in contact with the sick and milk utensils as well, by contact of milk with flies and by contact of milk with persons handling human excremeint.

The lesson which should be taken to heart is that no sick person or one coming in contact with persons sick with communicable diseases, shouid be allowed to have anything to do with the handling of milk, milk utensils or be permitted entrance to barn or dairy. Milk should be kept in a room separate from human habitation, and all the utensils should be kept and cared for in this milk room. Young children should be excluded from barn and dairy, as they are much more prone to contagious diseases than adults. Dogs and cats may be carriers of germs, dirt and parasites, and should also be kept out of these places. The water used in connection with the dairy should be examined for purity by a competent chemist.

All forms of disease conveyed by germs in milk to

* Physicians are required by law to report all cases of infectious disease to the local board of health. It should also be made nuandatory that physicians state the name of the millk dealer supplying the patient with nilk, in the case of every report of infectious disease, as is done in MI. Vernon, N.Y. In this way endenics originating in milk contamination with human infections could be readily traced. 
human adults are as nothing in comparison with the damage wrought by germ-laden milk upon infants. Cholera infantum, in fact, is but another name for acute milk poisoning. Practically almost all the cases of summer diarrhœa in babies are caused by germs in milk. These are probably chiefly of the putrefactive type which enter milk from manure on the cow. Indeed, in some localities from 40 to 60 per cent. of the deaths in infants. from all causes result from dirty milk. The wonderful reduction in the death rate of infants in some of our large cities-which is one of the remarkable signs of modern progress-has been brought about solely by the recognition of this fact.

This reduction is directly traceable to the use of pure milk or, where this is not obtainable, to milk heated to $165^{\circ} \mathrm{F}$. for thirty minutes, at which temperature the growth of germs is killed or checked. Violent and often fatal poisoning, resembling cholera, is produced by a substance (tyrotoxicon) formed by certain germs in milk kept in dirty, covered vessels during hot weather. The same poison has sometimes been found in cheese, cream and ice cream and has also caused fatal results. Heating impure milk will destroy this poison. Chiefly through the laudable and efficient work of Health Officer G. W. Goler, M.D., in supplying certified milk to the public of Rochester, N. Y., the infant mortality has been reduced as follows: i $\$ 87$-I $\$ 96$, before milk work was done, the average mortality in infants under I year in the month of July was I,OIO; I \$97-I906, after the milk work was begun the average mortality was only 4 I 3 in July under the same circumstances. 


\section{CHAPTER II.}

\section{COMPOSITION OF MILK AND CREAM AND THEIR PRODUCTS}

\section{M}

ILK is a white, opaque fluid, when seen in bulk, but appears transparent in thin layers. It has a peculiar, pleasant odor and taste which cannot be described. They can best be appreciated-by comparison -when they are absent. Thus, milk which has been heated in open vessels or passed through a separator loses some of its finest flavor. This flavor resides in a volatile substance which escapes in either process.

Chemically, milk is composed of all the essentials of a complete food. That is, it is a single substance which contains all the foodelements necessary to indefinitely support life. These food-elements are known technically as Proteids, Fat, Sugar and Mineral Matters.

Proteids in milk have the same food value as flesh or eggs. Water is, of course, the largest constituent of milk, forming about 87 per cent. of it.

The solids make up the remainder of milk, amounting to about 13 per cent. and comprising the substances we have just enumerated, proteids, fat, sugar and mineral mat. ters. Omitting the mineral matters or salts, we may, in a general way, remember the proportion of proteids, fat and sugar as four per cent. of each, the percentage of proteids being slightly below and that of sugar slightly above these figures. The fat is the only one of these constituents which 
varies greatly and this indeed varies tremendously (from I.5 to I3. per cent.) and owing to a great variety of circumstances which will be noted.

If the fat is all removed from milk - which can practically be done with the separator-we have left the skim milk, which is composed of the proteids, sugar and water. The sugar is of a kind peculiar to milk and therefore called milk sugar. It is found in no other substance and is not nearly so sweet as ordinary or cane sugar. The souring of milk is due to fermentaton of milk sugar which takes place through the action of certain germs (lactic acid germs), which we have already mentioned and which are always present in the cleanest milk. These germs lead to the breaking up (fermentation) of the sugar in milk into lactic acid (or milk acid). We have accounted for the sugar in the skim milk; we have left for consideration the proteids and mineral matters. The proteids are of two kinds: Casein (or caseinogen) and Albumin. Casein forms nearly four-fifths of the proteids and is that part of milk which makes the curd of skim milk or the part of milk which forms the bulk of cheese. The word caseous means cheesy. The other kind of proteid or albumin remains mostly in the whey when milk is curdled. Casein exists in the form of microscopic solid particles floating in the milk, while the albumin is in actual solution, together with the mineral matter, in the water of the milk.

This will be apparent if milk is kept a long while, when the cream (mostly fat) rises to the top; the casein settles as another white layer to the bottom of the vessel, while in between these is seen a third clear layer (serum) consisting of water, in which remain dissolved the mineral matter and albumin (Fig. 2). 
FiG. 2

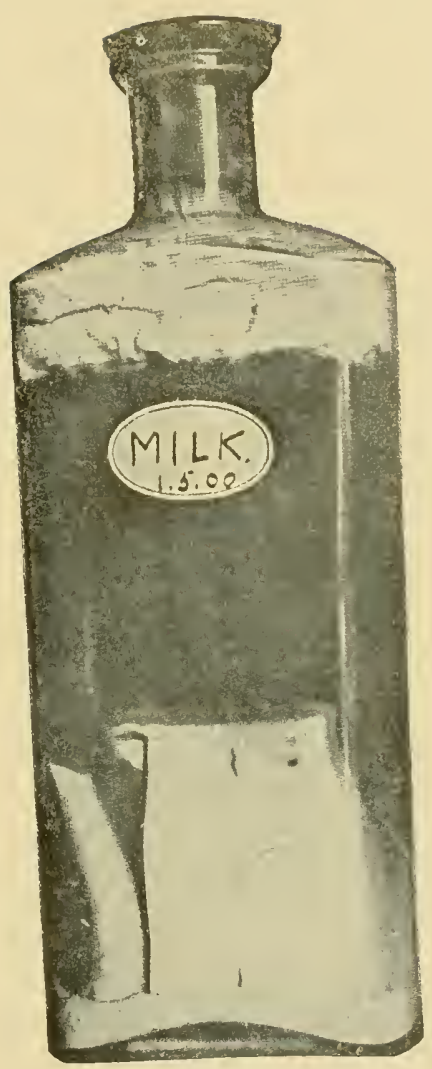

The Constituent Elements of Milk-Fat, Sern11, and Casein. (From Swithinbank \& Newman). 

Milk curdles because the casein in it clots or coagulates by the action of dilute acid (the lactic acid of sour milk), or by the ferment, rennet, which represents the dried secretion scraped from the calves' stomachs. The second form of curdling is what naturally happens when milk is taken into the stomach as food. The albumin of milk is not curdled by the souring of milk or by rennet, but is, to a slight extent, by heat at a temperature over $162^{\circ} \mathrm{F}$.

The fat in milk occurs as the most minute, microscopic globules which float through the milk and, on account of their buoyancy, rise more or less quickly to the surface and there form cream. These minute droplets of fat are apparently surrounded by a wonderfully thin pellicle or covering which is thought to consist of a layer of casein adhering by capillary attraction. If the fat were not thus surrounded the globules would run together and produce an oily mass. The fat globules vary greatly in size, some being six times the diameter of others. They average about $1-5,000$ of an inch in diameter, and one drop of milk no larger than a pinhead may contain $1,500,000$ fat globules. The larger globviles of fat are most buoyant and rise to the surface; only the smallest remain in skim milk. The fat globules are larser in some breeds of animals, particularly the Jerseys, and the cream therefore rises more rapidly and completely. The fat globules are arranged in groups or clumps in milk instead of being uniformly scattered throughout the fluid. This is of considerable practical importance, for milk which has been separated or heated (pasteurized) does not cream so well because the clumps of fat globules are broken up and so do not rise so quickly or completely. For example, milk is passed through a separator not revolving fast enough to separate the milk from the cream (which is sometimes done to 
remove the dirt from milk), and the milk is bottled. The cream will rise from this milk slowly and incompletely, and the cream, when it has risen, will appear so thin that a twenty per cent. cream may not seem thicker nor richer than rich milk.

Pasteurizing milk will cause much the same result, if the milk is subjected to considerable agitation in the process.

The mineral matter in milk comprises a very small amount of variety of salts and altogether they do not form quite one per cent. of the whole milk.

The following table perhaps fairly represents the composition of what might be called average milk $\nmid$ from a large herd of average cows of various breeds:

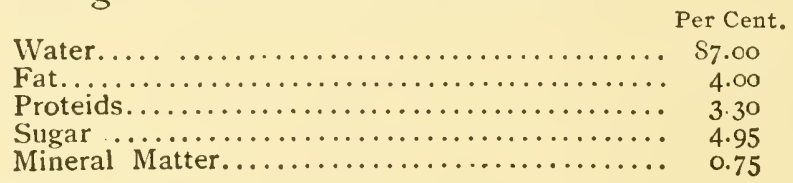

We will now consider in detail the various circumstances which modify the composition of milk. It is a curious fact that the character of the food of cows has little influence upon the composition of milk although it affects tremendously the yield of milk. The composition of the milk is dependent on the cow and breed, and is as much a characteristic as her color and as difficult to change. The following table illustrates the average composition of the milk of herds of different breeds of cows :

\begin{tabular}{|c|c|c|c|c|c|c|c|}
\hline & $\begin{array}{l}\text { *Durham } \\
\text { or } \\
\text { Shorthorn }\end{array}$ & Devon & Ayrshire & $\begin{array}{l}\text { Holstein- } \\
\text { Friesian }\end{array}$ & Jersey & $\begin{array}{l}\text { Mrown } \\
\text { Swiss }\end{array}$ & $\begin{array}{c}\text { Common } \\
\text { Native }\end{array}$ \\
\hline Fat...... & 4.04 & 409 & 3.89 & $2: 8$ & 522 & 4.00 & 369 \\
\hline Sugar..... & $43 t$ & 432 & $4 \cdot 41$ & 4.33 & $4 \mathrm{~S}_{4}$ & 430 & 4.35 \\
\hline Proteids... & 4.17 & 4.04 & 4 OI & 3.99 & $3.5 \mathrm{~S}$ & 400 & 409 \\
\hline Min':m't'r & 0.73 & o 73 & o 73 & 0.74 & 0.73 & 0.76 & 0.76 \\
\hline
\end{tabular}

* Abstract of tables compiled hy Mr. Gordon, of Walker Gordon Laboratory. The figures for Holstein-Friesian in the case of fat are ralher low ; 3.2 per cent. fat would be nearer the minimum average. $-\mathrm{K}$. IV.

+The U. S. Pure Food Act of 1906 fixes the standard for milk as follows: Solids not fat, 8.5 per cent.; milk fat, 3.5 per cent.; milk solids, total, 11.75 per cent. Skimmed milk to contain 9.25 per cent. of total solids. 
According to the statutes of the various states, ${ }^{*}$ the required standard of composition of milk differs to a slight extent, but as much as three per cent. of fat is demanded in every state, except Rhode Island, and solids amounting to twelve per cent., in most states, and as high as thirteen per cent. in some.

The composition of milk varies according to the period of milking, the milk growing richer in fat and the fat globules larger as milking advances, the last of the milking or "strippings" being very rich.

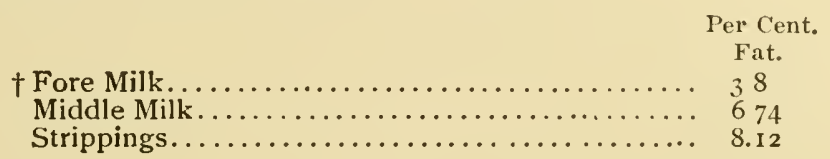

The reason for this is said to be that the fat globules are retarded by friction on the sides of the milk ducts in the udder and are forced out in abundance towards the last of milking. The percentage of the other solids remains practically unchanged at different periods of milking.

If cows are milked at frequent intervals the yield of milk is greater and the percentage of fat larger. The milk is formed in the cells of the udder and is conducted through numerous fine tubes of increasing size until it empties into a reservoir (holding about one-half pint on an average) connected with the upper end of the canal or opening in the centre of each teat. There are therefore four milk cisterns in the udder, one for each teat. It is probable that when the udder has become accustomed to hold in its ducts and cisterns a certain quantity of milk it will for a time secrete nearly the same amount during each interval between milk-

* Laws in force in June, Igoo.

$†$ Dr. Charles Harrington's analysis. 
ings. After a while, however-if the cow is milked more frequently than usual - the udder will not continue to secrete the same amount of milk and the exceptional quantity obtained by frequent milkings will cease. Milking three times daily is practiced in some parts of Europe, but milk. ing more than twice in the twenty-four hours is rarely considered economical in the United States; and is not done except in the case of very heavy milkers or in cows newly calved.

The longer the interval between milking the larger the quantity of milk and the poorer the quality of the milk; the shorter the interval, the smaller and richer the yield of milk. In the summer the nights are short and therefore the morning milking is apt to be richer. In winter the reverse is true and the night milking is likely to be the richer.

The following analyses of the milk of one herd at the Delaware Experiment Station show this :

$\begin{array}{lcc} & \begin{array}{c}\text { Night Milk. } \\ \text { Per Cent. Fat. }\end{array} & \begin{array}{c}\text { Morning Milk. } \\ \text { Per Cent. Fat. }\end{array} \\ \text { July } 24 \text { th. } \ldots \ldots \ldots \ldots \ldots \ldots \ldots \ldots \ldots \ldots \ldots \ldots & 376 & 4.67 \\ \text { February } 5 \text { th. } \ldots \ldots \ldots \ldots \ldots \ldots & 4.56 & 3.53\end{array}$

The season of the year influences the composition of milk. In the summer the percentage of fat and other solids is lowest. In the winter months the milk is richest in fat and solids not fat. Thus in the months of November, December and January, the solids may average I 3.36 per cent. and the fat, 4.16 per cent.; while in May, June and July the solids may average 12.68 per cent. and the fat 3.82 per cent.

The changes in the composition of one cow's milk are great and may be brought about through various influences, as, for instance, fright, excitement, rough handling, change 
of milker, exposure to bad weather, unfamiliar surroundings, sudden change in the character of food, and irregularity in time of milking. It follows without saying that all these unfavorable influences are, as far as possible, to be avoided.

In an analysis of hundreds of samples of milk from single cows, Farrington found that in the case of a Holstein there was as much difference between the highest and lowest percentage of fat as between 6.6 per cent. and I.5 per cent., while in the case of the Jersey-in which sudden changes are most common-the highest was I 2.3 per cent. of fat; the lowest, 2.9 of fat.

The mixed milk of a large herd is pretty constant in composition except as influenced by the season and by the times the cows calve. For the composition of milk varies at different times in the milking period. The milking period of the cow lasts about 323 days on the average after calving, she going dry about eight weeks before she calves again.*

In cows which are well tended and fed the percentage of fat increases as the milking period progresses, so that the milk is richer at the close than at the beginning of the period of milking.

The period of heat in a cow is often accompanied by a diminished yield of milk which is poor in fat (so that the fat may be reduced to one per cent.), and the milk curdles on boiling. The fat after this period is, however, proportionately increased over that usually present.

The milk-yielding capacity of cows generally increases up to the eighth year of age, and then decreases. With the decrease of yield there appears to be often a decrease in fat and total solids in the milk. It was thought at one time

\footnotetext{
* The interval between two calving day's averages about 398 days.
} 
that the spaying of cows would prove of advantage in sustaining the yield and improving the richness of their milk, but it has not been found so in practice, except in those animals which are constantly in heat owing to disease.

The dehorning of cattle is said to improve the yield of milk, but there can be no conceivable reason for this other than in the freedom from fighting and wounds which this practice accomplishes.

The composition of milk is of great importance in that the value of milk depends upon the amount of fat it con. tains, other things being equal.

It has now become the custom for creameries in most parts of the country to pay a sum for milk proportionate to the amount of butter-fat it contains as estimated by the use of the Babcock machine at certain stated intervals. First-class, pure or "certified" milks now sold for an advanced price in cities should contain a high average of fat. Such milk often averages five per cent. Then again it is for the farmer's advantage, if he is to produce a high quality of milk, that he know the composition of the milk of all his individual cows so that the poorer ones may be weeded out. This may be accomplished by the use of a. Babcock machine on the farm (see p. 142).

Colostrum (common name beastings, etc.).-Colostrum is the milk secreted immediately after calving and differs very markedly in composition from ordinary milk. Colostrum is of a slightly yellowish or brownish color and has a peculiar smell, a slimy consistency and salty taste. The proteids are at first large in amount and represent albumins rather than casein. For this reason the milk becomes curdled on boiling and this is a test for colostrum; if it curds on boiling it is unfit for use. 
The sugar in colostrum is not milk sugar, but represents several other varieties. The percentage of fat is variable, while that of mineral matter is high. Colostrum usually separates into two layers on standing. Under the microscope there are to be seen in it very large globules of fat, called "colostrum corpuscles," and these are characteristic of this form of wilk. The colostrum varies in composition from one milking to another after calving, becoming more and more like ordinary milk.

The following analysis will give an idea of its composition :

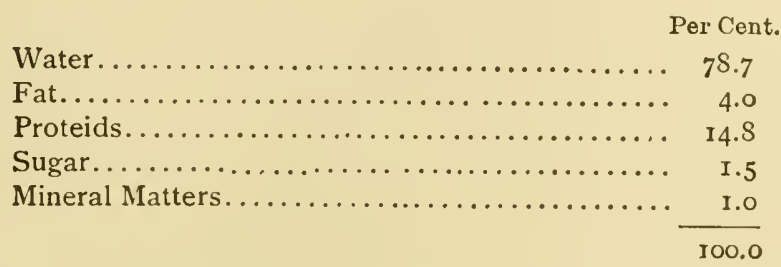

While the proteids in colostrum are so soluble that they can be absorbed by the calf without any tax on its digestion, and appear to start up digestion in this animal, yet colostrum is not wholesome for man for from five to twenty days after calving. Legal requirements vary somewhat, but usually demand that cows' milk shall not be sold for fifteen days before, nor from five to twelve days after the calving of the cow supplying the milk.

The boiling test, referred to above, will show when the milk is fit for human consumption. The milk is not fit for churning until five days after calving, nor from ten to twelve days for making cream cheese.

Colostral milk and the milk obtained from the cow within fifteen days before calving have produced disease in man. Colostrum has caused high fever, inflamed throat and mouth, which were covered with small sores or ulcers; 
while milk from cows, withdrawn a few days before calving, is sometimes the source of colic and diarrhœa in the human. The milk from a cow immediately after calving frequently contain's blood, coming from that which soils the udder and tail after flowing out of the vagina. 


\section{CHAPTER III}

\section{MILK PRODUCTS}

T $T$ is a curious fact that the quantity of cream obtained from setting rich or poor milk is about the same for rich as for poor milk, but the cream from the poor milk is much thinner and contains less fat. As seen in a glass quart milk-jar, the layer of cream forms almost a quarter of the bulk of the contents of the bottle, at first, but after twenty-four hours or longer the layer of cream becomes less, owing to the crowding together of fat globules. When cream rises in tall vessels it contains a great deal more fat in its upper than in its lower layers.

In fact, of the cream which rises in a bottle of milk, the upper ounce contains as much sometimes as 25 per cent. of fat, while the fat in the cream regularly diminishes until at the lowest part of the layer of cream, which can be seen as a sharp line above the milk, the percentage of fat is not quite ro per cent. As we have already said, the higher the creaming temperature the richer will be the cream, and for this reason the quantity of it will be much less than from the same amount of milk which is set at a low temperature. For the lower the cream temperature, especially at the end of the creaming period, the greater will be the amount of cream and the thinner will it be owing to the greater quantity of water in it. Milk which has been watered throws up its cream much more rapidly than other milk.*

* This accounts for the custom, with many farmers, of pouring a considerable amount of cold water into their milk cans when they wish to secure cream quickly for their own use. 


\section{Separator Cream}

By the use of a separator, which consists of a rapidly whirling steel bowl (5,000 revolutions, more or less, per minute), the heavier portions of the milk-the skim milk and dirt-are thrown against the inside of the rotating bowl by centrifugal force, while the lighter portion-the creamremains near the centre. The dirt sticks to the side of the bowl, where it forms a tough, sticky layer known as separator slime. This separator slime is not composed by any means of filth entirely, because a good part of it is made up of the proteid constituents of the milk (curd); one authority says that nine-tenths of the dried slime is formed of this natural product of the milk. That there is a great amount of filth in ordinary market milk has been abundantly shown. It has been estimated that the citizens of New York eat daily ten tons of barn filth and refuse in their milk. This amount is probably exaggerated, since Berlin is said to furnish its inhabitants but 300 pounds of cow dung in its daily millksupply, and, allowing a wide margin for our native progressiveness, we could hardly be credited with beating the Germans so tremendously in this international filth contest. In the separator slime are to be found, in addition to the cheesy matter from milk, manure, fodder, hairs, particles of skin, insects, down from birds, threads from clothing, bits of bedaing, cobwebs, bristles, soil, etc., and large quantities of germs. The slime forms from .04 to. 3 of I per cent. of the weight of the new milk, depending upon its original state of cleanliness. The use of the separator is superior to all other methods of obtaining cream on account of its power to more rapidly and thoroughly extract fat from milk. Thus it shortens the period for growth of germs permitted by the 
older methods of creaming, and-to some extent-removes yerms already present in the milk. The cream, however, will be found to contain as many or more germs as the milk did before separation, although the skim milk leaving the separator may show one-third to one-half less germs in pretty clean milk, but in filthy milk the number of germs after separation is practically unaltered.* Cream, after separation, must therefore be rapidly cooled down from the high temperature of separation $\left(86^{\circ} \mathrm{F}\right.$.) to $40^{\circ} \mathrm{F}$. in order to prevent the growth of germs which have not been removed to any great degree by the process.

The use of the separator to free milk of germs is not a success, although this method has been practiced in large cities to cleanse milk.

None of the disease germs occasionally present in milk is certainly removed by separation. When used to cleanse milk the separator is run at a comparatively low speed so as not to separate the cream from the milk, but sufficient to remove much of the filth and therefore the so-called animal odor. Although there may be an improvement in the flavor and odor of the milk, it will not keep any longer, showing that germs are not removed. Filtering milk by various devices has about the same value.

The filth and dirt are removed more or less completely, and the taste and odor improved thereby, but the essential contamination-the germs-are not removed. For, as Prof. Conn has pointed out, the germs are so minute and so much smaller than the fat globules that it would be necessary to employ a filter which would remove all the fat in the milk in order to catch the germs in the filter.

* Recent experiments show that of the germs present in whole milk before separation, 47 per cent. appear in slime, 29 per cent. in milk and 24 per cent. in crearı after separation.-Eckles \& Barnes, Iowa Sta. Bull., 1902. 
Complete separation of milk into cream and skim milk is sometimes done for cleansing purposes, the skim milk and cream being reunited. Many physicians believe that milk thus treated is often the cause of indigestion in infants.

Neither these nor any other methods will make dirty milk clean.

Contamination of milk begins at the farm, and only at the farm can it be eradicated. Absolute cleanliness with respect to milking and everything which comes in contact with the milk, together with immediate cooling to $50^{\circ} \mathrm{F}$. or below, will alone insure success. The importance of germs in relation to milk is as great as to the operating surgeon, and the amazing progress in both surgery and dairying is due chiefly to the appreciation of this fact.

Exclusive of fat, the percentage of the other constituents of milk-proteids, sugar and mineral matters-is about the same in cream as in milk, unless the cream be of unusual richness. For the same reason, the composition of skim milk is about the same as whole milk, the fat excepted. The fat is practically absent from separator skim milk and is present in skim milk, from which the cream has been removed by hand, to the extent of one-half to one, or even one and one-half per cent. The following tables. illustrate these statements :

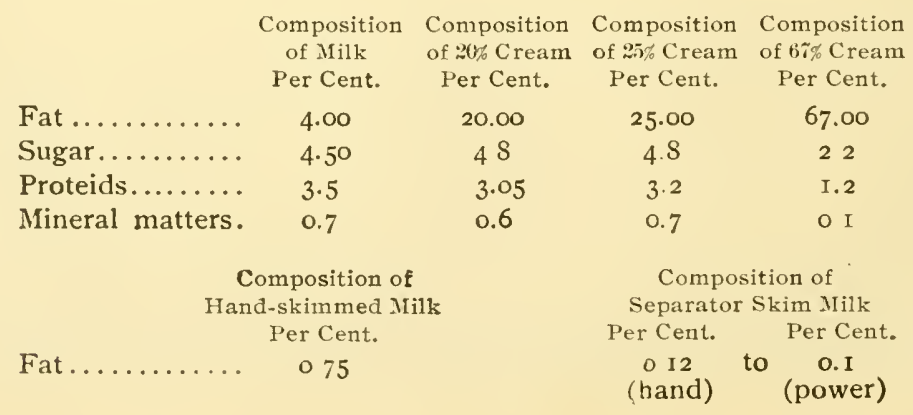


The cream from set-milk contains 90 to 99 per cent. of the germs which were present in the whole milk, because in rising the fat globules entangle the germs and carry them along to the surface. These germs are chiefly made up of the varieties which cause the souring of milk or cream (lactic acid bacilli), and these increase for forty-eight hours at favorable temperatures $-60^{\circ}$ to $70^{\circ} \mathrm{F}$. - in cream, and then gradually die out, owing to the unfavorable influence of the acid formed in souring, so that in a week few remain. During the first few hours there are to be found a great variety of germs in milk and cream, but the lactic acid bacilli crowd these out, because they grow so much more readily than do the other kinds of germs, and at the end of forty-eight hours there may be as many as 500,000,000 lactic acid germs to the quarter teaspoonful. Butter is commonly made from cream which has "ripened." By ripening is meant the changes which occur in cream owing to the growth of germs in it during the process of souring.

The ripening of cream may be compared to the change which takes place in grape juice when it turns to wine. Both changes-in the grape juice and cream-are brought about by fermentation, and fermentation is simply a term for describing the changes-chemical and physical-which occur in a substance owing to the action of germs and their products upon it.

In the ripening or fermentation of cream the germs alter the character of the cream and supply bodies which give to the butter its peculiar flavor and improve its keeping qualities. Butter made from fresh cream has less flavor and does not keep well. The sour milk germs give butter part of its flavor, but the miscellaneous germs which are crowded out by the former also are responsible for much of 
the flavor. In this country the popular palate requires a much stronger flavored butter than the European taste, which regards our butter as rank in flavor. Therefore abroad it is often customary to pasteurize fresh cream to kill the miscellaneous germs and add the sour milk germs in the form of a "starter," thus getting a butter made from ripened cream, but avoiding the stronger flavor caused by the miscellaneous germs. The flavor and aroma of butter, then, depend upon the varieties of germs in cream. Butter is thought to possess the finest flavor in May and June because at this season the greatest variety of germs flourish in the milk.

The chief reason why butter is so much better from certain dairies than others is because the better dairies are the homes of special kinds of germs, which give butter a good flavor and aroma, while in the others-owing to want of cleanliness of the cows, barns, milk rooms, employees or utensils-special germs of filth which are unfavorable to good dairy products come to occupy the premises.

The action of the germs is, then, the essential factor in the production of good butter, as in all other departments of dairying. As we have pointed out, the lactic acid germs, while in the minority in the milk just drawn from the cow, soon gain ascendancy by multiplying in milk or cream, and it is to this type of germ that the ripening of butter and of cheese is chiefly due.

We have also shown that, to the miscellaneous germs in milk and cream, butter also owes some of its flavor. But as some of these are deleterious to flavor and aroma, ancl are not to be depended upon, the endeavor has been made to employ only the lactic acid bacilli to ripen cream. These are present in pure culture; that is, they form the only type 
of germ in the commercial starters, which may be bought in market in various shapes, as bottles of milk, pastes, powders and pellets, all merely vehicles for the growth and preservation of lactic acid germs. This starter is added to fresh cream to ripen it. If the cream is already sour it is useless to add a starter. It is best to first heat cream to $155^{\circ} \mathrm{F}$., to destroy the miscellaneous germs, before adding the starter containing the lactic acid germs, but in this country, where the added flavor caused by the miscellaneous germs is desired, the starter is more commonly added to fresh cream. The starters which were first used consisted simply of a quantity of sour milk or cream containing a great number of germs, suitable for ripening cream, which was added to fresh cream to quickly sour and ripen it, especially in cold weather. These are called natural starters, and are still used extensively. To prepare such a starter the milk is withdrawn from the cow in the most cleanly manner; the milk is then separated and the skim milk is collected in an absolutely clean vessel and set aside at a temperature of $60^{\circ}$ to $70^{\circ} \mathrm{F}$. to sour. This sour milk may contain all sorts of germs, but if it is clean there are apt to be few miscellaneous germs and these are likely to be crowded out by the growth of the lactic acid germs, so that the result may be almost as pure a culture or collection of lactic acid bacilli as is found in the commercial starters. We quote the following from Farrington :

The foundation material for both kinds of starters is usually skim milk. This is first freed from most of its bacteria by heating it to i $80 \mathrm{deg}$. F. or above, for at least one-half an hour. It is a good plan to keep this hot milk well stirred and covered while it is being heated. After this period of heating, the skim milk is cooled. The cooling is usually done by setting the can of hot skim milk into cold water. The quicker it is cooled the better. When the temperature of the skim milk reaches $80 \mathrm{deg}$. F., it is then in condition to 
receive either the pure culture which lias been bought from the dealer, or the sour milk which has been selected and allowed to sour naturally.

The so-called commercial starters are made by adding to about a gallon of this skim milk a small quantity (about an ounce) of the pure culture which has been bought from a dealer in this material. After the pure culture has been added to the skim milk the mixture is kept at a temperature of about 80 deg. F. until the skim milk has become soured by the pure culture bacteria. This preparation is sometimes called "startolene," and it may amount to about four quarts of sour milk. This is added to a larger quantity of pasteurized skim milk, which has been prepared by heating and cooling as previously described, and the mixture is allowed to stand at a temperature near so deg. until it becomes sour and has an acidity of about six-tenths of one per cent.* If the cream in which the starter is to be used is now ready, the starter may be added to it in about the proportion of ten pounds of starter to one hundred pounds of cream. A small quantity of this starter is saved each day and added to a new lot of pasteurized skim milk. In this way the starter is carried on from day to day and a new lot for use in ripening cream is prepared every day.

The natural starter is made in exactly the same way as the commercial starter, except that in place of the ounce of pure culture which is bought from a dealer, a small quantity of selected sour milk is added to the pasteurized skim milk. The starter is then built up from this mixture as before described.

This in general is an outline of the methods used for making cream ripening starters. The successful handling of starters depends entirely on the carefulness with which the skim milk is pasteurized and the skill used in protecting the starter from outside contamination by dust, dirty cans, etc. In some cases the butter maker often goes so far as to wash his hands before handling his slarter. These refining precautions used to protect the pure culture and the starter from contammation are very important.

If the starter does not give satisfactory results, it is best to throw it away. and begin a new one; but, when once obtained, a good starter should be propagated from day to day as long as possible, and the length of time which it may be kept pure depends on the care with which it is made from day to day.

It is always better to seed a new lot of pasteurized skim milk with a portion of fresh starter taken out just before it is poured into the cream, than to attempt to propagate a mew starter every day by means of buttermilk obtained from a cluming of cream in which the starter was used. A buttermilk starter may often give good results; but, as a rule, it cannot be depended on, because some unpleasant flavors may develop in the cream during its ripening. These, of course, are carried into the buttermilk, and when this is used for making the next starter, the unpleasant fiavors may be continued in the butter from day to day.

\section{* See page}


One of the important elements in starter making is the ability to detect a satisfactory starter when it is made. A person with a keen sense of smell and taste is able by inspection to select a good starter and know that it will Iroduce good results, while other persons, without this ability, are unable to accurately judge between two different starters and they may keep on using a poor one day after day without noticing it. This faculty of judging starters may be cultivated by practice, and the butter maker who is most successful in training himself to detect a good starter, and a poor one as well, will be the most successful in making butter of a fancy grade.

The commercial starters are more expensive, but uniform, certain and convenient; while the natural starter costs little or nothing and is less uniform but generally successful. Both are in common use.

Butter made from ripened cream, besides having more flavor, aroma and better keeping qualities, is more readily churned and can be obtained in somewhat larger quantities than from fresh cream. Butter made from fresh cream is preferred by many persons and, perhaps it may be said, by those with the most refined taste. However, the market for such butter is limited and it must be sold immediately it is made. Fresh separated cream is much more readily churned than gravity cream.

Cheese is made from the curd (casein or cheesy portion) of milk obtained by souring milk or by curdling it with rennet, chiefly by the latter method. The whey is removed in different ways. In soft cheese, as Brie or Camembert, the whey is merely permitted to drain naturally from the curd. The whey being not all removed, soft cheeses keep poorly.

In the case of hard cheeses, the curd is cut up, and sometimes heated to $110^{\circ} \mathrm{F}$. to toughen it, and pressed for day-s. Both soft and hard cheeses must ripen, which process takes days or months. The lactic acid germs are those chiefly instrumental in ripening hard cheeses, while 
molds and miscellaneous germs ripen the soft cheeses. In ripening, the various flavors characteristic of the special cheese are developed through the action of chemical products formed by the growth of these vegetable parasites or germs. In addition, the cheese becomes softened, and therefore easier of digestion through the action of a ferment natural to milk, resembling rennet, the latter being a secretion of the animal stomach.

How important is the influence of special varieties of germs in the successful making of cheese may be appreciated from the fact that it is a practice to smear shelves and walls of new factories with fresh cheese (as Brie and Limburger) to convey to them the special germs necessary to produce the flavor and characteristics of the cheeses which it is desired to make. A starter is often added to milk from which American cheese is to be made. As in the case of cream for butter, the addition of the lactic acid germs tends to crowd out miscellaneous and undesirable germs and give a more certainly uniform product. The commercial starters are most reliable for the ripening of cheese, as for butter. As a general practice, milk cannot be pasteurized to kill the undesirable germs before adding the starter, when cheese is to be made, because heating the milk destroys the ferment in it which assists in ripening cheese, and heated milk does not curd so well with rennet. Certain of the sour milk, and of the soft and hard cheeses are, however, made successfully from pasteurized milk or cream to which is added a starter.

If cheeses made from unpasteurized milk, to which starters containing lactic acid germs have been added, are ripened in low-temperature cellars, the miscellaneous germs are not likely to develop. 
The chemical composition of buttermilk and whey, bye products in the manufacture of butter and cheese, is given below.

Buttermilk is usually sour from lactic acid, while the proteids are more digestible than in ordinary milk because existing in a flaky form.*

Whey possesses but slight food value, containing only the ash, sugar and albumin of milk. It is sometimes the only food, when combined with a little cream, which infants with delicate digestion can tolerate.

We also append a table showing the composition of butter.

\begin{tabular}{|c|c|c|c|}
\hline Proteids. & $\begin{array}{c}\text { Buttermilk } \\
\text { Per Cent. } \\
\text {. } 4.06\end{array}$ & $\begin{array}{c}\text { Whey } \\
\text { Per Cent. } \\
\text { o.SI }\end{array}$ & $\begin{array}{l}\text { Butter } \\
\text { Per Cent. } \\
\text { I.oo }\end{array}$ \\
\hline 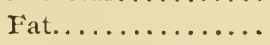 & 0.93 & 0.36 & 84.00 \\
\hline Sugar and Ash.... & $4 \cdot 40$ & $5.7 \mathrm{I}$ & 3,00 \\
\hline
\end{tabular}

Good cheese contains about 33 per cent. each of proteids and fat, and possesses two to three times the food value of meat, providing it is well digested, as it is more apt to be if cooked with macaroni or vegetables.

\section{Skim Milk}

Skim milk forms a valuable food for man or beast, especially for calves and pigs. The milk should be fed young animals sweet, and warmed to the temperature of the body, when it possesses about one half the value of whole milk for food. The use of the hand separator at the farm will often be found lucrative, for the reason that the skim milk may then be obtained warm and fresh for calves or pigs and the cream bring as large a price as the whole milk, while retaining the most valuable element-the nitrogen in the proteids

*Quite recently the advantages of concentrated and preserved butternilk have been advocated. Its use will probably become much extended in time. Also an innovation is buttermilk made from clean skim milk. This should be set at $700-800 \mathrm{~F}$. to clabber when it is churned and until the casein is in a finely divided state and immediately cooled to below $50^{\circ} \mathrm{F}$, and sold within 24 hours. A pasteurized skim milk may be used. There is a great field for absolutely clean buttermilk thus made for consumption in cities. 
of the milk-on the farm. This because the nitrogen is returned to the soil in manure. For man, skim milk, through its proteids, is said to be three times as cheap as meat, though a much more bulky food. If the skim milk is returned from the creamery for feeding, it is best that it be first pasteurized to kill any germs of tuberculosis which may be contained in it and to prevent souring. Calves should be permitted to suck the first three days of their existence, and then may be given whole and skimmed milk for ten days, gradually reducing the whole milk. After that time they may be given only skim milk, five to six quarts daily in three feedings for the first two weeks. At the end of this time five pints of skim milk may be fed twice daily with a tablespoonful of flaxseed or Indian meal to supply the deficiency of fat in the food. A liking for corn meal may be encouraged by placing a little on the tongue after feeding milk. Skim milk is fed pigs in the proportion of three pounds to one of corn meal; to fowls, also, with grain. The utensils and troughs in which the skim milk is fed to young animals should be kept scrupulously clean, and the milk should not be fed sour.

\section{Bye-Products}

In speaking of milk products the bye-products of milk are used to an extent in the arts but little appreciated. This has recently been brought out in an address at Chicago by Dr. Nowak, the inventor of a process for using skim milk in the tanning of leather. The curd or casein of skim milk is the essential part of the milk employed for the following manufactures :

For sizing straw and felt hats; for making and glazing paper; for glazing and finishing leather; finishing and 
sizing silk, cotton, woolen and linen goods; for making wall paper, roofing paper and linoleum. Also, casein is an important ingredient of cements, glues, putty, woodfillers, paints (especially dry paints), imitation ivory for balls, and buttons, etc.

Some of the most lasting of the old Roman structures were made from a mixture of milk, lime and sand, and the most celebrated old mural decorations of Europe from casein mixed with color. 


\section{CHAPTER IV}

\section{FEEDING FOR MILK}

I $\mathrm{N}$ feeding cows for milk the most essential fact to grasp is that the composition of milk can not be altered to any extent by feeding. The solids may be increased slightly by a food very rich in protein, or, on the other hand, the solids may be lessened, if the diet is very watery, but the percentage of fat, sugar and proteids in the milk is not affected to any degree by different kinds of foodstuffs. One often reads of the marked influence of a change of food in increasing, or otherwise, the percentage of fat in the milk. But, while a sudden change in the ration may produce a corresponding alteration in the percentage of fat in the milk, it will be found only a temporary matter. The single exception to the rule that the composition of milk is not changed by feeding is when the animals are not in a normal condition. If an animal has not enough food to be maintained in a normal condition, there may be a disturbance of the functions of the udder, as of any other function in the body, and therefore alteration in the composition of the milk.

Milk is formed by the constant breaking down of the substance of the cells of the udder into the proteids, fat, anci perhaps to some extent the sugar, of milk. This process is followed by a rapid rebuilding of the udder cells. The constituents of the food of cows are not transformed directly into milk, but are altered and absorbed into the blood and 
serve only to build the cells of the udder, as they do any other part of the body. The quality of the milk from any cow depends upon the natural characteristics of the cells of the udder; the quantity of milk depends on the capacity for rapid cell-building and, to a degree, upon the size of the udder. The cells of the udder being made of a substance similar chemically to the proteids of the milk, there must be an abundance of protein in the food to constantly rebuild these cells as they liquefy into milk. Indeed, the proportion of protein in the food has to be higher in feeding for milk than for any other purpose. This proportion has been determined by experience and experiments (see Wolff's table below).

While it is possible to secure the proper proportion of protein by the use of the greatest variety of fodders, the special foodstuffs which may be employed in any given case should be determined chiefly by the local cost of special fodders and the price of milk.

The richer a food in protein the more costly is it, and, if the price of milk is low, it may not pay to increase the amount of proteids in the food sufficiently to attain to the maximum milk-yield. A food rich in protein tends to sustain the period of lactation and keep up the flow of milkwhich is ordinarily greatest soon after calving-for a considerable period. In case of large milkers which receive an insufficient supply of protein, the proteids of the tissues of the body are called upon to make up for the loss of protein in the formation of milk from the udder cells, and the animal rapidly loses flesh.

Notwithstanding the fact that the composition of milk can not be materially altered by feeding under ordinary circumstances, yet by good feeding and breeding (taking 
advantage of increased fat yield in milk through careful selection), it has been found possible in several generations to produce an animal giving milk one per cent. richer than that common to its breed. This has been accomplished by some in the case of the Holsteins.

Wolff's original feeding standard for milk cows, per day and I,ooo pounds live weight, is as follows :

Pounds

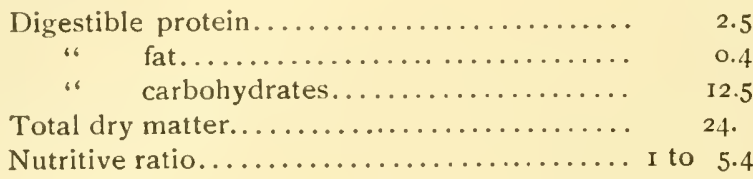

The nutritive ratio means the proportion of nitrogenous to non-nitrogenous constituents of the food. The protein represents the nitrogenous, and the fat and carbohy. drates together represent the non-nitrogenous nutrients, as the food constituents are called. But to put fat on the same basis as carbohydrates, in calculating the nutritive ratio, the percentage of digestible fat is multiplied by 2.5 and the result is added to the total of digestible carbohydrates. The reason for this is because fat is thought to have two and one-half times the food value of carbohydrates, since a given weight of fat produces two and one-half times as much heat in burning as carbohydrates. This method of reasoning is realized, however, to be very imperfect. In books* on cattle feeding tables showing the composition of foodstuffs may be found. The carbohydrates are found under the headings Crude Fibre and Nitrogen-Free Extract. There are other tables showing the percentage of digestibility of the fat, protein, crude fibre and nitrogen-free extract in the various fodders.

*Armsby's "Marual of Cattle Feeding." 
By multiplying the amount of any of these constituents iis any given fodder by the percentage of the constituent digestible, we get the quantity of the digestible constituent in the fodder. Thus, if we look at a table showing the composition of hay: Average hay we find contains in the roo lbs. as follows: 9 lbs. protein, 2 lbs. fat, 43 lbs. nitrogenfree extract, and $26 \mathrm{lbs}$. crude fibre. To find the digestibility of these nutrients we look in another table and there discover that 46 per cent. of the fat in hay is digestible, 57 per cent. of the protein, and that the total amount of nitrogenfree extract in a coarse fodder represents the total quantity of digestible carbohydrates it contains. So in our roo lbs. of hay we calculate that there are 5 . I 3 lbs. of digestible protein (multiply $9 \times .57$ ); and 0.92 lbs. of fat (multiply $2 \times \cdot 46)$ and 43 lbs. of carbohydrates digestible.

When we can not figure the amount of nitrogen-free extract as equal to the total digestible carbohydrates, as we do for convenience in a coarse fodder, we find the amounts of digestible crude fibre and nitrogen-free extract in the tables and add them together to represent the total digestible carbohydrate in the foodstuff. Fat is often spoken of as ether extract by some writers. It is not necessary, of course, to try to secure a ration which shall be the exact chemical counterpart of Wolff's table above, buc only to approach it as nearly as may be, especially in the matter of protein. The general idea should be to take the foodstuffs at hand and look up the amounts of digestible nutrients* they contain and combine them in the proper proportions as indicated by Wolff's table. Protein $\uparrow$ is an expensive food con-

\section{*Armsby's "Manual of Cattle Feeding."}

† In cattle foods protein costs, by weight, twice as much as carbohydrates and about one-half as much as fat, but there is ordinarily enough fat in a ration. 
stituent or nutrient, and it should be fed in the cheapest form of fodder available in the locality. The best manner of feeding is to weigh out the food necessary for the whole number of cows at one feeding and distribute the amount to each cow in proportion to her weight, secretion of milk, etc. Professor Haecker's work on cattle feeding teaches that the daily quantity of nutrients should be proportioned to the amount and richness of daily milk-yield as displayed in the following table :*

FOR COWS WEIGHING I,OOO POUNDS

\begin{tabular}{|c|c|c|c|c|}
\hline \multicolumn{2}{|c|}{ Milk-Yield } & \multicolumn{3}{|c|}{ Digestible Nutrients Required } \\
\hline $\begin{array}{l}\text { Daily Amount } \\
\text { lbs. }\end{array}$ & $\begin{array}{c}\text { Testing in Fat } \\
\text { per cent. } \\
\end{array}$ & $\begin{array}{l}\text { Protein } \\
\text { lbs. } \\
\text { I. IO }\end{array}$ & $\begin{array}{c}\text { Carbohydrates } \\
1 \text { bs. } \\
8.8 \mathrm{I}\end{array}$ & $\begin{array}{l}\text { Fat } \\
\text { Ibs. } \\
.24\end{array}$ \\
\hline 10 & $\left\{\begin{array}{l}4 \\
5\end{array}\right.$ & $\begin{array}{l}\text { I. } 17 \\
\text { I. } 24\end{array}$ & $\begin{array}{r}9.14 \\
9.47\end{array}$ & $\begin{array}{l}.26 \\
.28\end{array}$ \\
\hline 20 & $\left\{\begin{array}{l}3 \\
4 \\
5\end{array}\right.$ & $\begin{array}{l}\text { I. } 50 \\
\text { I. } 63 \\
1.78\end{array}$ & $\begin{array}{l}\text { IO } .62 \\
\text { I I . } 28 \\
\text { II . } 94\end{array}$ & $\begin{array}{r}.37 \\
.42 \\
.47\end{array}$ \\
\hline 30 & $\left\{\begin{array}{l}3 \\
4 \\
5\end{array}\right.$ & $\begin{array}{l}1.90 \\
2.10 \\
2.30\end{array}$ & $\begin{array}{l}\text { I } 2.43 \\
\text { I } 3.42 \\
14.4 \mathrm{I}\end{array}$ & $\begin{array}{l}.51 \\
.58 \\
.65\end{array}$ \\
\hline 40 & $\left\{\begin{array}{l}3 \\
4 \\
5\end{array}\right.$ & $\begin{array}{l}2.30 \\
2.57 \\
2.85\end{array}$ & $\begin{array}{l}14.24 \\
15.56 \\
16.88\end{array}$ & $\begin{array}{l}.65 \\
.74 \\
.83\end{array}$ \\
\hline & 3 & 2.70 & I6.05 & .68 \\
\hline $5 c$ & $\left\{\begin{array}{l}4 \\
5\end{array}\right.$ & $\begin{array}{l}3 \cdot 04 \\
3 \cdot 39\end{array}$ & $\begin{array}{l}1770 \\
19 \cdot 35\end{array}$ & $\begin{array}{r}.90 \\
1.01\end{array}$ \\
\hline 60 & $\left\{\begin{array}{l}3 \\
4 \\
5\end{array}\right.$ & $\begin{array}{l}3 \cdot 10 \\
3 \cdot 5^{0} \\
3 \cdot 9^{2}\end{array}$ & $\begin{array}{l}17.86 \\
79.84 \\
21.76\end{array}$ & $\begin{array}{r}.92 \\
1.06 \\
1.19\end{array}$ \\
\hline 70 & $\left\{\begin{array}{l}3 \\
4 \\
5\end{array}\right.$ & $\begin{array}{l}3 \cdot 50 \\
4 \cdot 00 \\
4 \cdot 4^{6}\end{array}$ & $\begin{array}{l}1967 \\
21.98 \\
23.82\end{array}$ & $\begin{array}{l}1.05 \\
\text { I. } 22 \\
1.36\end{array}$ \\
\hline
\end{tabular}

In practice it may also be broadly stated that there should be a certain proportion of coarse fodder, or roughage, to the more concentrated foodstuffs, as grain and byeproducts. Haecker's rule giving one pound of concentrated food for every three pounds of milk yield, affords a very useful basis for calculating a ration.

* This table and following rations were selected at random from Hoard's Dairyman. 
Thus, for a daily ration, 20 to $40 \mathrm{lbs}$. of roughage, including hay, silage, stover, etc., may be fed with about $S$ lbs. of concentrates (consisting preferably of a mixture of a variety of grains) to a cow of average size and giving about $25 \mathrm{lbs}$. of milk daily. To cows giving daily $35 \mathrm{lbs}$. of milk, Io lbs. of concentrates are suitable, and if the milk contains 5 per cent. of fat, 12 lbs. may be fed. The great milkers are often fed 30 to $40 \mathrm{lbs}$. of roughage with i 5 to 16 lbs. of a grain mixture daily.

Some such rations as the following may be used for milk cows of average weight and giving about 25 pounds of 4 per cent. milk:

Roughage, $20 \mathrm{lbs}$, of timothy hay, with a mixture of oats, 2 lbs.; bran, 4 lbs.; and gluten, 4 lbs. This contains as follows: Dry matter, 26.3 lbs.; digestible nutrients-protein, 2.18 lbs.; carbohydrates, J 3.09 lbs.; fat, $0.58 \mathrm{lbs}$.

Roughage, $20 \mathrm{lbs}$. of timothy and clover hay, with a mixture of oats, 4 lbs.; barley, 3 lbs.; and oil meal, I lb. This is equivalent to: Dry matter, $24.3 \mathrm{lbs}$; digestible nutrients-protein, I.88 lbs.; carbohydrates, I 2. I lbs.; fat, 0.6 lbs.

Roughage, 30 Ibs. of ensilage and 10 lbs. of clover hay, with a mixture of bariey, 4 lbs., and bran, 4 lbs. This ration is equivalent to: Dry matter, 25.5 lbs.; digestible nutrients-protein, k. 92 lbs.; carbohydrates, 1 I.92 lbs.; fat, 0.56 lbs.

Roughage, ensilage, 30 lbs., and oat hay, 30 lbs.; with mixture of ground rye, 4 lbs., and gluten feed, 4 lbs. This feed is equivalent to: Dry matter, $23.56 \mathrm{lbs}$; digestible nutrients-protein, 2.08 lbs.; carbohydrates, I 3.32 lbs.; fat, o 54 lbs.

It will be seen that the protein is a little low in all 
these rations. * Cottonseed (or linseed) meal is one of the richest foodstuffs in protein we possess, and may be added to advantage to bring up the proportion of protein in the ration. as one pound of the meal is equivalent to about one-third pound of digestible protein. Not more than two to three pounds daily of cottonseed meal should be fed, however, on account of its poor digestibility in considerable amounts, and because in excess it may render milk unfit for use as an infant food.

The following mixtures of concentrates may be employed with an appropriate amount of roughage (if hay is. used, as much may be given as the cow will eat without waste) as daily rations for an average cow :

Bran, 4 lbs.; corn chop, 3 lbs.; oil meal, I lb. Or, 2 parts bran; 2 parts ground oats; 2 parts gluten, and I part oil meal, giving $8 \mathrm{lbs}$. of the mixture daily. Or, 4 lbs. oats; 3 lbs. bran; I lb. oil meal. Or, 4 lbs. of bran and 4 lbs. of oats; or, a mixture by weight of bran, 3 parts ; gluten feed, 2 parts; corn chop, 2 parts; and oil meal, I part, giving 8 to Io lbs. daily. A ration having the proper proportion of nitrogenous to non-nitrogenous nutrients, or, in other words. the proper nutritive ratio according to Wolff, is now called a balanced ration. Oil meal is linseed meal. The exact amount of fat in the daily ration is not of much moment, but we should endeavor to approximate Wolff's feeding standard with the more recent modification (page 50) of adjusting the ration somewhat to the quantity and richness of the milk-yield. An amount of salt equal to one teaspoonful should be given with the feed of each cow twice daily.

* That is according to Wolff's standard of fifty years ago, but these rations. are calculated from the table to be found on page 50 . 
Cows may be watered to advantage twice daily; once before they are turned out for pasture or airing, in the morning, and again before the evening feeding.

The matter of a pure water supply in the pasture, farm and dairy is of great significance. This is the case, not because the milk is contaminated by germs or poisons swallowed by the cow in impure water, but because the cow's udders become contaminated from wading in impure water. The clairy utensils may likewise be contaminated by washing them in an infected water supply containing the germs of typhoid fever or dysentery. The presence of pools of water in pastures which in any way can be polluted with human excrement or urine should be aroided. Germs or microörganisms existing in stagnant pools in pastures may impart a fishy taste to milk when such water is wallowed in or swallowed by cows. Water* for cattle and for dairy purposes is best obtained from a public water supply of known purity, but when this is not possible a spring, away from sources of pollution, or a driven well, may afford excellent water. The neighborhood of a privy or manure pile should always be shunned, and surface drainage of any kind should be prevented from entering the well. Below the depth of of three and one-half feet germs do not live in the soil. Where there is any doubt-and some doubt must always exist concerning open wells and those situated near dwellingsa half gallon of the water should be submitted to a competent chemist for analysis. Wells must be free of all solid objects, even stones, and water containing over 300 germs to the cubic centimeter is unfit for dairy purposes.

The kind of food and manner of feeding cows has an I. siis c.

* Cows do not like very cold water. Avoid giving it to them when 
influence upon milk which is of much importance, especially when the milk is to be used by infants.

Many chemical substances in the food are eliminated - either changed or unchanged - in the milk, and may impart to it an unnatural odor, taste or appearance, and may render it unfit for food. A sudden change from dry fodder to grass, or any other green food in considerable amount, is apt to give rise to milk which will cause digestive troubles in babies.

Fresh corn fodder in considerable quantity, when fed to cows, will often render the milk harmful to infants. While roots and ensilage are commonly said to produce a milk which will disagree with infants, yet I believe these are harmless when fed in moderate quantities and after milking.

Silage should not be given in a greater amount than twenty pounds daily, and not more than two pounds of oil meal should be fed, when the milk is especially intended for infants' use. The feeding of spoiled, moldy ensilage, and remnants of ensilage which have been allowed to accumulate about the barn, are chiefly responsible for the harm this foodstuff inflicts upon milk. In fact, some authorities say that a ration of under $40 \mathrm{lbs}$. daily per cow is not damaging to milk. Some of the largest buyers of milk in the United States, however, refuse milk from ensilagefed cows, and those versed in the use of milk for baby feeding find that a small feed of ensilage is safer. Grass, hay, clover and grains constitute the best food for cows supplying milk for lise by babies.

The time of feeding is a matter of great moment. In general, it may be said that milk cows should only be fed after milking to avoid dust in the barn, and fodder, when given at this time - as mangolds, turnips, rutabagas, carrots 
or their tops - will not impart a bad odor or taste to the milk. It is not necessary to feed cows in order that they be quiet during milking; they can soon be habituated to being fed after milking. Indeed, so great is the danger of disseminating germs in the air when cows are fed before or during milking, that it is now recognized that when dry fodder is thus fed it is impossible to secure clean milk. Moreover, when hay is kept in mows open to the cow-barn, it is very difficult to produce clean milk. If feeding is done at milking time, it should only be moistened grain.

There are certain pasture plants which are harmful to milk, and sometimes to human consumers of it. Among these are the following: Poison ivy, poison oak, meadow saffron, Jamestown weed, sorrel, poisonous mushrooms, wild mustard, carrot tops, milkweed, sumach, henbane and skunk cabbage. The disease known as milk sickness, or trembles, which sometimes attacks man, and is exhibited by vomiting, great weakness and twitching of the muscles, is attributed to the drinking of milk from cows feeding on poison iry. Meadow saffron consumed by cows may lead to severe diarrhœa in man drinking their milk.

Milk is not of good quality for any purpose when the animals yielding it are fed upon swill, brewers' grains or food in a state of marked fermentation or putrefaction. Such milk may cause digestive disturbances in man-particularly in babies-and the manure is very soft and stinking from cows eating fermented food, and splashes about, and is therefore more apt to soil the cow and milk. The milk produced with brewers' grain does not keep sweet so long as good milk should, neither are the cows consuming large quantities of it long-lived. The use of this food is now prohibited by law in most cities. Dried brewers' and 
distillers' grains constitute wholesome food for cows. Moldy hay, straw or grain; decayed leaves, salt hay, onions, garlic and cabbage may give to milk a bad odor or flavor.

The expressed pulp from the sugar beet is inadvisable as a food for cows, because of its richness in potassium salts, which find their way into the milk and render it unfit food for human beings or animals.

The milk of cows receiving drugs is unsuitable for food, since many medicines are eliminated in the milk. Furthermore, the milk of cows sick in any manner should be withheld from feeding purposes, as poisons in the blood or germs of disease may be conveyed to man or animals in the milk from the sick cow. The milk of cows undergoing the tuberculin test may be used as food unless the animal reacts to the test, when it should be permanently rejected for human consumption, or boiled before feeding it to animals. 


\section{HOUSING AND CARE OF COWS}

T $\mathrm{N}$ considering the practical details concerned with the housing and care of cows, and the handling and marketing of milk, our object will be to emphasize the essentials required for the production of clean milk.

Many different methods may be employed to attain the same end, but certain principles are essential. Ideal methods are unfortunately expensive, and the most approved appointments of the modern stable and dairy rival those of the surgeon's operating room in elaborateness and cost. Nevertheless, milk which will fulfil all the requirements necessary for "certification" can be produced by care and cleanliness in an ordinary stable, and without any great outlay for plant.

\section{The Barn}

The essentials are that it shall be clean, light, airy, free from dust, flies and odors. In regard to the air space in a barn, this is a matter which depend's wholly on the ventilation. When the ventilation is good, 500 cubic feet of air per cow is sufficient, as the air is in constant movement. The number of cubic feet of air, rather than air. space, is the important matter. The King system for stables is that commonly used, the principle being to secure a current of air traveling at the rate of 200 to 500 cubic feet per minute through the barn. 
The animal's heat is used to aid the movement of air. If the stable is too high, the animal-heat will be lost, so that in cold climates a height of $\delta$ feet is sufficient, while a good width for a stable is 36 feet. The cows are to be placed in two rows running the length of the stable, and either facing each other or toward the outside of the building. There is much disagreement as to which arrangement is the better. If the cows face outward, there should be feeding alleys in front of them at least 6 feet wide, while the central aisle in the barn behind them is used for removing manure. If the cows face inward, the central aisle between the rows of cows is used for feeding purposes. In either case an overhead railway is often used for removing manure from the centre aisle, when the cattle face outward, or for carrying feed when the animals face toward each other. The writer gives the preference to the plan of facing the cows towards the outside of the building. By this arrangement the cows get more air and light, and their breath does not commingle. At the same time the manure can be more readily removed, which is more important than ease of feeding, for the production of clean milk. In the cow stall, the chief object should be to have an arrangement which keeps the cows wholly apart and does not cumber the floor so as to make places where dirt can collect. The best floors are of concrete, covered with cement, and made somewhat rough, so that the cattle will not slip. Some competent dairy men cover the cement with movable wood flooring, under the cows, to prevent them from lying on this hard and cold substance. (See Appendix.) If not of cement, the floor should be of planed, matched planking, and the cracks filled in with tar. In case planking is used, it is best at any rate to have the gutters of cement. 
To secure drainage of the floor of the stall, the rear half of it - that is, the half nearest the manure trenchshould have a fall of two inches. The manure trench should be sixteen inches wide and about eight inches deep. The trench should have a fall for drainage, being, for instance, six inches deep at one end and ten inches deep at the other; or, the whole floor of the stable may be made to slope, with the trench of the same depth from end to end.

A number greater than forty cows is not desirable in one barn. There should be a continuous window space along each side of the barn. The windows may hinge from below, or be made to open and close as one, by means of a continuous rod. In cold climates, the sides of the barn mayi be built of two layers of inch, matched boards with a space of eight inches between, filled in with cut straw or sawdust. Besides this, building paper should be laid inside each layer of the boarding. The inner layer of boarding should be without beading and laid perpendicularly. The ceiling overhead should be perfectly tight. If it is composed of a double floor with building paper between, there is no reason why hay should not be kept overhead, providing it is brought down into a room separate from the main stable. There should be tightly-fitting double windows in winter in cold climates. The King ventilating system consists of numerous flues on all four sides of the building for the intake of air, $4 \times 4$ inches in diameter, and opening three or four feet below the ceiling outside the stable, and entering the stable just under the ceiling. These are furnished with sliding doors, or closed with an arrangement like a furnace register in a dwelling house. The outake for air should be only one for every twenty cows or less, being a shaft with 
openings - the same size as the shaft - at the floor and just below the ceiling. This shaft should be placed on the outsicle of the centre of one side of the barn, and should be carried straight upward like a chimney, six feet higher than the top of the roof.

The shaft or flue should be absolutely air-tight, and may be macke of metal, or preferably of two layers of wood, with filling of sawdust or building paper between, and covered with a cap, to keep the rain out, one foot above the top. The openings near the floor and at the ceiling should be provided with loors or dampers of some kind. The number of flues and size of flues are governed by the number of cows in the barn. Only one flue is necessary for the outtake of air when there are less than thirty cows in the barn.

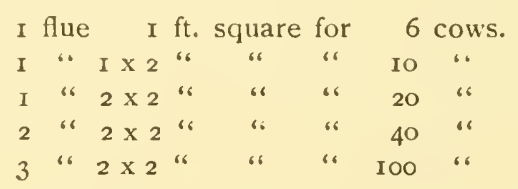

The movement of air in the ventilating system is brought about by the following forces: Wind pressure against the barn, forcing air into the building; wind suction on leeward side, tending to suck air out; wind blowing across top of ventilating shaft, tending to suck air out of it; by difference of temperature between the air inside and that outside the building. Thus air enters the intake near the ceiling and is distributed over the building. The air at the bottom of the barn is the foulest, because carbonic acid gas exhaled by the animals is heavier than air. This air is also the coldest. In cold weather the bottom opening of the out-take shaft should be open, and the upper opening near the ceiling shut. The cold, foul air is then sucked from the floor of the barn up the flue into the outer air. In hot 
weather the upper opening in the out-take flue may be opened, and the lower closed. This permits of escape of heated air from the stable, and may be done at any time to secure better ventilation, but at the expense of the animal heat. In order that the system work well, it is essential that every part of the barn be absolutely tight, with well-insulated walls to prevent chilling and condensation of moisture, as about ten pounds of water are eliminated daily from the lungs and skin of a cow. The doors leading outdoors should be double. There must be no leakage of air in or out anywhere, except through the ventilating system-even hay shutes must be closed, and no escape of air into the loft be permitted. It is not possible to state just how many intake flues there should be, but it is better to have them numerous on each side of the barn, as they can easily be closed if necessary.

It is feasible to sustain a pretty even temperature in a tightly built stable properly ventilated-somewhere between $55^{\circ}$ and $60^{\circ} \mathrm{F}$. in cold weather. If the air is too hot, the out-take flues are not sufficient; if too much cold air rushes in, the intakes should be closed to some extent, as there should be no considerable drafts when the system is working properly. The intake flues are commonly built in the walls of the barn, and the out-take flues may also be so constructed, in which case they are made of two layers of tight boarding with roofing paper between.

Metal flues are not so advisable as wooden ones, because moisture condenses more readily in them. The following sketches of some barns ventilated by the King system are taken from King's "Physics of Agriculture," to which the author wishes to acknowledge his indebtedness for some of the matter concerning ventilation pre- 
sented above. Old stables can be remodeled with concrete floors, and later the ventilating system, with stuffed walls and tight ceilings, doors and windows, may be added.

Sketch A shows two methods of ventilating a dairy barn. On the right (Fig. I) the ventilating flue D F rises Fig. 1 .

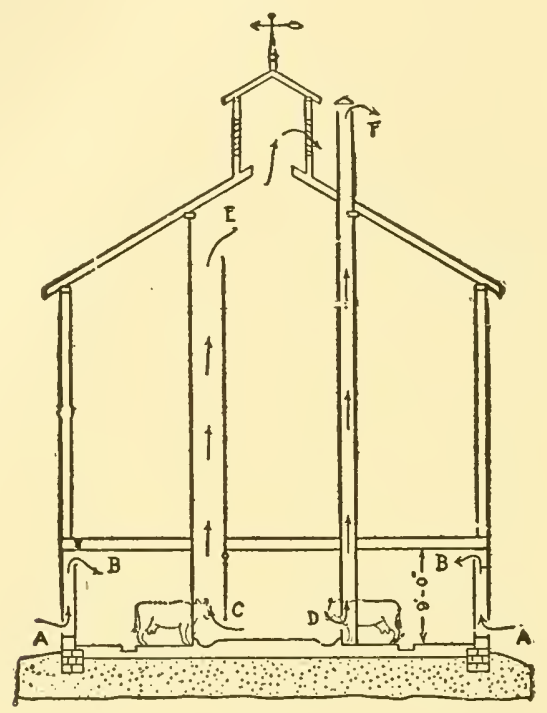

Fig. 2.

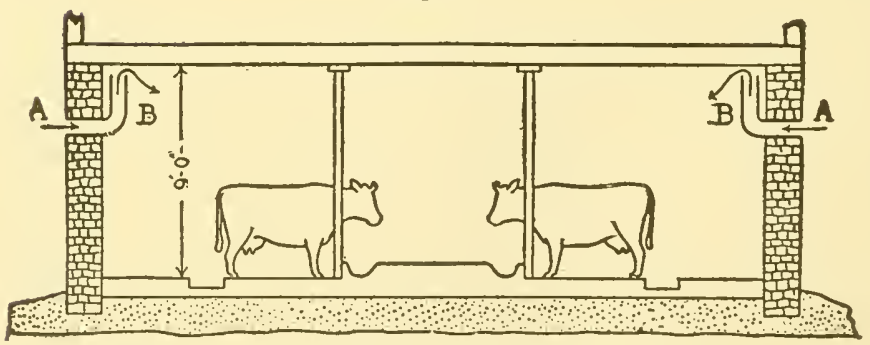

Sketch A-Two methods of ventilating a dairy farm.

straight from the floor, passing out through the roof and rising above the ridge. One, two or three of these would be used according to number of cattle. The flues should be at one or the other side of the cupola rather than behind it. On the left $\mathrm{C} E$ represents how a hay shoot may be used 
also for ventilating flue. In each of these cases the ventilating flue would take the place of one cow. This method would give the best ventilation but has the objection of occupying valuable space. $\mathrm{C}$, in the feed shoot, is a door which swings out when hay is being thrown down, but is closed when used as a ventilator, the door not reaching quite to the floor. To take air in to this stable, if it.is built of wood with studding, openings would be left at $\mathrm{A}$ about $4 \times 12$ inches every twelve or sixteen feet, and the air would

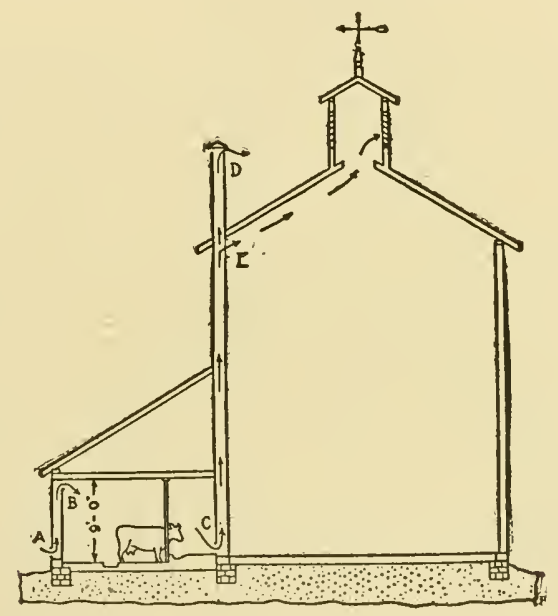

Sketch B-Method of ventilating a lean-to stable.

enter and rise between the sheathing of the inside and the siding on the outside, entering at $\mathrm{B}$ as represented by the arrows. Fig. 2 shows intakes through a brick wall.

Sketch B shows a method of ventilating a lean-to stable. The air enters as represented by the arrows at $A B$ and passes out through a flue built on the inside of the upright or main barn. This flue may rise directly through the roof or it may end at $\mathrm{E}$ as shown in the figure, the air passing through a cupola. If the upright barn has a balloon frame, then the space between the studding could be used 
as ventilating flues. These flues could be made tighter by covering inside and out on the studding with the lightest galvanized iron.

Sketch C shows a section of the cow stable of the dairy barn at the Wisconsin Experiment Station. A single

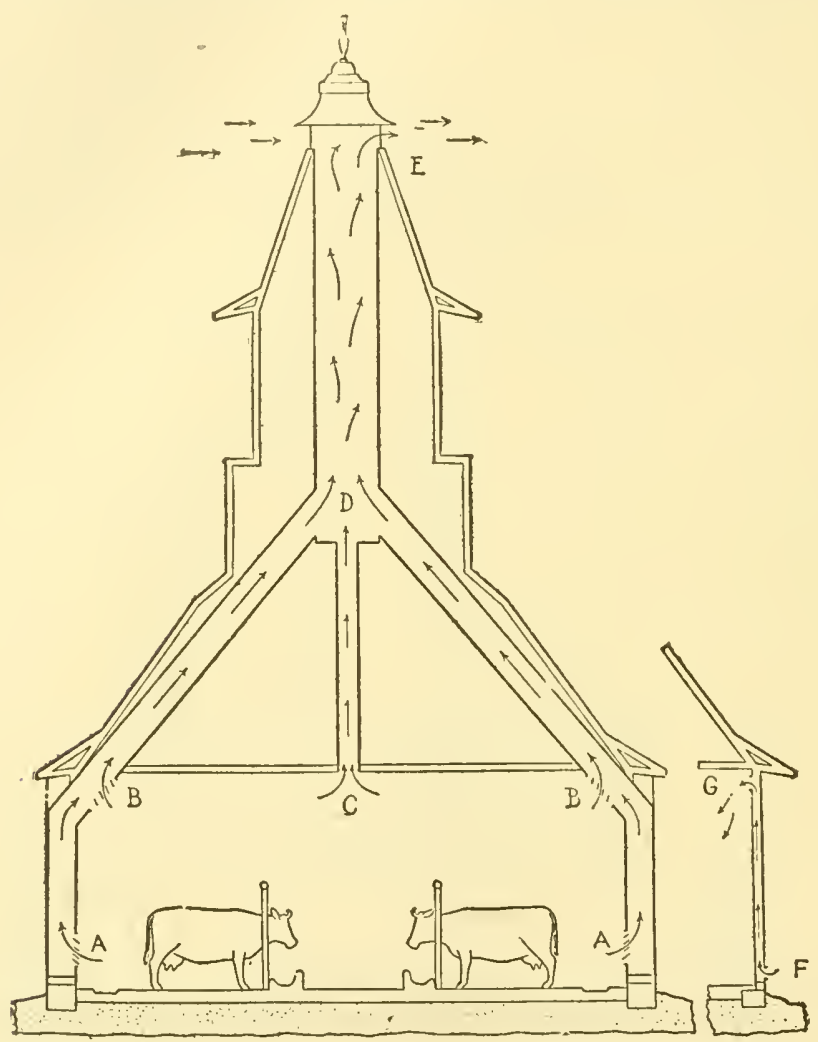

Sketch C-Section of the cow stable of the dairy barn at the Wisconsin Experiment Station.

ventilating flue $\mathrm{D} E$ rises above the roof of the main barn, and is divided below the roof into two arms A B D, which terminate at or near the level of the stable floor at A A. These openings are provided with ordinary registers, with valves to be opened and closed when desired. Two other ventilators are placed at $B B$, to be used when the stable is 
too warm, but are provided with valves to be closed at other times. $\mathrm{C}$ is a direct $\mathrm{I} 2$-inch ventilator leading into the main shaft, and opening from the ceiling, so as to admit a current of warm air at all times to the main shaft to help force the draft. This ventilating shaft is made of galvanized iron, the upper portion being 3 feet in diameter. The covering on the outside is simply for architectural effect. G F show method of intake of air.

\section{Cow Stalls}

It is generally considered of advantage to be rid of stanchions and tie-ups of all kinds, and confine the cow in a stall giving entire freedom to the head. The partitions between the cows are made in the form of metal or wooden gates about five feet high, but not touching the floor. The cows are held in place also by a chain or rope fastened by snap hooks to the uprights at either side of the back of the stall, and in front there is a movable partition of metal or wood adjusted to the length of the cow, so as to keep her standing well back to the edge of the manure trench. The whole length of the stall is six feet to six feet eight inches, according to the length of the cow. The cow is fed off the floor, or from a gutter cut in cement inside of the front partition. Metal stalls are comparatively expensive. The chief object is to keep all of the stall structure off the floor, as far as may be, to have a clean floor-space free from nooks and crannies to harbor dirt and dust. The width of the cow stall varies between thirty-eight to forty-five inches, according to the size of the animals. The milker opens the gate of the stall just behind him when milking, which gives him more room and keeps the next cow away from his back. 
IVhen the cows are let out the chains may be retained in place and the gates are opened. For details and illustrations of serviceable stable arrangements see Appendix.

It is well to round up the cement floor to a point six inches or so up the wall of the stable. The urine should be drained into a tank, which can be emptied once or more daily, or be received into a regular drain with a trap.* Chains or ropes should be stretched lengthwise with the stable under the cows' necks to prevent them from lying down after grooming and before milking. The manure must be removed as soon as it falls, $\nmid$ except at milking time, and carried not less than several hundred feet from the barn, so as not to attract flies. Flies convey germs to the milk and annoy cattle. One fly falling into the milk pail is said to bring as many as 250,000 germs into the milk. Many of the preparations for spraying cows with the purpose of keeping off flies are of great service, and are widely advertised in the agricultural journals. Shutters are useful in hot weather to darken the stable and, with netting, aid to keep out flies. Water may be run in the feeding gutter of cement floors, before feeding time, or supplied in iron vessels raised from the floor.

Before sweeping the barn floor it should be sprinkled to avoid dust, and neither sweeping nor removal of manure should be done within half an hour of milking - to prevent contamination of the air. While most of the germs in milk come from dirt on the cow, nevertheless there is also danger of contamination from dust in the barn. For this reason the most ideal way is to keep a barn, built with cement floors, entirely for milking purposes. The floors are sprinkled and the cows only driven in the building at milking time

* If the urine can not be so removed it is well to have the gutters tight (withont ontlet) and use rotted sod, sawdust, or leaf mold to absorb the moisture and save the fertilizing properties of the urine.

+ When this is not feasible, by using absorbents, as above, and occasionaliy sprinkling 5 per cent. creolin solntion in the gutters (if of wood), the stable may be kept clean. The manure shonld be taken out at least once daily. Sprinkling wood ashes and slaked lime in the trenches daily after removal of manure, is of service. 
and removed immediately after. In the air of the ordinary barn germs are fifty per cent. more abundant, owing to the clust in the air, than in a school room at the close of the day.

It is advisable to have a number of box stalls for sick animals, for cows about to have calf, and for calves. These had preferably be in a separate stable, because contagious diseases may thus be kept away from the rest of the herd, as contagious abortion, for instance.

A milk receiving room in the stable is useful, in which the milk from separate cows may be weighed and recorded before the milk is carried to the milk room. (See Appendix, page i 82.)

The most suitable bedding for cows in the production of clean milk consists either of shavings from kiln dried lumber (which have, in the process of kiln drying, been sterilized), or sawdust, or straw.

IVe have been laying down ideal rather than the essential requirements in the housing of cattle to secure clean milk. Suppose we take an ordinary barn. The hay is probably stored over the cows. If this is so, then either the hay must be removed, and also the ceiling over the cors, or the ceiling must be made dust-tight and the hay never removed before milking time, to avoid dust. It is probable that there are not enough windows. More windows, or, better, a continuous row of windows should be put in. There will be also probably unnecessary feed boxes which can not be readily cleaned, rubbish and implements and dirt to be removed.

Everything which may collect dust or dirt should be done away with. The whole premises then should be washed, swept and painted or whitewashed. The material sold in the form of a powder and known in the trade as 
water paint, and which is mixed with water by the user, is not much more expensive than whitewash and is infinitely better. The floors of the cow stalls must be smooth and tight, to be kept clean, and may be of matched woodalthough the gutters are preferably of cement. The floor of the stall must not be too long or too short, so that the cow when up will just stand on the edge of the gutter. If the cows are of different breeds and sizes this may be regulated by arranging the ties at proper distances from the gutter. It is well to have a sufficient space behind the gutters, so that one can walk without being soiled with manure, five feet at least, and in some stables this space is made wide enough to drive a wagon for filling with manure. This, however, is not necessary, nor the best way to remove the manure, as it should not be allowed to collect at all. The gutters must be deep enough' (eight inches or more) to keep the cows clean when lying down, or may be made six inches deep at one end and ten inches at the other end of the barn to secure a fall for flushing them out with water. They should be made watertight. It is well to keep land plaster or lime always in the gutters to absorb odors. Extra ventilation may be added by installing the King system without great expense.

Feeding should only be done after milking. A sufficient supply of hot and cold water and basins, soap and towels should be provided in a convenient place for the milkers to wash, and this may be used as a dressing room. No manure should be permitted to remain within several hunclred feet of the barn, and the ground about the barn must be kept clear of rubbish, dirt and stagnant water, and sprinkled when very dusty. Children and cats and logs must be excluded from the barn at milking time. 
The essentials in relation to the stable, then, are: Sufficient pure air and light; freedom from dust; clean floors, gutters, walls and ceiliogs; and clean surroundings, free from manure and rubbish.

\section{Care of the Cows}

All cows should be tested with tuberculin before their milk is used for human consumption, either as raw milk or in the form of cream, butter or possibly even cheese. The germs of tuberculosis have been freçuently found in milk, cream and butter. Those remarkable surgeons, the Mayos, of Rochester, Minn., have recently shown the large proportion of tuberculosis of the abdominal organs among their patients who come from the agricultural regions. The natural inference which they draw is that the source of the infection in these people must be from milk, since they are milk-users, and germs entering the lungs in the air would cause tuberculosis of the lungs, or consumption.*

The milk of cows which are being tested with tuberculin may be used, providing that they do not react to the test. It is well, also, that a veterinary surgeon familiar with cattle examine each herd of cows twice a year.

Cows with garget $\uparrow$ should be milked by one who does not milk the other cows, and animals about to calve should be kept apart from the herd. In view of the wonderfully successful results from the use of air for inflating the udders of cows suffering from milk fever, it will be wise for

* Having caked udders or pus (slime) and blood in the mill:.

$\dagger$ In the light of most recent scientific studies and experiments tuberculosis in man appears to start more frequently in the digestive tract than was formerly supposed even when the disease is situated only in the lungs and other parts of the body. No cow should be placed in a herd until it has been tested and found free from tuberculosis. Such testing must be repeated once a year. One tuberculous cow may infect the entire herd. 
the farmer to keep the simple apparatus on hand for practicing the treatment. Every agricultural paper advertises information for obtaining and using the apparatus.

The hair about the flanks, udder, and the brush of the tail should be clipped short and the cows groomed onceor twice daily, if necessary, - one-half hour before milking, to allow dust to settle.

Before each milking, the udder should be wiped with a clean, damp towel, or washed, if necessary, with soap and water and dried with a dry towel.

The towels must be clean and the water pure for this purpose. The teats and udder should always be dry during milking. It is well to tie up the cow's tail to the stall while milking. Handling the udder stimulates the flow of milk. So that the udder should be cleaned by a man or boy especially devoted to this work, who goes immediately ahead of the milker with pail of warm water, wash cloth, soap and clean towels. He can thus clean as many udders as would require ten milkers to milk. If the udders are cleansed some time before milking begins-as by the milkers themselves - the cows are apt either to leak their milk or to shrink in milk-yield. The general grooming of the cow's bodies may well be done some time before milking. Do not allow the cows to become excited by hard driving, abusive treatment or even loud talking.

The best plan is to allow no talking whatever to the cows at milking, and then, when there is a change in milkers, it will not influence the animals so much. 


\section{CHAPTER VI}

\section{HANDLING OF MILK AND CREAM}

\section{Milkers and Other Employees}

7 HE milker should be clean.* Before milking he must wash his hands thoroughly with warm water, soap and a nail brush. The hands must be well dried on a clean towel before milking is begun.

A special suit of clean, washable outer garments should be worn during milking and at no other times. When not in use they must be kept in a clean and airy place. Each milker must be provided with a lantern when milking is not done in daylight, unless the barn can be otherwise lighted.

Milking ought to be performed at the same hour, morning and evening. Milking must be.accomplished quietly; jerking the teats causes dirt and germs to drop in the milk and is not permissible. $\nmid$ The first few jets of milk from each teat must be rejected, because the germs are washed out of the milk cistern by the first part of the milk. If any of the milk in the pail becomes contaminated through accident or through mixture with stringy or bloody milk from the udder, the whole must be thrown away. Milking stools must be clean; iron stools, painted white, are recommended (see Fig. 3), or, better, the use of a milk pail as a seat (see Fig. 3c, page 74).

* Milkers should be clean shaven and wear clean, washable coats. Hair on the face is inadvisable.

$\dagger$ For more detailed account of milking and use of milking machine, see Appendix, p. I89-I92. 
After the milker has donned his milking suit and washed his hands, he should touch absolutely nothing but the cleaned teats of the cow and his clean stool and milk pail. Where great care is observed the milker is required to wash his hands after milking each cow.

No person employed to milk, or handle milk in any way, should have, or have come in contact with, any contagious disease. In case of illness in the household of an employee a physician's certificate should be required of the employee stating that the illness is not communicable before permitting the employee to come in contact with milk in any manner.

FIG. 3 .

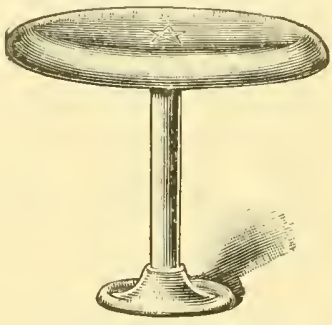

Iron Milking Stool.

The safest rule is to debar a person from handling milk who has throat trouble or any disease, or has come in contact with a patient suffering from contagious disorder, or entered a dwelling in which there has been contagious disease.

The milk pail is an important factor in the production of clean milk. The writer first employed a pail which has a removable cover crowned up so that it is about four inches above the top of the pail, with a hole in the cover six inches in diameter. The pail has a spout arising from its upper part and reaching a little above the cover of the pail when it is in place. The spout on the pail is covered by a removable metal cap. 
Two layers of sterilized cheese cloth are placed across the top of the pail and then the cover is fitted on over the top of the pail, stretching and holding the cheese cloth in place. When the pail is full it may be emptied through the spout without disturbing the cheese cloth, and so be used through a whole milking. The gauze is washed in warm water, then in soda and water, and rinsed in cold water and boiled 20 minutes, or placed in the steam sterilizer before being used again. The Gurler milk pail (Fig. $3 a$ ) is very similar, with a removable cover, the opening in which is

FIG. 3B

FIG. 3A

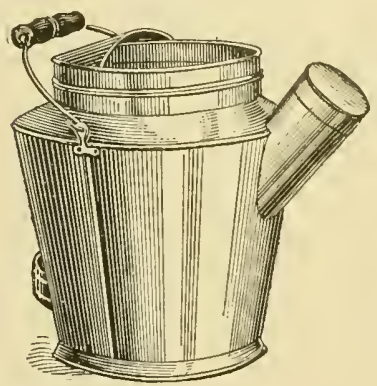

The Gurler Milk Pail.

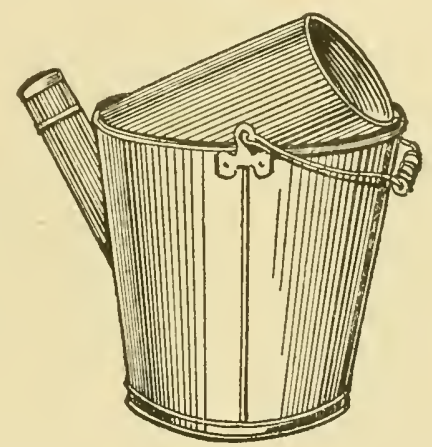

A recent improvement on the Gurler Pail.

larger than it need be, however. Otherwise it is a very satisfactory pail. Cheese cloth is laid over the top of the pail and the cover is fitted on, stretching it into place. Experiments have shown that milking through a clean cheese cloth strainer is capable of yielding a comparatively clean milk, even in rather dirty premises.

The writer has recently known excellent results with the use of a milk pail modified from one described by Stewart of Philadelphia. This is made of spun steel, IO $/ 2$ inches high, and is covered with a flat, removable lid on which the milker sits. The milking is done into a spout 
which has an expanded opening 7 inches in diameter. The spout is covered at the end by a removable pan, and the bottom of the pan is a wire strainer-roo meshes to the inch. The opening of the spout is nearly vertical, so that dirt will not easily fall into it. A ny metal worker can make such a pail. Stewart's pail may now be procured of the Star Milk Cooler Co. Stewart found that milk in this pail contained only 29 germs, as against 125,000 germs to the quarter teaspoonful of milk drawn into an open bucket.

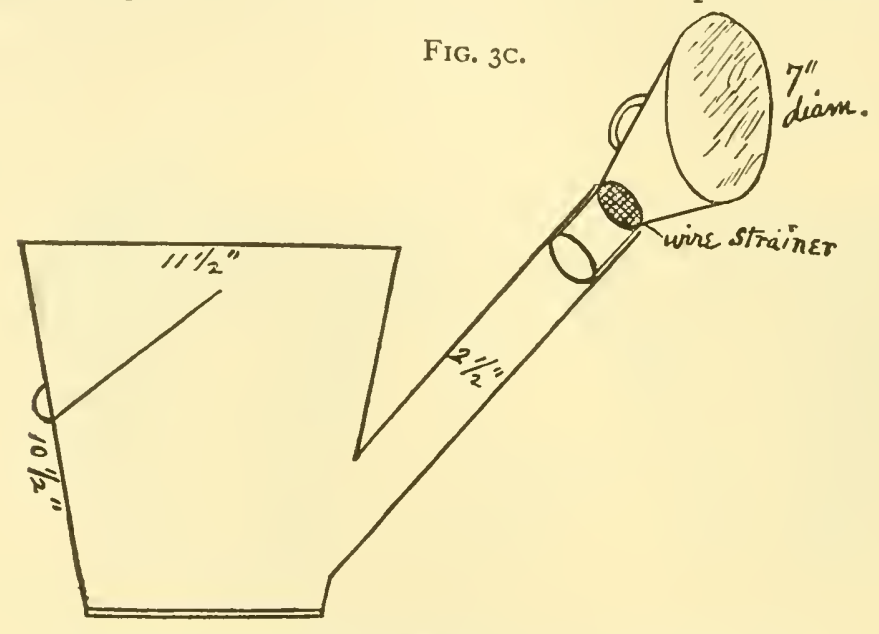

Modification of Stewart's Milk Pail, the most satisfactory to the author.

The metal strainer is safer where milkers are unreliable, as they will handle cheesecloth strainers and lay them down in dirty places. Cotton wool laid between two layers of cheesecloth to strain milk-while milking-into the pail, is more effective than cheesecloth alone, but we have found that the cotton wool is matted in lumps by the jets of milk and that only those absorbent cotton strainers made by dairy supply companies for the purpose are to be recommended. We have been content with the good results obtained from cheesecloth alone. 
The handling of milk may be conducted properly in many ways. Some of these are very simple and inexpensive ; others, which are quite expensive and elaborate, are required for convenience and certainty when large quantities of milk are to be handled in the most approved style.

To such a degree of refinement has this matter been carried, and such a multitude of utensils have been devised, that the inexperienced, would-be dairyman is disheartened at the very outset by the great number of appliances which he finds are alike recommended and reviled by his various advisers. The matter of the best way to handle milk is a source of constant study, and improvements are as constantly taking place, and while there will never be a time when competent men will all agree on special details, yet they are agreed on the principles and essentials of the business. We have already described the principles, and dwelt upon the facts which have led up to the establishment of those principles; we now propose to devote our attention to the essentials in handling clean, pure milk. First: We will consider those essentials necessary to insure the continuance of the cleanliness of the milk until it reaches the consumer, and then the various devices for convenience, laborsaving and system required in handling large quantities of milk in the best manner known at the present time-alway's with the admitted possibility of improvement in details.

The milk room is the first essential. It must be clean, proof against dust and extreme weather conditions, and separate from barn and house. It need not be expensive or elaborate. The floor, although preferably of asphalt or cement, may be of oiled or painted wood (if smooth and tight), and if on the level with the bottom of the milk wagon, will make it easier in loading the milk. 
All water and washings from the room must be carried away in pipes to a point fifty yards from the milk house.

The milk room should be surrounded by grounds free from rubbish, pools of milky water, or dust (fifteen grains of dust have been shown to contain as many as seventy million germs), and should be at least forty feet from the barn.

It must be well lighted, with mosquito screens at the windows and doors. The windows and doors should be closed, as far as possible, at the time the milk is handled in the house, to exclude dust-ventilation being obtained by the King system. If there is a closed porch or vestibule, it will be an added safeguard against the admission of dust in windy weather, by providing an entrance with double doors. The construction of the milk room may be of wood, with walls and ceiling of wood or plaster, preferably painted. Whitewash may, however, be used on the inside of the room and should be renewed every three months. Scrupulous cleanliness must be observed in the milk room, and it should be kept as dry as possible in all its parts, with no spots of mold on the walls. No sour milk should be left in the room, as the sour milk, or lactic acid germs, will get into the fresh milk. The milk room ought not to be used for any other purpose than to handle the milk, and should contain nothing that is not required in handling milk.

When milk is to be shipped in cans, the following utensils are essential :

Milk pails.

Receiving tank or cans.

A strainer.

A cooler or aerator.

A collecting can.

Shipping cans with all seams flushed with solder. 
A tank for washing purposes.

A tank for immersing cans in cold water.

Also washing soda or soap powder, brushes to scrub utensils and inside of cans, and cheese cloth for straining purposes.

Pure hot and cold water, and steam if busi- ess is conducted upon a large scale.

\section{Method of Handling Milk To Be Shipped in Cans}

Cooling the Irilk.-I can not agree with such authorities as Dr. Chapin, of New York (than whom no one has done more to introduce clean milk into that metropolis), when he says on page $13 \mathrm{I}$ in his book on "Infant Feeding": "For cooling the milk to best advantage a can placed in ice water is better than the commercial coolers." Clean milk calls for milk cooled to below $50^{\circ} \mathrm{F}$. within an hour.

This will not be accomplished by placing milk warm from the cows into large cans and then immersing the cans in ice water, unless by constant stirring of the milk in each can. Warm milk placed in quart bottles and immersed in ice water can be cooled properly - that is, to $45^{\circ} \mathrm{F}$.-within the hour. When milk is, obtained from cows giving milk varying greatly in composition, as is usually the case, it must be thoroughly mixed before bottling. But, inasmuch as half an hour or more is commonly required to milk sufficient milk to mix, and inasmuch as one can not keep warm milk for this period without great increase in germs, the only way is to cool each pailful as soon as it is milked.

Then the milk may be kept an hour or more before it is mixed and bottled. I started out prejudiced in favor of cooling milk by immersion of cans or bottles in ice water, but did not find it practicable, except under certain conditions (see p. 84).*

The chief essential consists in immediate cooling of the milk. When milking begins, as soon as a milk pail is filled,

* Tliere is no doubt but that the cooler and all apparatus, not necessary in handling nilk, should be abandoned when possible. Tlie oftener milk touches objects the more likely will contamination result, especially by aeration in a dusty atmosf,here. But immediate cooling is essential. 
the milk should be taken directly to the milk house and the milk poured into the strainer, which is placed in the receiving tank of the cooler. The milk runs over the cooler and is received in the shipping can, which, when filled, should be immersed in a tank of cold or iced water above the shoulder of the can with the cover of the can left off until shipping time. The milk, falling from the cooler, should pass through two layers of cheese cloth laid over the top of the shipping can. The milk should be cooled below $50^{\circ} \mathrm{F}$. Two types of coolers or aerators are in common use. Aeration,* or exposure of the milk to air, is not essential if the milk is withdrawn from the cow in a cleanly manner, but if the milk is more or less contaminated with manure, by impure air or by odors caused by imperfect feeding, aeration frees it to an extent of so-called animal odor. The coolers in ordinary use do, however, aerate the milk at the same time that the milk is cooled. The conical cooler (Fig. 4) may be employed when a moderate quantity of milk is to be handled, but requires more labor, as, in order to cool the milk satisfactorily, the water in the aerator must be constantly stirred to continually change the layer of water lying against the inner surface of the tin over which the milk runs. This aerator is fitted with an inflow and outflow pipe for running water, at either side of the base of the aerator, but unless the water is near the freezing point, it is better to fill the aerator with cracked ice, salt and water. In this case the aerator may be simply used as a storage tank for ice water, and both the inflow and outflow pipes are closed. By constant stirring of the ice water in the ærator while the milk is flowing, it is possible to reduce the tem-

\footnotetext{
* Aeration is inadvisable, in so far as the milk is exposed to germs in the air during the process.
} 
perature of the milk coming from the cooler to below $50^{\circ} \mathrm{F}$. In this style of aerator the milk flows from the reservoir at the top through fine holes all about the base of the reservoir out on to the surface and corrugations of the cooler, collects in the gutter below, and is carried off by the pipe leading from the gutter (in the front of the aerator in the cut) into the shipping can. Often these holes are too large

FIG. 4.

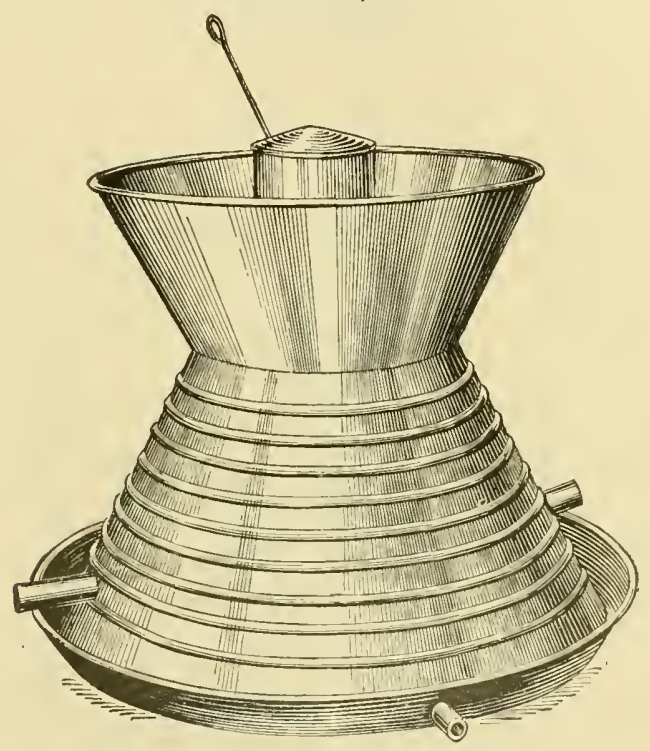

The Conical Cooler.

or too numerous, allowing the milk to flow too fast, when some must be closed by solder. This kind of aerator works very unsatisfactorily if the water is not constantly stirred, and is not to be recommended if running water is at command and permits of use of a star or tubular cooler.

The Star cooler (Fig. 5), or that of the tubular variety (Fig. 6), are by far the most efficient, certain and convenient coolers, although more expensive in first cost than the 
conical ærators. The much greater surface offered by the tremendously corrugated form of the cooler, together with

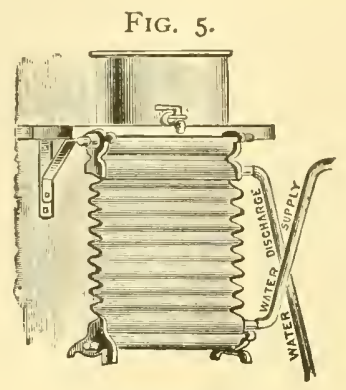

Star Cooler.

the forced circulation of water which flows continuously from below upward through the cooler, account for the superiority of this type of cooler.

Fig. 6.

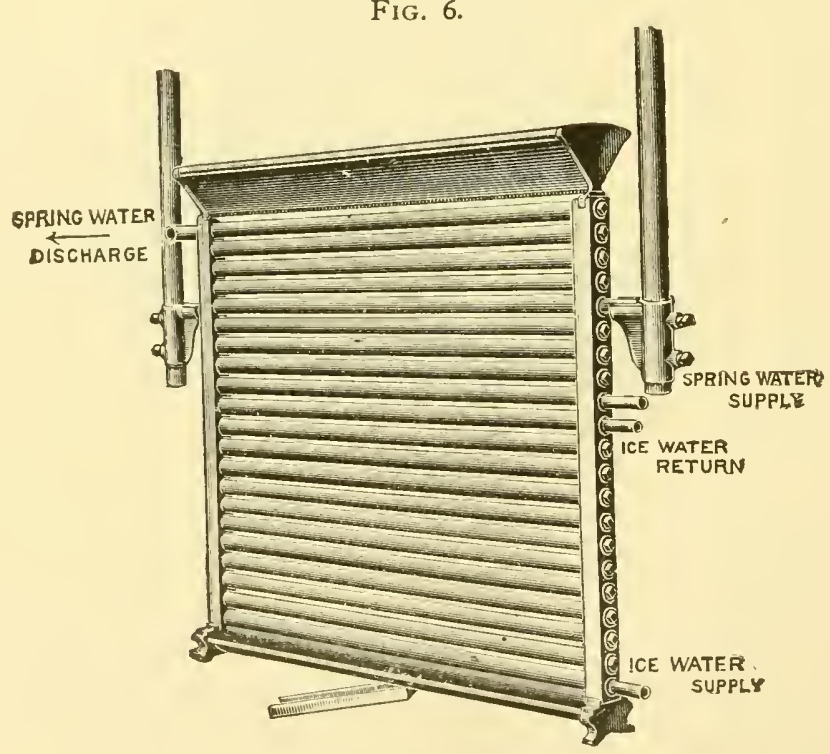

Tubular Cooler.

The temperature of the milk may be lowered to a point two degrees above that of the water circulating through the cooler. 
The Star cooler is made of two sheets of corrugated copper, tinned on its outer surface, which comes in contact with the milk. The water enters below, filling the entire space between the copper sheets, and flows upward through the cooler, while the warm milk drops through the holes punched along the whole length of the feed trough at the top of the cooler and flows down over both cooling sheets. As the milk is cooled, flowing down the outside, the water is warmed as it moves up the inside of the cooler (see Fig. 5).

FIG. 7 .

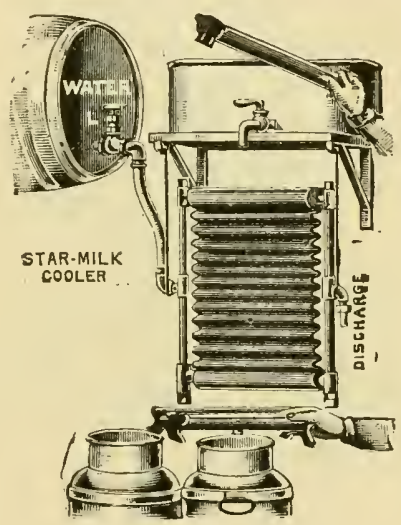

Star Milk Cooler.

The water supply for the cooler may be obtained in various ways: From a common source of water, as a town supply ; from a barrel or tank over the cooler (see Fig. 7); or from a barrel beneath the cooler by means of a siphon attachment (see Fig. 8). If it be desired to cool the milk much under $50^{\circ}$, it may be necessary to use ice water in a part of the cooler.

This is most economically accomplished by an ice water section, which is made to be hung on the bottom of the Star cooler and is practically a small counterpart of the 
larger cooler above (Fig. 9). Ice water is run through the ice section alone and is obtained from an overhead barrel holding broken ice, over which water is sprayed from a large-surface nozzle, and flows from the barrel through a short hose through the ice water section.

A similar result may be secured by using a tubular cooler (Fig. 6), arranged so the general water supply may be run through the upper half of the cooler, and the ice water or cold brine through the lower half. By either of

FIG. 8

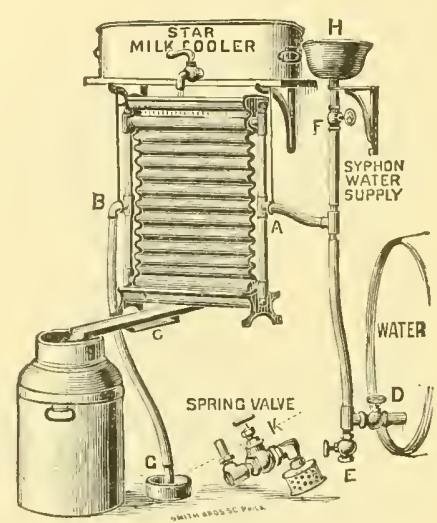

Star Milk Cooler

these contrivances milk may be reduced to a temperature below $40^{\circ}$.

In place of the spray-head for sprinkling water on cracked ice in a barrel, to supply the ice water section of the Star cooler, it has been found (by my friend Mr. Paulhamus, of Sumner, Wash.) that the following arrangement is better: A medium-sized cask is lined from top to bottom with a coil of a hundred feet or more of half-inch pipe. The water supply is connected with the bottom of the coil, and the top of the coil is connected with the ice water section of the Star cooler. Large pieces of cracked ice are 
used to fill the cask to the top, to which may be added rock salt and then water. If salt is used, care must be taken to have the water running constantly through the coil in the cask, otherwise the water will freeze in the coil. This way of cooling the water supply for the water section of the Star cooler is both more convenient and satisfactory because the cask may be placed directly on the floor of the milk room, instead of up in the air as required for the sprinkler, and much less ice is used than when a sprinkler is employed.

\section{FIG. 9.}

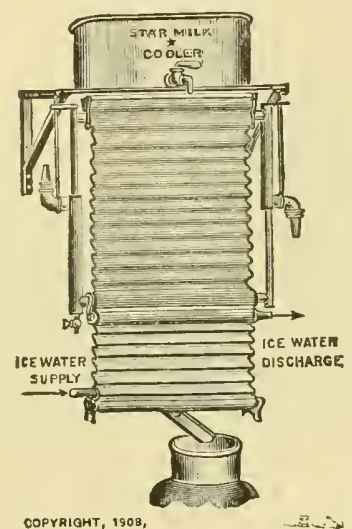

Star Milk Cooler.

The advantages of such arrangements consist in utilizing the natural temperature of the regular water supply of the dairy to do the chief part part of cooling the milk, while the ice water is only required to complete the smaller part of the reduction of temperature in hot weather. There are many different sizes of both the conical, tubular and Star coolers adapted to the quantity of milk which is handled. The tubular coolers are constructed to withstand high water pressure, while the Star coolers are not.

While milk may be simply poured from the milking 
pails through two or three thicknesses of cheese cloth into a receiving can, from which it is transferred to the receiving tank of the cooler, a better form of strainer is the trap variety (see Fig. 10), which is placed in the receiving tank of the cooler. The milk is poured into the upright funnel, and has to rise from below up through the cheese cloth strainer to seek its level.

Particles of clirt and foreign matter would naturally, through gravity, fall to the bottom of the vessel and not be forced through with the milk, as commonly happens when milk is poured from above through a strainer.

FIG. Io

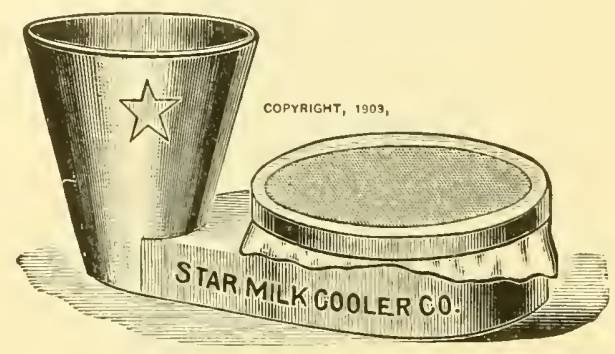

Trap Milk Strainer.

The simplest, cleanest and most inexpensive method of handling milk is to place it-as soon as milked-in a bottlefiller tank and run it at once into bottles and immerse the bottles in ice water. By this method, the need of a cooler is avoided and the chance of germs getting in to the milk during its exposure to the air in running over the cooler. On the other hand, there are two objections. There should be four milkers or so to supply enough milk at any time, so that the mixed milk from a number of cows may be bottled. If one waits until milk from several cows is obtained, with one or two milkers, the germs will have a chance to multiply in the warm milk. The other objection consists in the 
immediate bottling of milk without aeration. This objection does not hold if the milk is withdrawn from clean cows in well ventilated stables, and milk is handled in this manner in many of the best dairies.

The milk will be cooled to $45^{\circ} \mathrm{F}$ in ice water in an hour and by no method will the cream rise more rapidly.

Hot Watcr.-Hot water may be readily obtained at comparatively small expense from a tank, such as is commonly employed for supplying households with hot water when attached to the kitchen stove, by connecting the tank with a coil of pipe placed in an ordinary air-tight, wood stove. If a steam boiler is in use, the steam may be run into a tank of cold water.* In either case the stove or boiler should be placed in an adjoining room, to avoid dirt, while the tank is in the milk room.

Cleaning Utcnsils.-After milking, all the utensils, including milk pails, receiving tank, cooler, straining cloths, etc., should be at once rinsed in cold water, then washed in hot water and soap powder or washing soda (sodium carbonate in 3 per cent. solution), and rinsed again in clean, cold water. Finally, all metal dairy utensils should have boiling water poured over them, which sterilizes and dries them at once. Dairy utensils should never be dried with towels. The cans should be scalded with boiling water or have live steam turned in them and be placed upside down on bars to drain in the milk room, thus also admitting air. Rusty cans should never be used; they sometimes impart a fishy taste to milk. A fishy flavor is said to be given to milk and butter when washing powder is not well rinsed from dairy utensils, also by cows drinking stagnant water.

The strainer cloths used over the milk pails and other utensils may be of various materials. The writer has em-

* The steam heating tee is a most convenient appliance for heating water (see page 95 ). 
ployed chiefly cheese cloth or rather gauze (which is cheese cloth prepared by washing, to remove the sizing and impurities, and dried), of the finest mesh, and two layers in thickness.

A single thickness of coarse cotton flannel or Turkish towelling may be used, however. When the strainer cloth can not be sterilized in a regular sterilizer, it should be boiled for twenty minutes wrapped in a towel or clean cloth and left enclosed in this wrapping until used. Then it should be removed, but the fingers should not touch that part of the strainer cloth which will come in contact

FIG. II.

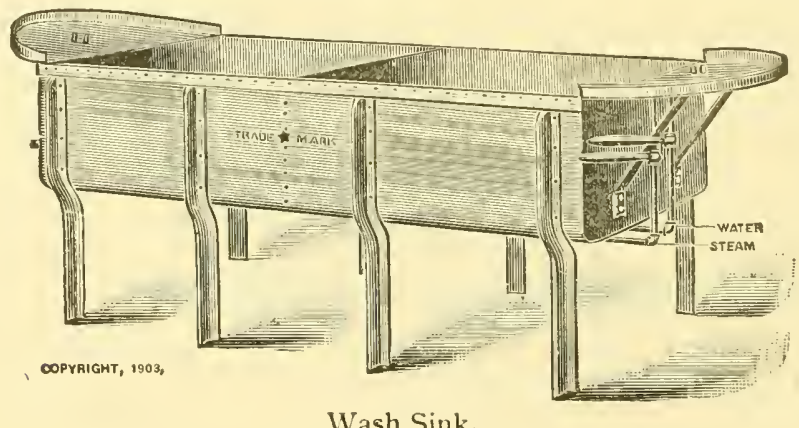

with the milk. Before sterilizing the cloth, it should be well rinsed in cold water, washed in hot water and washing soda, and rinsed in cold water again. Every little detail must be carried out conscientiously, as one failure in caring for the milk properly will spoil the result entirely.

A convenient arrangement, when steam is employed, is the wash sink (see Fig. I I), provided with draining trays at each end. The can is placed upside down over the two nipples in the tray, one supplying a jet of water to rinse the can, and the other a jet of steam to sterilize or kill germs in it. Various forms of brushes are desirable for scrubbing 
the utensils (see Fig. 12). They should be boiled daily for ten minutes after use.

To keep milk cool in cans during shipment the refrigerator car is commonly employed. Where this is not possible, the writer has known of the use of a cylindrical, hollow can of tin, with open top and closed bottom, being suspended bottom down, well into the milk or cream, from the mouth of the shipping can, and filled with cracked ice. The milk can jacket, made of hair, felt and canvas, will protect cans against the effect of heat and cold to a considerable extent (see Fig. I 3 ).

FIG. 12.
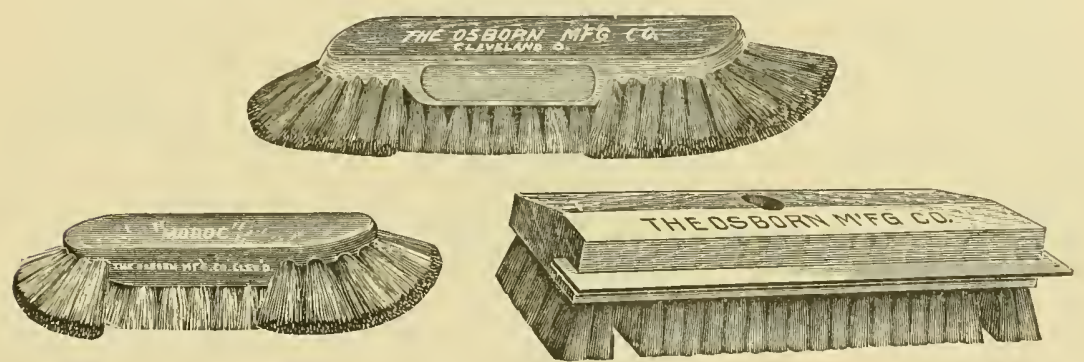

Various Forms of Brushes.

Bottled Milk.-If milk is to be shipped in bottles instead of cans, the following utensils will be essential in the milk room :

Glass Bottles, made to withstand heat, and Delivery Boxes.

A Receiving Tank, with Trap Strainer.

A Cooler, with Ice Water Section.

A Collecting Tank.

A Bottle Filler, with Table.

A Sterilizer.

A Washing Outfit.

The cooling arrangement is precisely as described above for cooling milk to be shipped in cans. When there are eight or ten milkers, so that the milk from as many cows may be mixed as soon as milked without loss of valuable 
time when it should be cooling, then the warm, mixed milk may properly be drawn directly into the bottles from the bottle filler. The bottles should, on being filled, be instantly immersed to the neck in ice water. In this way bottled milk may be suitably cooled, with the avoidance of the unnecessary exposure to two tanks and the air in passing over the cooler. The bottle filler is indispensable (see Fig. I4) for conveniently filling several bottles at once. By moving a lever one can fill from four to eighteen bottles to the same level at one time. The prices of these contriFIG. I3.

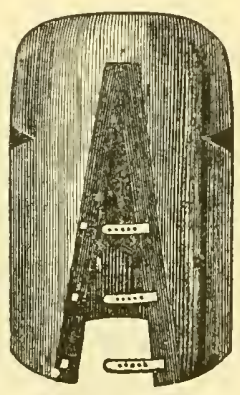

Milk Can Jacket.

vances vary greatly with the size and material used in their construction.

The sterilizer is an important utensil. It is a tight chamber into which steam is turned, with the object of destroying germs, and is made to hold the bottles and absolutely every other dairy utensil with which milk comes in contact.

The germs are not only those which may have inhabited the milk, but occasionally there may be germs of disease contaminating the returned bottle, owing to it having been in a house in which such disease existed.

There are two styles of steam sterilizers-those in 
which the steam is not under pressure, and those confining steam under pressure.

The latter type is more efficient, in that with steam under pressure it is possible to obtain a much higher temperature than when it is not. Steam, when not under pressure, will not exceed in temperature boiling water $\left(2 \mathrm{I} 2^{\circ} \mathrm{F}\right.$.). IVith a pressure of ten pounds and a temperature of $24 \mathrm{I}^{\circ} \mathrm{F}$.

FIG. I4

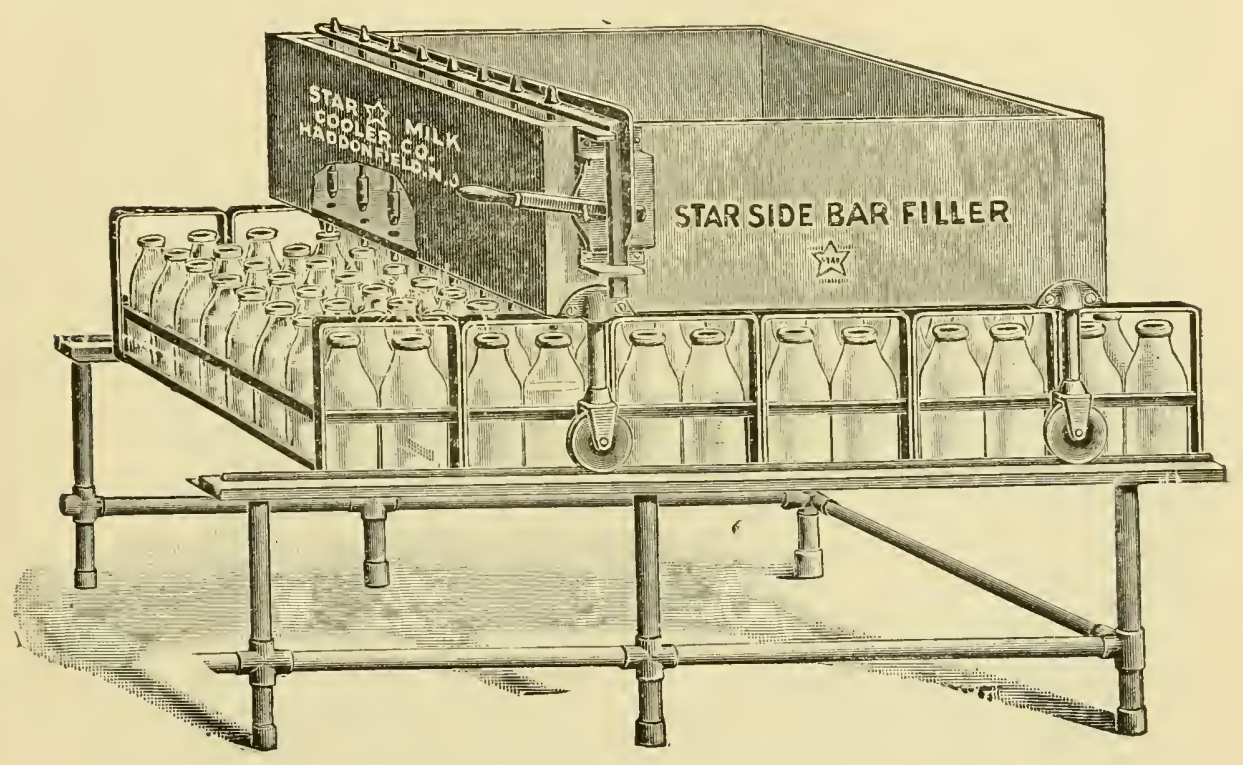

Star Side-Bar Filler.

in the high pressure sterilizers, it is possible to destroy the germs in the milk utensils with as much certainty in twenty minutes as with steam at $22^{\circ} \mathrm{F}$. in the low pressure sterilizers in an hour. The heavy pressure or high pressure sterilizers are, however, exceedingly expensive, and, if the bottles are properly washed, there is practically no danger in relying upon the less expensive steam sterilizers in which the steam is not confined under pressure.* In Fig. 15 is

* Indeed, washing and sterlizing may be done at the same time (see page I85). 
shown a high pressure sterilizer. It must be built very strongly to withstand the pressure, which is over fifteen tons against the door alone, with a pressure of ten pounds of steam in the sterilizer. The matter of a sterilizer in

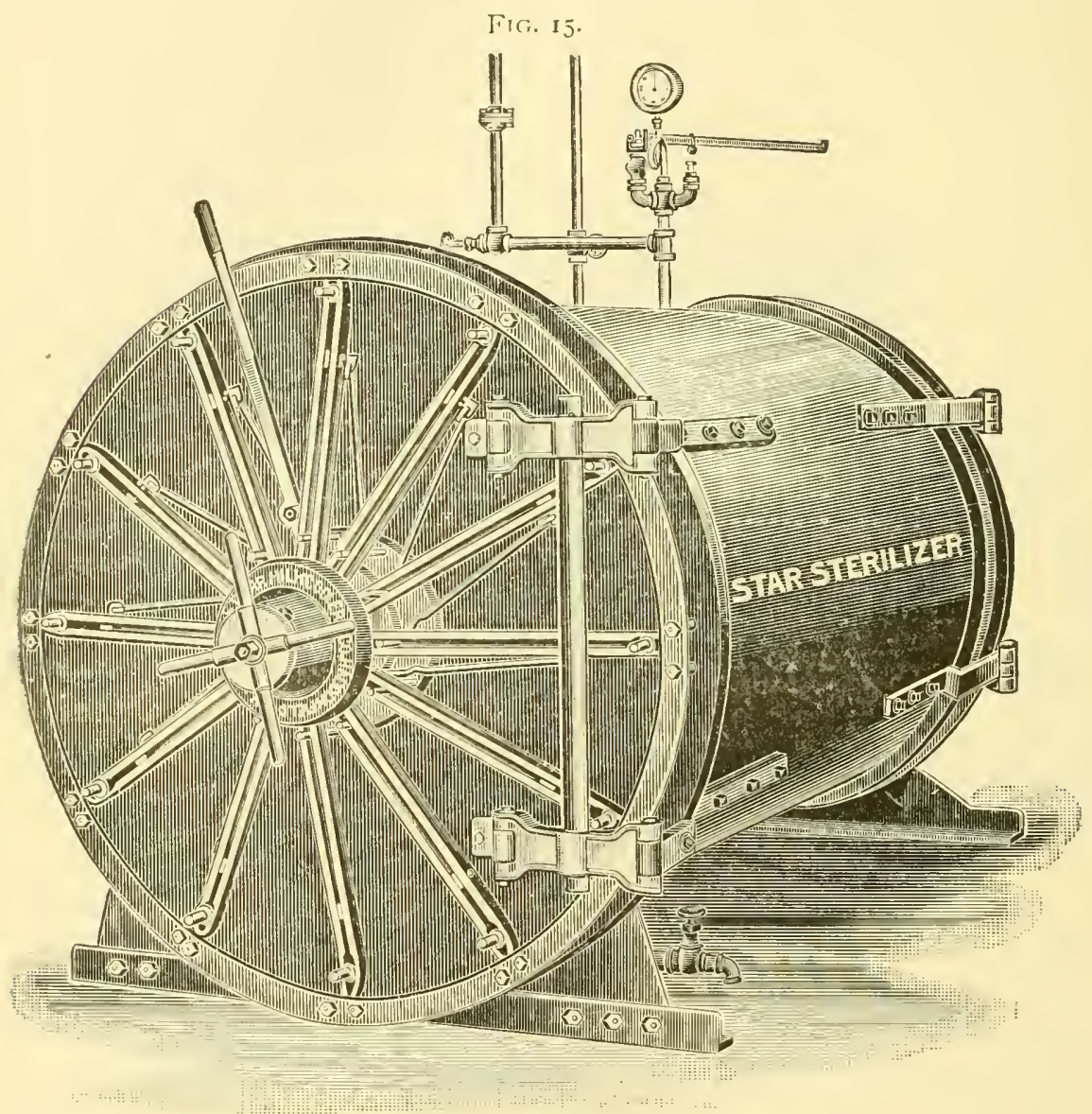

Star High Pressure Sterilizer.

which the steam is not confined under pressure is a comparatively simple affair.

One may be home-made. The writer had a sterilizer built of two-inch plank, lined with galvanized iron, with double doors fastened with an iron bar across the front. 
The shape was nearly square and the capacity was about 250 quart bottles. There was a movable sheet of galvanized iron, partitioning the sterilizer in two, and movable shelves of the same, perforated with holes, in which the bottles rested upside down on their shoulders. The shelves stretched horizontally across the sterilizer, from each side to the partition in the centre, resting on galvanized angle irons soldered along both sides and on cach side of the partition in the centre.

The shelves were just far enough apart to give room for a tier of bottles. Shelves and partition were removed to allow of room for sterilizing the milk pails, cooler, bottle filler and strainer, cheese cloths, and tanks supplying and receiving milk from cooler, etc. The sterilizer was fed from a ten horse power boiler with steam from below, and also had an exit or exhaust in the bottom, while at the top there was a hole in which was a cork holding a thermometer in place, with bulb inside and recording part outside of sterilizer. The doors were not steam-tight, and no pressure of steam was attempted or possible in the sterilizer, but the temperature was raised to $212^{\circ}$ in about twenty minutes, and maintained for the time-one hour-occupied by sterilization.

A very successful sterilizer has recently been made by my friend, Hon. W. H. Paulhamus, of Sumner, Wash., entirely of concrete faced with cement, and costing about $\$ 75.00 . *$ It is a rectangular chamber $61 / 2$ feet high by 8 feet wide and about 14 feet long and 6 inches thick, with one iron door. In the top, iron bars were used to reinforce the concrete. Two half-inch pipes enter one side of the chamber just above the floor for intake of steam from a twenty-five horse power boiler, and, at the top, there is a single

* See plate opposite page 184 . 
pipe for outlet of steam when sterilization is over to cool off the oven, and one to drain the floor. In the middle of one side there is also a pipe inserted, large enough to hold a thermometer. This sterilizer is enormous, and will hold soo dozen bottles and every bit of dairy apparatus used on four farms, including the milk pails and milk cans, coolers, and bottle filling apparatus, strainer cloth, etc. If one does not wish to make a sterilizer, the largest size only should be bought

FิIG. I6.

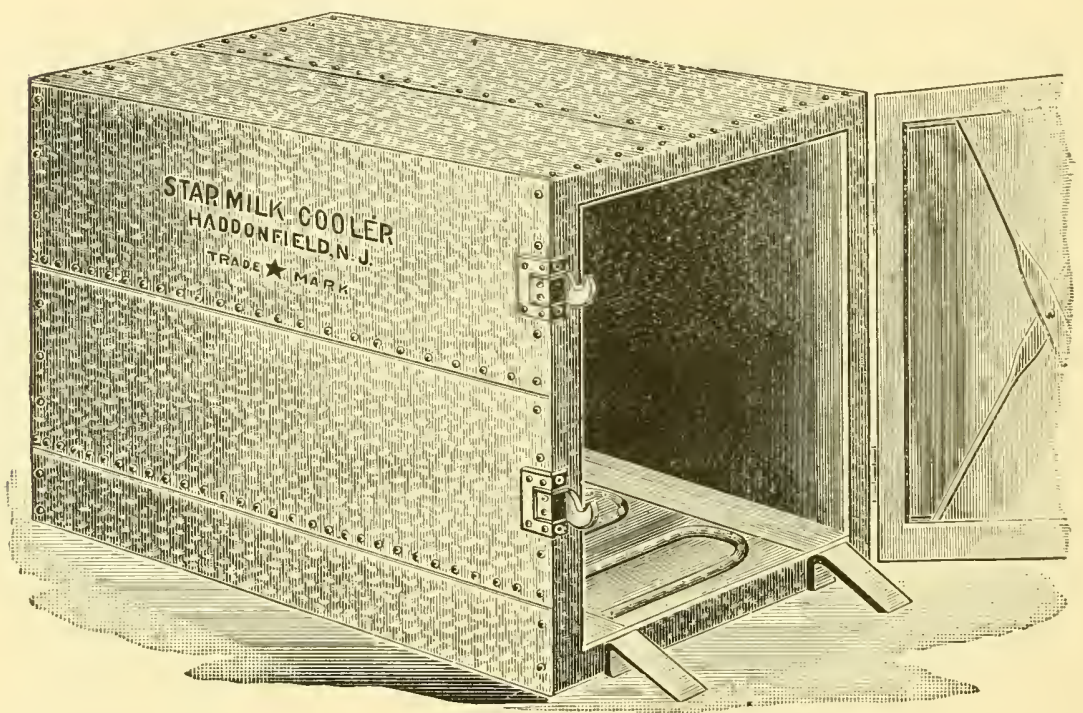

Star Sterilizer.

(Fig. 16), as it is most economical in saving the expense of doing several sterilizations daily, because with it all bottles and every article of dairy utensil can be sterilized at one time. In case the Star galvanized sterilizer is used, the bottle carriers described on page 102 may be employed to hold the bottles in the sterilizer, or a rack and truck similar to that pictured on page IO3 and IO4 may be utilized.

This sterilizer is made of heavy galvanized iron, 
riveted and soldered together, and holding from 240 to 632 quart bottles; according to the size. It is supplied with perforated steam coil and trapped drain outlet, and it is well to have an exhaust to carry off surplus steam, although the doors are not steam-tight when closed. A thermometer placed in the center of the door is also advisable. Both the heavy pressure and the galvanized iron sterilizers are made either with a door at one end or a door at each end. The latter arrangement is a convenience when there is a separate room for washing the bottles, the sterilizer being placed in the partition between the washing and bottling room and the bottles passed in the sterilizer through a door in the wash room and taken out through the other door in the

FIG. 17.

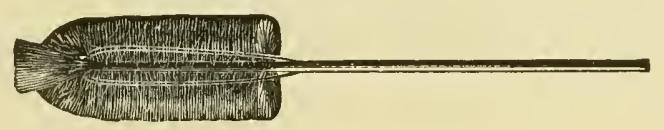

Bottle Brush.

sterilizer in the bottling room. Every single utensil with which milk comes in contact, including the various tanks and strainer cloths, should be thoroughly washed and sterilized after each milking for one hour at $212^{\circ} \mathrm{F}$. To avoid sterilization twice daily, however, it is better to have two sets of utensils, which may be sterilized all together once daily.

IVashing Outfit.-A separate room should be provided for washing milk utensils where the best plan is pursued. Since we are considering the essentials for handling clean milk we have not included a wash room separate from the milk room, as clean milk can be handled in a combination bottling and wash room, although not to the best advantage. The bottles should be rinsed in warm water and washed with 
washing soda and hot water (in 3 per cent. solution) with a bottle brush (see Fig. I 7 ), and then rinsed in clean hot water and inverted over the trays or shelves, which are placed in the sterilizer. The most convenient arrangement is such as that shown in the cut (Fig. Is), two tanks, one holding lukewarm water in which the bottles are soaked and the other hot water containing washing soda, while at the end there are projecting nipples over which the bottles are inverted, and, by turning the lever, several bottles are rinsed at once. Each tank has an overflow standpipe to carry off the grease floating on the top of the water.*

FIG. 18 .

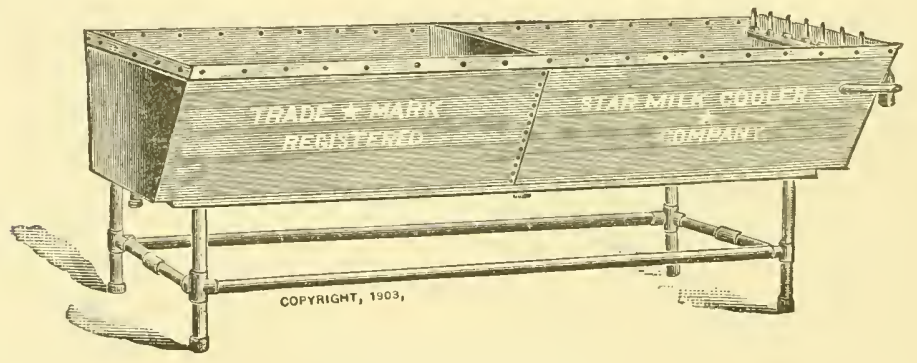

Star Metal Wash Sink.

An additional improvement is the turbine bottle washer shown in the illustration (Fig. I9). It consists of a revolving brush which is turned by a turbine wheel with steam at a pressure of twelve to fifteen pounds. In this cut are shown the two large tanks on the left, for soaking and washing bottles in washing soda and water, and then the small tank, next the bottle washer, over which the bottles are inverted to be rinsed inside. This is accomplished by nipples as shown in the cut (Fig. IS) spraying water into the interior of a number of bottles at one time, which are

\footnotetext{
* For a washing apparatus, where 1,000 or more bottles are handled, see Appendix,
} 
then dipped in the small tank below to wash the outside of the bottle, and are transferred to the tank at the extreme right to drain.

None of this special bottle-washing outfit is essential. Any convenient arrangement of tubs and hot water by which the bottles are put through three processes in washing-first rinsing in warm water, then in hot alkali and water, and finally in clean hot water-will suffice.

FIG. I9.

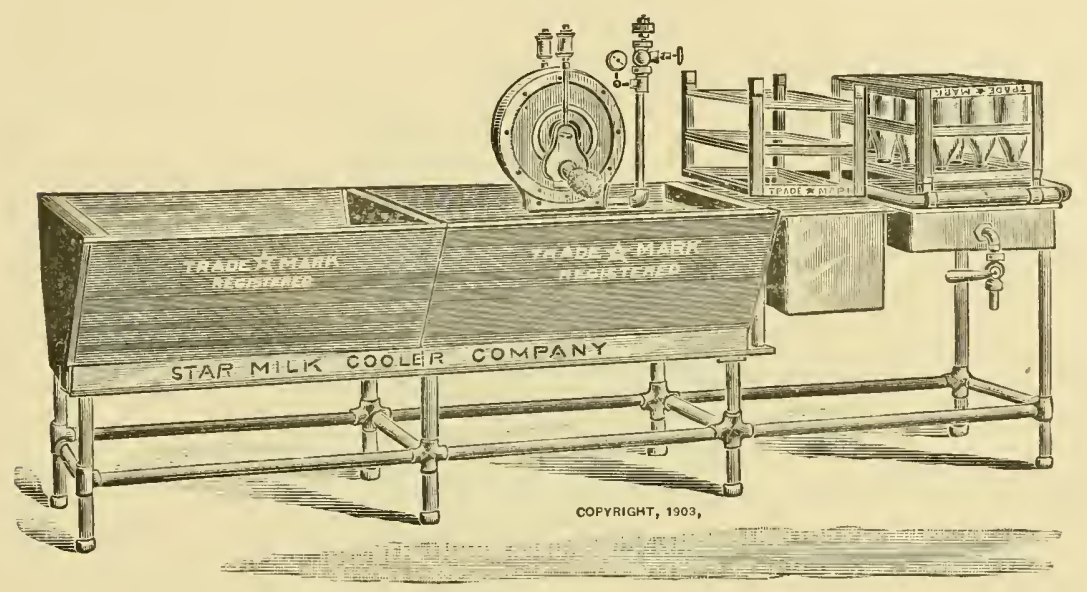

Star Bottle Washing Outfit.

If the bottles are thoroughly rinsed at the consumer's house the first rinsing in plain water may even be dispensed

FIG, 20

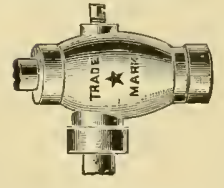

Steam Heating

Tee. with, provided the bottles are thoroughly scrubbed inside with a brush and hot alkali water and well rinsed in clean hot water. The hot water may be supplied from a hot water tank, as suggested (p. 85), or by means of a steam heating tee (Fig. 20).

This is an arrangement by which water may be heated to almost any temperature desired (short 
of boiling), by steam and cold water coming in contact, in varying proportions, according to the amount of either which is permitted to flow into the tee. Thus the steam enters the side and the water the top of the tee, both being regulated by valves in the steam and water pipes, and the hot water flows out below. Cold water or steam may be obtained separately also, from the device, which is comparatively inexpensive. A very convenient bottle-washing machine is shown in the Appendix (p. I 85.)

The routine of operating the dairy would be as follows: The empty, returned bottles would be taken from the wagon boxes into the milk room and there rinsed in warm water, in one tub, and then scrubbed with a brush in another tub holding alkali and water,. as hot as the hand can bear.

FIG. 2I.

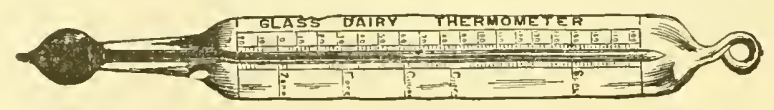

The bottles should be next rinsed in clean, hot water, inverted in the racks and placed in the sterilizer, where they are sterilized at $2 \mathrm{I}^{\circ} \mathrm{F}$. (by a reliable thermometer) (Fig. 21 ) for an hour. The bottles should remain inverted until used.

The milk is brought from the barn in milk pails or cans, as soon as milked, and poured into the Star trap strainer resting in the receiving tank of the Star milk cooler with ice water section. The milk flows from the collecting tank of the cooler through sterilized cheese cloth into a large can, if it is desired to thoroughly mix the milk of many cows before it is bottled. Instead of a can for mixing the cooled milk, it is better to use the large tank for filling the bottles--that is, the bottle-filler tank; and after twenty gallons or more of milk have flowed from the collecting-tank 
of the cooler into the bottle-filler tank, the milk should be well stirred with a sterilized stirrer and the bottles filled while the milk is being mixed. The stirrer may be made like a huge fork, from heavy tin.

The warm milk of several cows may be mixed in the barn by pouring the contents of a number of milk pails into a large can. But unless there are enough milkers to do this within a few minutes, it is better to carry each milk pail to the cooler, as soon as it is full and mix the milk after it

FIG. 22

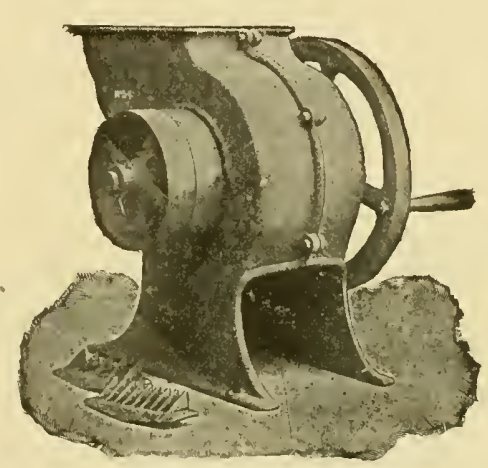

Machine for chopping ice used to pack about milk bottles.

has cooled. The time elapsing between milking and bottling should be as short as possible. The milk must be cooled instantly after milking, and be bottled within an hour of milking. In some establishments the milk is bottled within eight minutes of milking. The cooled, mixed milk is poured into the bottle filler and flows immediately into the bottles, which are then quickly capped with sterilized paper caps, and placed in the wagon boxes well surrounded with ice in warm weather. The milk should be delivered to the consumer the year round at a temperature not over $45^{\circ} \mathrm{F}$. If not shipped immediately-as in case of the night's 
milk-the milk may be stored in the wagon boxes over night with ice or kept in cold storage or in sufficiently cold water. (Fig. 22).

All the dairy utensils should be rinsed in clean warm or cold water as soon as the milk has been bottled and then washed with scalding alkali water and rinsed with clean cold water, and sterilized an hour in the sterilizer, including the cheese cloth used in straining the milk in the milk pails, in the Star trap strainer, and that used over the can in which the cooled milk is mixed. The floor must be kept damp to avoid dust, and the windows and doors should be closed while the milk is being handled for the same reason. W'hen dairy utensils are not in use, they may be kept in a sterilizer,

FIG. 23.

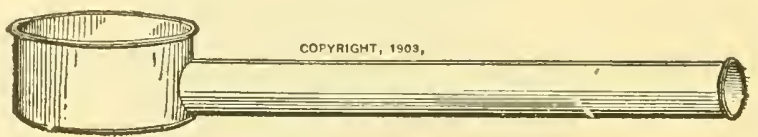

Banjo Conductor for carrying milk through a wall.

or, if this is not practicable, it is well in many milk rooms to cover them with a clean sheet, to keep off the dust, and to rinse the cooler with clean, cold water just before using, for the same reason. A properly constructed and managed milk room should be dust-proof and dust-free, and such precautions should be entirely unnecessary.

Turning live steam against the walls of the milk room each day is useful as an aid to cleanliness, provided that they are constructed to withstand the process.

The employees in the milk room ought to wear clean, washable clothes. Linen gowns, like those worn by butchers. which may be slipped over the clothes, are most convenient.

The final test of perfection of cleanliness of the rilk, produced as described, is the laboratory. Such tests should 
be made once a week. If the milk is sold as "certified," it must receive the sanction of some reliable and disinterested society or person. The bacterial content or number of germs should not exceed $30,000 *$ to the cubic centimeter, according to the consensus of authorities at the present time, in so-called certified milk. It is perfectly possible to produce milk which shall not exceed in number 2,000 to 4,0oo germs to the cubic centimeter by the comparatively simple and inexpensive plant which has just been clescribed above, as the author has practically demonstrated.

FIG. 24 .

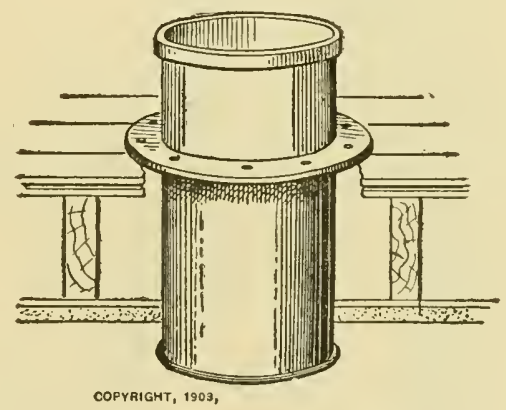

Cylinder for conveying milk through a floor.

A more perfect arrangement in a dairy building for handling clean milk is of advantage when one can afford it. The most important improvement consists in separating the bottling or milk room proper from the wash room, in which the sterilization and washing of the milk utensils are done, and to devote two rooms to these different processes. (I) The boiler and engine should have a separate room, and, adjoining this, (2) a room for washing and sterilization, and then a room (3) in which the milk is cooled and bottled. sions.

* I0,000 germs is the maximum number permitted by many Milk Commis- 
A still further development comprises the following in the dairy building :

A Milk Receiving Room.

A Milk Room.

A Bottle Room.

A Wash Room.

An Engine Room.
A Boiler Room.

A Cold Storage Room.

A Shipping Room.

A Lavatory.

A Laundry.

F1G. 25.

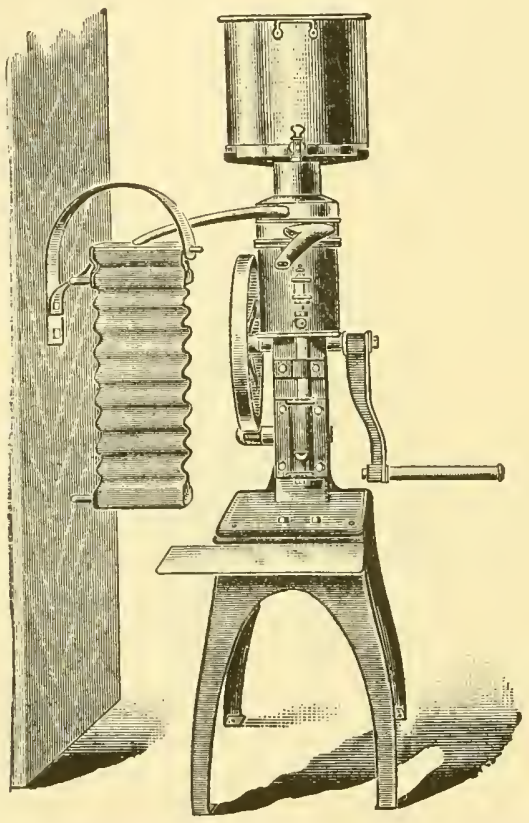

Cream Cooler connected with Separator.

The milk receiving room may be connected with the barn by a cable system by which two 5 to 10 gallon cans are suspended on can carriages running on an overhead wire. The milk receiving room is on a higher level than the milk room, so that the milk flows from it through the floor through a funnel or cylinder, or through the wall by a Banjo conductor (see Figs. 23 and 24) directly into the receiving tanks of the cooler or separator in the milk room below, thus avoiding unnecessary handling. 
The milk room should not be connected with tne outer air by a door or open window, but must be ventilated so as to exclude dust and only be connected with the other rooms. It contains the appliances for cooling and bottling milk we have already noticed, and also a separator, cream cooler and cream bottle filler (Figs. 25 and 26 ), if cream is to be made.

The bottle room adjoins the milk room, in which the clean bottles are kept after being sterilized. One end of the sterilizer projects into this room from the wash room.

FIG. 26.

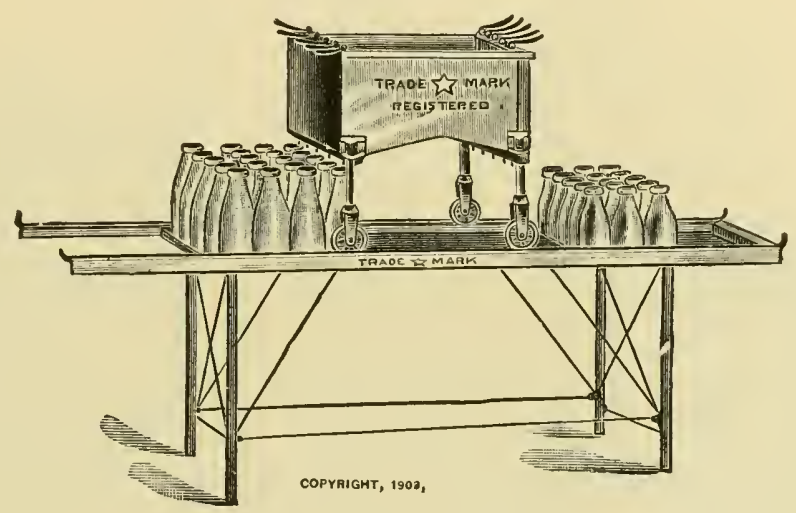

Cream Bottle Filler.

The wash room contains the sterilizer, the bottle washing outfit, and a Babcock tester. The cold storage room is of great convenience where large quantities of milk are handled and may be arranged with natural ice, or by means of ammonia compression and an artificial refrigerating and ice-making plant. The lavatory and laundry are for the use of the employees in the dairy, the former with a shower bath, set basin and dressing room, and the latter to wash the clothes used by the employees. In the shipping room are the cases for holding the bottles, and the floor platform for loading the wagons should be on a level with them. Where 
there is machinery, as for a refrigerating plant, it is well to separate the boiler by a partition from the engine and fire room and thus avoid the dust, ashes and dirt from fuel.*

Space does not permit of more than a brief outline of the more elaborate dairy plant, but we would refer to onet who makes a business of planning and installing such, from whom we have derived many valuable suggestions. The object of this book is to detail the less elaborate and more essential

FIG. 27

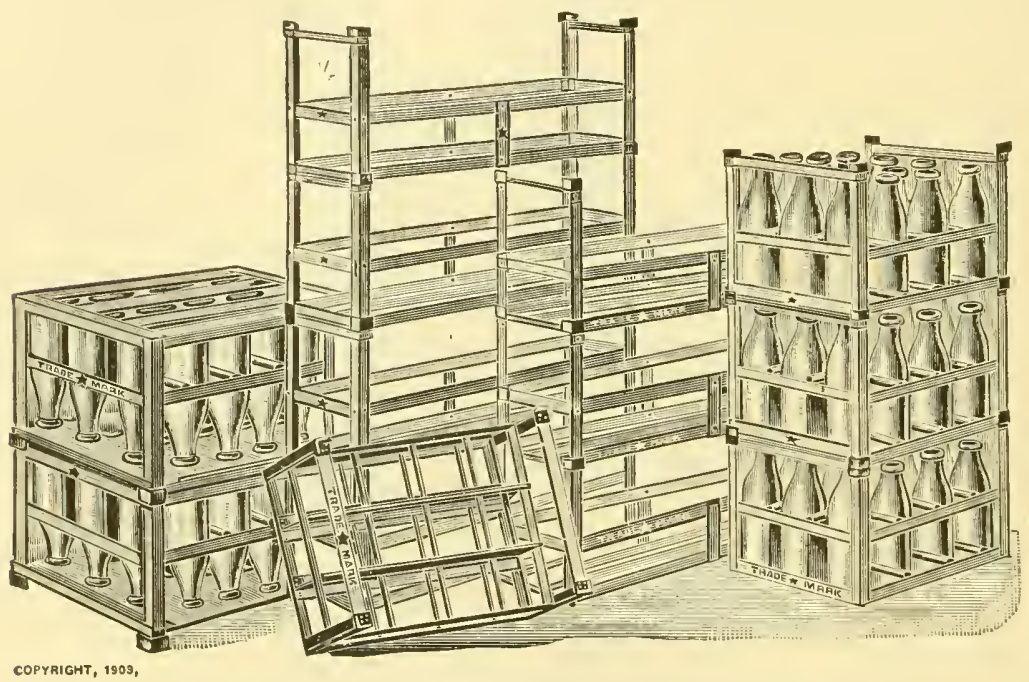

Bottle Carriers.

methods which may be used by the farmer without great expense in the production of clean milk on a moderate scale.

In the handling of milk bottles in the dairy, it is much more convenient-though not essential-if they can be transported and inverted in numbers without handling each bottle separately. Thus carriers have been invented for holding them, with reversing racks, so that the bottles may be inverted-as when they are sterilized-by turning over

* For plan of milk house, see p. 179.

† Samuel M. Heulings, Haddonfield, N. J. 
as many as 20 bottles at once (see Fig. 27). Cars are also made which are used to transport these carriers and the cars, carriers and bottles are all wheeled directly into the sterilizer and out again without handling the individual bottles (see Figs. 28 and 29).

Shipping Cases and Bores.-Milk bottles of glass must be shipped in some sort of box. The writer has had such boxes made of strong galvanized iron ( 24 gage) with rolled edges at all the joints, with a hinged cover and padlock, and

FIG. 28.

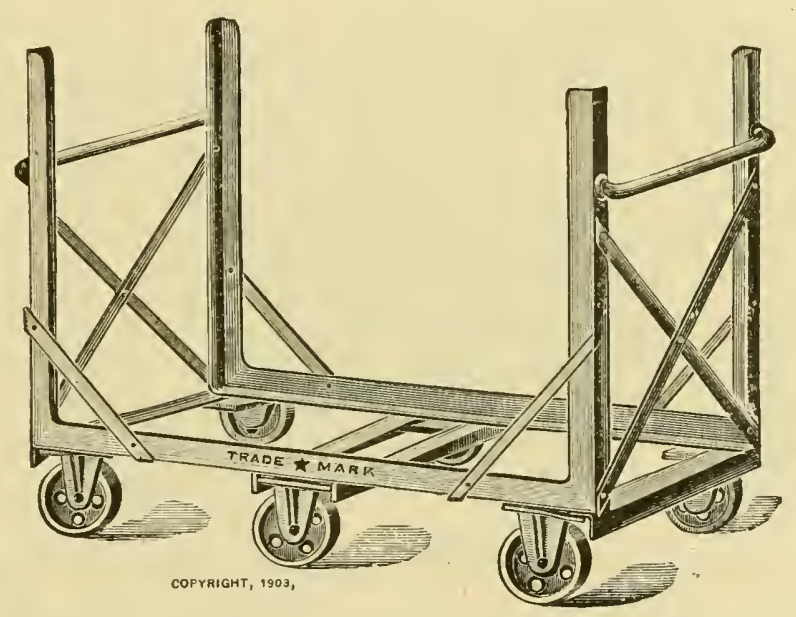

A Car for conveying carriers and bottles.

with metal handles at either end. Padlocks must be made to have the same key fit them all; but we have found great trouble in getting padlocks which were not continually getting out of order. For this reason, and because keys for such padlocks are readily obtained by outsiders, I recommend the use of a lead seal having an opening through which the ends of short wires are passed. The seal is then compressed by a special punch, thus locking the ends of the wires and serving as a perfect padlock which is not likely 
to be tampered with without detection. The seal and wire for each shipping box cost about one-sixth of a cent and may be obtained complete with the punch. One called? "The Enterprize Punch \& Seal" has proved efficient. The boxes hold I 2 quart bottles, which are separated by a framework of galvanized iron on the same plan as the pasteboard partitions or fillers in egg cases. These frames lift out of the boxes and are $31 / 2$ inches deep. The boxes are $12 \mathrm{~T} / 2 \times 17 \mathrm{~T} / 2 \times$ io inches deep and have a small hole

FIG. 29.

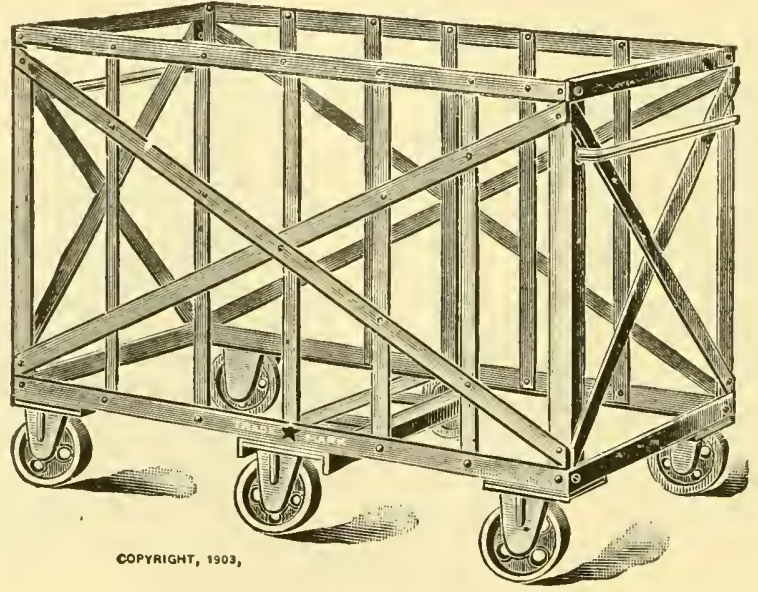

A Car for conveying carriers and bottles.

punched in the bottom to allow the water, from melting ice, to drain away. This is advisable in saving ice and the weight of the water in transportation. I have found the locked boxes necessary to prevent theft of the milk and empty bottles in transportation. Boxes may be bought holding various quantities of bottles, as 20 or 14 pints (see Fig, 30).

Bottles.-In regard to glass bottles there is not much to say except that a bottle of good material and proper 
annealing must be secured to stand the repeated sterilizations (Fig. 3I). The shapes are more a matter of taste than anything else. The bottles with the long and slender necks make a greater display of cream. The latest departure in the way of a milk bottle is the Single Service Paper Milk Bottle sold by the Renno Case Co., 395 Market Street, Philadelphia. This does away with the breakage, the cleaning, the sterilization, and the loss incurred in collection of empty milk bottles. The paper bottles are made in quarts, pints and half-pints, are saturated with paraffin and are absolutely sterile-that is, free from germs. The paper bottle weighs 2 ounces, as against 24 to 26 ounces in the case of

FIG 30.

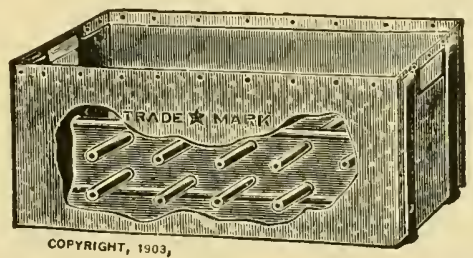

Wagon Box for carrying bottles and ice, not covered or locked.

the glass quart bottle. The chief advantages of the paper bottle lie in the saving of expense in not having to collect (and lose) bottles, as they are only made to be used once and rejected; and in the saving of weight in transportation, as almost twice as much milk can be carried on a wagon. Then the bottles are about $2 \mathrm{r} / 2$ inches shorter than the glass bottles, on account of their thinner walls; the paper lids fit down into the bottle and allow of no leaking; and the necks are wide enough to remove the cream with a spoon. The cost is about I cent each for quart, and eight-tenths of a cent for pint paper bottles. The only disadvantage which occurs to the writer is the fact that quality and quantity of 
the cream would not be so apparent in the paper bottles, nor would dirt.

The advent of the paper bottle would seem then to be of enormous advantage to farmers in enabling them to ship milk in bottles without all the expense and labor of the washing and sterilizing outfit now required for glass bottles. At present writing it is, however, impossible to secure the bottle as the makers are as yet not supplying dairymen at large, and the writer has had no practical experience with

FIG. 3 r.
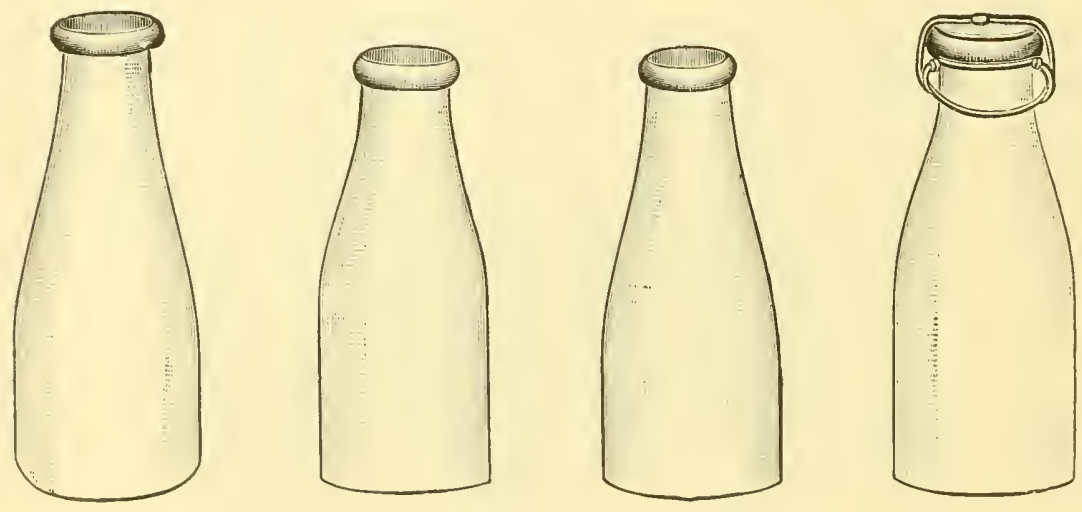

Star Milk Bottles.

the paper bottle. The foregoing statements were taken from the report of Dr. A. H. Stewart, who made a study of the paper bottle, in Sanitation for December 6th, I905.

The same care should be exercised in the production of cream as in the case of milk. While 99 per cent. of germs in milk are to be found in the cream which rises naturally on that milk, separated cream contains about one-fourth of the germs in the milk from which it is obtained. But as the cream constitutes only a small part of the original milksay one-sixth-the actual number of germs in a given amount of separation-cream would be greater than in the 
same quantity of the milk from which the cream was separated.

Cream in cities is consumed largely on the table and for making ice cream and whipped cream. Fatal poisoning has occurred from ice cream made from unclean milk (see p. 22). Babies are chiefly fed nowadays on cream and

FIG. 32.

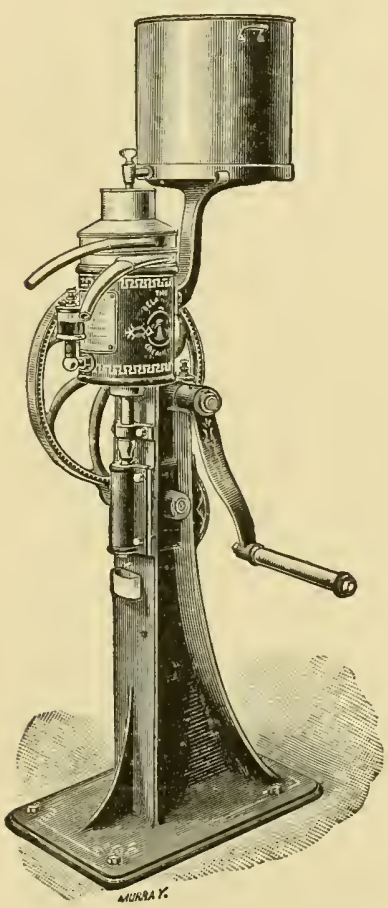

Hand Separator for separating cream from milk. water. The cream is usually removed from milk at the infant's home, but market cream is often used for this purpose.

When cream is used for any of the purposes recited, it is imperative that the cream should be clean or as free from germs as possible. We have already alluded to the value of clean cream for buttermaking.

The warm milk direct from the cow must be immediately separated, as a temperature of $86^{\circ} \mathrm{F}$. is most favorable for separation. Nor must time be permitted for grerms to multiply in the warm milk between milking and separation; the milk must be separated as fast as milked. As soon as the cream is separated it should be immediately cooled to below $50^{\circ} \mathrm{F}$, preferably to $40^{\circ} \mathrm{F}$. This is best accomplished by allowing the cream to run directly from the separator into the receiving tank of a tubular or Star cooler. The cooler is identical with that for milk, but the holes are larger in the receptacle which feeds the cooler. The cream is 
transferred from the collecting tank of the cooler to a cream bottle-filler, and then is run into sterilized bottles. The bottles are shipped like milk in shipping boxes and, except in cold weather, are packed in ice. The bowl and all movable parts of the separator must be washed as carefully as any other dairy utensils by first rinsing in cold water, then scrubbing in warm water and washing soda with a brush, and rinsing again with clean, cold water. Finally, the parts should be sterilized with boiling water or by placing them in a sterilizer. All this should be done after each use of the separator. For this reason a separator having as simple construction and as few parts which come in contact with milk as possible should be preferred. The Sharples separator is one of the simplest in this respect and therefore most readily cleaned.*

If the cream is shipped in cans, it may be kept cool in the same manner as that recommended for milk (see p. 87). Cream thickeners of gelatin are not uncommonly used to thicken cream. Starch and syrup of lime, known as "Viscogen," are also employed. Separated cream does not whip quite so readily as set cream, and syrup of lime may be used to aid its whipping, without injury to the consumer, provided that only a small amount-not over $1 / 2$ teaspoonful of the syrup to the pint of cream-is used. In fact, this proportion is often employed in cream mixtures for feeding babies to increase the digestibility of the cream. Viscogen should not be added to cream for sale in the market. For tests for adulterants of cream, see p. I40.

Cream of varying composition is sold in the market. It generally varies from 20 to 50 per cent. in fat-content. Cream must contain at least 18 per cent of fat according to the U. S. Pure Food Law, June, 1906.

\footnotetext{
* See page 175 for management of separators.
} 
In order that cream may be readily whipped, it should contain over 20 per cent. of fat, preferably 30 to 40 per cent., and be below 50 per cent. in temperature. Cream should be at least 24 hours old-to contain a small amount of acid-in order to whip well. Pasteurized cream will not whip satisfactorily unless viscogen is added to it; or a starter, to develop slight acidity in it. The vessel in which the whipping is done should be cold and round-bottomed; the whipping should be done with great speed; and the whipper should not be more than three-fourths covered with cream. The cream sold in this city (Seattle) commonly contains from 3 I to 33 per cent. of fat.

In concluding the subject of the production and handling of clean milk and cream, I wish to emphasize the fact that most farmers can produce clean milk without great expense in ordinary barns and milk rooms, and can, by so doing, make more money-even with the added expense.

If paper bottles come into general use, the greater part of all the extra trouble and expense now entailed in bottling milk at the farm will be abolished. Clean milk may be shipped in cans, with but slight cost over ordinary milk, and is just as satisfactory, providing the cans go directly to the consumer and their contents are used wholly by him. It is the constant dipping into cans in retailing small amounts of milk which causes the contamination, as noted on p. Is. 


\section{COST OF PRODUCING AND DISTRIBUTING CLEAN MILK}

\section{$\mathrm{A}$}

FEIV words first in regard to the cost of production and profits on ordinary milk sold to creameries, for butter and other products; and for consumption as market milk in cities and towns throughout the United States.

It has become only too evident to readers of dairy literature of late that a large number, perhaps the majority, of milch cows in this country do not yield any considerable profit to their owners. Thus, in a report of the Ohio Cow Census in Hoard's Dairyman* of April 2S, 1905, we find that among 87 herds representing 635 cows, with a yearly average of $3,839 \mathrm{lbs}$. of milk per cow, the average yearly return was $\$ 29.93$ per cow. Among this number of 87 herds, 29 herds were kept at a loss, and out of the whole 87 , only 26 herds paid a yearly profit of over $\$ 5$ per cow to the owners.

Yet in this same report we note one herd of 24 cows, mixed breeds, yielding annually per cow an average of

* In the Cow Census made by Hoard's Dairyman in Vermont (see the number for August Ist, 1905), it was shown that out of Ioo dairies, 69 did not pay the cost of keeping the cows. The cows were natives or grades.

The estimated cost of feeding ranged from $\$ 33.50$ to $\$ 4$ r.oo per cow, per year. The annual profit per cow, of the $3 \mathrm{r}$ dairies which paid any profit, varied from 43 cents to $\$ 22.57$. The losses per cow annually, in the dairies which did not pay ran from 2 cents to $\$ 2 \mathrm{I} .46$. The production of the dairies varied from 72 to $270 \mathrm{lbs}$ of butter fat per cow annually. 
$7,75^{6}$ lbs. of milk and giving a yearly profit of $\$ 167$ per cow. Again, in this same report, we discover another herd which paid its owner an annual average profit of Io cents per cow. How may we explain such an enormous inequality in returns? Let us compare the report of the two herds:

$\begin{array}{cc}\begin{array}{c}\text { Herd No. 12 } \\ \text { (2 Jerseys,3 grades) }\end{array} & \begin{array}{c}\text { Herd No. } 100 \\ \text { (Mixed breeds) }\end{array} \\ \$ 25.00 & \$ 70.00 \\ 3.048 & 7,756 \\ \$ 0.10 & \$ 167.00 \\ \$ 1.00 & \$ 3.40 \\ \$ 0.62 & \$ 3.05\end{array}$

In herd No. I 2, we find that the annual cost of keep was $\$ 25$, and the yield 3,048 lbs. of milk, which brought 82 cents per Ioo lbs. at the creamery, or a little less than 7 cents a gallon the year round. A gallon of milk weighs 8.6 lbs. Herd No. 100 paid yearly $\$ 167$ per cow, while the cost of keep was $\$ 70$ per cow, and the milk brought a little over 25 cents a gallon, or over 6 cents a quart the year round.

Certain remedies there are for such a disparity in profits, but, under some conditions, this disparity can only be remedied in part.

In the cases in point, the most essential cause of the difference in profits in the two herds is the difference in price, which depends upon circumstances. The owner of herd No. 100 was near enough to the city of Cleveland to retail his milk for over 6 cents a quart, whereas the product of herd No. I 2 was sold for less than 2 cents to a creamery.

In this comparison, there are, however, other points to consider: the fact that the cows in herd No. Ioo gave over twice the quantity of milk yielded by the cows in herd No. 12 is an important matter. This may have partly 
depended upor the care of the cows and feeding, but was very probably chiefly due to the character of the cows themselves. While it would be impossible for any one to make much profit in milk at less than 2 cents a quart, yet it may be accepted that, unless a cow comes up to a certain standard in regard to quantity and quality of milk, it is unprofitable to keep her, and the sooner that cow and her owner are parted the better. Just what that standard should be will depend somewhat on local conditions, and prices of food, and milk; but, in a general way, the cow that will not average about so quarts daily during 10 months of the year (6,ooo lbs. annually), and whose milk falls much below 4 per cent. on the average (unless the quantity is very large), will not pay to keep. In this region, there are many herds of grade Holsteins, containing as many as So to I 20 heads, which average 16 quarts and over per cow during the summer months-on pasture alone-in the rich valley lands. In order to determine whether individual cows are profitable, the farmer must weigh the daily amount and test the butter fat of each cow's (see p. 176) milk at frequent intervals. Each cow's milk should be weighed separately, directly the cow is milked, by hanging the milk pail on a balance scale and recording the weight on a record sheet which is gotten up for this purpose (see Appendix, P. I 76). The record sheet should be kept near the weighing balance in a room devoted to this purpose in the barn. To determine the percentage of fat in the milk, a composite sample-that is, a sample of a mixture of the same quantity of night's and morning's milk of each cow for several days - should be examined by the Babcock test at the beginning and end of each month. The composite sample is obtained by pouring the fresh milk from one pail to another, and 
from the mixed milk one should remove a gill with a longhandled dipper at each milking. The gill is placed in a clean labelled and covered Mason glass jar, which is shaken each time a new sample is added. Fifteen drops of formalin or a corrosive sublimate tablet will preserve the samples for days, and two ounces, or half a cup of the composite sample, is sufficient for the Babcock test. If a Babcock tester is not at hand, the testing may be done at a creamery for a small charge. The number of pounds of milk yielded by each cow monthly should be multiplied by the average per cent. of fat in her milk. This will give the number of pounds of fat in the cow's milk for the month, which should be the basis for comparing her value. The average per cent. of fat in her milk for the month will be obtained by adding together the results of the two fat tests and dividing the sum by two. Then the general care and feeding governs to a considerable degree the quantity of milk, and intelligent study of a good newspaper devoted to the dairy industry will prove of much value in this respect. As we have repeatedly emphasized, the cleaner the milk the better it is for any purpose, and the farmer who devotes himself to producing a clean milk should receive a larger price for it. Of course, local conditions will largely determine the advisability of investing extra money and time in the food, care and cost of cows, but very rarely will it pay to keep cows. which do not pay for their keep. It may be necessary to keep cows for their manure, but this is usually considered as merely offsetting the cost of their care, and so the cost of keeping cows is commonly figured in estimating the cost of their food. The yearly cost of feeding a cow varies from \$I 7 to $\$ 70$, averaging perhaps throughout the United States about $\$ 35$. At the experiment stations, with the 
best selected stock and breeds and the most expert care, the cost of producing I quart of milk varies from 0.7 to 2.9 cents, according to breed and individual characteristics of cows. When a farmer receives on the average 2 cents or less per quart for milk, there can be little profit to him. Yet two cents is about the price paid for years to farmers who have shipped ordinary market milk to New York City.

It has been stated by many authorities that one-third of the cows in this country is kept at a loss; that one-third just about pays for its keep, and that one-third pays a profit to their owners.

The most striking fact which impresses one in this whole matter of profit in milk production is the folly of keeping poor cows. A poor cow makes a poor owner.

The production and transportation of clean milk is attended with much greater expense than that of ordinary or " market" milk.

The following figures, showing the cost of milk production and distribution, must, of course, be considered only approximate. Local conditions alter circumstances tremendously. Thus in this region (Seattle, $\mathrm{I}^{\top} \mathrm{ash}$.), the climate is so mild that ice has to be used on the milk during transportation on the railroad and delivery in the city wagon the year round. Then again, the city is very hilly and the streets, many of them, very bad, and the milk route is not concentrated in a thickly settled district.

IVe may place the average cost of the production throughout the country of ordinary market milk at 2 to $2 \mathrm{I} / 2$ cents per quart as the result of the figures obtained from the experiment stations. Perhaps the average figure paid the farmer for ordinary market milk hereabouts is 
$3 \frac{1}{2}$ cents a quart. This does not differ materially from the price paid in many parts of the country.

The cost of producing clean milk in this region, over and above that of ordinary milk, may be set down at 2 cents a quart. This includes the extra care necessitated in the barn and dairy, the fuel for running the boiler, the ice, etc. In the milk room, there is the washing and sterilizing of all the bottles and apparatus, and the bottling of milk and packing of the bottles in boxes with ice. The farmer must make a considerable outlay for the paraphernalia in his milk room, but the bottles, in this vicinity, are supplied by the distributors in the city.

The cost of transporting milk by rail in bottles to the city, some 30 miles, is I cent a quart in this region, and it costs about the same in other cities. This figure includes the cost of carriage for the galvanized iron box, holding one dozen bottles and ice, the whole weighing 68 lbs., and also the return of empty. bottles and cases to the farm.

The cost of distributing clean milk is much greater than ordinary milk, when ice is used, owing to the weight of the ice and cases holding the bottles and the fact that customers of high priced milk are apt to be scattered about. The cost of distribution of milk has been set down at two cents a quart, but three cents a quart would be nearer the mark in this vicinity for milk sold on ice the year round. The farmer should then receive at least six cents a quart net for certified milk as the minimum figure, according to my experience in this region, or about double what he receives for ordinary market milk. This is a uniform price for the year around. For the ordinary milk he gets from nine cents to sixteen cents per gallon, at different seasons, and it retails at about seven cents a quart. 
The distributer of milk, if he pays the farmer six cents per quart and one cent per quart freight, should get eleven cents as a minimum price per quart to make any profit. This figure is a low estimate when various unavoidable losses are taken into account, as repairs and deterioration of milk boxes, harness, sickness and death of horses, loss of accounts, bottles, etc. I believe that seven to eight cents a quart for the farmer, and twelve to fifteen cents a quart for the distributer of clean milk in the city, is a much safer estimate as a basis on which a profitable business for both may be done.* It is impossible to keep up the standard of clean milk unless a reasonable profit is being made at both ends of the business.

Every step by which the milk is improved costs money in labor or material, and it has been my experience that it is useless to expect the farmer to carry out all the necessary details of cleanliness unless he can really afford to do so. The actual price at which certified milk retails varies in various cities from eight to twenty cents per quart. Rich milk, as milk containing five per cent. fat, should bring a higher price, though it is not preferable for infant foodrather the reverse, as we have noted.

In this vicinity there has been an attempt to employ one farm as a bottling station in which the utensils of all the farms are washed and sterilized and to which milk, which has been milked and cooled at neighboring farms, is brought. When the milk was supplied by the farm doing the bottling,

* In Hoard's Dairyman of a recent date the proportionate receipts from a. quart of milk retailing for $\mathrm{S}$ cents in New York City, are given as follows :

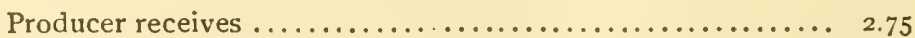

Railroad for transporting, receives $\ldots \ldots \ldots \ldots \ldots \ldots \ldots \ldots \ldots \ldots \ldots .6 .5$

Dealers handling, bottling and distributing the same, receive.. 4.75 
and one other about a mile away, the result was very good. The highest number of bacteria in the milk bottled from these two farms was I 7,000 per cubic centimeter during six months. Pressure being brought to bear to increase the milk supply, two more farms were taken into the combination with disastrous results. This unfortunate outcome was largely due to the fact that the owners of the two farms which were taken into the combination last had not time given them to arrange their barns and milk-rooms properly, and had not got into the routine necessary to produce clean milk. Whether an arrangement of this kind for producing certified milk is wholly practicable is somewhat doubtful. There are so many more opportunities for contamination of the milk with dirt and germs. If a like attempt is elsewhere undertaken, the milk from each farm should be examined once a week before bottling it and mixing it with milk from the other farms, to ascertain the number of bacteria and the amount of fat in the milk. The plan has the advantage of bringing several farmers to a higher standard than would otherwise be possible, and enables the farmer who supplies all the dairy apparatus to make a more economical use of his plant.

When an individual wishes to begin to sell clean milk in a neighborhood in which certified milk is unknown, it is well for him first to interest the local medical profession in the project. The local medical society, or individual physicians, should form a committee with laboratory facilities. The work can be done under the committee's direction by an intelligent druggist. Any dairy, supplying clean milk, may receive a certificate from the medical commission, if the milk fulfils the required standard, as' the result of weekly examinations. Providing, however, that the milk has fulfilled all the re- 
quirements of the milk commission for a probationary period of at least two months prior to the granting of a certificate.

\section{Estimation of the Value of Milk and Cream for Ordinary Purposes.}

The value of milk and cream throughout the country is generally determined by the price of butter. And the butter maker pays for milk or cream according to the pounds of butter fat each contains. Clean milk or cream of the purity of the certified milk or cream, however, bring a price greatly above that fixed by a butter-fat valuation.

In churning a pound of butter fat (in milk or cream) into butter there is a gain; that is, a pound of butter fat will produce more than a pound of butter. The weight of the butter fat subtracted from the weight of the butter (made from it) is the overrun. ${ }^{*}$ The reason for this gain in churning butter fat into butter is that there are ingredients $i$ in the milk or cream, and also the salt contributed by the butter maker, which add to the fat in the butter. Thus butter contains on the average about $\delta_{4}$ per cent. of fat, and the remaining 16 per cent. consists of water ( 12 per cent.), and curd (I per cent.), salts ( 2.5 per cent.), and milk sugar ( 0.5 per cent.). This is the average composition of butter, $\uparrow$ but the water may vary in amount from $\delta$ to i 6 per cent. and the fat proportionately. The overrun, then, does not clepend

*For detailed information concerning overrun, see Bull. I29. Some Creamery Problems, E. H. Farrington, Univ. Wis. Agric. Exper. Sta., to which the author is greatly indebted.

†Since the U. S. Pure Food Act of 1906 requires that butter shall contain 82.5 per cent. of butter fat as a minimum, it follows that creamery butter will not in future exceed this requirement. This, therefore, may be regarded as the present average consent of fat in butter. 
upon nor refer to the percentage of fat in butter. It is always estimated by determining the fat in the milk or cream by the Babcock test, and then subtracting the weight of the fat from the weight of the resulting butter.

The amount of butter which can be made from a given weight of cream depends upon the amount of fat it contains. The richer in fat it is, the less the loss of fat in the buttermilk in churning. Thus buttermilk contains about 0.3 per cent. of fat, and cream containing i 5 per cent. of fat would yield almost four times as much buttermilk as cream containing 40 per cent. fat. Moreover, the buttermilk from rich cream contains absolutely less fat (less than 0.3 per cent. fat) than that derived from churning thin cream. Then there are mechanical losses of fat from cream and butter sticking to various utensils used in the course of making and handling butter. This naturally influences the amount of butter which can be made from a given quantity of fat in milk or cream. Two to five pounds of butter-fat may thus be wasted for every hundred pounds handled.

The Overrun.-As an example we will estimate the overrun in making I 6 pounds of butter from 2,500 pounds of 4 per cent. milk. We first determine the weight of fat in the milk : 2,500 pounds multiplied by .04 equals r oo pounds of fat. Subtracting this from I 6 pounds of butter made from it gives us the overrun as 16 pounds, or i 6 per cent., because it is 16 per cent. of the 100 pounds of fat in the milk.

The overrun is usually less on account of various losses. Thus in skimming the milk in the separator there is a loss of about o. I per cent. of fat contained in the skim milk; after churning there is the loss in the buttermilk we have noted equal to 0.3 per cent. fat in the buttermilk; and there are the mechanical losses we have referred to, equivalent to about 
2 to 5 per cent. of the total fat in the milk. So of the roo pounds of fat in the 2,500 pounds of 4 per cent. milk there may be only 93.13 pounds of fat available, which would make I I .86 pounds of butter containing 84 per cent. of fat. Subtracting from this I I0. $\$ 6$ pounds of butter the roo pounds of fat contained in the 2,500 pounds of milk gives 10.86 pounds, or I0.86 per cent. as the amount of the overrun. The overrun varies, not only owing to the conditions noted, but also as the churning leaves more or less water in the butter, and according to the accuracy of testing the milk or cream for fat, and in weighing the same. The normal range in overrun for milk varies from Io to I 5 per cent. An overrun above or below these figures demands an investigation. The overrun from cream is somewhat higher than these figures, since there is no loss from skimming, as from milk. The cream overrun varies from 16 to 20 per cent.

Estimation of the overrun is not in any way essential in calculating the money due patrons of a creamery for milk or cream. The simplest, fairest, and generally most satisfactory way is to weigh and test each sample of milk or cream of the patron's for butterfat and subtracting the cost of making the butter from its selling price, to give the balance of the returns to the patrons in proportion to the butterfat they supplied. Thus, if 232 pounds of butter were made during a given time from 200 pounds of butterfat, and the butter sold at 25 cents a pound, the butter fetched $\$ 58.00$. Subtracting from this 4 cents a pound for making gives $\$ 48.75$ to be divided among the patrons according to the amount of butterfat each supplied. 4S.70 divided by 200 gives us 24.35 cents as the price to be paid each patron for each pound of fat supplied in his milk or cream. The following correction should, however, be made: 
The milk patron is paid for all the butterfat in his milk brought to the creamery while the cream patron is not, as part of the butterfat in his milk remains at the farm in the skim milk. Besides, he saves the creamery the expense of skimming the milk. Therefore, in calculating the amount of fat supplied the creamery by its patrons the cream patron should be credited not only with the fat actually present in his cream, but to it is added 3 per cent. of its total to put him on the same basis as the milk patron. (The 0.12 fat lost in the skim milk from hand separators equals about 3 per cent of total fat in the whole milk.)

Thus, supposing four patrons supplied the 200 pounds of fat, as follows:

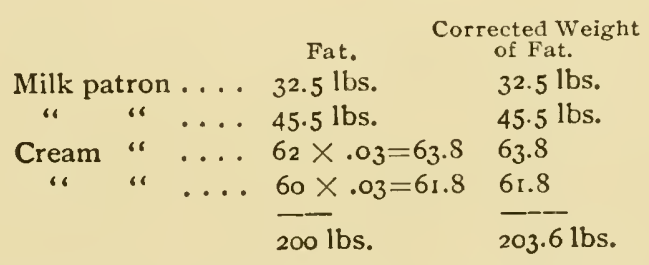

We correct the weight of fat supplied by the cream patrons, as above, and divide the price the butterfat brought ( $\$ 48.70)$ by the corrected weight of the fat (203.6 lbs.), which gives 23.92 cents. This is the price per pound of butterfat to pay the patron of the creamery according to the corrected weights of fat in the last column above.

To consider this matter more in detail, especially in regard to the price a given quantity of milk will bring if sold in different forms, suppose we take, for example, 290 gallons of milk. A gallon of milk weighs 8.66 pounds, 290 gallons of milk will then weigh 2,500 pounds, and, containing 4 per cent. of fat, will give us Ioo pounds of fat. In converting this into butter the first process will be to skim the milk in a separator, which will give us a loss at the creamery 
of o. I per cent. fat in the skim milk. The skim milk may be assumed to be $S_{5}$ per cent. of the whole milk; $S_{5}$ per cent. of 2,500 pounds equals 2, 125 pounds skim milk; 2, I 25 multiplied by $0.00 \mathrm{I}$ equals 2.12 pounds of fat in the skim milk. Subtracting this from the 100 pounds of fat in the 290 gallons of milk gives us 97.85 pounds of fat in the cream arising from this amount of milk; 326 pounds of 30 per cent. cream will contain just about this amount of fat, that is, 97.8 pounds. In churning this into butter there will be a loss of 0.3 per cent. of the total fat in the buttermilk. The amount of buttermilk is the difference between the weight of the cream and the fat in the cream, or, roughly, so per cent. of the whole milk. In 326 pounds of 30 per cent. cream there are 97.8 pounds of fat; subtracting this from the weight of the cream gives us the weight of the buttermilk, $22 \mathrm{~S}$ pounds; multiplying this by 0.003 equals .684 pounds, or the loss of fat in buttermilk; subtracting this loss of fat in buttermilk from the fat in the 30 per cent. cream gives us 97.12 pounds of fat for butter. This would make I I 7 pounds of butter containing $\delta_{3}$ per cent. of fat. (To arrive at this result we divide $97 .{ }_{2}$ by $0.8_{3}$, equals I I 7.) Then, to get the (theoretical) overrun, we subtract the 100 pounds of fat in the original milk from the 100 pounds of butter made from it (I I 7), which gives us 17 as the percentage of overrun. We will, however, have mechanical losses equal to 2 or 3 pounds, so we will consider that we shall actually get i 4 pounds of butter from 290 gallons of 4 per cent. milk.* With butter wholesale at 22 cents a pound, and subtracting 4 cents for

* The cost of making a pound of butter varies from four cents to a fraction less than two cents in the largest creameries. In calculating the amount of butter which can be made from a given amount of butterfat we add one-sixth for butterfat in milk and one-seventh for butterfat in cream. 
making, the butter would net the farmer only $\$ 20.05$ for his 290 gallons of milk.

Cream is often bought in cities by ice cream and cream lealers at a rate of 2 cents (more or less) above the value of the cream for butter; that is, if butter was 22 cents the cream would be bought at a valuation of butter at 24 cents; 326 pounds of 30 per cent. cream equals about 40 gallons (a gallon of 30 per cent. cream weighs nearly 8 pounds actually; if free from much air or gas, 8.3 pounds); this, making I 4 pounds of butter valued at 24 cents, 2 cents above current butter price, would give $\$ 27 \cdot 36$ as price for 290 gallons of milk in form of cream. In either case the farmer has the skim milk to feed, which may be roughty valued at 35 cents per 100 pounds for feeding, and I I cents additional (in passing through the calves) for fertilizer; 21.25 pounds of skim milk at 46 cents per roo pounds equals $\$ 9.77 ; 290$ gallons of 4 per cent. milk may bring the farmer I 2 cents a gallon net if sold for city consumption, equals $\$ 34.80$.

For clean, pure 30 per cent. cream, bottled at the farm, as much as $\$ 1.20$ per gallon should be gotten. If the cream is shipped in cans on ice or in special ice-containing cans (see p. 87), it should bring \$1.00 per gallon for a clean article. If the milk were sold in bottles from the farm as certified milk it should bring 7 cents a quart, at least, which amounts to $\$ 8$ r.20 for the 290 gallons.

The returns from 290 gallons of 4 per cent. milk, sold as follows, are:

As II4 pounds of butter, at 22 cts. per lb. with value added of skim milk to farmer.........\$30 29 As ordinary milk in cans at 12 cents per gallon.... 3480

As cream, with value of skim milk added........ $37 \quad 13$

Clean, cooled cream shipped on ice in cans, with

value of skim milk added................. 4977

Clean, cooled bottled cream, with value of skim milk added........................... 5777

Certified bottled milk.................... 8I 20 
These figures, of course, can not be taken as applying precisely to conditions in any given locality. They are only given to show how to figure approximately relative returns from milk products, and it will be found that the returns for ordinary market milk are about the same as can be gotten from a creamery for butter. Moreover, the higher returns received from the sale of bottled certified milk must not be taken as necessarily indicating that the maximum profit accrues from selling milk in this form. It may well be that the extra cost of labor, fuel, ice and plant, required for its production, will amount to 2 or 3 cents a quart.

It is impossible to fix the value of skim milk for feeding and fertilizer, as it depends upon such variable factors as the value of veal and pork, the price of other food stuffs, the value of milk in the locality and the knowledge of the person using it as to the best way to feed it. Skim milk is said to be worth $\$ 1.00$ a hundredweight in midwinter to feed to hens with corn meal, while for feeding calves it is valued from 20 to 40 cents a hundredweight, according as the price of veal varies from $\$ 3$ to $\$ 5$ per Ioo pounds. To be fed with most economy to calves it should be given in proportion of two to three pounds of skim milk to every pound of meal. I have known skim milk to be used with excellent result when poured on the soil as a fertilizer in the cultivation of cauliflowers. H. B. Gurler claims that for feeding pigs skim milk is worth one-half as much per soo pounds as corn is worth per bushel. 


\section{CHAPTER VIII.}

\section{SOME HINTS CONCERNING MILK DISTRIBUTION}

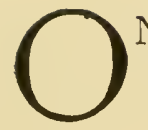

$\mathrm{NE}$ of the chief difficulties to contend with in retailing milk is the almost instinctive desire of the public to get their milk in the early morning hours. Customers apparently labor under the false impression that milk left in the early morning hours is a product of the night, like the dew, or early morning paper on the doorstep. As a matter of fact, milk which is delivered before $8 \mathrm{~A}$. M. at the customer's door is usually twenty-four to thirty-six hours old. This happens because milk trains do not often arrive before 8 A. M., and the milk on these trains represents that milked the night before and in the early morning of the day of arrival in the city. This milk is often delivered in the early morning of the day following that of its arrival in the city.

Although we have seen that clean milk may be kept sweet on ice for several weeks (see p. 14), yet we have also learned that germs will develop in milk at a temperature of 40 degrees Fahrenheit, or lower, and that they may increase tremendously at low temperatures in time (see pp. 6, I 4 ). It is safer, therefore, that clean milk be not sold when it is twenty-four hours old; and the requirements of some medical societies certifying milk forbids its sale after it is twenty-four hours old.

The milk arriving in the city on any morning will represent the night's milk of the previous day and the milk 
which has been milked very early on the morning of its arrival. Or, as in the writer's experience, the milk arrives very early in the morning, before $7 \mathrm{~A}$. $\mathrm{x}$, representing the milk of the previous night, while the morning's milk arrives at noon and the delivery of the milk is continued from 7 1. M. to 6 P. x.

In some localities-where night's milk can not be kept

FIG. 33 .

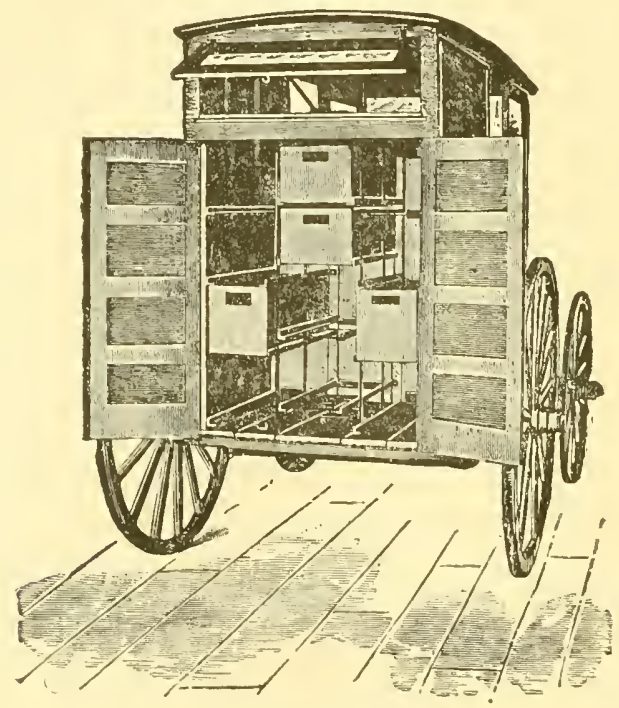

Milk IVagon.

cool-only the morning's milk is sent to the city, the night's milk going to the creamery.

IVe have found it possible by instructing the customers concerning the folly of demanding delivery of milk to their cloors in the early morning hours to, in a measure, ignore this desire, and so distribute milk during the whole of the day, with an intermission of an hour for the men and horses at noon.

The nature of local conditions will determine to a con-. 
siderable extent the cost of delivery and also many of the practical details as to the kind of wagon, bottle boxes, use of ice in wagons, etc. To obviate overhauling of the boxes in the wagons they should not be piled in layers one over the other. This may be accomplished by means of a special arrangement in the wagon shown in Fig. 33. I have personally had no experience with this wagon, but have consid-

FIG. 34 .

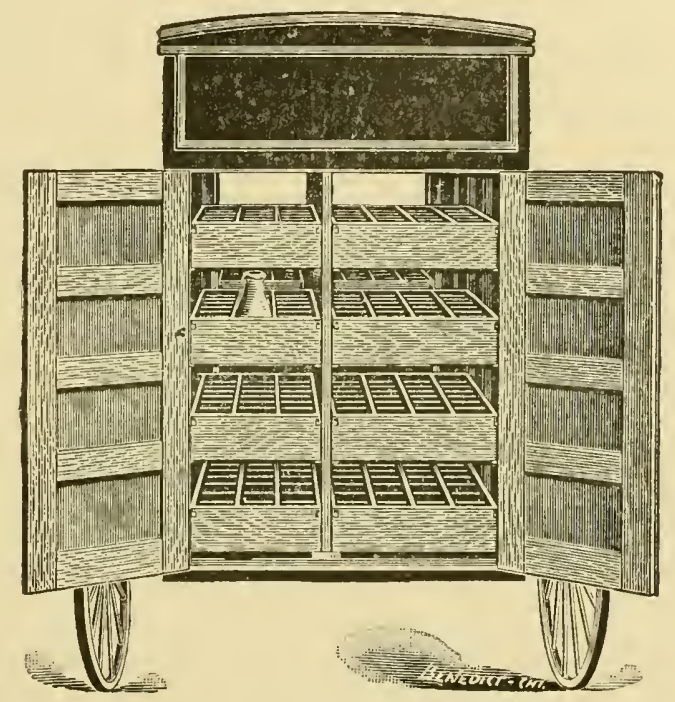

Milk IVagon.

ered that simplicity is one of the chief aims in any scheme, and by making the wagon wide and long enough one can carry about all the boxes of bottles proper on the floor. Thus the wagon body may hold fifteen boxes on the floor and five or more placed directly on top of the first tier without any inconvenience in handling them. These twenty boxes weigh, when filled with milk, bottles, and ice, about I 400 pounds and constitute a load in a hilly city for two horses. In the wagons built under our direction there is a round hole cut 
in each side of the top, a few inches above the floor, about. fourteen inches in diameter and just back of the driver's seat. This permits of bottles being taken out of the boxes in the wagon without requiring the driver to mount the front of the wagon. A wide step is affixed to the wagon behind on which the driver stands when getting bottles at the rear of the wagon. The floor is of sheet iron with an open slit at either side running the whole length to permit water draining through the bottom of the wagon. There is a high tail-board, and the upper part of the top of the wagon at

FIG. 35

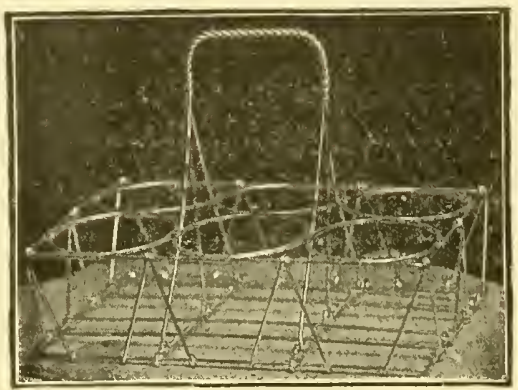

Delivery Basket.

the back is closed in for perhaps two feet from the top to keep out the sun. Each of the boxes contains twelve quart milk bottles and the load consists of 240 quarts. The capacity of the wagon arranged for sliding bottle-cases is a maxi. mum of 204 quarts, but special arrangements might allow of greater capacity., A wagon similar to that seen in Fig. 34 may be used for bottles alone and will have a capacity of 256 quarts. The wooden cases slide and may be easily reached from the seat as well as rear. Ice can not, however, be used on the bottles in this wagon. Such wagons have been used with an ice chamber overhead to secure cooling of the whole 
wagon, but with the doors continually open the result in hot weather is far from satisfactory.*

Three sets of bottles are necessary in distributing milk, one remaining at the customer's house, one on the way to and from the farm, and the other at the farm. Two whole sets of bottle boxes are required, one at the farm and the other passing two and fro each day. The delivery baskets (Fig. 35) are convenient in carrying bottles from the wagon to the customer's house.

The matter of bottles is an important one. The loss from the customers not returning empty bottles has wrecked many enterprises. The men on the delivery wagons should be required to charge patrons for bottles each day and credit them with returned bottles. Those bottles not returned at the end of the month are charged with the milk on the bill. Some loss of this kind and from breakage is unavoidable until the paper milk bottle comes into general use. The surest way of escaping loss of milk bottles, which is one of the most serious causes of disaster, and also loss in collection, is through the use of tickets. If milk sells for ten cents a quart and a customer begins to take one quart of milk daily he may be sold a package of ten tickets for one dollar. Then the first day two tickets are withheld, one paying for the milk and the other for the bottle. If the bottle is returned the following day and another bottle of milk is delivered, then the customer gives but one ticket to the milkman. But if the first bottle is not returned, then the milkman takes two tickets the second day and so on. Every returned bottle by a customer means that he receives a ticket or credit for a ticket for each bottle re Illinois.

* These milk wagons are made by the Sycamore Wagon Works, Sycamore,

† Patrons must be instructed not to place milk tickets in empty milk bottles, as they otherwise will invariably do. The tickets stick to the botton of the wet bottle and can not be readily removed by the driver of the delivery wagon. 
turned. And an empty bottle is regarded of the same value as one quart of milk. If for any reason a responsible customer is out of tickets and can not pay for more at the moment of arrival of the milkman, the latter gives the customer a package of tickets and requests the customer to sign a regular receipt for same. A bill for the tickets is then sent at once through the mail to formally notify the customer of his indebtedness.

Another method which has been employed consists in the use of the time-book, " made to fit in the pocket, and which the man on the delivery wagon carries. This book is ruled so that when the book is opened there are columns on each two pages, facing one another, for all the days of the month. The customers' names are written down in a column on the left-hand edge of the page and his account kept on a horizontal line extending across the two open pages. Two such books are used, the delivery man having one on one day and the other book the following day, so that each lay one book may be turned into the office for inspection. On each day two of the perpendicular columns are used for each customer. In the first column is entered the amount of milk or cream taken and in the second column the number of bottles returned. This method is not so good as the preceding. $\uparrow$

If the milk is to be marketed in the best possible manner, especially if sold for infants' use, there should be placed a parchment paper bottle cap over the ordinary cardboard cap. The object of this extra paper cap, which is water1roof, is to prevent dust, dirt, and water (from melting ice) containing germs from soiling the cap which directly covers the milk. In removing the latter any material on the cap might easily fall into the milk. The parchment paper caps

\footnotetext{
* The names of customers in the account book should follow the same order as that observed in visiting then on the milk route.
}

t See page 195 for forms used in keeping accounts. 
are held in place by a rubber band about the neck of the milk bottle and cost less than one-tenth of a cent when bought in quantity. On them may be printed the day and month the milk is produced, the name of the farm and the fact that the milk is certified by a certain commission. The tinfoil caps, while presenting an elegant appearance, are very expensive, costing five to ten times more than the parchment bottle caps.

The appearance of the men on the delivery wagon is of importance. In this region the use of uniforms of khaki in summer and corduroy in winter has proved satisfactory.

Clean milk is of special value in feeding babies. For this reason endeavor should be made to inform the public of the existence of the opportunity to obtain clean milk by those selling this article, and its use for infant feeding should be made as easy as possible.

The following circular has been used for distribution among the physicians of a city and embodies matter which they may pass on to their patients :

\section{Certified Milk For Infant Feeding.}

The Dairy desires to call the attention of physicians to the opportunity offered them for not only feeding pure milk to infants, but, by means of analyses of this milk and cream, to prescribe an infant food of known composition.

A dipper isfurnished by which the top-milk may beremoved from the bottle. The upper 9 ounces of the milk contains approximately 13 per cent. of fat when thus removed. One part of this top-milk with 5 parts of water gives Fat, 2.I per cent.; Proteids, 0.6 , suitable for feeding infants from 3 rd to r4th day of age. Diluted with 4 parts of water, gives Fat 2.6 per cent.; Proteids 0.8 per cent.; suitable for feeding from 2 nd to 6 th week of age. Diluted with 3 parts of water, gives Fat 3.2 per cent.; Proteids r.oper cent.; suitable for feeding from 6 th to I I th week. For feeding from IIth week to $5^{\text {th }}$ month, the upper pint is removed with dipper from the bottle, and diluted with $13 / 4$ parts of water, gives Fat 3.4 per cent.; Proteids r. 45 per cent. The milk for feeding from the fifth to roth month is obtained by pouring off the upper pint from the bottle and diluting it with an equal quantity of water. This gives Fat 4.0 per cent.; Proteids 2.0 per cent.

Instead of water, barley water, lime water or dextrinized gruels may of course be used as a diluent. Milk sugar may be added in proportion of I ounce to 20 of the milk mixture. 
The milk is obtained from tested cows and under the most cleanly conditions pertaining to the animals, stables and paraphernalia. The milk is drawn into covered pails, through a small aperture in the top, and falls through sterile cheesecloth into the bottom of the pail. It is immediately aerated and cooled, is put into bottles at the farm, and kept on ice until it reaches the consumer. The milk contains riearly 5 per cent. butter fat and averages but 8,000 to I0,000 bacteria to the c.c.

It will not be necessary to sterilize this milk, and the modified milk mixtures above recommended will be found much superior to dirty milk which has been sterilized and modified. The top-milk should be removed from the bottles on their arrival, and kept on ice, to give good results. This milk is subject to frequent bacteriological and chemical tests by Dr. and $\mathrm{Mr}$. at the County Medical Society Laboratory. The formulae are taken from Holt, as recommended by him for healthy infants, and the following table is also from his book :

Schedule for Feeding a Healthy Child During the First Nine Months.

\begin{tabular}{|c|c|c|c|c|c|c|}
\hline 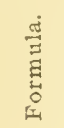 & Age. & $\begin{array}{l}\text { No. of } \\
\text { feed- } \\
\text { ings } \\
\text { in } 24 \\
\text { hours. }\end{array}$ & $\begin{array}{l}\text { Inter- } \\
\text { val be- } \\
\text { tween } \\
\text { feedings } \\
\text { by day. }\end{array}$ & $\begin{array}{c}\text { No. of } \\
\text { night } \\
\text { feedings } \\
\text { (I0 P. M. } \\
\text { to 7 A. M.). }\end{array}$ & $\begin{array}{l}\text { Quantity } \\
\text { for one } \\
\text { feeding. }\end{array}$ & $\begin{array}{c}\text { Quantity } \\
\text { for :4 } \\
\text { hours. }\end{array}$ \\
\hline $\begin{array}{l}\text { I } \\
\text { II } \\
\text { III } \\
\text { IV } \\
\text { V }\end{array}$ & $\begin{array}{l}2 \text { to } 14 \text { days............ } \\
2 \text { weeks to } 5 \text { weeks.... } \\
5 \text { weeks to } 10 \text { weeks... } \\
\text { Io weeks to } 4 \text { months.. } \\
4 \text { months to } 9 \text { months.. }\end{array}$ & $\begin{aligned} \text { IO } \\
\text { 10 } \\
8 \\
7 \\
6\end{aligned}$ & $\begin{array}{l}2 \text { hours } \\
2 \text { " } \\
21 / 2 " 6 \\
3 \text { " ، } \\
3\end{array}$ & $\begin{array}{l}2 \\
2 \\
1 \\
1 \\
0\end{array}$ & 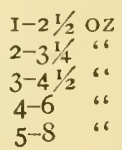 & $\begin{array}{l}10-250 z \\
20-32 ، 6 \\
24-36 ، \\
2 S-42 ، \\
30-48 ،\end{array}$ \\
\hline
\end{tabular}

One of the chief difficulties physicians have in prescribing milk mixtures for babies is their ignorance of the exact composition of the milk and cream which their patients will use. The milk from the same herds will be of very uniform composition, varying somewhat with the season, but hardly enough to make any material difference in calculations for infant feeding. The dipper used for removing the cream is shown in Plate $\mathrm{D}$, and is two and one-fourth inches long and threefourths of an inch in diameter. It holds a tablespoonful or one-half an ounce of milk, and is used to remove any part of the top milk without mixing the milk with the cream. A siphon (Plate D) is also furnished customers to remove the skim milk from the milk bottle. This we find is generally employed and liked by families who use cream on the table, 
PIAT'T, D

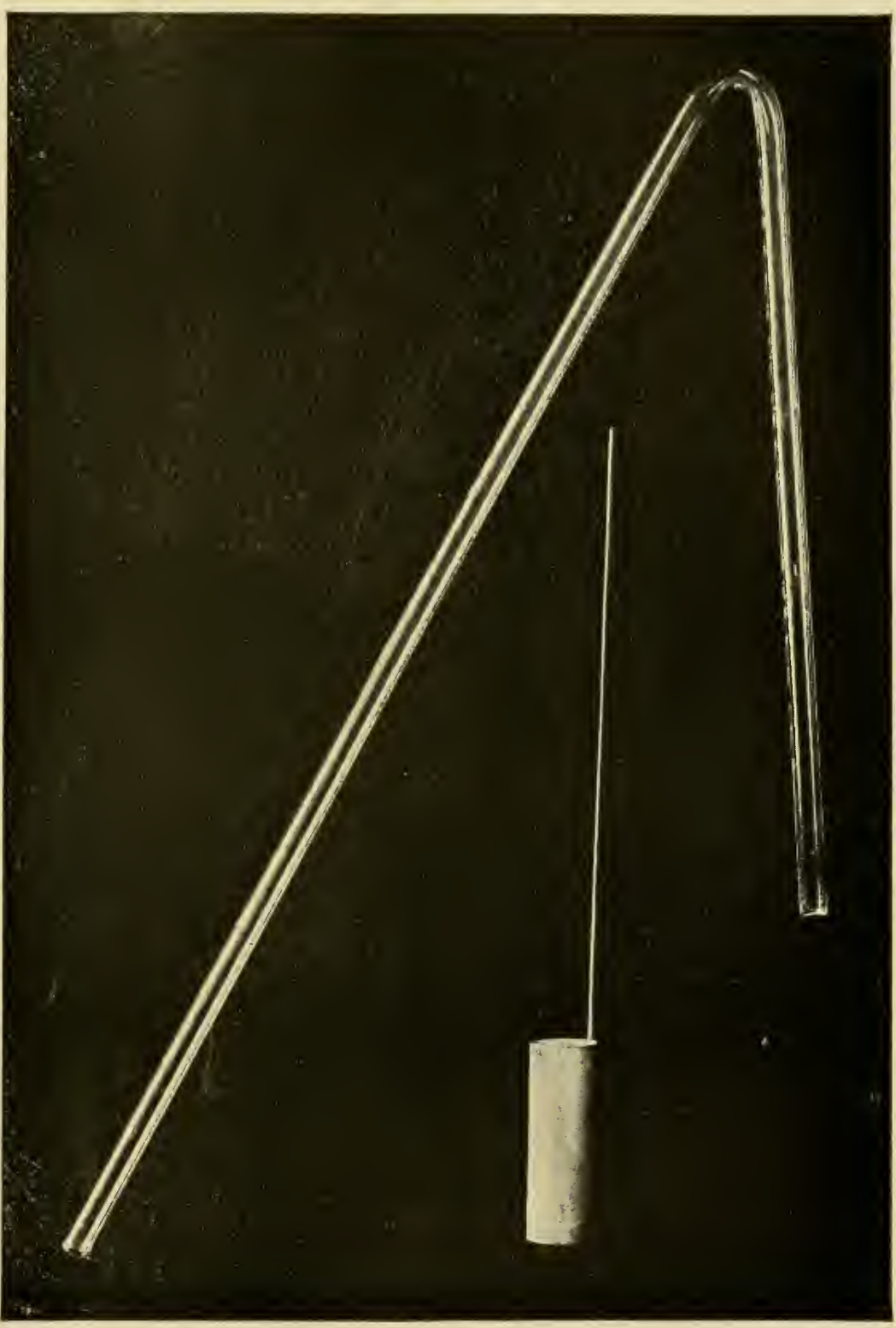

Showing Dipler and Siphon for Removing Cream and Milk respectively. (See page I32.) 

and at ten cents a bottle for milk containing five per cent. of fat the customers get as much, or more, cream than could be bought for this sum and have the skim milk to use in cooking. The siphon, of glass tubing, three-eighths of an inch outside diameter, has a short arm, just long enough $(9 / 2 \mathrm{in}$.) to reach to the very bottom of the milk bottle, and a long arm five inches longer. The siphon is filled with clean water by holding the shorter arm under a water faucet, and when the water appears at the end of the longer arm this end is closed by the thumb and the shorter arm is inserted to the bottom of the bottle and the thumb released, allowing the tube to rest in the bottle. First the water flows out and then the milk. The cream gradually settles in the bottle until the lower border of cream touches the bottom of the bottle, when the siphon is at once removed. 


\section{CHAPTER IX.}

\section{MILK INSPECTION.*}

The duties and tests of the milk inspector are divided into those performed in and out of the laboratory. Out of the laboratory, the tests are mainly those of the senses. A temperature test is, however, required by the most enlightened cities, and when the milk is found to have a temperature above $50^{\circ} \mathrm{F}$. it is condemned. The inspector, in taking samples of milk for the laboratory, should thoroughly stir the milk. This is best accomplished by "stirrers, "made like the dasher of the old-fashioned dasher churn. The two chief reasons for agitating the milk are to thoroughly mix the cream for determining the fat, and, again, to estimate by a bacteriological test the number of germs. In the latter case it is especially important, as ninety-nine per cent. of the germs in milk become entangled in the cream. Two ounces of milk are sufficient for a fat or bacteriological test, and four ounces for a test for preservatives. The inspector seals the corks of the bottle, and, also, should place some sealing wax on the edge of the label, as the labels are often soaked off and placed on a similar sealed bottle. This happens where the inspector is required to give a duplicate sealed sample to the milkman; and the milkman, when he knows his sample is adulterated, may get a sealed bottle given to another milkman (which contains pure milk) and take the

The author is indebted to Mr. A. G. Smith, city chemist, Seattle, for much aid in the preparation of this chapter. 
label from the aaulterated sample and place it on the pure sample. He then brings the pure sample into court with the label number the inspector placed on his adulterated sample and in a bottle with an unbroken official seal on the cork.

Milk may be condemned on account of risible dirt. This is ascertained by straining milk from one can to another through cheesecloth, or by straining only the bottom portions of several cans. The taste may be bad, as from the odor of manure, or from improper feeding, or clisease (mastitis) of the cows, and may suffice to condemn the milk. The color may be unusual, as when the cream is highly colored on milk which has been obtained from cows recently calved. Curdling of the milk on boiling will occur if the sample is colostrum. The brilliantly colored milks, caused by special bacteria, are seldom seen in this country. The odor of milk may be bad from various causes, as from improper feeding of the cows, manure in the milk, or from the milk remaining a long while in dirty barns. Sour milk may be condemned. Stringy milk is not uncommon, but is generally only noticeable several hours after milking, and so usually escapes attention until in the consumer's hands. The existence of garget in cows may produce stringy milk; also it occurs in the milk of cows which have been milked late in the period of lactation ; certain herbs are said to cause it. It is somewhat doubtful whether the condition is always due to special germs or whether it is caused, at times, by chemical substances (ferments) which occur in certain plants. Fishy milk is caused by rusty cans, and cows inhabiting pastures containing stagnant pools of water may yield milk with this oclor or taste.

Milk which is to be examined to estimate the number of germs it contains should only be placed in bottles which 
have been boiled for twenty minutes or sterilized in a regular sterilizer. The corks should be sterilized in the same manner. The bottle must be filled to the cork and be packed in a vessel with enough ice to last until the examination is made.

Milk Prescrvatives.-The most commonly used preservatives are formaldehyde, borax and boric acid. Occasionally salicylic acid and sodium carbonate are employed. Formaldehyde may be detected, during the process of determining fat by the Babcock test, by observing the color of the line of contact of the acid with the milk. When pure milk is used for the Babcock test, the color of this line is dirty brown, but, when formaldehyde is present in the milk, a distinct purple hue will appear at the junction of the acid and milk.

This test may be applied in other ways by using a separate sample of milk. Place about 20 cubic centimeters* of milk in a small glass vessel, dilute with an equal volume of water, and add commercial sulphuric acid, allowing it to flow slowly down the inside of the vessel. If formaldehyde is present the purple color will appear at the junction of the acid and milk.

Boric acid or borax are detected by adding to a few drops of milk, contained in a white dish, a drop or two of hydrochloric acid, and then several drops of a saturated alcoholic solution of turmeric. Heat the dish gently for a few minutes and, if boric acid or borax are present, a pink or dark red color will appear. Cool, and add a drop of ammonia, when a dark blue-green should be seen.

*A cubic centimeter (metric system) is a volume of fluid equal to 16 drops of water. Any apothecary can prepare the substances required to make the above tests and at the same time could perform the tests with the assistance of the description given above and show the farmer or dairyman how to perform them himself. 
Sodium carbonate is detected by adding to the suspected sample of milk an equal volume of alcohol and then two drops of a one per cent. solution of rosolic acid. If sodium carbonate is present a red-rose color will appear. The test may be performed with more certainty if a comparison test is made with a sample of milk known to be pure.

Salicylic acid is rarely used but may be detected by adding a few drops of sulphuric acid to a small quantity of milk and then shaking gently with a mixture of ether and petrolic ether. The mixture is made of equal parts of ether and petrolic ether and equal volumes of acidulated milk and ether mixture are taken. Then, after standing for several hours, the upper ethereal solution is poured off and the remaining liquid is evaporated in a porcelain evaporating dish. Add, to the residue on the white evaporating dish, a few drops of water and, if salicylic acid is present, a drop of ferric chloride solution will produce a violent or purple color on being added to the solution.

It sometimes happens that it is desirable to determine whether milk has been heated above the proper temperature of pasteurization. To test this, add to a few cubic centimeters of milk a few drops of a freshly prepared solution of diamido-benzene ( $\mathrm{I}$ part of latter to 4 of water), and then a few drops of hydrogen peroxide. Unheated milk gives a blue color when thus treated, but milk heated over $174.2^{\circ}$ F. gives no color.

The simplest test for preservatives is to place some milk in a warm place (at temperature of $80^{\circ}$ to $90^{\circ} \mathrm{F}$ ) in a corked, clean bottle for 24 hours. If it does not sour or curdle the addition of a preservative may properly be suspected, unless the milk has been pasteurized. The tests 
described on pp. 1 36-7 may then be tried to determine positively the presence or absence of preservatives.

For testing the acidity of milk, an alkali and phenolphthalein are commonly employed. The basis of this test rests on the fact that phenolphthalein turns pink in the presence of an alkali and is colorless in the presence of acid. Therefore in the tests, by adding a known quantity of alkali to a known quantity of milk and phenolphthalein, we may know just how much acidity is present in the milk. For when enough alkali has been added to the milk and phenolphthalein tc turn the mixture pink, we know that all the acid in the milk has been neutralized and the mixture is becoming alkaline.

Roughly speaking, increased acidity in milk means increase in number of lactic acid bacilli. The degree of acidity is commonly tested by health boards in cities to determine the fitness of milk for food. But, as has been recently shown by Bergey, the acid test will not apply to pasteurized milk. There may be hundreds of millions of germs in pasteurized milk without marked acidity. This happens because the germs are not of the acid forming type but belong chiefly to the hay bacillus group (B. subtilis).

These are not usually rated as disease germs, but they make the milk less digestible and nutritious and may pro. duce substances in the milk which cause severe vomiting and diarrhœa in infants.

By far the easiest and most convenient method of test. ing milk or cream for acidity, for those not versed in chem. istry, is by means of (Farrington's) alkaline tablets, which may be had of any wholesale dairy supply company. Milk which contains more than 0.2 per cent. of acid (lactic acid) is not considered sweet, and the acidity of sweet cream varies from 
O. 5 to 0.2 per cent. The Farrington tablet contains an alkali and phenolphthalein. Two tablets are dissolved in I ounce of water and this is added to an ounce of milk. If the mixture remains pink, then the milk contains less than O.2 per cent of acid, but if the pink coloration fades and disappears it shows that the mixture contains more than this amount of acid and is unfit for retailing, for pasteurizing, or for cheese or butter making. A more exact method of using the tablets for testing the acidity of cream may be done. This is very useful for the butter maker in informing him of the progress of the ripening of cream, and also in showing whether or no two lots of cream may be mixed safely, and again it may be used to test the acidity of whey. When cream contains 0.5 to 0.6 per cent. acidity, it is as sour as it should be for butter making. Full directions for use of the Farrington alkaline tablets are supplied with the tablets.

A test by which the percentage of acidity of milk may be more accurately determined than is necessary by the dairyman, is that in which the alkali is lime water.

To make lime water, used in testing the acidity of milk, we may get from a grocery store an ounce or so of lime; add a pint of water, and stir thoroughly. Allow the undissolved lime to settle, and pour off the clean lime water, which will contain any potassium or sodium that may have been present in the lime. Do this several times. Now pour on a quantity of distilled water depending on the sized bottle the lime water is kept in, and cork; when the lime has settled so the water is clear, it is ready to be used and may be removed as wanted with a pipette, as will be described presently. Always have some undissolved lime at the bottom of the jar, as by this means the lime water is 
reaclily kept saturated. As fast as the lime water is used, add distilled water to take its place. It is well to use a fresh lump of lime every two or three months, as in time the sediment may consist of carbonate of lime, owing to absorption of carbonic acid from the air.

An easy way to test the acidity of milk* is: (1) First mix the milk thoroughly, and (2) with a graduated I c.c. pipette (such as is shown in Fig. 4I) place I c.c. of the milk in a small evaporating dish or test-tube. (3) To this add one drop of an alcoholic solution of phenolphthalein ( $1 \mathrm{gm}$. to 30 c.c. alcohol). (4) With another I c.c. pipette add drop by drop clear lime-water, and shake the tube to mix thoroughly, until the milk is colored a faint pink. Now note how many c.c. of lime-water were used.

\begin{tabular}{|c|c|c|c|c|c|c|c|c|}
\hline I " & ." & "، & “" & .2 & " & “ & .09 & " \\
\hline I “ & " & 6 & " & $\cdot 3$ & " & "6 & I 35 & . \\
\hline I " & " & “ & “ & .4 & " & “ & .180 & “ \\
\hline I “ & ، & “" & 6" & .5 & “ & “" & .225 & 6 \\
\hline I “ & “" & “ & “ & .6 & " & "، & .270 & 6 \\
\hline I “ & " & " & " & .7 & " & ، & .315 & " \\
\hline I “ & " & “" & " & .8 & "، & “' & .360 & “ \\
\hline I " & “ & " & " & 9 & ، & "I & .405 & "6 \\
\hline I “ & "6 & “ & 6 & 1.0 & " & “" & $.45^{\circ}$ & " \\
\hline I “ & "6 & " & “ & I.I & “ & “ & .495 & “ \\
\hline 16 & " & “ & 16 & I. 2 & " & “ & .540 & " \\
\hline I “ & "6 & “" & "1 & I. 3 & $"$ & " & $.5^{8} 5$ & "، \\
\hline “" & " & " & "، & I. 4 & "6 & " & .630 & 16 \\
\hline I " & "، & “" & "، & $\mathrm{I}, 5$ & " & " & .675 & "6 \\
\hline
\end{tabular}

A simple rule is: Multiply 0.0045 , the weight in grams of lactic acid neutralized by i c.c. lime-water, by the number of cubic centimeters of lime-water used, and divide by roo, which gives the percentage of acidity.

Cream Thickeners.-Viscogen, a solution of sugar, lime and water, is commonly used to thicken cream. This

\footnotetext{
* This test is taken from Chapin's Theory and Practice of Infant Feeding.
} 
adulteration can only be determined by a chemist, makingan exact analysis for sugar and estimating the percentage of lime. Gelatine is sometimes employed as a thickening agent. This can be detected by adding, to about 10 or 15 cubic centimeters of milk, twice the volume of water and 10 cubic centimeters of acid mercuric nitrate solution (I o per cent). Shake the mixture vigorously and allow it to stand a few minutes and filter. If much gelatin is present it is impossible to filter a clear fluid. To verify a suspicion of gelatine. add to a small amount of the filtered fluid an equal volume of a saturated aqueous solution of picric acid. If any gelatin is present, a yellow cloudiness will appear in the fluid.

Milk which has been either watered or skimmed, or both watered and skimmed, is considered according to law to be adulterated and is the commonest form of adulteration. Another form of adulteration consists in the adding of preservatives to milk. The preservatives most frequently used are formaldehyde (sold under the name of Freezine, etc.) and boric acid, sold under various trade names. These are added to keep milk from souring. To determine whether milk has been watered or skimmed three determinations are necessary: viz, the determination of the total solids in milk; fat; and the specific gravity. For the determination of the specific gravity and approximate determination of milk solids, see page 147 . The determination of the fat alone is usually sufficient to estimate the quantity of milk for the farmer who does not adulterate his mill.

The methods for determining the amount of fat in milk are based upon centrifugal separation of milk. The 
theory of these methods depends upon the fact that when milk is whirled at a rapid rate-several thousand revolutions per minute-the heavier portions of the milk are thrown outward, leaving the lighter or fatty portions nearer the center of the whirling body. The method of Dr. S. Mr. Babcock is the one in general use.

The milk is measured in a suitable bottle and an equal volume of sulphuric acid is added which dissolves the casein or curd of milk and liberates the fat. The bottle is then whirled at a high speed, allowing the fat to come to the top of

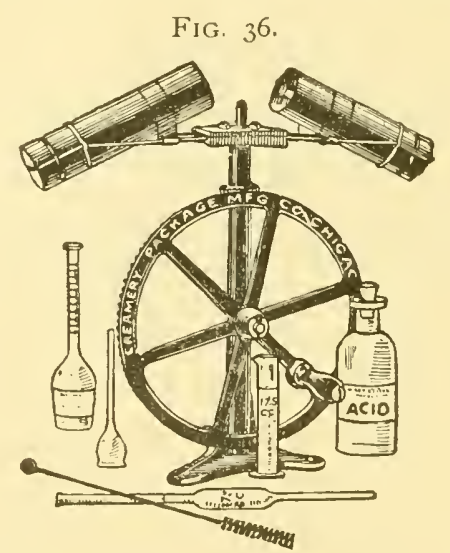

Small Babcock machine, with other necessary paraphernalia.

the bottle-that is, as the bottle is nearly horizontal when whirled, the fat approaches nearest the center of the whirling body. Hot water is added and the bottle whirled again and the percentage of fat is read off in the neck of the bottle,

The Babcock centrifugal machines are obtainable in sizes ranging from those holding two bottles (Fig. 36) to those holding 24 (Figs. 37 and 38 ), and the smaller are run by hand while the larger are often run by power (see Fig. 38 ). The smaller sizes may be clamped or screwed to a table, require but little space and are easy to operate. The Babcock 
bottle for milk-testing (Fig. 39) holds about 40 cubic centimeters, the neck is graduated from o to ro with sub-divis-

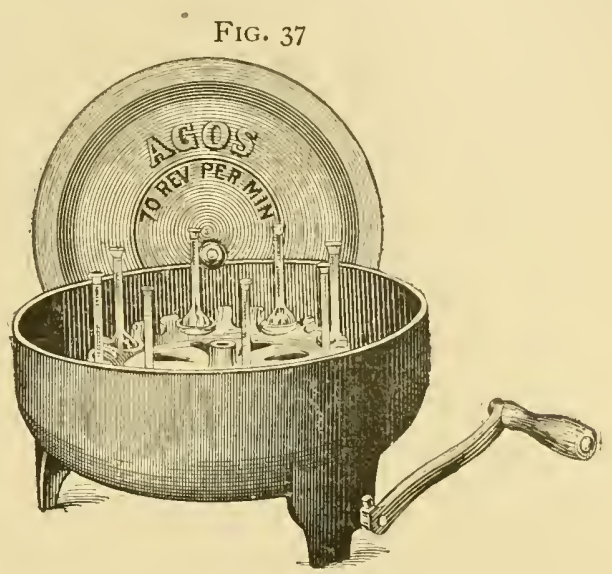

Eight-bottle Babcock machine.

ions of 0.2 per cent.- 2 cubic centimeters being the exact volume of the space between o and io-or io per cent. of

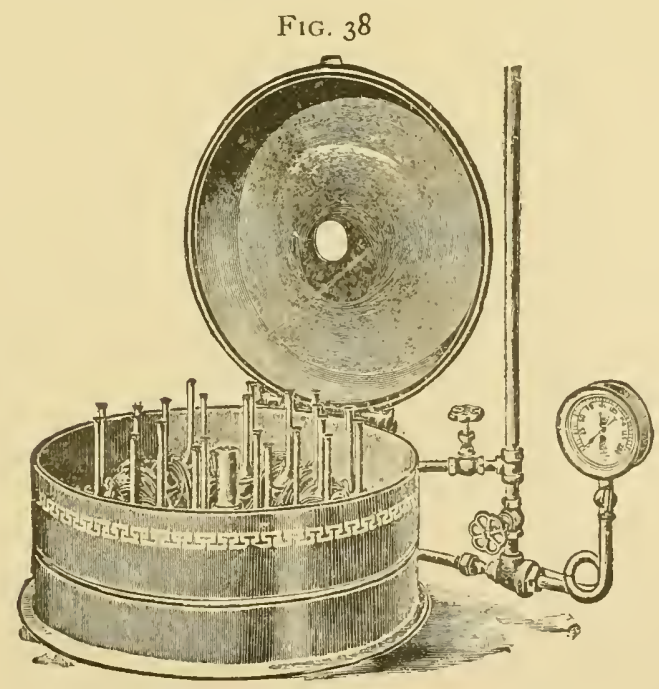

Power Babcock machine.

20 cubic centimeters, which volume of milk would be used had milk and melted fat the same specific gravity as water. 
It happens, however, that 2 cubic centimeters of melted fat weighs 1.8 grams, so in working with the test, 17.6 cubic centimeters of milk (the average volume of $\mathrm{S}$ grams of milk) are used. It is apparent then that the subdivisions on the stem of the bottle read per cent. direct. To

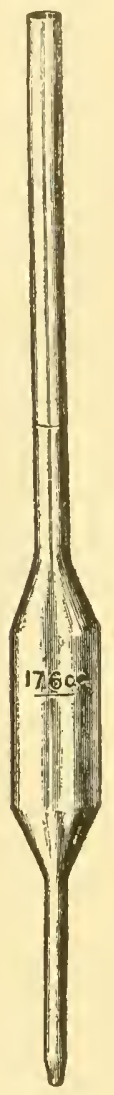
illustrate: Suppose a given sample reads 5 on the neck, the volume occupied by this fat would be just one cubic centimeter and that would weigh 0.9 grams, and 0.9 grams equal 5 per cent. of I 8 grams, or the per cent. of fat by weight in the milk.

To make the test: The milk should be well mixed, and both it and the acid should be at a temperature between $60^{\circ}$ and $70^{\circ} \mathrm{F}$. The pipette, graduated to I 7.6 cubic centimeters, should be filled precisely to this point, by sucking up the milk into it. The milk bottle is to be held in a slanting position and the point of the pipette just introduced into the neck of the bottle (see Figs. 40 and 4i). By gradually raising the finger from the end of the pipette, the milk is permitted to flow into the bottle, the last drop being expelled by gently blowing through the pipette. To the milk in the test bottle, 17.6 cubic centimeters of commercial sulPipette for making the Babcock test phuric acid (specific gravity $1_{.} \delta_{2}$ ) are added in the same manner with the pipette, and, by gently rotating the bottle, the acid and milk are mixed.

The acid and milk become very hot and care must be taken to mix gradually, and to allow no lumps to collect in the neck. It is well to then let the bottles stand for a few minutes, and mix again by rotating the bottles. 
The bottles are now placed in the machine (it is wise to have duplicates of each sample of milk) and the machine is rotated at full speed for five minutes. Then the machine is stopped and boiling soft water is added to the contents of each bottle, by means of the pipette or otherwise, till the contents of the bottle rise to the lower end of

\section{FIG. 40.}

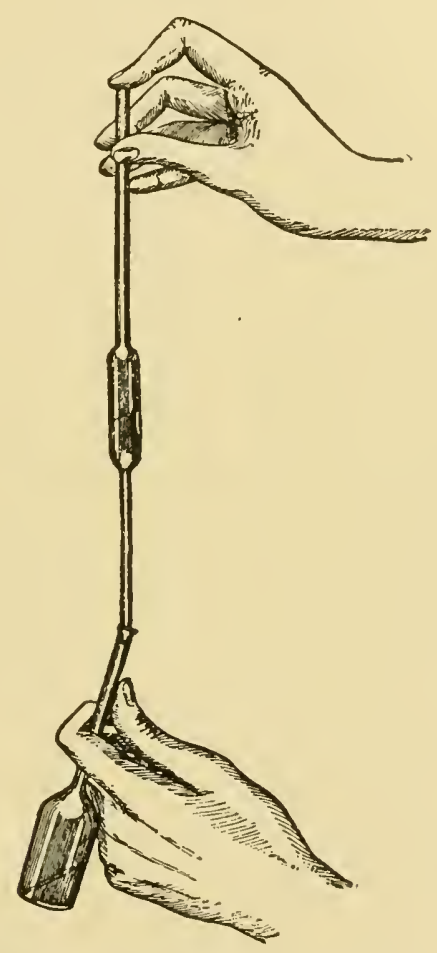

Shows method of introducing milk into Babcock bottle with pipette in making the fat test.

the neck of the bottle. The machine is whirled at full speed again for two minutes. More boiling water is then added to the contents of each bottle by pipette until the fat rises in the neck to the 8 or 9 mark. The machine is once more turned one minute and the percentage of fat is read off in the neck of the bottle by measuring with calipers 
from the lower to the upper border of the fat in the neck. The reading must be done before the contents or the bottle cool off. The addition of the hot water may be accomplished without removing the bottles from the machine.

\section{Estimation of Solids in Milk by Quevenne's Lactometer.}

Since most cities require that market milk shall contain a standard percentage of milk solids, it is of advantage that the farmer be able to determine this matter for himself.

Quevenne's lactometer is an instrument by which the solids can be roughly estimated. It consists of a glass bulb weighted with mercury and terminating in a stem like a thermometer, and marked by lines on the stem from i 5 to 40. It should also carry a thermometer.

The principle upon which the lactometer is based depends upon the fact that, when it is placed in milk, in floating it displaces a bulk of milk equal in weight to the weight of the lactometer. The milk must be thoroughly mixed-but free from bubbles of air--and the reading is taken at the actual level of the milk; not at the point of the stem to which it is drawn by capillary attraction.

The lactometer is then used to determine the weight of milk (or in other words, the specific gravity) as compared with the weight of an equal bulk of water when both are at the same temperature.

If $\mathrm{I}, \mathrm{OOO}$ is taken as the weight of a certain quantity of water, the weight of the same quantity of milk, at the same temperature, is about $\mathrm{I}, 030$ to $\mathrm{I}, 034$. This is shown in practice by floating the lactometer in milk, placed in a cylindrical glass tube, when it will sink in the milk to a mark on the stem corresponding to the specific gravity of 
the milk. The greater weight of milk (as compared with water), or its specific gravity, is due to the solids-not-fat it contains, $i$. $c$, the casein, albumin and milk sugar. While the lactometer may be used to determine the solids in unaltered milk as it comes from the cow, it will not determine the solids in milk which has been watered and skimmed.* Milk fat weighs less than water, and, of course, less than milk. Removing cream raises the specific gravity of milk. Then if water were added the specific gravity might be lowered again to the normal for untampered and unadulterated milk.

To estimate the solids in milk by the lactometer, the temperature of the milk should theoretically be $60 \mathrm{deg}$. F. But the milk may be at any temperature between $50 \mathrm{deg}$. and $70 \mathrm{deg}$. F. providing a correction is made for the temperature of milk above or below $60 \mathrm{deg}$. F. Thus, if the milk is above $60 \mathrm{deg}$. F., one must add to the lactometer reading $0 . \mathrm{I}$ for each degree of temperature above this point ; if the temperature of the milk is below $60 \mathrm{deg}$. F., one should subtract 0 . I from the lactometer reading for each degree of temperature below this point.

For example, if a sample of milk at a temperature of 65 deg. F. shows a lactometer reading of 29 , then one should add to this reading: $-5 \quad$ O. I $=0.5$, which gives the corrected reading as 29.5 .

If, on the other hand, the lactometer should float in milk to a mark on its stem indicating 29 , and the temperature of the milk was $55 \mathrm{deg}$. F, then one should subtract O. I for each degree of temperature below $60 \mathrm{deg}$. F. from this lactometer reading, which gives us 28.5 as the corrected reading.

Now, to estimate the solids in milk we must have prev-

* In conjunction with the fat test and the determination of solids it will show either watering or skimming of milk. 
iously determined the percentage of fat in the milk by means of the Babcock machine. To find the total solids in milk we divide the lactometer reading by 4 , and, to the result, add the per cent. of fat multiplied by r.2. For example, we have a milk containing 4 per cent. of fat and a lactometer reading of 32 , to find the total solids :

$$
\begin{aligned}
32 \div \quad 4 & =8 . \\
4 \text { per cent. } \times \text { I. } 2 & =\frac{4.8}{\text { I } 2.8 \text { per cent. of total solids. }}
\end{aligned}
$$

To find the solids-not-fat, divide the lactometer reading by 4 , and, to the result, add the per cent. of fat multiplied by o.2. Thus, in the same milk as in the last example:-

$$
\begin{aligned}
32 \div \quad 4 & =8 . \\
4 \text { per cent. } \times 0.2 & =\frac{0.8}{8.8} \text { per cent. of solids-not-fat. }
\end{aligned}
$$

The percentage of casein and albumin increasesthough not in a proportionate degree-with the increase of fat, as shown in the following table from Woll's Handbook, summarizing the analyses of 2,400 samples of milk:

$\begin{array}{ccc}\begin{array}{c}\text { Fat } \\ \text { per cent. }\end{array} & \begin{array}{c}\text { Casein and } \\ \text { albumin. }\end{array} & \begin{array}{c}\text { Total } \\ \text { solids. } \\ 3.07\end{array} \\ 2.92 & \text { II.00 } \\ 3.29 & 3.0 & 11.50 \\ 3.50 & 3.07 & 12.00 \\ 3.75 & 3.19 & 12.50 \\ 3.99 & 3.30 & 13.00 \\ 4.34 & 3.44 & 13.50 \\ 4.68 & 3.57 & 14.00 \\ 4.92 & 3.79 & 14.50 \\ 5.39 & 4.00 & 15.00 \\ 5.69 & 4.15 & 15.50 \\ 6.00 & 4.30 & 16.00\end{array}$




\section{Quantitative Analysis of the Bacteria in Milk*}

Glassware.-At the outset there should be carefully washed a number of test-tubes, liter flasks, petri dishes (Fig. 44), cubic centimeter pipettes (Fig. 4I), a number of small flasks which are marked to hold 99 c.c. (Fig. 42), together with a considerable number of small vials, like homeopathic vials, marked to hold I9 c.c. (Fig. 42). These various pieces of glass plugged with cotton, are placed in a sterilizing oven and heated for about an hour to a temperature approximating $180^{\circ} \mathrm{C}$. It is well to sterilize a considerable number of them at the outset, so as to have them on hand. Some of the cubic centimeter pipettes should be graduated to one-tenth of a c.c., and it is best to place them in a larger glass tube whose ends are plugged with cotton, as shown in Fig. 4I, in which the pipettes can be kept after being sterilized. After this apparatus has been sterilized it should be set aside where it can be kept free from dust until needed.

(Sterilized agar culture medium may be made as below -a somewhat difficult process-or bought of Park, Davis \& Co., Detroit, Mich., or other such makers of laboratory products. -K. W.)

Preparation of Culture Media.-Any of the methods of preparation of culture media used in bacteriological laboratories are satisfactory for the purpose of milk analysis. The method of making a satisfactory medium for quantitative analysis is as follows :

\section{PEPTONE-AGAR CULTURE MEDIUM.}

A. In a large porcelain cooking dish place the following ingredients:

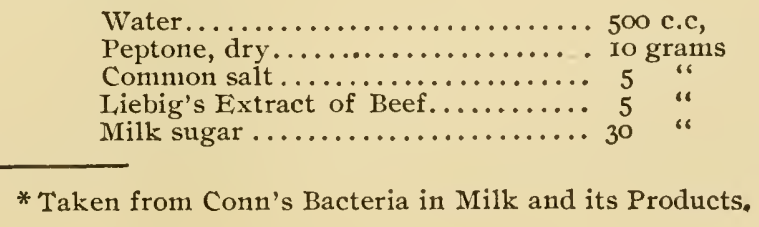


These materials are to be mixed together and heated to a temperature not above $150^{\circ} \mathrm{F}$., which will bring the materials into solution. There should then be added to the mixture a sufficient amount of water to make up for that which is evaporated in the heating. This may best be determined by weight rather than by measure, weighing the dish with its contents before heating, and then weighing again after the solution is complete, adding water to make the weight equal to the original weight.

B. Cut into fine pieces 15 grams of agar and dissolve it in 500 c.c. of water. This will require considerable heat. After the agar is

Fig. 42.

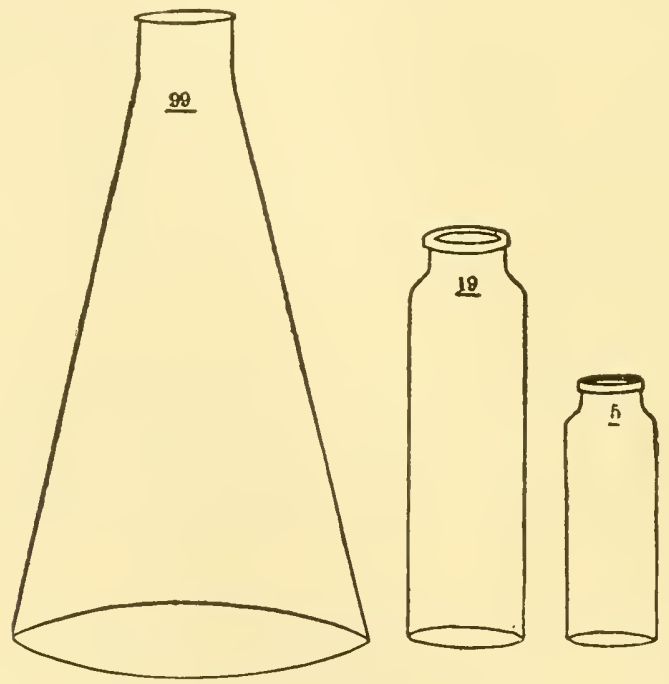

Flasks and vials for quantitative bacteriological analysis.

dissolved, cool to $150^{\circ} \mathrm{C}$., add water to restore evaporation, and $\mathrm{mix}$ with solution A. The mixture must then be neutralized carefully. This neutralization is the most important step in the whole preparation. A satisfactory method of neutralization is as follows :

Remove 5 c.c. of the mixture by a pipette and place in an evaporating dish. Add 45 c.c. of distilled water, boil for 3 minutes, and add I c.c. of phenolphthalein solution ( $5 \mathrm{gm}$. of phenolphthalein powder in Ioo c.c. of 50 per cent. alcohol). Place in a burette having a rubber pinch-cock (Fig. 43), a quantity of one-tenth normal solution of sodium 
hydroxid.* Add this solntion, drop by drop, to the material in the evaporating dish until it turns to a very faint pink color. This indicates the neutral point. Treat two other samples in the same way, and if the amount of the sodium hychoxid added is the same in each case it indicates the amount necessary to neutralize 5 c c. of the culture medium. The average of the three tests should be taken. By calculation, determine the amount necessary to neutralize the whole liter, and add sufficient amount to the whole for neutralization.

* To make strictly accurate normal solution of $\mathrm{NaOH}$ and $\mathrm{HCl}$ requires familiarity with quantitative chemistry. Solutions accurate enough for Jacteriological work may be made as follows :

Normal NaOH.-Dissolve 40 grams of fresh, $d r y$ NaOH in one liter of distilled water. This will not be a strictly accurate normal solution, but very nearly so. The solution should not be kept in a glass-stoppered bottle. It loses its strength and it is best to use solutions which are fresh. To make a one-tenth normal solution dilute any quantity of the normal solution with ten times its bulk of distilled water. This should be made fresh from a normal solution at the time of using.

Normal $\mathrm{HCl}$.-To 700 c.c. distilled water add Ioo c.c. of concentrated c.p. $\mathrm{HCl}$, which, assuming that the $\mathrm{HCl}$ is 30 per cent. acid, would give 30 grams of $\mathrm{HCl}$ in $\mathrm{Soo}$ c.c. of the solution. This gives about the right strength (i. e., 36.5 c.c. per liter), but since the $\mathrm{HCl}$ varies in strength, the solution must be standardized with a normal $\mathrm{NaOH}$ prepared as described above. To do this proceed as follows: Place ro c.c. of the $\mathrm{HCl}$ solution in all evaporating disl1. Add 40 c.c. of distilled water and I c.c. of phenolphthalein solution. Fill a burette (see Fig. 39) with some freshly prepared normal $\mathrm{NaOH}$, and allow the $\mathrm{NaOH}$ to flow from the burette into the evaporating dish, drop by drop, until the faintest pink color appears in the acid solution and remains. This indicates the neutral point. Read from the burette the antount of $\mathrm{NaOH}$ which was required to neutralize the Io c.c. of acid. If the $\mathrm{HCl}$ solution were exactly normal, Io c.c. would require exactly Io c c. of $\mathrm{NaOH}$ solution for neutralization. The solution prepared as above described ( 100 c.c. of $\mathrm{HCl}$ in 700 c.c. of water) is usually too strong and requires more than io c.c. of normal $\mathrm{NaOH}$ for neutralization. It must, therefore, be diluted with water. The amount of water that nust be added can be calculated as follows: Suppose there were required in c.c. of the NaOH to nentralize Io c.c. of the $\mathrm{HCl}$ solution. This would indicate that the $\mathrm{HCl}$ was eleventenths of its proper strength. To make it normal there should be alded to it one part of water to every ten parts of solution. The solution prepared now contains 790 c.c., and $790 \times \frac{1}{1^{1} 0}=79$ c.c. Hence 79 c.c. of distilled water should be added to tle 790 c.c. of $\mathrm{HCl}$ to give a normal $\mathrm{HCl}$ solution. Add 79 c.c. of water and test again to correct any error. If the original $\mathrm{HCl}$ solution slould prove to be too weak it is easier to make another solution a little stronger than to calculate the amount of acid necessary to bring the solution to a normal strength.

The normal HCl solution once made will keep a long time without deterioration if kept in a stoppered bottle. A one-tenth normal HCl solution may be urade by diluting the normal solution with ten times its bulk of water at the time of using. 
Instead, however, of adding to the mixture the one-tenth normal $\mathrm{NaOH}$, add a nomal solution, which is ten times as strong, and of which, therefore, only one-tenth as much should be added as would be required of the one-tenth normal. The whole of the medium is thus to be neutralized. It is well to test the accuracy of the neutralization by adding a few drops of phenolphthalein to a little of the neutralized medium. This should give the faint pinkish tinge ; if it does not, it means that the neutralization has not been properly effected.

After neutralization, boil for five minutes and restore to the original weight, after which the reaction should be tested again and corrected if necessary.

The material thus neutralized is too strongly alkaline for the proper growth of bacteria and must be rendered less alkaline by adding $\mathrm{HCl}$. The amount to be added should be such as to bring the reaction to I.5 per cent. acid. To produce this acidity add to the neutralized medium i 5 c.c. of normal $\mathrm{HCl}$ for each liter. The acidity thus obtained is found to be that at which common milk bacteria grow most readily.

After adding $\mathrm{HCl}$ in proportion of I 5 c.c. to each liter of solution,

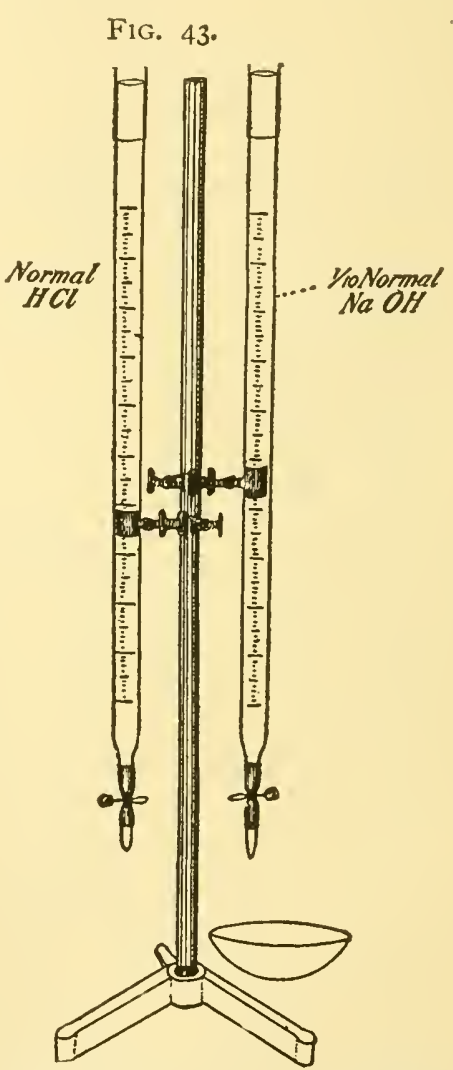

Two burettes arranged for neutralizing culture media. pour into the mixture slowly the white of an egg mixed in a little water. Boil vigorously for a few minutes to coagulate the albumen, and then filter through absorbent cotton or through filter paper moistened with hot water. The material filters rather more easily through absorbent cotton, and if the directions above given are followed closely it will filter perfectly clear. After filtering the material is to be collected in a sterilized flask. 
Fill a considerable number of test tubes with the material from the flask, placing in each test tube about ro c.c. of the medium, carefully replace the cotton stoppers after the test tubes have been filled witl the medium, and the whole quantity-both that in the test tubes and the flask--should be sterilized in a stean sterilizer for 20 minutes.

To produce complete sterilization it is necessary to repeat the steaming on three successive days. The second and third sterilization require a longer time than the first, inasmuch as it requires some time to melt the agar, and, until the agar is thoroughly melted, the sterilization is not effective. Upon the second and third days, therefore, the material should be steamed at least one-half hour. If an autoclave is at hand, sterilization at $120^{\circ} \mathrm{C}$. for 20 minutes is sufficient.

Fig. 44.

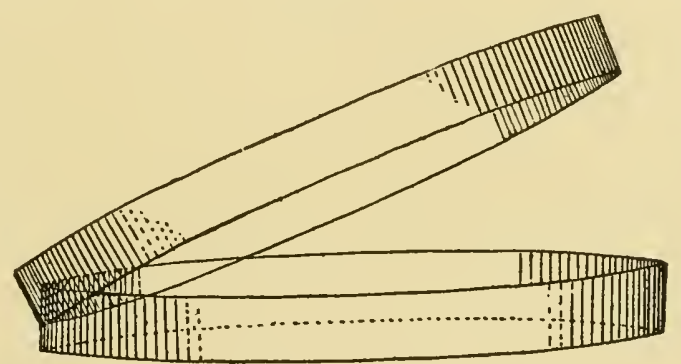

Petri Dishes.

Method of Making Quantitative Analysis of Milk.-In order to make an analysis of the bacteria in milk it is necessary to have an approximate idea of the number of bacteria which are to be expected. The reason for this is that the bacteria are commonly so numerous that it is necessary to dilute the milk highly with sterilized water in order that reliable results may be obtained. In the quantitative analysis of ordinary market milk it is commonly satisfactory to dilute the milk one hundred times with sterilized water, provided the medium to be used is the agar culture medium above described. If the milk is old and contains large numbers of bacteria, a much higher dilution than this is desirable (see p. I57), but for the kind of milk usually found in milk-distributing carts a dilution of one hundred times is usually satisfactory for the purpose here considered. 
Several of the small flasks marked to hold 99 c.c. are filled to this mark with water and placed in an antoclave for sterilization. If it is desired to dilute the milk more than one hundred times there should, at the same time, be placed in the autoclave a number of the smaller vials filled witl water to the I9 c.c. mark and others to the 5 c.c. mark (Fig. 42). All of these vessels of water are to be sterilized for an hour at a temperature of $120^{\circ}$ (a steam pressure of ten pounds will do), after which they are to be removed. If an autoclave is not at hand the water may be sterilized by steaming for two hours.

There is now taken from the milk to be tested a single cubic centimeter in one of the sterilized pipettes. Taking of the sample of milk is the most important point in the analysis and most liable to introduce errors. The number of bacteria found in different parts of a can of milk is by no means uniform, the surface layers containing different numbers from the deep layers of the milk. To avoid this irregularity it is necessary to give the milk a very thorough stirring or shaking immediately before the sample is taken, so as to distribute the bacteria as uniformly as possible.

A cubic centimeter of milk is transferred by a sterilized pipette into one of the roo c.c. flasks of sterilized water. The mixture is then to be very thoroughly shaken, so as to distribute the milk uniformly through the water. This thorough shaking is extremely important to break up the clumps of bacteria.

Meantime six test-tubes of the agar culture medium have been melted by placing them in water over a gas flane. The tube should be kept in warm water at a temperature just sufficient to keep its contents from solidifying. A single cubic centimeter of the mixture of milk and water is removed with a second sterilized pipette and placed in each of the test-tubes of melted culture medium. The test-tubes are then to be gently but thoroughly shaken, so as to distribute the inoculated material uniformly. It is necessary to avoid shaking too vigorously, or otherwise bubbles will make their appearance, which will interfere with the accuracy of the test. The shaking should be thorough but not violent.

Six sterilized petri dishes (Fig. 44) should liave been placed upon a plate of glass which is held in as nearly a level position as possible 
and cooled artificially. This can be accomplished by taking a large, flat dish, filling it with water and ice then laying a large plate of glass upon the top. The ice will rapidly cool the glass plate, and the petri dishes placed upon the plate will also rapidly become cooled. The contents of each of the test-tubes inoculated with the diluted milk are now to be poured each into a petri dish and the cover quickly replaced. The culture medium will distribute itself in a thin layer over the bottom of the petri dish and soon harden. The dishes are to be labelled and then set aside in a proper place for growth. If desired to hasten the analysis the dishes may be placed in a culture oven kept at a temperature of $98^{\circ} \mathrm{F}$. For ordinary study of milk bacteria it is usually most satisfactory to leave the petri dishes at a room temperature of $70^{\circ} \mathrm{F}$, allowing them to remain for three or four days before the final study is made.

The Study of the Plates. - The solidified culture medium fixes each bacterium at a single point. As the bacteria feed upon the culture medium they grow and multiply, but, unable to move through the solidified medium, the descendants of each bacterium remain together in a mass and, in the course of two days, become abundant enough to produce a spot which can be seen with the naked eye. The plate, therefore, becomes dotted over with little points of various size and shapes known as bacteria colonies. It is only necessary, therefore, to count the number of colonies on one of these plates and we know approximately the number of bacteria that were present in one onehundredth of a cubic centimeter of the original milk; and multiplying the number by one hundred we get the number of bacteria per cubic centimeter of the milk. (See Plate T.) In counting these bacteria on the plate it is sometimes necessary to use various devices for dividing the plate into areas. If the number is small they can be connted without difficulty, but if the number of colonies on the plate is large it is more convenient to place underneath the plate a piece of black paper with white lines ruled upon it, dividing the plate into a series of sections of equal size. Such cards for aiding the counting can be obtained from dealers in bacteriological material, and a quantity of them should be at hand in every laboratory to assist in the counting. If the numbers are not very great the counting may 
be done without the aid of these slips, by simply marking the under side of the petri dishes with a waxed pencil, and thus dividing the plate into a series of sections which may be counted individually. The actual determination of the number of bacteria on these plates is not difficult, though it requires a little practice (see Plate $T$ ).

The number thus obtained represents approximately the number of bacteria in a cubic centimeter of the original milk, but the number is only an approximate one. Different tests of the sample of milk will show considerable irregularities, and it is for this reason that six petri dishes have been made. Each of the six should be counted and the average result of the six regarded as the average number of bacteria per one one-hundredth cubic centimeter. But, apart from this irregularity in the samples, there are at least three other facts which make the analysis only approximate. First, if in the diluted milk there chance to be several bacteria clinging together, as is quite probable even after thorough shaking, these, when placed within petri dishes, would develop into a single colony and would be counted as one. This will naturally give a number in the analysis somewhat too low. A second and more serious difficulty is the fact that not all bacteria present in the milk will grow in the culture medium as above prepared. While a large proportion of the bacteria will develop on plates and make their appearance in analysis, there are some that do not grow at all, and, therefore, do not appear in the analysis. Third, it is impossible to pour out all of the contents of the tube into the petri dish, for some will inevitably stick to the tube. To obtain the absolute number of living bacteria present in a cubic centimeter of milk is quite impossible by any means at our command.

The number obtained by the method described will always be an underestimate. But while it must always be recognized as approximate, the results in different cases may be compared with each other. If two samples of milk show, one ten thousand and the other ten million, it is quite certain that these numbers express approximately the relative number of bacteria in two samples, though neither expresses the number accurately. 


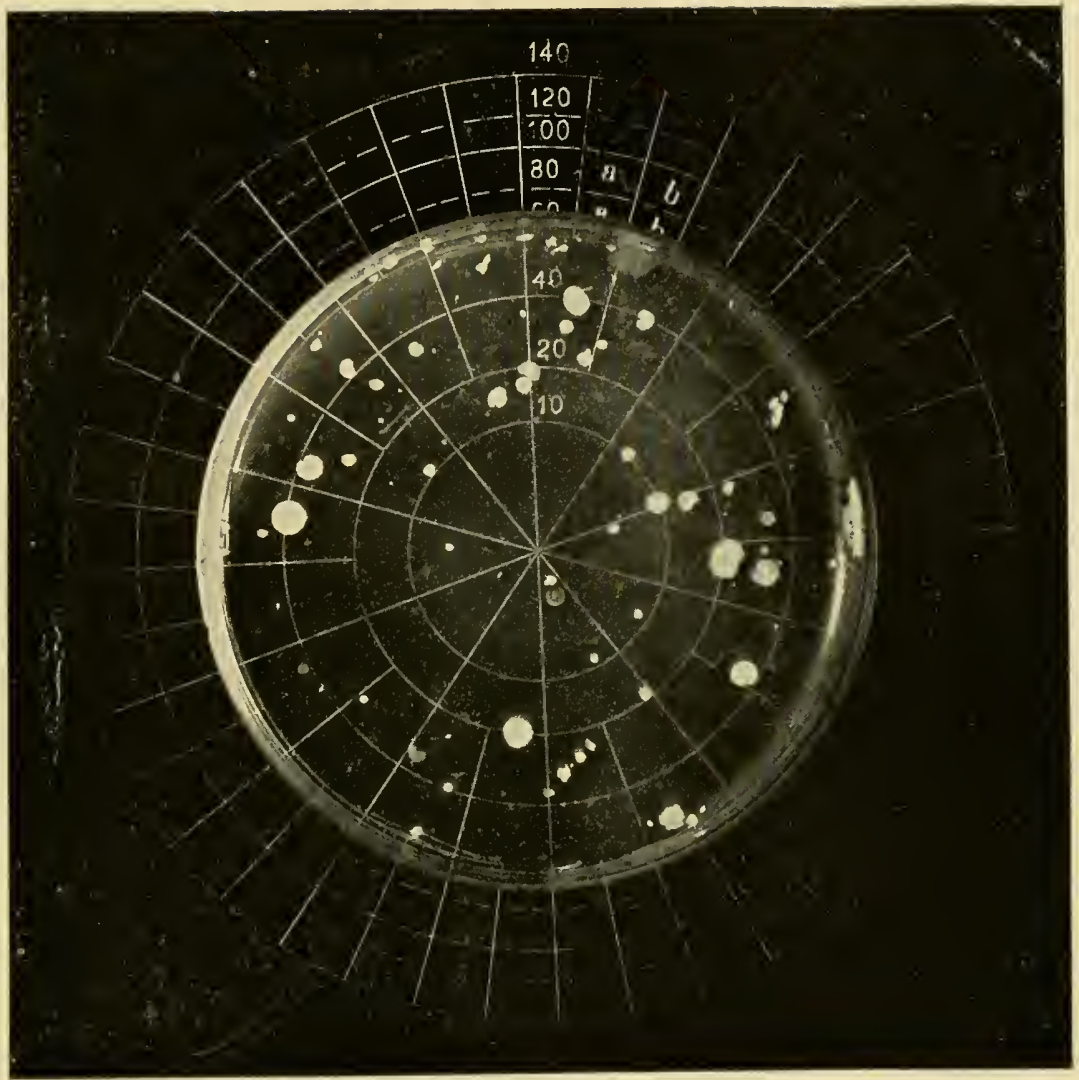

Petri dish containing I cubic centimeter of a mixture of milk (I c.c.) diluted with 499 c.c. of sterilized water and mixed with sterilized agar culture medium. The white spots in the plate are colonies or collections of germs.

Each colony is supposed to represent a single germ at the time the milk was examined. The dish rests on a glass plate lined in white with a black background to facilitate counting the colonies. When the colonies are small and numerous, only those in every other sector of the circle need be counted an 1 the result multiplied by two. In the above plate there are only about so plainly visible, but with a common magnifying glass-and one is generally used for counting-about 125 colonies may be seen.

In the dish photographed, 272 colonies were counted, and, multiplied by 500 (the I c.c. of milk was diluted 500 times) gave 135,000 , germs in I c.c, of milk. 

The following report, * describing the method of counting bacteria in Boston's milk supply, gives the most improved details of technique. The reporters are well recognized experts and have worked out some very ingenious improvements which will be found of much practical value.

The method decided upon after consideration of those employed in about ${ }_{5} 5$ laboratories throughout this country was as follows: For media, one and one-half per cent. nutrient agar (B. C.), ro c.c. to a tube, reaction plus 0.7 . The collection outfit was devised anew and consists of a case for carrying the samples made of copper with double walls interlaid with one-half inch felting. This case is divided into three compartments; the central one for samples, the other two for ice. When iced and closed, a constant temperature of $34^{\circ} \mathrm{F}$. is maintained. The samples are carried in sterilized test tubes, the compartment holding eight racks of four tubes each. A smaller case was also made holding but three racks. These racks are made from copper tubing as suggested by one of is. (H. W. H.) Holes in the partitions of the case allow the ice water to circulate around the bottoms of the tubes. The use of the test tubes for carrying samples was suggested by S. C. Keith. For collecting, glass pipettes are used. These are carried in a detachable copper case, adapted for sterilizing, divideả into two compartments, the upper for fresh sterile pipettes, the lower for the pipettes after use.

For plating the samples, the agar, after being melted, is kept in a water bath between $40^{\circ}$ and $45^{\circ}$ C. until needed. In order to bring down the actual number of colonies in a plate to a countable figure, a standard dilution of $\mathrm{I}$ to 10,000 is used. For dilution water, square eight-ounce bottles, marked at Iooc.c., are used. This water is sterilized in the autoclave under 15 pounds steam pressure for 20 minutes at a temperature of about $250^{\circ} \mathrm{F}$. Two bottles are used for each sample, giving a dilution of $\mathrm{r}$ to Io,000, with $\mathrm{I}$ c.c. of milk. Each dilu-

* Herbert Winslow Hill, M.D., Director, and Francis Hervey Slack, M.D., 2 A Asst. Bacteriologist, Boston Board of Health Bacteriological Laboratory. In American Journal of Public Hygiene, November, I904. 
tion is slaken 25 times for thorough mixing, as is also the sample. A sterile pipette marked to contain I c.c. and calibrated in the laboratory is used at each stage, three being required for each sample. After expelling the milk into the first bottle, the pipette is rinsed to the I c.c. mark in the dilution water; I c.c. from the first dilution bottle is transferred to the second dilution bottle; then I c.c. from the second dilution bottle is transferred to the petri dish. The agar is then carefully added, mixed with the diluted milk in the plate and allowed to harden.

The plates are incubated in a saturated atmosphere at $37^{\circ} \mathrm{C}$. $\left(98.6^{\circ} \mathrm{F}\right.$.) for $2+$ hours. The colonies in a saturated atmosphere are not only more numerous, as shown by Whipple, than in a dry atmosphere, but also larger and therefore more easily counted; $37^{\circ} \mathrm{C}$. is used in preference to room temperature because the latter requires more time for satisfactory development of the colonies, and is also so variable as to give no standard for the comparison of results. The 24-hour incubation is used in preference to the 48-hour because, though the latter shows a slightly higher average count, the counts are not sufficiently higher to materially change the report. One thousand consecutive plates incubated at $37^{\circ} \mathrm{C}$. and counted at 24 and 48 hours gave the following results :

679 or 68 per cent. showed an increase in the number of colonies at the 48 -hour count.

In 195 , or 19.5 per cent., the count remained the same; 126 or I 2.6 per cent. showed a decrease.

799 or So per cent. of these plates had counts below roo.

The average 24 -hour count on these plates was $15^{\frac{T}{2}}$; the average 4 S-hour count IS $1 / 4$.

I93, or 19 per cent., had between 100 and 1,000 colonies averaging at the 24 -hour count 275 , and at the 4 S-hour count $2 S_{3}$.

Eight plates, about I per cent., had over I, 000 colonies each, averaging $\mathrm{I}, 2 \mathrm{~S} 7$ at the 24 -hour and $\mathrm{I}, 3.34$ at the 48 -hour count.

Only i 3 plates changed their relation to the legal limit, nine going from below to above 500,000 and four decreasing.

In many plates, the count is lower with the 48 -hour incubation on account of small colonies becoming obscured in the growth of larger ones. There are also more spreaders. 
This annoying difficulty with spreaders, frequently met with even in the 24 -hour plates, we now overcome by the use of earthenware petri covers suggested by one of us. (H. W. H.)*

Spreading seems to be caused principally by water condensing on the petri covers and agar. The dry porous earthenware covers absorb this condensation water, still leaving the atmosphere saturated, as proven by the large size of the colonies. Organisms having an inherent tendency to spread from unusual motility are not prevented from spreading by this method.

In Counting.-A box, a child's slate, a reading glass and a "'lumber counter" are used.

The box is $6 \mathrm{x}_{6} \mathrm{x}_{5}$ inches, with open bottom, glass front, and a four-inch circular opening in the top, painted black within and without, except the glass front.

The slate has a circle cut in the surface, $4^{\mathrm{T} / 2}$ inches in diameter, divided into ro equal segments, the lines filled with red lead.

The reading glass is a common four-inch lens magnifying about two diameters.

The petri disl is placed over the circle on the slate and uncovered. The box fits over the circle, the reading glass over the box, thus protecting the plate, keeping a constant focus and setting botli hands of the operator free.

A slight pressure of the thumb for each colony seen on the lumber counter accurately adds and records the count. As the dilution is I to Io,ooo, the actual count must be multiplicd by ro,ooo to obtain the number of bacteria in I c.c. of the milk.

In addition to simply counting the bacteria it is essential to examine for pus and streptococci which enter milk from an inflamed udder (garget) and may cause sore throat, digestive disorders, tonsilitis and what closely resembles scarlet fever and diphtheria in man (see p. 20). To discover in milk the pus (or matter, such as comes from an abscess), and the germs which cause the inflammation of the cow's udder, Dr. Slack writes me as follows:

* Journal Medical Research, Nov., Ig04. 
" IV e centrifugalize the milk in small glass tubes (about 2 c.c. each, the ends being closed with rubber stoppers). Our apparatus carries 20 tubes and we centrifugalize for ten minutes at a speed of $2000-3000$ revolutions a minute.

"The sediment obtained on the rubber stopper is smeared evenly with a drop of sterile water over a space 4 sq. cm. By examining this sediment with a I-I 2 oil immersion lens, we determine the presence of pus or streptococci and are also able to make a microscopic estimate of the number of bacteria present."

Since it is impossible to differentiate between dead leucocytes and pus, and since a certain number of leucocytes are normal ( 3 or 4 in a $\mathrm{I}-\mathrm{I} 2$ immersion lens field) in milk, it is necessary to fix an arbitrary standard not to be exceeded by these cells. The standard, observed by the Boston Board of Health, is 50 cells to the field of a I-I 2 oil immersion lens (spreading the sediment from 2 c.c. of milk over a surface of $4 \mathrm{sq} . \mathrm{cm}$.). If this number is exceeded the milk is condemned. After the milk is centrifuged in small glass tubes (see above), the sediment is placed on spaced, glass slides, dried with gentle heat and stained with methylene blue. During the course of the microscopic examination for pus, the number of bacteria can be determined with a very fair degree of accuracy without plating the milk if the milk contains more than 100,000 bacteria in I c.c.

Milk is condemned by the Boston Board of Health for streptococci when 3 tests are positive: I. When the centrifuged sediment shows streptococci, cocci or diplococci. 2. When the plate from the same sample shows colonies resembling streptococci colonies, in excess of 100,000 to I c.c. 3. When such colonies transferred to broth and grown 
for 24 hours at $37^{\circ} \mathrm{C}$. show streptococci alone or in great excess of the other bacteria present.

In an excellent article by Slack* the methods pursued by this Board of Health are described in detail, showing the system perfected by their own experience modified by the study of that pursued in 15 other prominent milk laboratories in the bacteriological examination of milk.

\section{CIRCULARS.}

\section{1st. "Certified Milk."}

Circular of Information Concerning the Requirements of THE Milk Commission of the Medical Society OF THE COUNTY OF NEW YORK FOR "CERTIFIED" MiLK.

The Commission appointed by the Medical Society of the County of New York to aid in improving the milk supply of New York City invites the co-operation of the milk dealers and farmers in attaining that end. The sale of pure milk is of advantage to those furnishing it, as well as to those who use it. The Commission has undertaken to assist both consumer and producer by fixing a standard of cleanliness and quality to which it can certify, and by giving information concerning the measures needful for obtaining that degree of purity.

The most practicable standard for the estimation of cleanliness in the handling and care of milk is its relative freedom from bacteria. The Commission has tentatively fixed upon a maxium of 30,000 germs of all kinds per cubic centimeter of milk, which must not be exceeded in order to obtain the indorsement of the Commission. This standard must be attained solely by measures directed toward scrupulous cleanliness, proper cooling, and prompt delivery. The milk certified by the Conmission must contain not less than four per cent. of butter fat, on the average, and have all other characteristics of pure, wholesome milk.

In order that dealers who incur the expense and take the precautions necessary to furnish a truly clean and wholesome milk may have some suitable means of bringing these facts before the public, the Commission offers them the right to use caps on their milk jars stamped with the words, "Certified by the Commission of the Medical Society"

* Journal of Infectious Diseases, Supplement No. 2, Feb. Igo6, pp. 2I4-222. 
of the County of New York." The dealers are given the right to use these certificates when their milk is obtained under the conditions required by the Commission and conforms to its standards.

The required conditions are as follows:

I. The Bamyard. - The barnyard should be free from manure and well drained, so that it may not harbor stagnant water. The manure which collects each day should not be piled close to the barn, but should be taken several hundred feet away. If these rules are observed not only will the barnyard be free from objectionable smell, which is always an injury to the milk, but the number of flies in summer will be considerably climinished. These flies in themselves are an element of danger, for they are fond of both filth and milk, and are liable to get into the milk after having soiled their bodies and legs in recently visited filth, thus carrying it into the milk. Flies also irritate cows, and by making them nervous reduce the amount of their milk.

2. The Stable. - In the stable the principles of cleanliness must be strictly observed. The room in which the cows are milked should have no storage loft above it; where this is not feasible, the floor of the loft should be tight, to prevent the sifting of dust into the stable beneath. The stables should be well ventilated, lighted, and drained, and should have tight floors, preferably of cement. They should be whitewashed inside at least twice a year, and the air should always be fresh and without bad odor. A sufficient number of lanterns should be provided to enable the necessary work to be properly done during dark hours. There should be an adequate water supply and the necessary wash-basins, soap, and towels. The manure should be removed from the stalls twice daily, except when the cows are outside in the fields the entire time betreen the morning and afternoon milkings. The manure gutter must be kept in a sanitary condition, and all sweeping and cleaning must be finished at least twenty minutes before milking, so that at that time the air may be free from dust.

3. Water Supply. - The whole premises used for dairy purposes, as $\pi$ ell as the barn, 1nust have a supply of water absolutely free from any danger of pollution with animal matter, and sufficiently abundant for all purposes and easy of access.

4. The Cows. - The cows should be examined at least twice a year by a skilled veterinarian. Any animal suspected of being in bad health must be promptly removed from the herd and her milk rejecterl. Never add an animal to the herd until it has been tested with tuberculin and it is certain that it is free from disease. Do not allow the corrs to be excited by hard driving, abuse, loud talking, or any unnecessary 
disturbance. Do not allow any strongly flavored food, like garlic, which will affect the flavor of the milk, to be eaten by the corvs.

Groom the entire body of the cow daily. Before each milking wipe the ndder with a clean damp cloth, and when necessary wash it with soap and clean water and wipe it dry with a clean towel. Never leave the udder wet, and be sure the water and towel used are clean. If the hair in the region of the udder is long and not easily kept clean, it should be clipped. The cows must not be allowed to lie down after being cleaned for milking until the milking is finished. A chain or rope must be stretched under the neck to prevent this.

All milk from cows sixty days before and ten days after calving must be rejected.

5. The Milkers. - The milker should be personally clean. $\mathrm{He}$ shotild neither have nor come in contact with any contagious disease while employed in milking or handling milk. In case of any illness in the person or family of any employee in the dairy, such employee must absent himself from the dairy until a physician certifies that it is safe for him to return.

Before milking, the hands should be thoroughly washed in warm water with soap and a nail brush and well dried with a clean towel. On wo account should the hands be wet during the milking.

The milking should be done regularly at the same hour morning and evening, and in a quiet, thorough manner. Iight-colored washable outer garments should be worn during milking. They should be clean and dry, and when not in use for this purpose should be kept in a clean place protected from clust. Milking stools must be kept clean. Iron stools, painted white, are recommended.

6. Helpers Other Than Milkers.-All persons engaged in the stable and dairy sliould be reliable and intelligent. Children under twelve years should not be allowed in the stable durnng milking, since in their ignorance they may do harm, and from their liability to contagious diseases they are more apt than older persons to transmit them through the milk.

7. Small Animals.-Cats and dogs must be excluded from the stables during the time of milking.

8. The Milk. - The first few streams from eacl teat should be discarded, in order to free the milk ducts from milk that has remained in them for some time and in which bacteria are sure to liave multiplied greatly. If in any milking a part of the milk is bloody or stringy or unnatural in appearance, the whole quantity of milk yielded by that 
animal must be rejected. If any accident occurs by which the milk in a pail becomes dirty, do not try to remove the dirt by straining, but reject all the milk and cleanse the pail. The milk pails used should have an opening not exceeding eight inches in diameter.

Remove the milk of each cow from the stable immediately after it is obtained to a clean room and strain it through a sterilized strainer.

The rapid cooling of milk is a matter of great importance. The milk should be cooled to $45^{\circ}$ within one hour. Aeration of pure milk beyond that obtained in milking is unnecessary.

All dairy utensils, including bottles, must be thoroughly cleansed and sterilized. This can be done by first thoroughly rinsing in warm water, then washing with a brush and soap or other alkaline cleansing material and hot water, and thorouglily rinsing. After this cleansing, they slould be sterilized with boiling water or steam and then kept inverted in a place free from dust.

9. The Dairy. -The room or rooms where the bottles, milk pails, strainers, and other utensils are cleaned and sterilized should be separated somewhat from the house, or when this is impossible have at least a separate entrance, and be used only for dairy purposes, so as to lessen the danger of transmitting through the milk contagious diseases which may occur in the home.

Bottles, after filling, must be closed with sterilized discs, and capped so as to keep all dirt and dust from the inner surface of the neck and the mouth of the bottle.

Io. Examination of the Milk and Dairy Inspection.-In order that the dealers and the Commission may be kept informed of the character of the milk, specimens taken at random from the day's supply must be sent weekly to the Research Laboratory of the Health Department, where examinations will be made by experts for the Commission; the Health Department having given the use of its laboratories for this purpose.

The Commission reserves to itself the right to make inspections of certified farms at any time and to take specimens of milk for examination. It also reserves the right to cliange its standards in any reasonable manner upon due notice being given to the dealers.

After January I, 1902, the expenses incurred in making the regular milk examinations and inspections will be borne by the dealers. In fixing the charges each farm or group of farms will be considered a unit. The Secretary of the County Medical Society will send the bills to the dealers about the middle of each month. Prompt payment is requested. 
The monthly charges, which are intended to cover all expenses, will be as follows :

For each group of farms sending daily less than roo quarts $\$ 8.00$

$\begin{array}{lllll}\text { " " } & 100 \text { to } 200 & \text { " } & 10.00 \\ \text { " } & \text { " } & \text { over } 500 & \text { " } 500 & 12.00 \\ & \text { i } 5.00\end{array}$

\section{2d.- "Inspected Milk."}

Circular of Information Concerning the Requirements of THE MiLK CoMmission OF THE Medical, Society OF THE COUNTY OF NEW YORK FOR "INSPECTED" Milk.

The Commission appointed by the Medical Society of the County of New York to aid in improving the milk supply of New York City has formulated the following requirements, affecting the farms inspected by it and the handling of the milk obtained at these farms. The Commission offers those dealers complying with these requirements the right to use caps on their milk bottles, stamped: "Inspected. Milk Commission Medical Society, County of New York."

The requirements are as follows :

I. The Barnyard.

(a) It must contain no nanure in summer and none in contact with the stable in winter.

(b) It nutst be well drained and kept reasonably clean.

2. The Stables.

(a) The ventilation and light must be sufficient for the number of cows stabled, so that the barn shall be light and the air never close.

(b) The floor shall be wood or cement.

(c) The ceiling shall be tight, if a loft above is used.

(d) Basins, hand brushes, clean water, soap and clean towels shall be provided in the barn or adjacent dairy room.

(e) The stable shall be whitewashed in the fall, and in the spring if necessary.

(f) A sufficient number of lanterns shall be provided to allow the milking to be carried on properly.

(g) Clean the ceiling and sidings once a month.

(h) The bedding shall be shavings, sawdust, dried leaves, cut straw, or other material that meets the approval of the Commission.

(i) The soiled bedding must be removed daily. 
(j) The manure must be remored daily from the stalls and open manure-gutter. If a covered manure-gutter is used, it must be kept in a sanitary condition.

(k) The application of land-plaster or lime on the floor daily is recommended.

(1) Sweep the entire floor ontside the stalls daily at least an hour before milking is begun.

3. Water Supply.

Pure water must be used for all purposes. It must be accessible and abundant.

4. The Cows.

(a) Discard milk containing mucus or blood and that from any diseased cow.

(b) Reject milk from any animal forty-five days before and six days after calving.

(c) The food given must be suitable both in amount and kind and must not give a disagreeable flavor to the milk.

(d) Keep the cows clean on flanks, belly, udder and tail.

(e) Clip long hairs about udders and clip the tail sufficiently to clear the ground.

(f) The cows must be kept from lying down between the cleaning and milking. The best means of accomplishing this is by throat latches.

(g) Clean the udder thoroughly before milking.

5. The Milkers.

(a) No milker or assistant shall have any connection with the milk at any stage of its production if he has any communicable disease, or if he has been exposed to scarlet fever, diphtheria, typhoid fever, or small-pox.

(b) After having everything prepared for milking, thoroughly wash the hands with soap, water, and brush, so that they may be clean when milking is begun.

(c) The hands and teats must be kept dry during milking. If they become moistened with milk, they must be wiped dry with a clean towel.

(d) Suitable clean outer garments, such as overalls and jumpers, must be put on before milking.

6. Utensils.

(a) Strainers, whether metal, gauze, or cotton, must be absolutely clean when used for straining milk.

(b) All dairy utensils must be absolutely clean and free from dust. 
THE MII,K.

I. The milk must not be adulterated in any way.

2. It must average 3.6 per cent. of butterfat.

3. Cooling must begin at once. The temperature of the milk must be reduced to $50^{\circ} \mathrm{F}$. within two hours and kept below that temperature until delivered to the consumer.

4. When delivered to the consumer the milk must not average over I 00, ooo bacteria per cubic centimeter from May ist to September 3 oth, and not over 60,000 bacteria per cubic centimeter from October ist to April 3oth. If the Commission's requirements are fulfilled, the bacteria will not be in excess of the number permitted.

\section{INSPECTIONS.}

1. The farms which furnish inspected milk must always be open to inspection by the Commission.

2. Samples of milk must be regularly submitted for bacteriological examination once a month.

\section{Feser's Lactoscope.}

This consists of a large, hollow, graduated glass cylinder, into the centre of the base of which is inserted a smaller white glass cylinder marked with horizontal black lines. The test with the lactoscope depends upon the amount of dilution of milk required in order that the lines on the inner cylinder be seen when diluted milk is placed in the outer cylinder. The richer in fat, the more opaque is the specimen and the greater the dilution required.

Thus 4 c.c. of milk are dropped from a pipette through the aperture in the top of the larger cylinder, and water is added in small amounts and thoroughly mixed with the milk by inverting the lactoscope with the finger over the top. When the milk is diluted sufficiently for the black lines on the inner white cylinder to be read, then the percentage of fat corresponds with the figures at the level 
of the mixture on the larger graduated cylinder (in an upright position).

As has been stated, the lactometer is unreliable when used alone, but, when employed in conjunction with the lactoscope, quite accurate results may be obtained. While milk which has been skimmed and watered may show a normal specific gravity by the lactometer reading, so milk which is exceptionally rich in fat may be only watered so as to still be within the legal requirements as shown by the lactoscope. By the use of both instruments, either skimming or watering, or both skimming and watering, may be detected--unless the milk is still of average richness.

Harrington (Practical Hygiene, p. 3) says : "A normal specific gravity with a low percentage of fat will indicate skimming and watering; low specific gravity with normal or low fat, watering; and high specific gravity and low fat, skimming. Low specific gravity with a high fat will indicate unusual richness; thus cream has a very low specific gravity, due to its preponderance of fat. As a test of the accuracy of this process of examination, the author caused to be analyzed under his supervision I,7 I 4 specimens, which appeared by those tests to be of good quality, and of this number but eight were found to have deviated materially from the statute requirement of $\mathrm{I} 3$ per cent. of total solids."

In case inspection by lactoscope and lactometer showed a specimen of milk below the legal requirements, this result should be corroborated by the exact methods of the laboratory before it would be wise to institute legal proceedings. 


\section{APPENDIX.}

\section{Dairy Cows}

$\mathrm{T}^{\mathrm{H}}$

$\mathrm{HE}$ writer has not said anything about the best kind of cow for producing clean milk, because it is as impossible to affirm positively which is the best breed of dairy cows as it would be to state which is the best race of human beings. Each breed has its own valuable characteristics which are in accord or otherwise with the views of different cattle owners, depending on the experience, temperament or characteristics of the owner.

The dairy breeds of chief importance are four: The Jerseys, Guernseys, Holsteins and Ayrshires. The Brown Swiss and Short Horn are called dual purpose cows; that is, useful for milk and beef. For dairy purposes alone they are inferior to the first four breeds mentioned, however.

The milk of the Jerseys and Guernseys is rich in fat, but moderate in amount (the Guernsey milk of especially deep yellow color); the Holsteins are large milkers, but the percentage of fat in their milk is low; while the Ayrshires occupy an intermediate position-in respect to quantity and richness of their milk-as compared with the Jerseys and Holsteins. The milk of Jerseys and Guernseys is not quite so digestible for infants on account of its large fat globules. The milk is said to vary more in composition, in case of the pure bred Jerseys (on account of their excitable temperaments), and these animals are possibly more prone to tuberculosis. Clean Jersey or Guernsey milk is, however, infinitely preferable to the ordinary dirty market milk of any other breed of cows, and the writer has found that clean milk from grade Jersey cows (containing 5 per cent. fat) will agree perfectly with infants, providing that it is diluted properly in accordance with its fat content, see p. I3I. The average consumer 
of milk places much more importance on the richness of milk than any other quality. He can easily see and appreciate this quality, and the cleanliness of the milk he can not judge of-except to notice that it keeps well. Moreover, the average consumer buys the milk largely for the cream, which is commonly used for the breakfast cereal and coffee. For this reason a rich milk should bring the largest price, providing that it is clean.

A Holstein or Ayrshire milk-or a clean milk obtained from cows of various breeds-may be sold for infants, and a 5 per cent. Jersey or Guernsey milk may be sold for general consumption at a little higher figure.

If the whole milk is drunk by adults its richness is considered its most valuable quality. In Boston a milk containing 6 per cent. of fat-which may be obtained from some Jerseys and Guernseys-is sold for 16 cents a quart, and is especially intended for invalids. It is not unusual to separate the milk from different breeds on the farm and charge different prices for their milk. Milk intended for babies may appropriately contain about 4 per cent. of fat, and must be of special cleanliness and freshness. Rapid delivery of it is therefore necessary, which may require a special express rate on train and special wagon in the city. The bottles should be thoroughly protected from dust by an outer cap of parchment, or tinfoil, over the ordinary paper cap. A milk for infants should constantly contain nearly the same quantity of fat, so as to give rise to a cream of uniform composition. This is essential for the physician to calculate the fat in the different layers of cream (see p. I31), and such milk may be supplied if it is obtained from one breed of corvs. For all these reasons the price of milk for infant feeding must be considerable-generally 15 cents a quart retail. A five per cent. milk from Jerseys or Guernseys (not quite up to the certified standard for babies) may be sold for general household use for from ro to 12 cents a quart.

To give the reader an idea of representative cows of the dairy breeds we have included an account of a Guernsey, which heads the list of officially tested cows (taken from Hoard's Dairyman), and also tables showing the records of a trial-at the St. Lotis Fair of 1905of Brown Swiss, Holsteins, Jerseys and Short Horns. The accom- 
Pr.ATI I (Fìg. 45.-Yeksa Sunbeam (Guernsey), No, 15,439, Adv. Reg. 33 T.

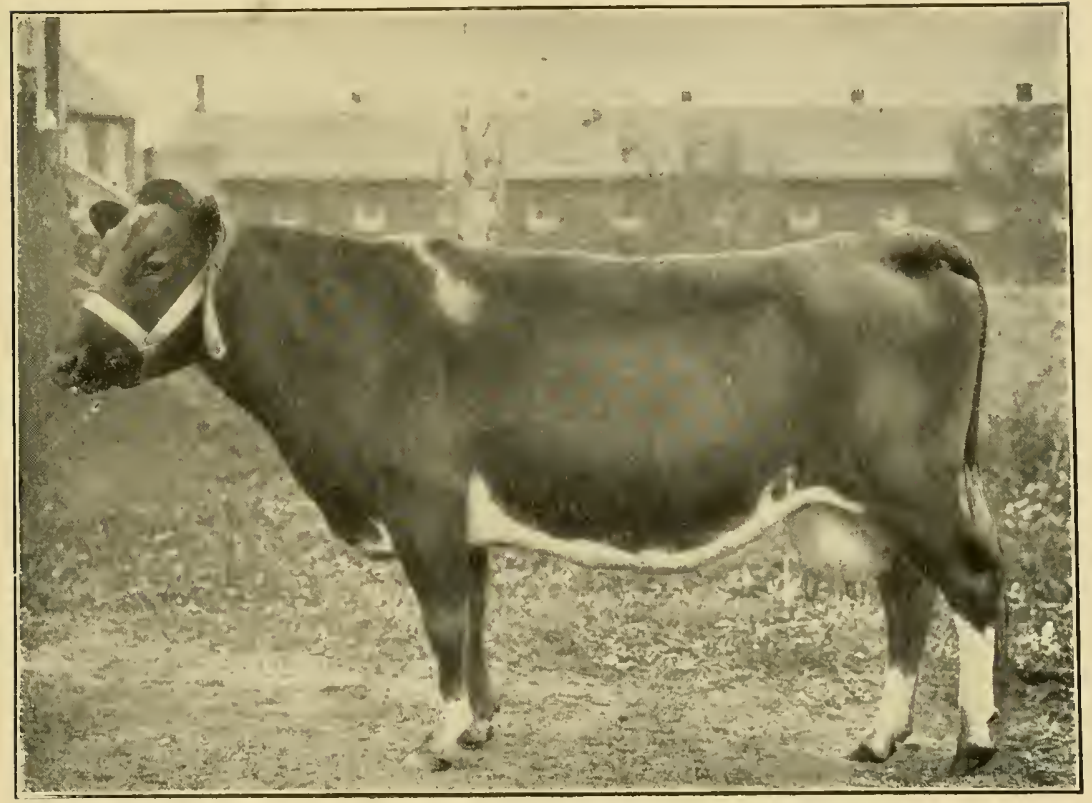

IIelendale Stock Yarm, Atliens, Wis. (Fred. Riethock, Milwaukee, Wis )

PLATE II (Fï. 46), -Shadybrook Gerben (IIolstein).

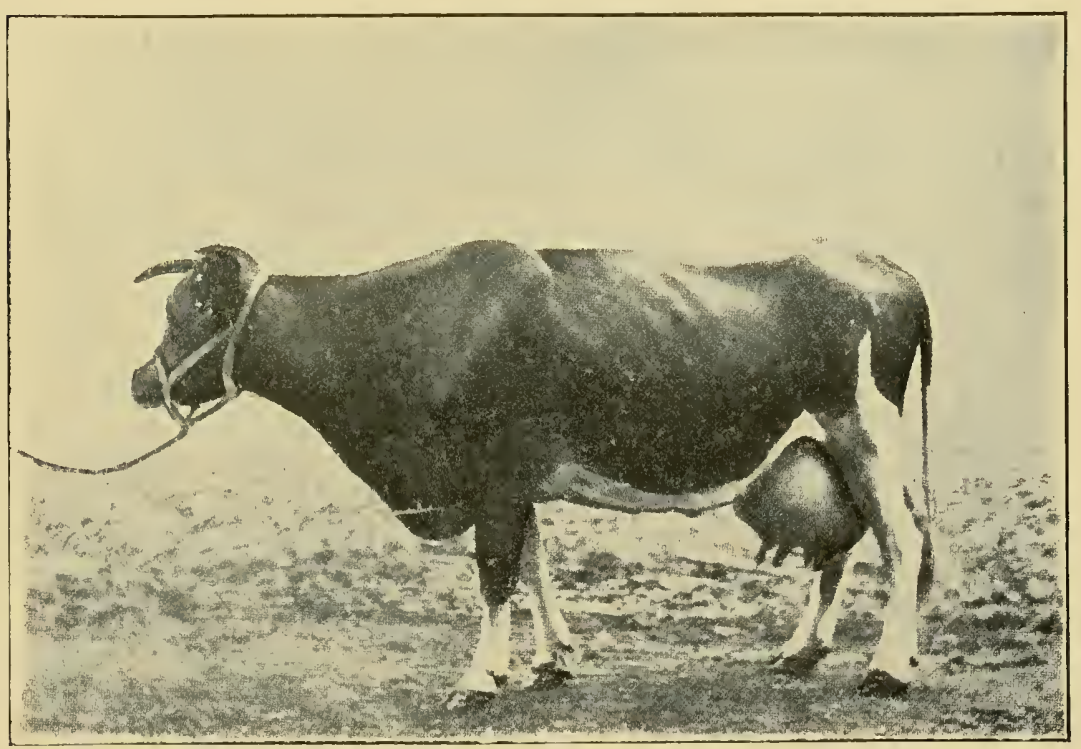

In I 20 days produced SIOI.7 1bs. mills; test 35 per cent. fat ; butter fat 282.6 ; butter, $330.361 \mathrm{bs}$; weirlit, I3Ig lbs. 

panying illustrations are of the best Jersey (Loretta D.) and the best Holstein (Shadybrook Gerben), at the Exposition, and of Yeksa Su11beam (Guernsey), and Pansy of Woodroffe (Ayrshire).

A Wisconsin Guernsey.-Mr. Rietbrock's Yeksa Sumbeam (Plate I, Fig. 45) heads the list of officially tested cows. Her record for twelve consecutive months is $14,920.8 \mathrm{lbs}$. milk, and 857 . I $5 \mathrm{lbs}$. fat, aud is as follows :

\begin{tabular}{|c|c|c|c|c|}
\hline $\begin{array}{c}\text { Month. } \\
\text { October ............ }\end{array}$ & $\begin{array}{l}\text { Milk. } \\
\text { I } 428.2\end{array}$ & $\begin{array}{l}\text { Per cent. } \\
\text { fat. } \\
5.69\end{array}$ & $\begin{array}{l}\text { Lbs. fat. } \\
8 \text { r.26 }\end{array}$ & $\begin{array}{c}\text { Total fat. } \\
-\end{array}$ \\
\hline November.......... & 1322.5 & 5.62 & $74 \cdot 32$ & $155 \cdot 58$ \\
\hline December.......... & I 294.4 & 6.08 & $7^{8 \cdot 70}$ & 234.28 \\
\hline January '05 ........ & 1217.0 & 6.04 & $73 \cdot 51$ & $307 \cdot 79$ \\
\hline February ............ & 106о. 8 & $5 \cdot 75$ & $6 \mathrm{r} .00$ & 368.79 \\
\hline March............. & II 55.1 & 6.05 & 71.70 & 440.49 \\
\hline April.............. & ro89.6 & $5 \cdot 79$ & 63.09 & $503 \cdot 58$ \\
\hline May................. & II 27.5 & $5 \cdot 75$ & 64.83 & $568.4 \mathrm{r}$ \\
\hline June............... & 1158.4 & 5.25 & 60.82 & 629.23 \\
\hline July .............. & โ266.o & 5.88 & $74 \cdot 44$ & 703.67 \\
\hline August...$\ldots \ldots \ldots$ & 1463.8 & $5 \cdot 42$ & $79 \cdot 34$ & $783.0 \mathrm{r}$ \\
\hline September.......... & I $307 \cdot 5$ & 5.67 & $74 \cdot 14$ & $857 \cdot 15$ \\
\hline
\end{tabular}

Yeksa Sunbeam, having given $14920.8 \mathrm{lbs}$. of milk, containing 857. I 5 lbs. fat, it follows that the average per cent. of fat in her milk was 5.744. Applying the Farrington scale to this quality of milk, we find that $100 \mathrm{lbs}$. of fat should yield $1 \mathrm{I} 8 \mathrm{I} / 41 \mathrm{bs}$. of butter, and consequently the 857.15 lbs. of fat would make Ior $3.561 \mathrm{bs}$. of butter.

Yeksa Sunbeam was $91 / 2$ years old at the commencement of the test. She was bred and reared by the late W. D. Richardson, at Garden City, Minn., and sold when a heifer to a milkman near Minneapolis, from whom she was purchased by Mr. Rietbrock. Her sire was Yeksa's Prince, a son of the cow, Yeksa, formerly owned by $\mathrm{Mr}$. I. J. Clapp, Kenosha, Wis., and her dam was The Sunbeam, also formerly owned in Wisconsin by Prof. Haecker, before he went to Minnesota. There is, therefore, some poetic justice in her return to Wisconsin to make her phenomenal record.

In respect of feeding, I would say that during grazing season, the pastures of clover and blue grass were very good. We supplemented 
this, during the fore part of last summer, with some clover hay fed in the barn, since the grass was very washy in the early part of the season on account of so much rain. During July and August we added to the pasturage a soiling ration of peas and oats, the peas being in a green state, the kernel formed in the pod, but not yet ripened, and fed it up to the time when the pea was quite hard, but will say that it was mostly during the period that we would call peas good to eat on the table as green peas.

In August and September, we also fed some green corn stalks. I cannot call it green corn, because there were no ears formed on it. It was from a planting made about the 2oth of June and close together.

During the late fall and winter of 1904, we also fed Yeksa Sunbeam, and some other cows, from 5 to 10 pounds of rutabagas. The roughage during the winter season was mostly clover hay. We fed also some alfalfa. I had 16 tons, and this was consumed by the calves, Io to 2 in number, the i 6 cows in the test and about the same number of other cows not being tested (the test cows got a larger allowance of alfalfa than the others).

During the winter, we also fed Yeksa Sumbean from 25 to 30 pounds of silage. This silage had very little grain in it, since our corn did not mature very well last year, but it was succulent, good feed.

Now, as regards grain ration, we made a grain mixture composed of four parts wheat bran, two parts ground oats, two parts Buffalo gluten feed, one part Old Process oil meal. During part of the year we fed this oil meal in pea size-little kernels big as a pea. During the months of January, February and March, we added to this grain mixture one part of corn meal.

Of the above grain mixture, we fed Yeksa Sunbeam, during the months of October, November and December, I 5 pounds a day. We reduced this by about I lb., feeding I4 lbs. a day, during January, February, March and April. For the month of May, we reduced her feed to I 2 lbs. of the mixture and, as we got her on to the grass, and the grass improved in June, I think we reduced it still more. I find that a report has been made that she was fed only 6 lbs. of grain a day during June. I think 9 or Io lbs. would be more nearly coriect. 
PIATE III (1*ig. 47). -Pansy of Woodroffe (Ayrshire), Yo. IS,9r5.

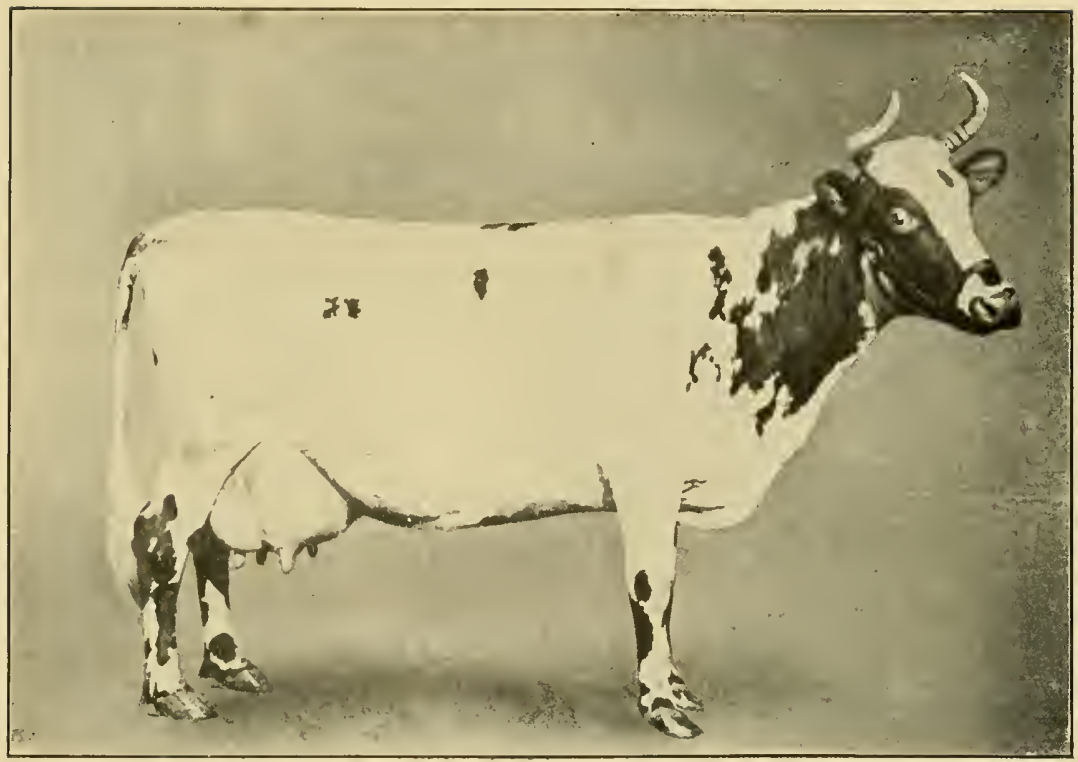

Champion at National Dairy Show, Chicago. (Property of Geo. Wun. Ballou, Iriddleton, N. Y.)

PLATE IV (Fig. 4S).-Loretta D. (Jersey).

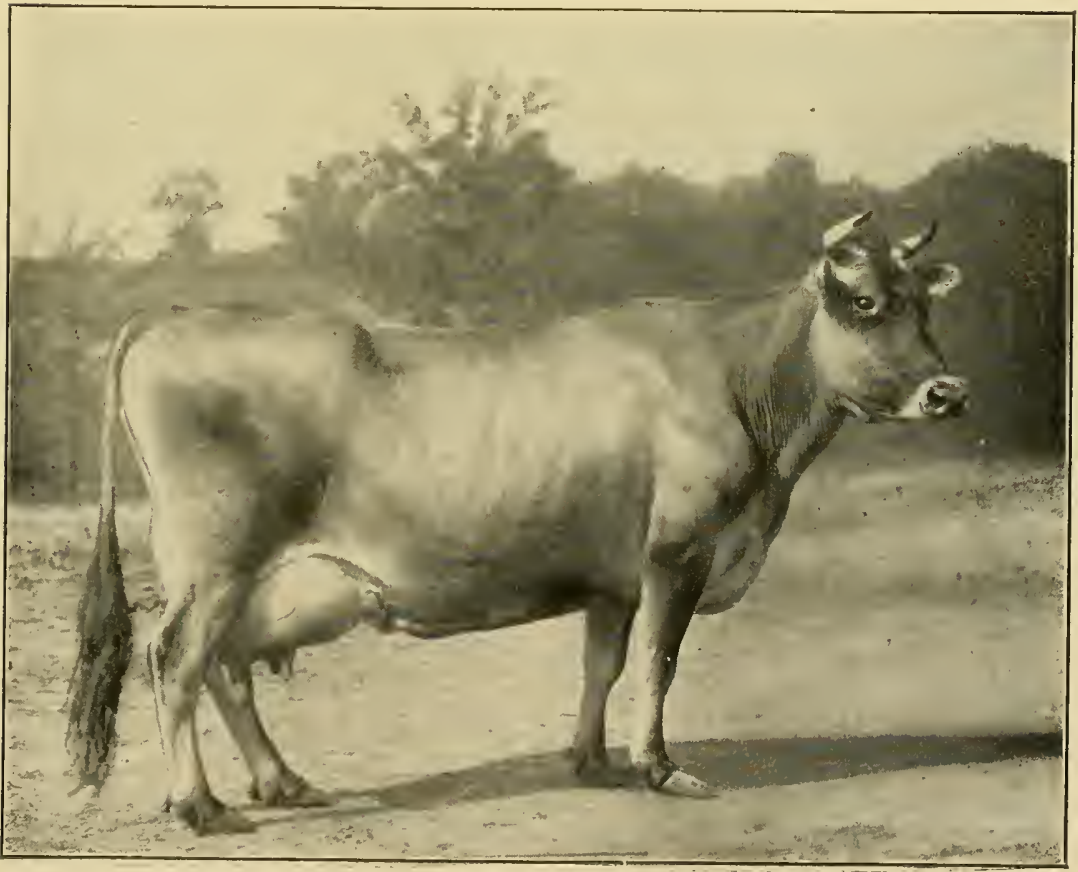



During July, August and September of this year, she was fed daily a grain ration of the above mixture of 9 to ro lbs. All these grain rations were fed in three meals, morning, noon and night.

RECORD OF THE BEST, POOREST AND AVERAGE COW IN EACH HERD FOR THE I20 DAYS AT ST. LOUIS FAIR, I905.*

Milk per day, lbs, -

Brown Swiss. Holstein. Jersey.

Shorthorn.

$\begin{array}{rrrrr}\text { Best cow ...... No. I-5I.0 } & \text { No. } 20-67.5 & \text { No. } 37-48.4 & \text { No. 63-43.4 } \\ \text { Poorest cow.... No. } 3-38.5 & \text { No. } 7-47.1 & \text { No. } 36-38.8 . & \text { No. 62-2I.4 } \\ \text { Average cow ... } & 44.2 & 53.4 & 41.5 & 34.6\end{array}$

Test of Milk-

Best cow .......

$3 \cdot 4$

$3 \cdot 5$

4.8

$4 \cdot 0$

Poorest cow....

3.8

3.2

4. I

$3 \cdot 9$

Average cow...

3.62

$3 \cdot 43$

$4 \cdot 7$

3.8

Butter fat per day, lbs.-

$\begin{array}{lllll}\text { Best cow....... } & \text { I.748 } & 2.355 & 2.334 & 1.737 \\ \text { Poorest cow.... } & \mathrm{I} .477 & \mathrm{I} .507 & \mathrm{I} .615 & 0.843 \\ \text { Average cow... } & \mathrm{I} .596 & \mathrm{I} .832 & \mathrm{I} .936 & \mathrm{I} .277\end{array}$

Butter per day, lbs.-

$\begin{array}{lllll}\text { Best cow....... } & 2.042 & 2.753 & 2.750 & 2.037 \\ \text { Poorest cow.... } & \text { I.73I } & 1.756 & 1.898 & 0.985 \\ \text { Average cow... } & \text { r.S70 } & 2.12 & 2.28 & 1.495\end{array}$

Solids-not-fat per day, lbs.-

$\begin{array}{lllll}\text { Best cow....... } & 4.363 & 5.17 \mathrm{I} & 4.357 & 3.720 \\ \text { Poorest cow.... } & 3.585 & 3.614 & 3.441 & 1.902 \\ \text { Average cow... } & 3.919 & 4.239 & 3.634 & 2.980\end{array}$

Feed cost of milk, per qt.

$\begin{array}{lllll}\text { Best cow...... } & .0109 & .0090 & .0110 & .0109 \\ \text { Poorest cow.... } & .0139 & .0122 & .0130 & .0215 \\ \text { Average cow... } & .0124 & .0107 & .0116 & .0132\end{array}$

Feed cost of butter, per lb.-

\begin{tabular}{|c|c|c|c|c|}
\hline Best cow...... & .136 & . IIO & .097 & . II 7 \\
\hline Poorest cow.... & . I 55 & .164 & .132 & .234 \\
\hline $\begin{array}{l}\text { Average cow... } \\
\text { No. of cows in }\end{array}$ & .147 & .135 & .105 & .153 \\
\hline herd ....... & 5 & I5 & 25 & $2 S$ \\
\hline
\end{tabular}

* Illustrations and tables of records and rations from Daity Cow Demonstration, at Louisiana Purchase Exposition, 1905. Edited by Prof. E. H. Furington.

+ Assuming two pounds to the quart. 
ONE DAY'S RATION OF ONE COW IN EACH HERD AT ST. LOUIS FAIR, IgO5.

$\begin{array}{ll} & \text { Brown } \\ \text { Feed in Pounds. } & \text { Swiss. Holstein. Jersey. Shorthorn. }\end{array}$

\begin{tabular}{|c|c|c|c|c|}
\hline 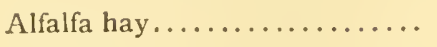 & 7 & - & I8 & 9 \\
\hline Cut alfalfa hay .............. & - & I5 & 6 & - \\
\hline Corn silage $\ldots \ldots \ldots \ldots \ldots \ldots$ & 一 & - & 16 & 24 \\
\hline Green cut corn............. & 40 & 15 & - & - \\
\hline Green cow peas............. & - & 35 & 一 & - \\
\hline Wheat bran............... & - & 2 & 3 & 4 \\
\hline Linseed (oil meal) ........... & 一 & 一 & 2 & 2 \\
\hline 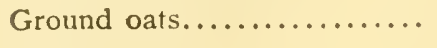 & - & - & $2 \cdot 5$ & 2 \\
\hline Hominy feed............... & 8 & 5 & $2 \cdot 5$ & 3 \\
\hline Gluten feed............... & - & - & $5 \cdot 0$ & 2 \\
\hline Corn meal................ & - & 一 & I. 5 & 一 \\
\hline Corn hearts............... & 一 & - & $2 \cdot 5$ & 2 \\
\hline Cottonseed meal............. & I & $\mathbf{I}$ & 一 & 2 \\
\hline Distiller's grains............. & - & 一 & - & 4 \\
\hline Union grains............... & $\underline{\text { I5 }}$ & I4 & - & - \\
\hline Total............... & $7 \mathrm{I}$ & $S_{7}$ & 59 & 54 \\
\hline Including grain ............. & 24 & 22 & I9 & $2 \mathrm{I}$ \\
\hline
\end{tabular}

Such records as these are probably a revelation to many a man who has fed and nilked cows for years. It is not customary to give more than five to ten pounds of grain per day to cows on the hoine farms, and the majority of them probably get less than five pounds. A capacity for assinilating large rations is necessary for producing large quantities of milk and butter, and most of these World's Fair cows were fed to their limit of endurance. A daily feeding per cow of near twenty pounds of grain, together with thirty to sixty pounds of green feed, was not uncommon, although there were some variations in the total amount during the r 20 days of the test.

\section{Dehorning Calves}

It is now generally recognized that all milch cows should be dehorned, to prevent injury to themselves (in tearing off a horn, etc.), to other animals, to stables and to persons. As the operation of removing the horus from grown animals is unpleasant; and detrimental for the time to the patient, the following simple method, 
recommended by the English Board of Agriculture and found successful in practice, should be followed in the treatment of calves:

"Clip the hair from the top of the horn, when the calf is from two to five days old; slightly moisten the end of a stick of caustic potash and rub the tip of each horn firmly for about one-quarter of a minute, or until a slight inpression has been made on the centre of the horn. Repeat this two to four times at intervals of five minutes. If a little blood appears in the centre of the horn, after one or more appiications, only one more slight rubbing with the potash will be necessary.

"The operation should not be performed on a calf over nine days old. Caustic potash can be obtained from any druggist in the form of a white stick (about as large as a pencil), and when not in use should be kept in a glass stoppered bottle in a dry place. One man should hold the calf while another uses the caustic. Roll a piece of tinfoil or paper about the end of the stick of caustic to protect the fingers of the operator from contact with it. Do not moisten the stick too much or the caustic will spread around the horn and destroy the flesh. For the same reason prevent the calf from wetting its head for several days after the operation. Be careful to rub the caustic on the centre of the horn and not around it. Caustic potash is a poison and must be kept in a safe place."

\section{Management of Hand Separators}

There is. no ligher authority on dairy matters than Prof. E. H. Farrington, of the University of Wisconsin Experiment Station, to whom we have had the pleasure of referring on several occasions in the previous pages. I can not do better than to quote the rules laid down by him for the management of hand separators.

I. Place the separator on a firm foundation in a clean, well-ventilated room where it is free from all offensive odors.

2. Thoroughly clean the separator after each skimming; the bowl should be taken apart and washed, together with all the tinware, every time the separator is used; if allowed to stand for even one hour without cleaning there is danger of contaminating the next lot of cream from the sour bowl. This applies to all kinds of cream separators.

3. Wash the separator bowl and all tinware with cold water and then with warm water, using a brush to polish the surface and clean out the seams and 
cracks ; finally scald with boiling water, leaving the parts of the bowl and tinware to dry in some place where they will be protected from dust. Do not wipe the bowl and tinware with a cloth or drying towel; heat them so hot with steam or boiling water that wiping is unnecessary.

4. Rinse the milk receiving can and separator bowl with a quart or two of hot water just before running milk into the separator.

5. Cool the cream as it comes from the separator, or immediately after, to a temperature near $50^{\circ} \mathrm{F}$. and keep it cold until delivered.

6. Never mix warm and cold cream or sweet and slightly tainted cream.

7. Provide a covered and clean water tank for holding the cream cans and change the water frequently in the tank so that the temperature does not rise above $60^{\circ} \mathrm{F}$. A satisfactory arrangement may be made by allowing running water to flow through the cream tank to the stock watering tank.

8. Skim the milk immediately after each milking, as it is more work to save the milk and separate once a day, and less satisfactory, than skimming while the milk is warm, since the milk must be heated again when saved until another milking.

9. A rich cream, testing 35 per cent. fat or more, is the most satisfactory to both farmer and factory. The best separators will skim a rich cream as efficiently as a thin cream and more skim milk is left on the farm when a rich cream is sold.

ro. Cream should be perfectly sweet, containing no lumps or clots when sampled and delivered to the haulers or parties buying it.

There is a good demand for sweet cream and a perfectly clean, sweet and satisfactory cream can easily be supplied either to a retailer, an ice cream.maker, or a creamery by keeping clean the separator, tinware, strainer-cloth and water tank, and the cream cold.

\section{To Keep Records of Individual Cows.}

Printed forms for making records* should be used. These consist of single sheets of stiff paper which are ruled so as to permit of keeping a record of the night's and morning's milk in pounds and ounces for one month, and also supply space to note the average per cent. of butter fat, if taken once or twice a month. One sheet may be used for Io or 20 to 30 cows according to the size ordered.

Each cow must be named or numbered to use these sheets. The metal tags for insertion in the cow's ear are most suitable for numbering. As soon as each cow is milked the milk is poured in a special weighing pail and the weight is then recorded on the milk sheet. A spring scale sold for the purpose is most convenient. This is arranged so as to allow for the weight of the weighing pail in order that it will not have to be subtracted from the total weight of pail and milk at each weighing.

* Printed forms for keeping cow records are sold very cheaply by Hoard's Dairyman, Fort Atkinson, Wis. 
The milk is poured back from the weighing pail into the mils pail, to mix it thoroughly, and a tablespoonful of the mixed milk is poured into a half pint bottle containing one corrosive sublimate tablet for preserving milk (to be had of any dairy supply company). The bottle should be corked and a similar sample of night's and morning s milk should be added to the bottie for three days to one week, the bottle being sliaken each time new samples of milk are poured into it. The bottle is to be labelled with the cow's name supplying the milk. The milk in the bottle then represents that from a number of milkings from the same cow and is called a composite sample. The composite sample is tested for fat by the Babcock machine (see p. 144). The night and morning milk of each cow ought to be weighed and recorded at least once a week during the year and a fat test made from a composite sample twice a month, in order to determine thoroughly the value of a cow.

\section{Value of Cows}

I may be permitted to submit the following quotation in regard to the value of a cow :

"The basis of valuation as set forth by Prof. S. F. Cooley, of Vt., is that a cow is worth, above what her carcass will fetch, the sum on which her annual profit will pay six per cent. interest, two per cent. taxes and insurance, twenty-five per cent. depreciation, or thirty-three per cent. total.

"Twenty-five per cent. depreciation means a sinking fund which will pay for the animal in four years, and presupposes the average period of usefulness to be four years. O11 this basis, we get the following results in regard to the values of cows of different grades:

\begin{tabular}{|c|c|c|c|c|c|}
\hline Kind of Cow. & $\begin{array}{l}\text { Annual pro- } \\
\text { duct lbs. } \\
\text { milk. }\end{array}$ & $\begin{array}{c}\text { Value of } \\
\text { milk at } \$ 1.50 \\
\text { per cwt. }\end{array}$ & $\begin{array}{c}\text { Cost of } \\
\text { feed. }\end{array}$ & Profit. & $\begin{array}{l}\text { Value of } \\
\text { cow. }\end{array}$ \\
\hline Average.......... & 3,000 & $\$ 45$ & $\$ 45$ & $\$ 00$ & $\$ 00$ \\
\hline Fair ............... & 5,000 & 75 & 50 & 25 & 75 \\
\hline Good............. & 7,000 & I05 & 60 & 44 & 135 \\
\hline Choice ........... & 10,000 & 150 & 75 & 75 & 225 \\
\hline Pietertje II......... & - 30,000 & $45^{\circ}$ & 100 & 350 & $1,05^{\circ}$ \\
\hline
\end{tabular}

"As a business proposition, the difference in value here represented appears correct. But the market does not so rate them. A 
poor cow costs $\$ 30$ and brings $\$ 25$ in four years, during which time she sunk $\$ 5$ more than she had brought. An average cow is worth what her carcass will fetch, and no more. A fair cow costs $\$ 35$ to $\$ 40$ and leaves her buyer $\$ 50$ to the good, in four years. A good cow costs $\$ 50$, and you double on investment the first year. A choice cow costs $\$ 75$, and that is the amount of her annual profit. Pietertje II is worth $\$ 1,000 . "$

\section{Plans of Barns and Milk Rooms}

In the following pages will be found illustrated and described the stables and milk rooms of two farms supplying clean milk to Seattle, Washington.

The first farm is owned by J. D. Farrell, Esq., and is not conducted solely for profit or the support of its owner and may be regarded as one type of plant. The other is owned by W. H. Paulhamus, Ess., of Sumner, Wash. Mr. Paulhanus was the first to attempt to supply Seattle with clean milk and is shipping some thousand quarts a day from his own and three neighboring farms. His arrangements for handling the milk are therefore adapted to caring for a considerable quantity.

Mr. Farrell's stable for 40 cows has a floor, manure trench and feeding gutter of concrete with cement finish. The cows face toward a central feeding aisle. Behind the manure trench there is a walk five feet wide to the side of the building. The manure trench is eighteen inches wide. The length of the stalls is--from the front edge of the manure trench to that of the feeding gutter-six and one-half feet. The width of the stalls is thirty-nine inches for some, and forty-three inches for others, to accommodate Jerseys and Holsteins. The feeding aisle in front of the cattle is nine feet wide. The feeding gutter is also used for watering each time before feeding, when the water is let out. The height of the stable, on the sides, is seven feet four inches, and the ceiling is arched up toward the centre.

The walls and ceiling are double, with air-space between, and the ventilation is after the King system. The cement is brought up four feet on the walls, and the rest of the walls and the ceiling are of matched and planed boards, tightly fitted, and the whole painted white. The gutters for manure slope from six to ten inches deep at 


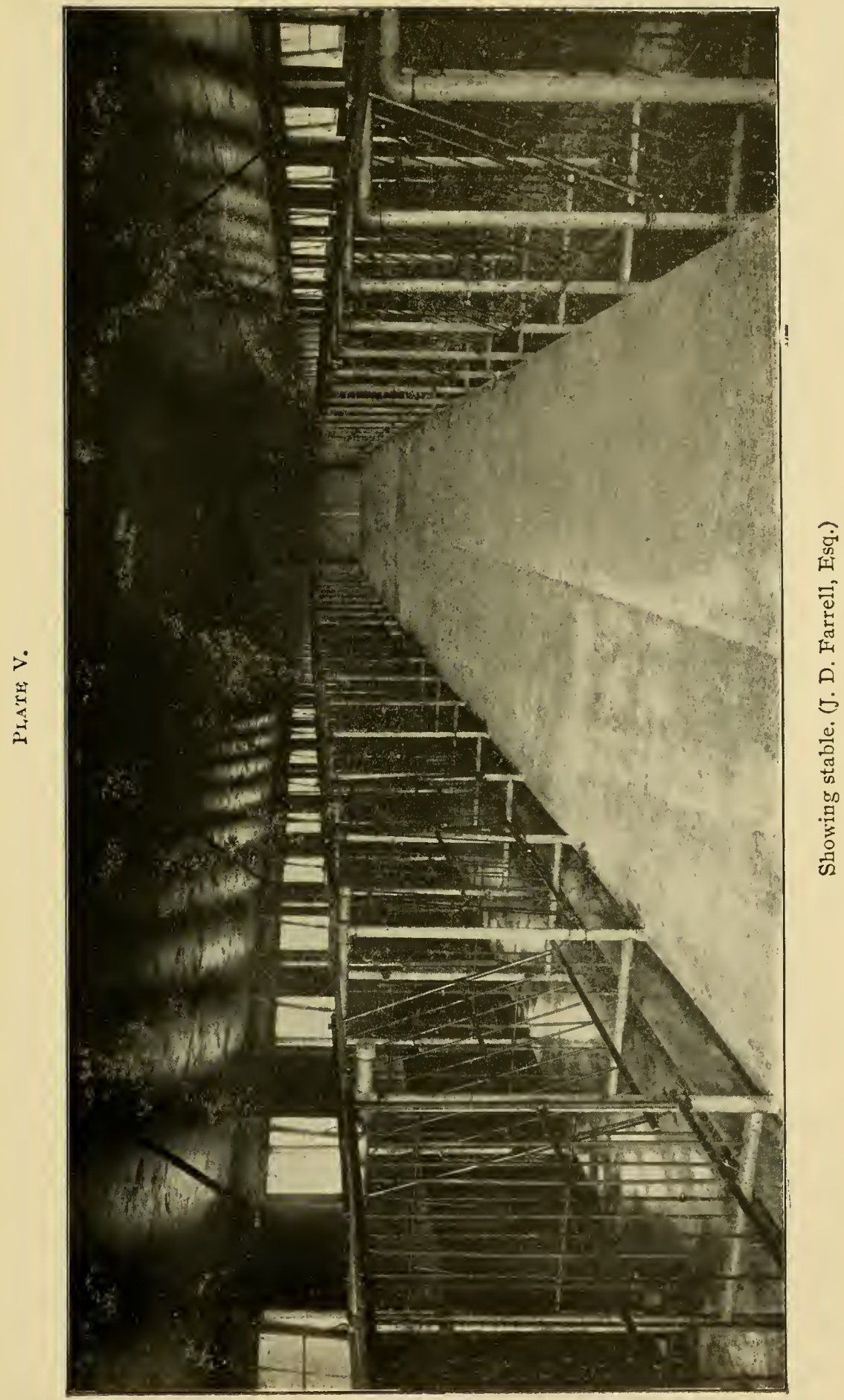



the lower end, and drain into pipes carried a considerable distance to $\mathbf{a}$ lower level than the stable.

Stalls. - The rear portion of each side of each stall is a gate. This gate is hinged and fastened as shown in plate. The dimensions of the gate are twenty-eight inches from top to bottom, and forty-four inches wide, and the lower edge is sixteen inches from the floor. The stationary front part of the side of each stall is thirty-four inches wide and fifty inches high, from top to floor. Its lower edge is ten inches from the floor, in the rear part, and two inches above the gutter for feeding in front. The feeding and watering gutter, of cement, is

Fig. 45.

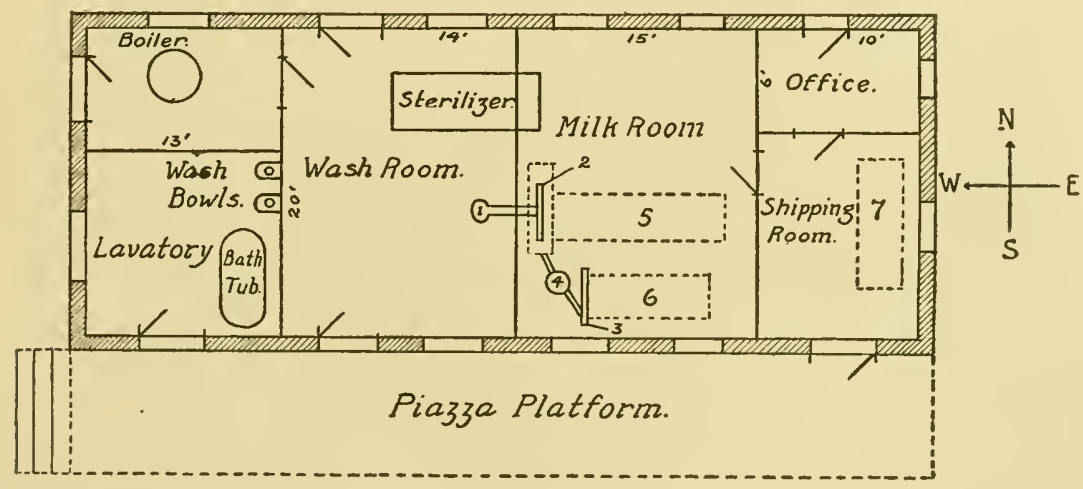

Sketch Showing Ground Plan of Milk House Owned by J. D. Farrell, Esq., Renton, Washington.

eight inches deep and one foot wide. The gates forming the front of each stall are forty-two inches in their perpendicular measurement. They are adjustable and affixed to the top and sides of the stall by small chains with hooks on the end.

For the larger cows, the upper part of the gate may be tipped forward and fastened to an extension of the top rod forming the side of the stall (see Plate V). In the case of the smaller cows, the top of the gate is tipped backward toward the manure trench, crowding the cow back so as to make her stand on the edge of the manure trench (see Plate V).

The milk from the stable is brought into the wash room and is hoisted onto a raised platform and poured into a strainer marked $d i$ ), 
from which elevation it flows into a funnel and conducting tube through the wall into the collecting tank for the Star cooler (2) and crean cooler (3). From this collecting tank a tube also supplies the separator (4), see Plate . The raised platform shown in Plate VI was a mistake, as it should have been lowered so far as would permit a man standing on it to pour the milk into the strainer shown. It is much too high, and the platform-instead of requiring a ladder-would have only required a few steps leading up to it. The tank under the platform was intended to hold cracked ice, on which water was to be sprayed for supplying the ice water section of the Star cooler in summer. But this was found unnecessary, as a cask could be placed on the floor containing a coil of pipe to cool the water as described on p. 82. The numbers $(5)$ and (6 in the milk room are supposed to represent the bottle filling apparatus for milk and cream shown in plate. The bottles, when filled, are kept over night in a series of tanks, one over the other (7), as water is had from a neighboring spring at a temperature of $46 \mathrm{deg}$. F. to fill the tanks. The bottles are shipped on ice in galvanized iron cases. The empty bottles are delivered on the elevated piazza platform, in front of the wash room, and the bottles and all the milk utensils are washed, put in the sterilizer and taken out through the other door in the milk room when it is desired to use them. The milk room is only connected (with one door). with the shipping room and is ventilated by a system similar to that recommended for barns. The floors of all the rooms in the milk house are of cement, and the walls of cement-plaster, covered with many coats of white enamel paint. The cement-plaster is laid on wooden laths and the construction of the building is of wood. It is steam heated in the lavatory and wash room. The climate is very mild hereabouts and rarely gets much below freezing.

Sketches of the barn and milk house owned by W. H. Paulhamus, Esq., are reproduced here with the hope that they may prove of practical value to those intending to handle clean milk on a considerable scale for profit.

The barn (Plate IX) is built of wood and ceiled within with smooth, matched boards (shiplap) painted with cold water white paint. The space between the outer and inter boarding of the walls is filled in with sawdust. The inside of the barn is eleven feet high, 


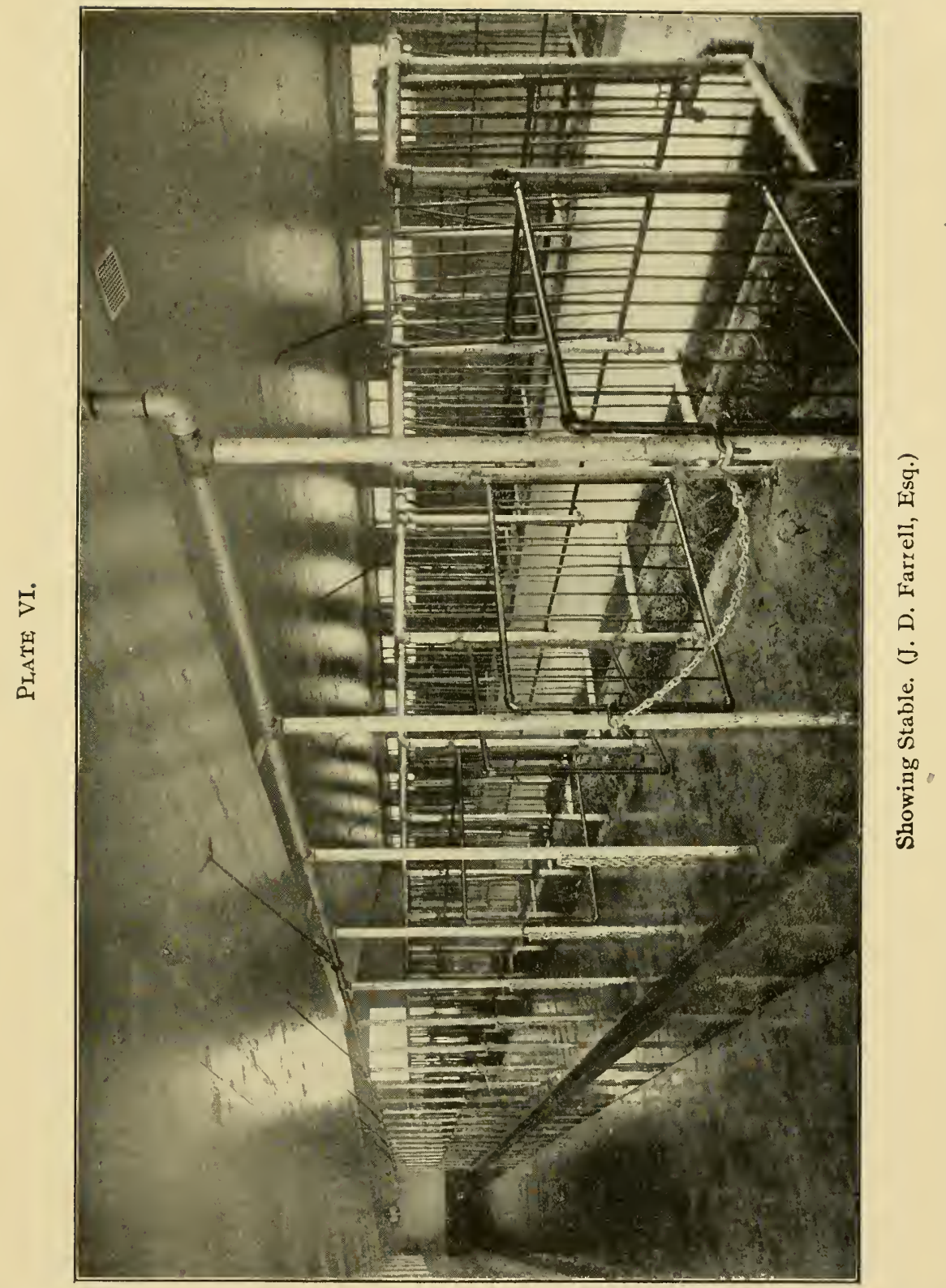




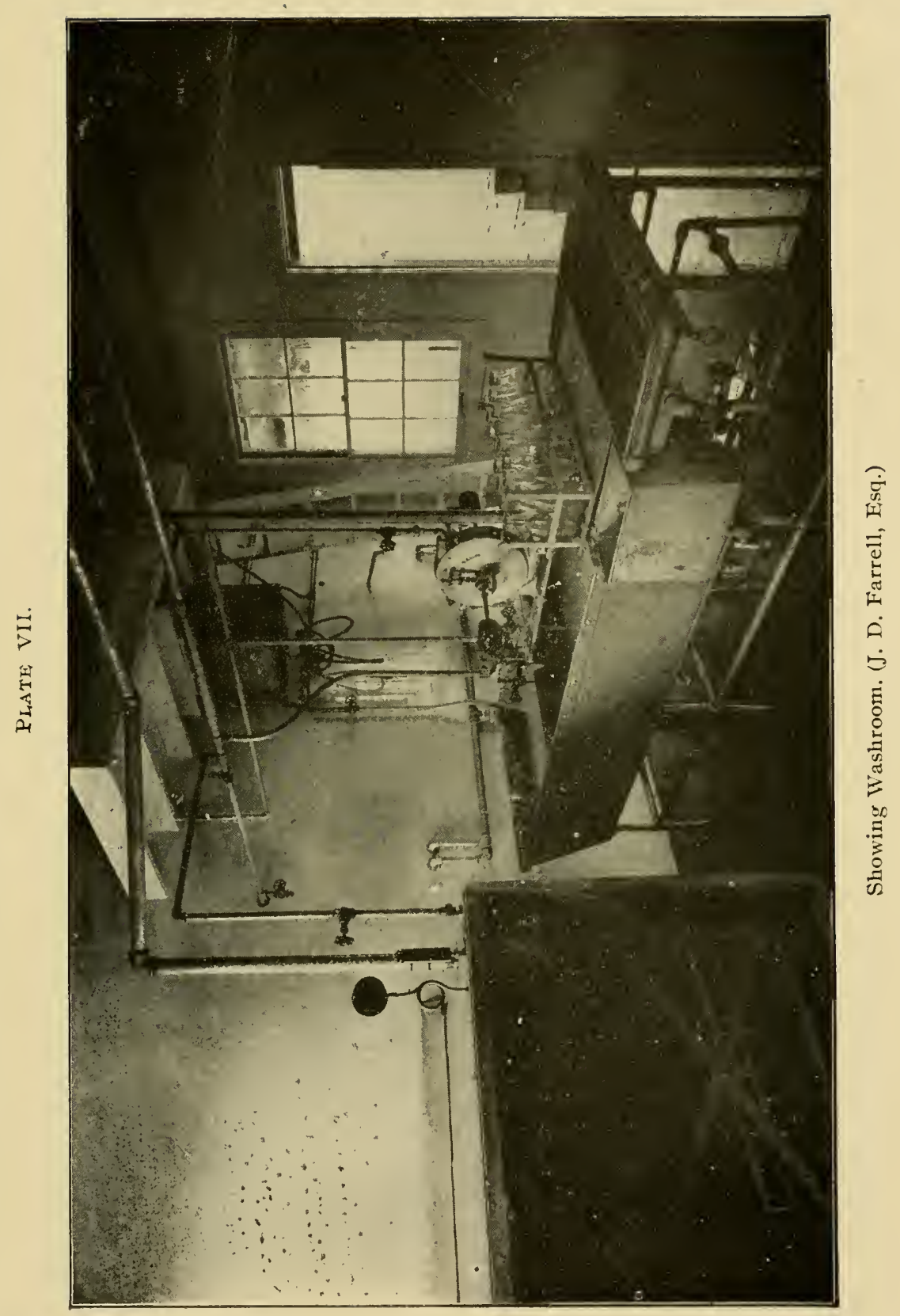





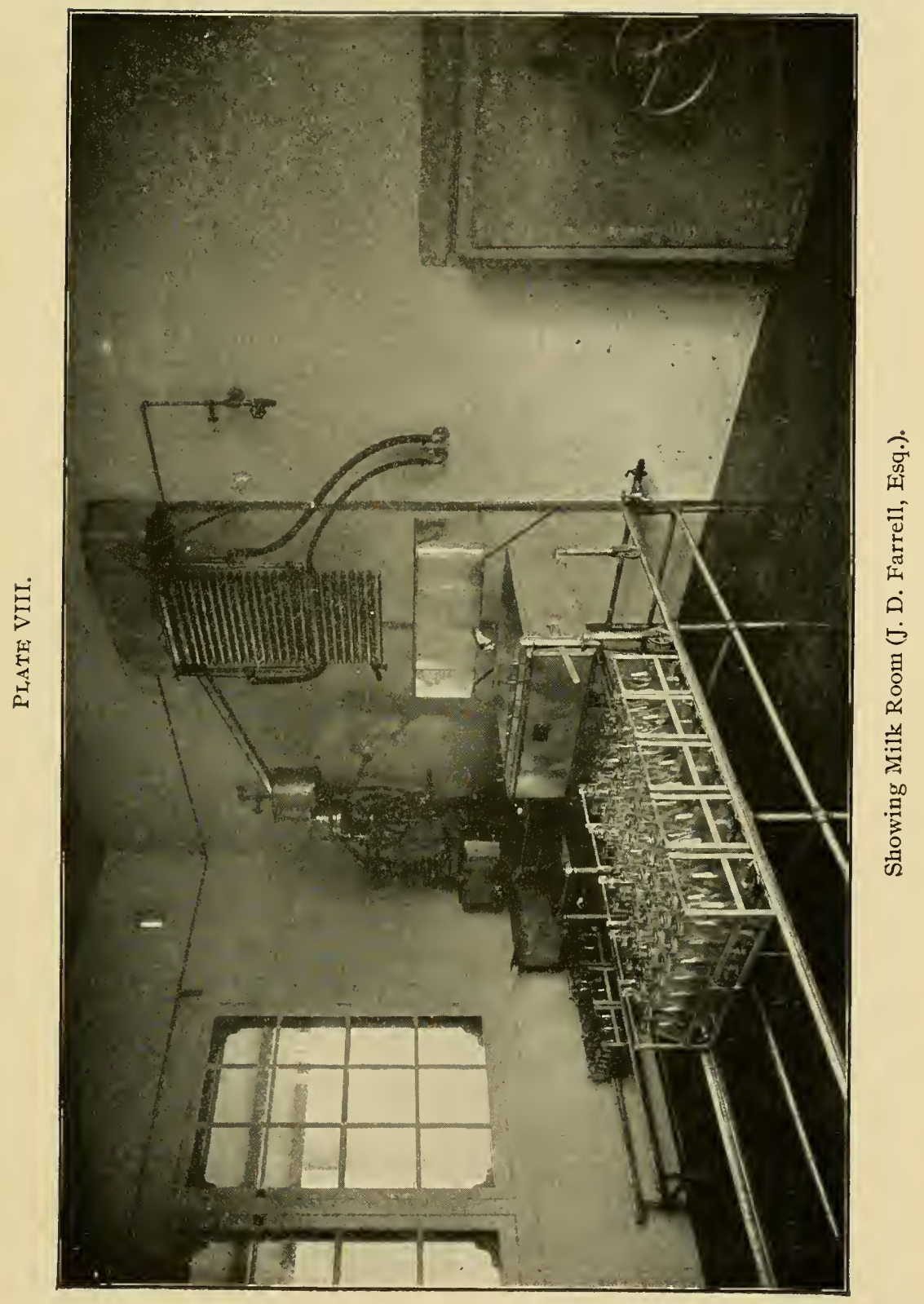





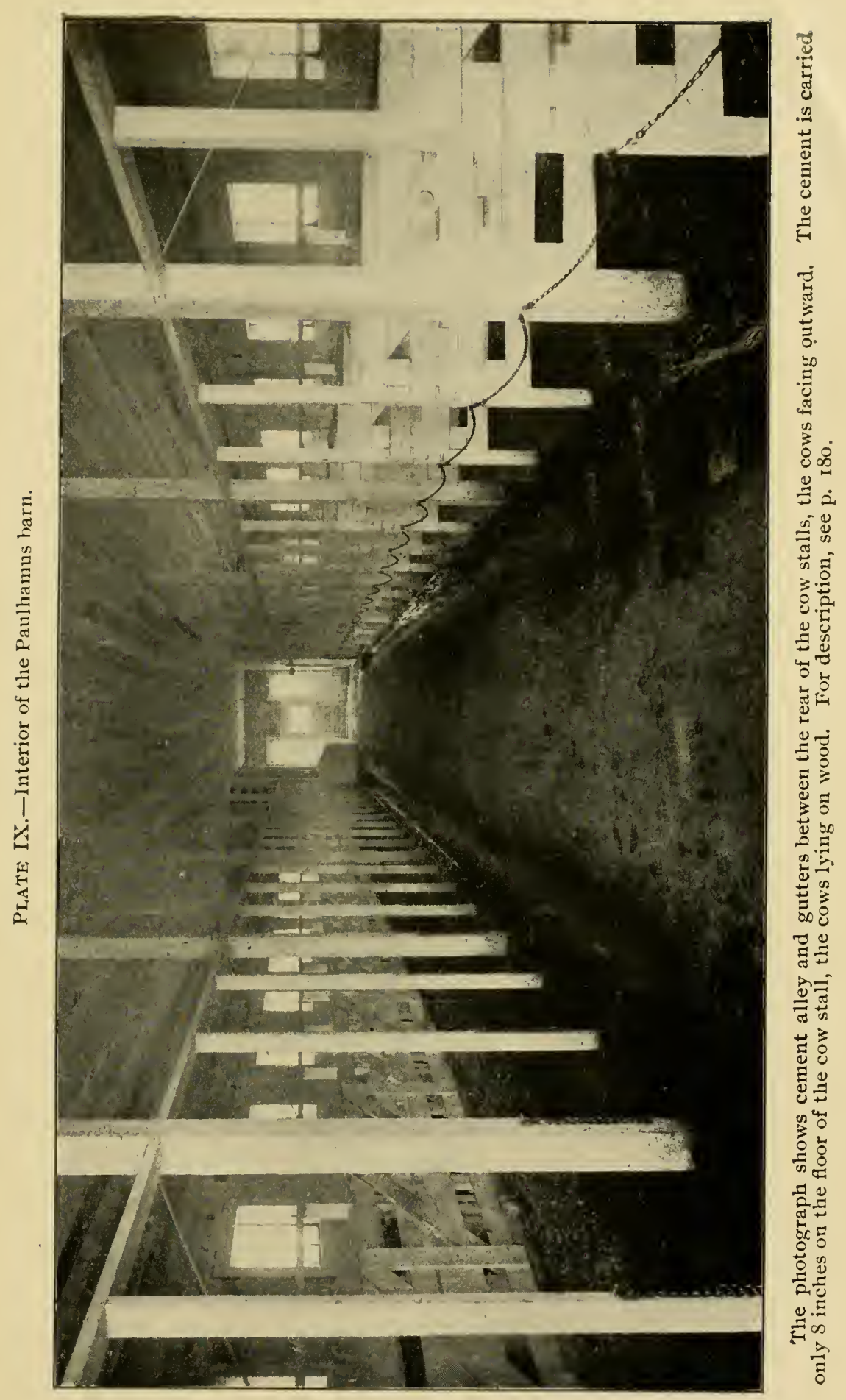



which is higher than is generally permissible with the King system of rentilation to prevent loss of animal heat.

The climate is, however, extremely mild, the temperature seldom dropping much below freezing in winter hereabouts. The King system. is nevertheless followed; there being ten inlets, between ten windows

Fig. 46.

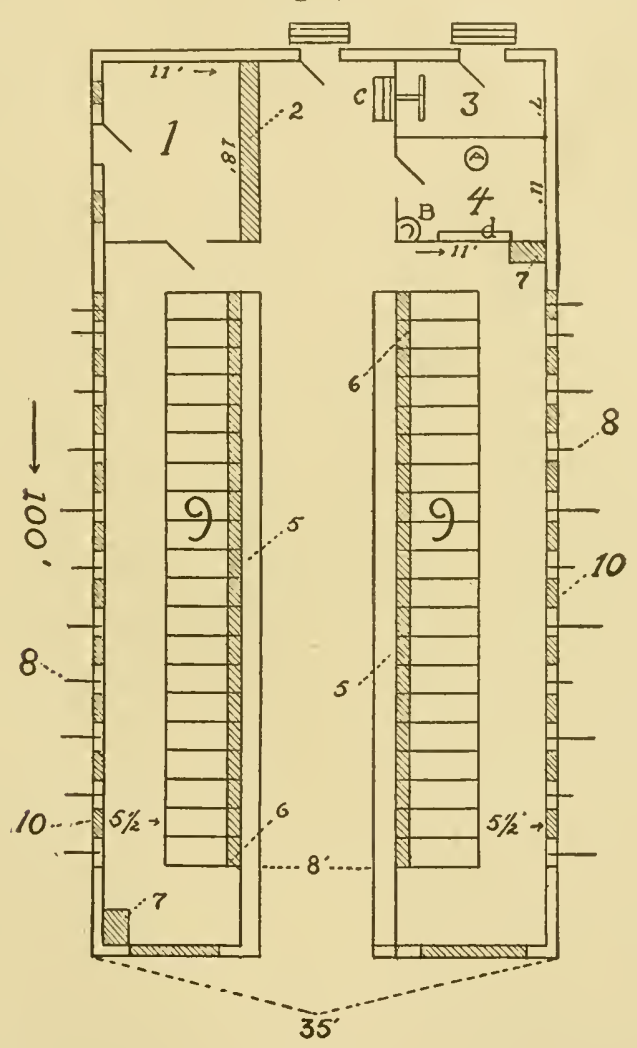

Rough Sketch of Ground Plan of Barn for Forty Cows, W. H. Paulhamus, Esq., Sumner, Washington.

(10) on each side of the barn, near the ceiling. These openings are six by six inches, and bring the air in shafts between the layers of the walls of the building from a point outside near the ground. The windows in the sides of the barn are three and one-half feet square, and between them in the sketch may be seen lines (No. 8) showing the point of entrance of the inlets for fresh air.

The shafts for outlet of air are in the opposite corners of the 
building (7) and are two feet square with openings at the floor of the same dimensions.

One special feature is the arrangement of the cement which covers the whole floor, except as noted. The entire floor slopes about one foot from one end of the building, so, while the gutters are the same depth, this permits of a flow for drainage. The cows face the outside of the building and the floor of their stalls is of two inch matched, planed Oregon pine, except for a strip of cement eight inches wide on the side of the gutter (6) on which the hind feet of the animal rest. All the rest of the floor back of the cows is of concrete with cement finish, while the side aisles in front of the cattle are of wood, like the floor of the stalls. The cows do not have the slippery, cold, cement floor to lie (or fall) upon, which Mr. Paulhamus believes an improvement over an entire cement floor. The stalls are shown in Plate IX. There are so many kinds of stalls that it is impossible to say which is the best, but these are simple, inexpensive and satisfactory, as soon as the cows get used to them.

At one end of the barn are several rooms. One ( $I$ ) is intended for keeping supplies, as baled hay, roots and grain in sacks, etc. One on the opposite side is a wash room with sink and hot and cold water (B), and a sheet iron stove (A) for wood with a coil of pipe inside to heat water (see p. 85). There is also a closet $(d)$ for keeping the milking clothes. The next room (3) is a rather novel arrangement of the owner and assuredly deserves attention.

This room has no connection with the inside of the barn, except by a tube for conveying milk at $C$. Here may be found a pair of steps which each milker ascends the moment he fills the pail. The milk is poured into a sterile tin funnel which carries it onto a Star cooler*, from which it falls, immediately cooled, into a can. The can, when full, is taken to the milk house (Fig. 47) some 200 feet away.

The room (3) is reached from outside the barn and-with screened door and window, and smooth, clean, painted walls and ceiling, and

* The milk flows from the funnel (which is in the open central aisle of the barn) through the wall, which separates it from room 3 , and in that room falls on the cooler. 


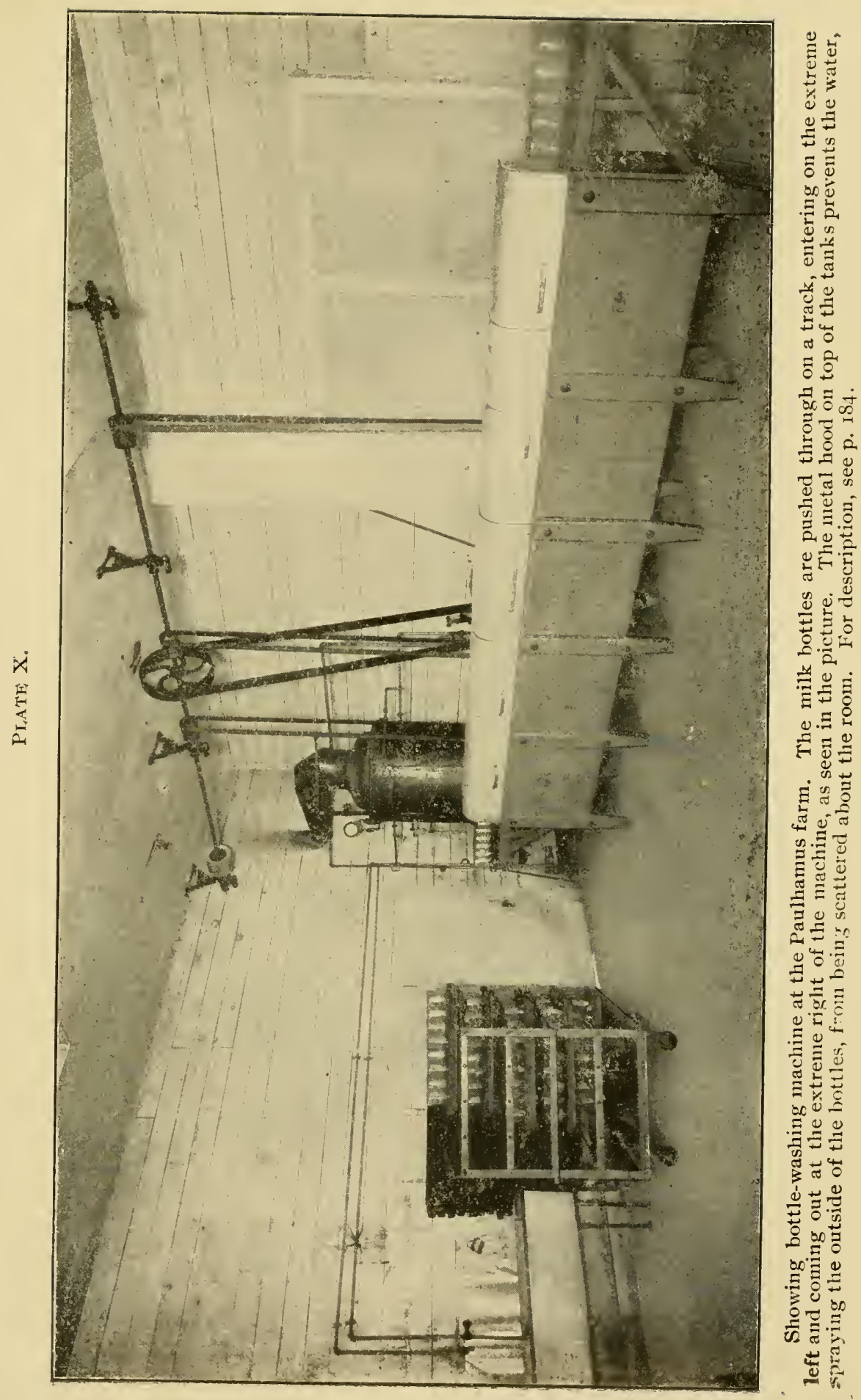



cement floor-makes a good place for immediate cooling of the milk. The horizontal ceiling of the barn leaves much space in the roof, in which grain is stored. The grain is brought down in spouts to the bins at (2) and hay could be delivered from the loft above in the room (I) without causing any dust in the barn. The ceiling of the barn is absolutely dust tight with double floor and paper between.

The barn is one hundred by thirty-five feet inside; the centre

Fig. 47 .

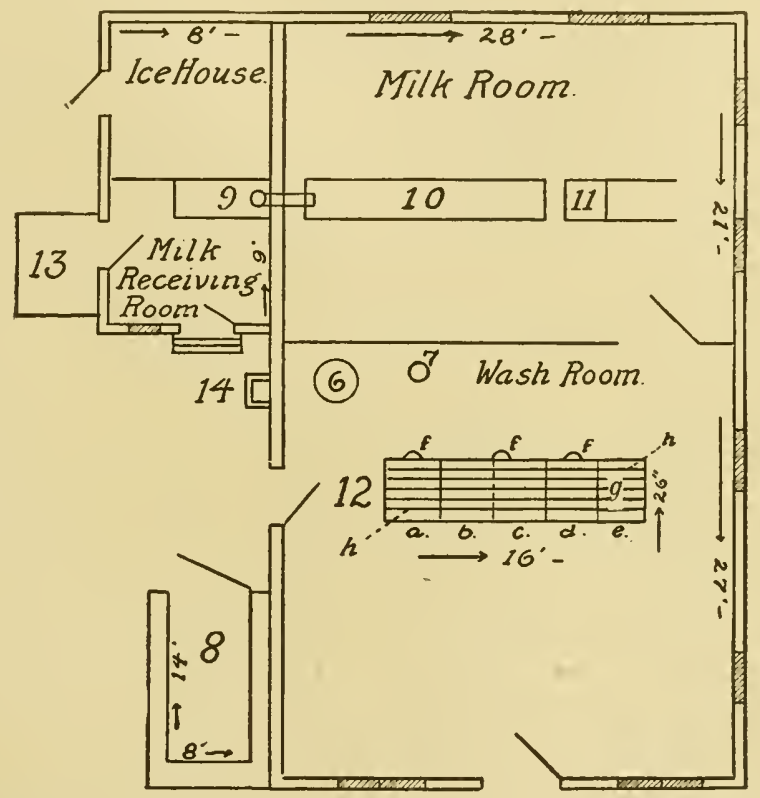

Rough Sketch of Ground Plan of Milk House. W. H. Paulhamus, Esq., Sumner, Washington.

aisle eight feet, and gutters eighteen inches wide. The side aisles are five and one-half feet wide.

Box stalls for sick cows, or cows about to calve, are in another building.

The buildings used for the milk rooms (Fig. 47) proper were altered for their present purpose and were situated farther from the barn than is necessary or desirable.

A sketch of the ground plan of the milk house is shown in Fig. 47 .

The floors of the milk room and wash room are of concrete with 
cement finish, boarded inside with planed, matched boards (walls and ceiling), painted white and ventilated after the King system. The space between the inner and outer layer of the walls is stuffed with sawdust and the rooms are very high-studded (fourteen feet). The sterilizer $(S)$ is wholly of concrete, which is described on p. $9 \mathrm{r}$, and, if the buiklings had not been already built before they were put to their present use, it is probable that the most convenient place for the sterilizer would have been in the wall between the wash and milk roons, as in Mr. Farrell's (Plates VII, VIII). The sterilizer is supplied with steam from the 20-horse power boiler (6) in the wash room.

This sterilizer is an original feature introduced by Mr. Paulhamus and works beantifully. It is of enormous size (see p. 9 I and Plate XI) and very inexpensive, costing some $\$ 80$. In cold climates it rould have to be inside the building as suggested above. Anotlier novel feature is the washing machine shown as (No. I2) in the sketch in the wash room. This was patented after its introduction at Mr. Paulhamus's farm and now sold by The Chas. H. Lilly Co., of Seattle. The machine consists of four tanks, $a, b$, and $c, d$ and $e$. In $a$, is held warm water, in $b$ and $c$, is contained alkali and warm water, and in $d$, is plain warm water. The three lines $(g)$ running lengthwise in the sketch, through the middle of the machine, represent three pipes running over the top of the tanks. These pipes are perforated with holes which are placed so as to correspond with the opening in each milk bottle when the bottles are inverted on wooden trays. Fach wooden tray is made of slats which, in crossing, leave holes fitting the neck of an inverted milk bottle. The trays holds twenty-four bottles in three rows, so that when the tray is slid in place on top of the machine, each row of bottles is over one of the three pipes in the centre of the machine, and each bottle is inverted over one of the perforations in the pipes. On one side of the machine are three rotary pumps $(f)$ worked by the engine at $(7)$. These continually pump water from the tanks into the the pipes, from which it is forced out in jets into the interior of each inverted milk bottle. The water then rums ont of the bottles back into the tank over which the bottles are resting. The pipe shown on either side of the top of the machine at $(h)$ is perforated with holes from which water is thrown over and cleans the outside of the bottles as they are pushed through the machine. 
Plate XI.

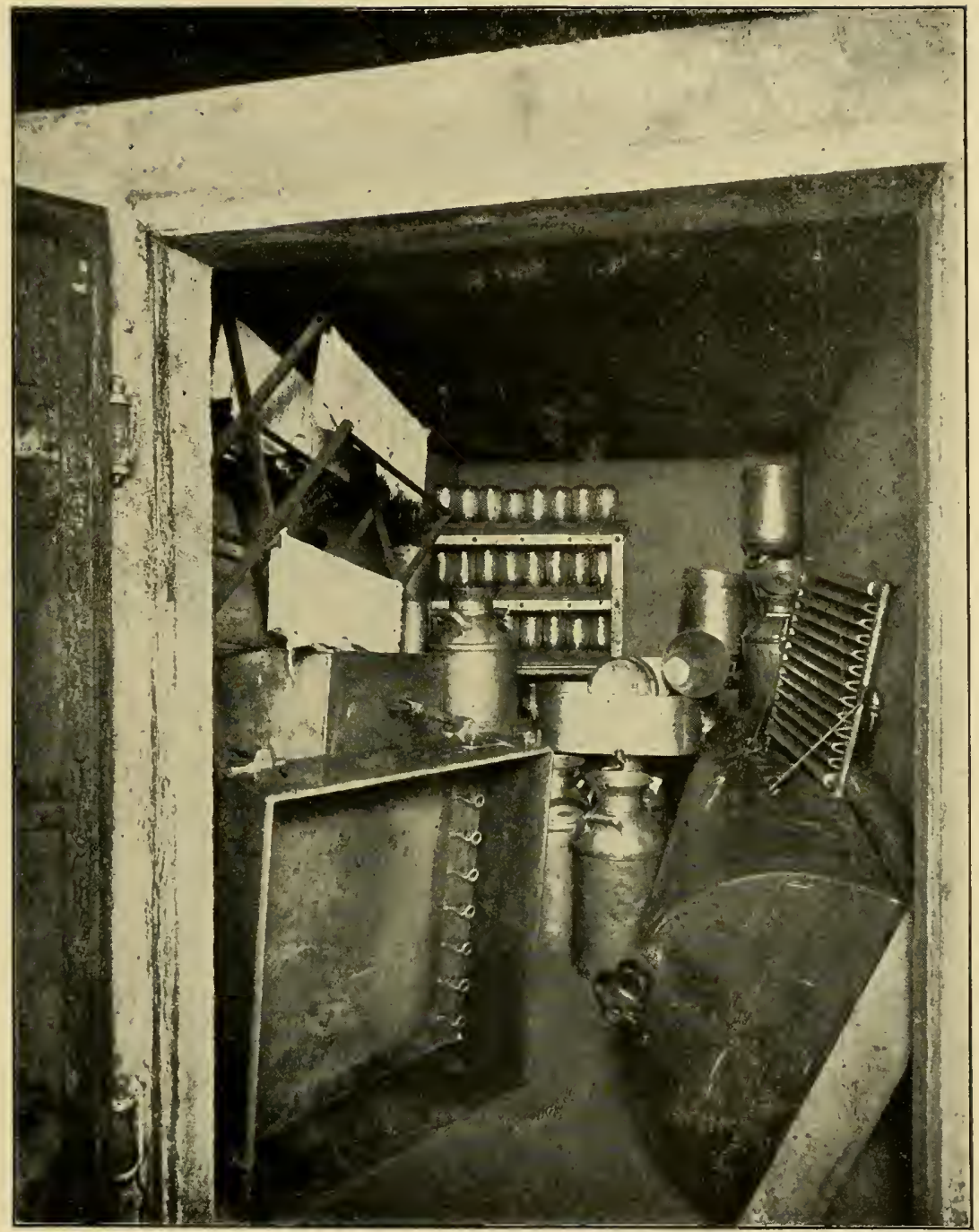

This photograph shows the interior of the large all-concrete and cement sterilizer at the Paulhamus farm. The door is of iron. All the dairy utensils which come in contact with milk in any way are put in this chamber and kept at $252^{\circ} \mathrm{F}$ for one hour daily. For description, see p. $9 \mathrm{I}$. 

The method of working is as follows: A tray loolding twentyfour inverted bottles is placed on the top of the machine orer the tank (a). The warm water in the central pipes is pumped up through the holes in the pipes into each bottle, thus rinsing it out. Another tray being pushed into the machine shoves the first tray over tank $(b)$. Here the interior of the bottles is sprayed with lye and water. The introduction of another tray moves the first tray over the tank $(c)$. The tank $(c)$ is really one with $(b)$, the bottles here merely draining back into the tank again, no water being pumped into them. Another tray being placed in the machine pushes the first tray to $(d)$. Here the bottles are rinsed with plain warm water to remove the lye, and, at (e), boiling water is injected instead of water to sterilize (for one minnte) the bottles. About $\mathbf{1}, 500$ bottles may be washed in one hour by this labor-saving device. The bottles must, howerer, be washed by hand if they contain old milk and have not been previously rinsed by the milk consumer. Also, one minute sterilization* is not sufficient and they must go for one hour's sterilization in the large sterilizer, when certified milk is desired. The water is heated by stean from the boiler (6) which runs the engine. A metal hood covers the whole top of the washing machine to prevent the escape of the water which is thrown from the pipes on each side over the exterior of the bottles. The machine with pumps costs about $\$ 200$, and is sixteen feet long and twenty-six inches wide (see Plate $\mathrm{X}$ ).

The platform (13) and floor of the milk-receiving room are some fifty inches from the ground. In the milk-receiving room at (9) is a raised platform three feet from the floor on which are scales holding a large milk-receiving tank in which is a Star trap strainer. After the milk is weighed it is run from a faucet into a funnel, conducting the milk through the wall, into a tank (IO) holding some one hundred gallons, and from thence is drawn off into the Star bottle filling tank (I I). The milk is cooled, as clescribed, at the barn (p. IS2), and the water supplying the Star cooler is cooled in summer by running it through a coil of pipe in a cask of ice water (see p. 82).

* It is perfectly possible to sterilize milk bottles absolutely, if boiling water is pumped into the bottles for a longer time, as shown oy bacteriological examinations of bottles washed by similar machines. The exhaust steam from the engine may be used to heat water to boiling point. 
A sketch of the cow stall used by Mr. Paulhamus is shown in Fig. 48 .

The floor has been described (p. I 82 ) as consisting of cement for eight inches in front of the gutter and (forward of this point) of two inches kiln-dried, planed, tongued and grooved Oregon pine. The dimensions are marked in the sketch, but the length of the stalls vary

Fig. 48.

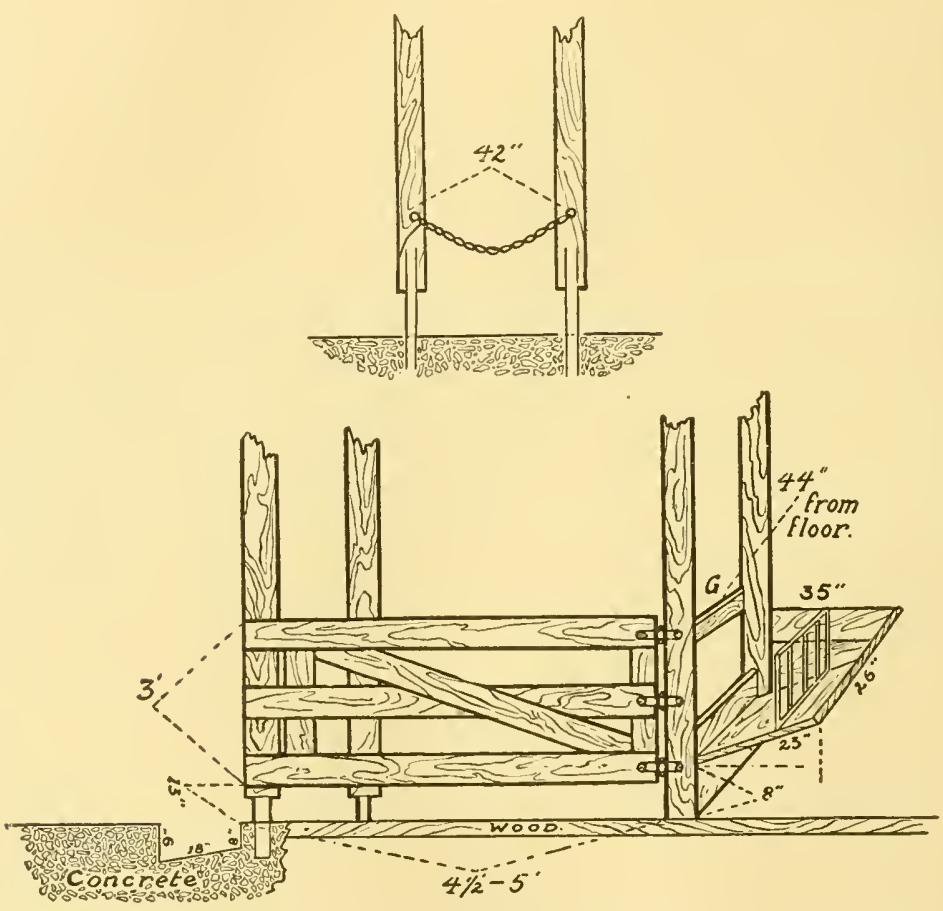

Side and Rear View of Stall in Cow Stable of IV. H. Paulhamus, Esq., Sumner, Washington.

from four and one-half feet to five feet long, from the gutter to the manger, to accommodate cows (Jerseys) of different sizes. The floor of the stall slopes some three inches from front to rear. The stalls begin four and one-half feet long at one end of the stable and gradually lengthen till they are fire feet long at the other end. Each side of stall is really a gate opening toward the right, to give more room to the milker and groomer, when open. They could of course be hung om hinges so as to swing in either direction. 
PLATE XII.-The improved "Drown" Stall.

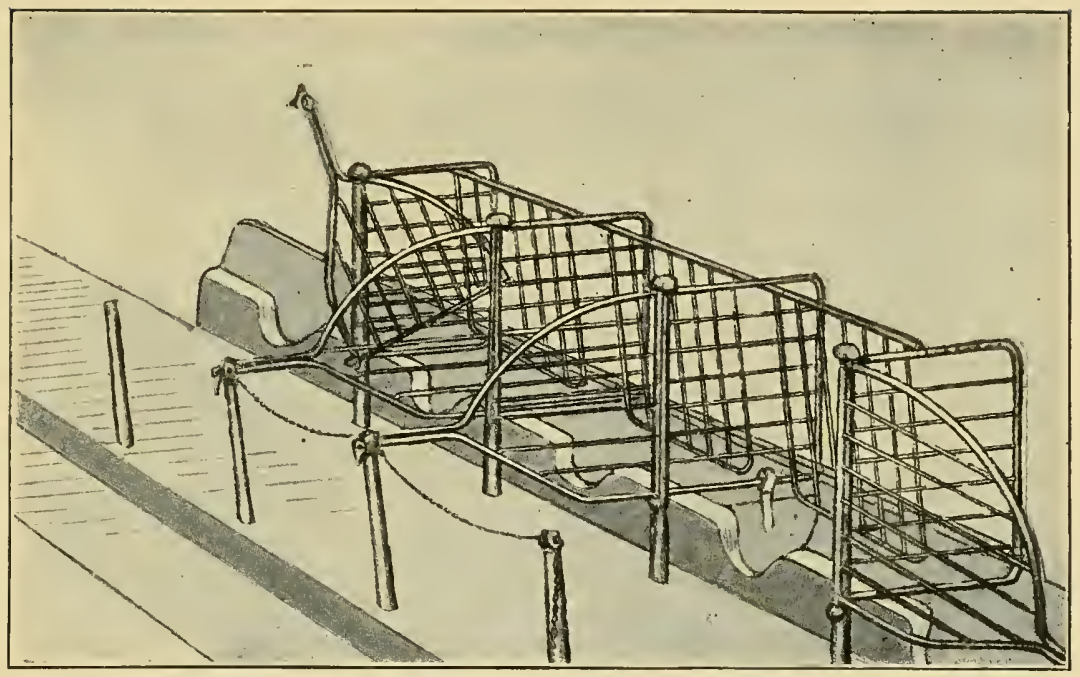

View shows cennent mangers and floors fitted with iron stalls having two-way movable partitions.

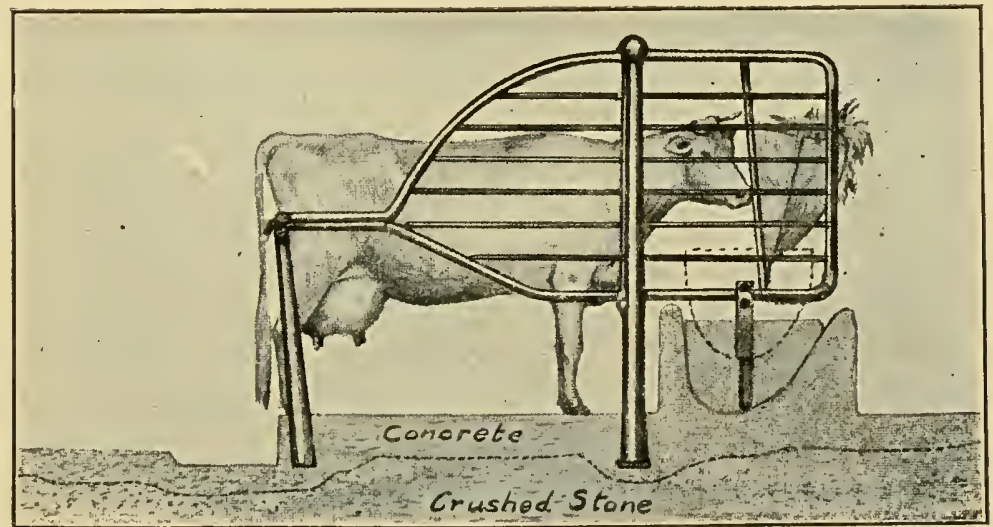

The Drow1 Stall is one of the best made and is an improvenent over either stall shown in that the sirle gates give nore roon to the attendant and open in either direction sideways and also upward. The raised feeding trench and hay rack are good features.

The stall is patented and sold by M. L. Drow11, of Madison, Wis. It is in nse by some of the agricultural experiment stations and leading dairy farmers of this country. 

The gates are fastened with a wooden sliding bolt (not shown). The bottom of the rear posts may (for the lower eighteen inches) consist of galvanized iron pipe set below in the cement and above in the wooden scantling, for the sake of cleanliness. At the rear of the stall is seen a chain which is attached to rings in the post, on either side of the stall, by means of snap hooks. The manger has two compartments, the lower for grain, and the upper or forward being for hay-with a sliding rack between the two which may be removed or lifted a little to clean out the floor of the manger. (Sometimes the whole manger, arranged with sides reaching to the floor of the stable, is made movable so that it may be adjusted to the length of the cow and locked by pegs fitting in the side posts.) The cross-piece at $(C)$ is necessary to keep the cows from pressing forward and climbing over the manger. It must be adjusted somewhat to the height of the cow. This stall is convenient and inexpensive as compared to the iron stalls (Plates V and VI). There is nothing on the floor of the stable to collect dirt, as the manger does not touch the floor, but is eight inches above it.

\section{Pasteurized Milk.}

Milk is now thought to be truly a living fluid for some time after leaving the cow-unless it is killed by pasteurization. Pasteurized or dead milk is known to be less digestible and nutritious than clean, raw milk. The basis of this statement is as fullows: Babies fed continuously on pasteurized milk are very apt to develop anemia, malnutrition, scurvy or rickets-the latter serious disorders dependent upon improper nutrition. Obstinate constipation is likewise generally seen in infants reared upon pasteurized milk. The same conditions are observed in calves which are fed exclusively upon pasteurized milk. They fail to gain properly in weight and suffer from under-development.

Heating milk coagulates to some extent its albumin, renders the milk less coaguable by rennet in the stomach, and destroys the enzymes or ferments of milk. All these results account for its lessened digestibility.

I.t has been shown that the poisonous waste-products, developed in the growth of germs in dirty milk, are not destroyed by pasteurization. As, for example, the special poisons arising from those types of 
gernis (colon bacilli) conveyed to milk in cow manure. Moreover, while the milk may appear by examination to be apparently free from germs after thorough pastenrization, what of the myriads of dead bodies of germs killed by the process which may remain in the milk! A milk contractor in Boston sent out a laboratory report on his milk to show that before pasteurization it contained seven million germs to the quarter teaspoonful of milk and only a thousand after the process.

Another serious objection to the use of pasteurized milk is the fact that its condition can not readily be discovered by ordinary tests. The lactic acid bacilli, being easily killed by heat, pasteurized milk may not show acidity or change in taste or appearance and yet be wholly unfit for food owing to the existence of millions of germs which do not cause the milk to change but are prejudicial to health.

The following method promises better than any yet known for the safe sterilization of milk.

Budde's Process for Sterilizing Milk. - Fifteen c.c. (or one tablespoonful) of three per cent. solution of hydrogen peroxide are added to each quart of milk in bulk, as soon after milking as possible, and the milk is then heated to 5 I deg. to $52 \mathrm{deg}$. C. (I $23.8 \mathrm{deg}$. to I 25.6 deg. F.) for three hours. By this method the oxygen in the hydrogen peroxide is liberated by an enzyme in the milk (catalase), with the aid of the heat, and the nascent oxygen acts as an efficient germicide. All the non-spore bearing micro-organisms are killed-including all disease germs-except those of anthrax. In fact, 99.9 per cent. of the germs in milk are destroyed by this method and nothing is left in the milk but a little water which is too small in quantity to alter the composition of milk appreciably.

The milk is unaltered in odor, taste or appearance, and the cream rises as usual while no trace of peroxide remains. Milk thus treated will, moreover, keep unchanged in warm weather for eight to ten days.

This process seems to solve the question of treating dirty milk when clean milk can not be procured, and would appear to be of inestimable benefit in the preparation of infant's 111ilk when of uncertain quality, and for keeping such milk to be used by an infant during a considerable journey. 
PrATE XIII. - The Burrell-I,awrence-Kennerly Cow Milker.

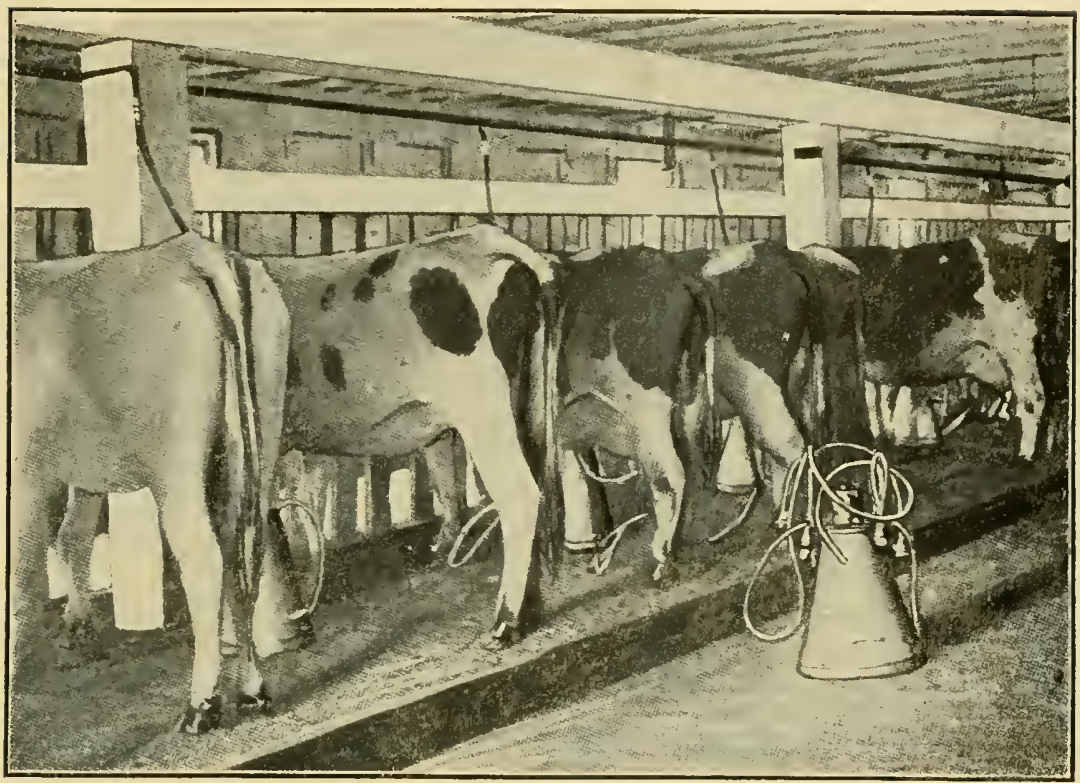

The plate shows the n11ain iron piping above the stanchions connected by rubber tubing with the pulsators placed on top of each milk pail between each two cows.

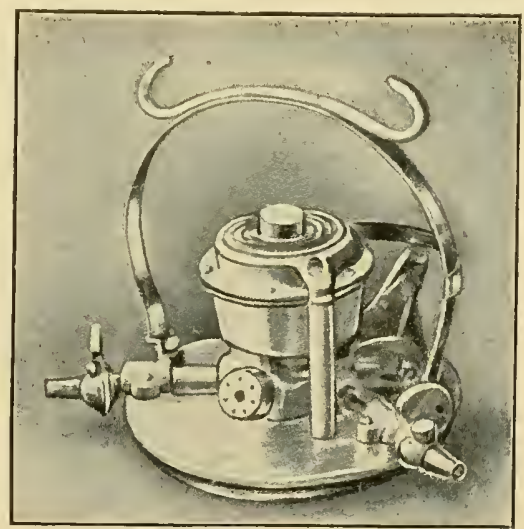

PLATE XIV. - The Pulsator. 



\section{Milking Machines.}

The milking machine, together with the single service paper milk bottle, bid fair to practically revolutionize the methods of producing clean milk.

If these trio inventions prove as valuable as they promise, the whole question of clean milk production will be solved. The milk will be obtained nearly sterile and be inmediately cooled and run into sterile bottles. The status of the milking machine seems still a matter of some uncertainty with every indication of a successful future. The machine we will describe appears to be one of the most efficient and has been in operation for some years. At present it is being used by the leaders in the dairy industry, as by the Walker-Gordon people and H. B. Gurler.

The Burrell-Lawrence-Kennedy Cow Milker comprises the following :

I. A vacuum pump operated by power, steam, electric motor, gas engine, tread mill (bull), a head of water over thirty feet, etc.

2. One inch iron piping connecting the vacuum pump with a vacuum tank, supplied with guage and safety valve, and thence about the barn for attachment to the milkers.

3. The Milkers. - A milker consists of a milk pail (heavy enough to withstand a vacuum), on which is placed a pulsator, which in its turn is connected with one-half inch rubber tubing to four teat cups fitted on the teats of the cow.

The vacuum is about equal to one-half an atmosphere, fifteen to seventeen inches, and the vacuum tank is connected with the system to insure a uniform, safe and known suction. The pulsator (Plate XIV) is the salient feature of this machine. It rests on top of the milk pail, to which it fits tightly as soon as the exhaust is turned on, because of atmospheric pressure and because it rests on a rubber gasket. The pulsator is connected with the iron pipes which run along over the stanchions (Plate XIII) by one-half inch rubber tubing fitted to the nipple at its base. The two stop-cocks, seen in the plate of the pulsator, are each connected with rubber tubes, one taking the 
milk from the four teats of a cow on one side, and the other from the cow to the other side of the pulsator.

When the machine is in operation the cow's udder is sleaned, the teat cups (of five sizes) are adjusted, and a milk pail-placed between each two cows - is surmounted by a pulsator attached by rubber tubing, both to the iron piping above, and to the teats of the cows on each side (Plate XIII). That is, each milker (milk pail, pulsator, rubber connections and teat cups) is capable of milking two cows at the same time.

A stop-cock is turned and the suction applied by the pulsator to the cow's teats. By this mechanism there is exerted intermittently not only suction but also compression on the outside of the teat, simulating the action produced in hand milking. Glass windows in the tubing leading from the teats inform the operator as to the flow of milk. Most cows do not object to the use of the machine.

This machine will practically prevent the initial contamination of milk, and will render the production of clean milk more simple and easy than by any method heretofore known. The rubber tubing, through which the milk passes, can be sterilized and made free of germs by boiling or by steam and is kept in brine. The pulsator and milk pail can be cleaned readily by the use of boiling water or steam.

As a labor-saver the device enables one man to do four men's work. One man can operate three or four milkers at once, each milking two cows at the same time, which means that he can milk thirty to forty cows an hour. With hand-milking this number of cows wonld require the work of four men for one hour.

Moreover, the results are much more uniform, and daily variations in milk-yield, depending on the persoinality of the milker, are elininated.

The difficulties in keeping milkers and the disastrous results from frequent change of milkers are also removed by the machine.

Cost.-The expensive parts of the milking machine are the milkers and the vacuum pump, each of these costing $\$ 75$ apiece. This pump is capable of operating five nilkers. The entire cost of the installation, power and milking machines is estimated by the sellers 
to amount to about $\$ 12.00$ per cow for a herd of forty cows, and $\$ 8.50$ per cow for a herd of seventy-five.*

With accumulating experience, the results obtained by the use of the Burrell-Lawrence-Kennedy milking machine appear to be generally favorable.

The more common doubts as to the amenability of cows to the milking machine, and the danger of drying up cows from incomplete emptying of the udder, have been dispelled. Cows hitherto unruly to hand milking, and heifers never milked before, have taken most kindly to the machine, and, on the whole, cows like machine milking better than hand milking.

Hand stripping-after the removal of the teat cups-is done, generally, into the teat cups themselves. Cows which are milked by the machine have a longer period of lactation than when milked by hand.

What appeared a serious objection to the milking machine was the complaint that the milk of single cows could not be separated from that of the herd-in case it was contaminated with blood or pus and germs from an inflamed udder; or the milk was needed for feeding a calf; or for making a periodical test for quantity and fat. Gurler has obviated this defect by having the pail of one machine divided into two compartments, one for each cow, and provided with corresponding outlets from which the milk from each cow can be drawn. Garget, and all troubles with the udder, are less frequent with the milking machine-probably because the teats are not so subject to abrasions and infection from other cows by the hands of the milker.

Mr. H. B. Gurler, of Illinois, one of the most noted dairymen of this country-writing in Hoard's Dairyman-says that in thirty comparative tests between hand and machine milking, the number of bacteria was reduced one-half by the machine-irom 5,000 to 2,500 per c.c. After fourteen months' use of the Burrell-Lawrence-Kennedy machine with two hundred cows he found but two or three cows which could not be milked by it; he gives it his unqualified approbation and affirms that it has come to stay.

* For details consult D. H. Burrell \& Co., Little Falls, N. Y., and Brockville, Ont. 
Gurler states that one man with the machine is equal to three hand milkers ; that no difficulty was experienced in keeping the apparatus clean by the use of rinsing in cold water, a solution of lye, and boiling water; and that great care slould be taken in accurately fitting each teat cup to each individual teat. He warns against completely filling the milk pails, lest milk be drawn into the vacuum pipes, and emphasizes the recessity of a uniform vacuum. If a teat cup pulls off or any accident occurs which reduces the vacuum, the machines should be shut off till the proper vacuum is secured. And when one of a pair of cows attached to a machine' is milked before the other, the racuum should be shut off from that cow, at the machine, and the machine kept running until the other cow is milked.

The Hegelund Method.-Extensive experiments with this method of manipulating the udder at the close of milking have been conducted by Woll at the University of Wisconsin Agricultural Station,* on one hundred and fifty cows during a summer and fall, and have proved its advantages to be as follows:

A daily gain of one pound of milk, and one-tenth pound of fat per cow was obtained. This is equivalent to a gain of about thirtyfive pounds of butter per cow per annum.

Most cows do not object to the manipulation; less than a dozen out of the number tested did so.

The gain in quantity of milk and fat is not a temporary increase ; not only is the gain persistent, but the method tends to maintain a large flow of milk during the lactation period.

The method taking the place of stripping, there is no loss of time in performing it.

The use of the method develops the milk-yield of heifers, and has even doubled that of cows which have been supposed to have reached their maximum flow of milk. It increases the fat in the milk so that the yield from this method contains ten per cent. of fat. It is of great value in preventing mastitis during the early period of lactation.

* Univ. IVis. Agric. Sta. Bull, No. 96. 
PLA'Tr XY. (Illustrating the Hegelund method of milking.)

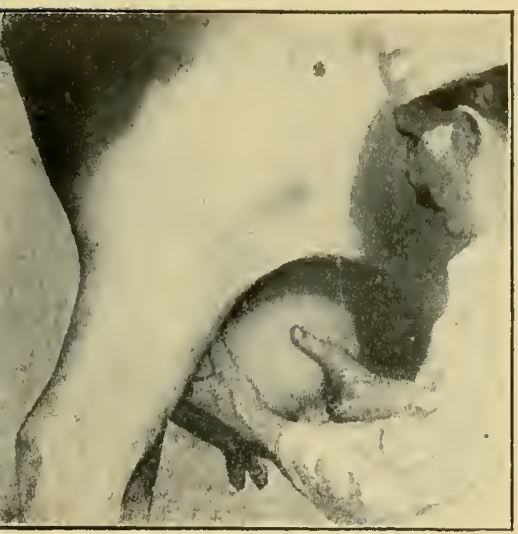

FIG. I.-First manipulation of udder, right quarters,

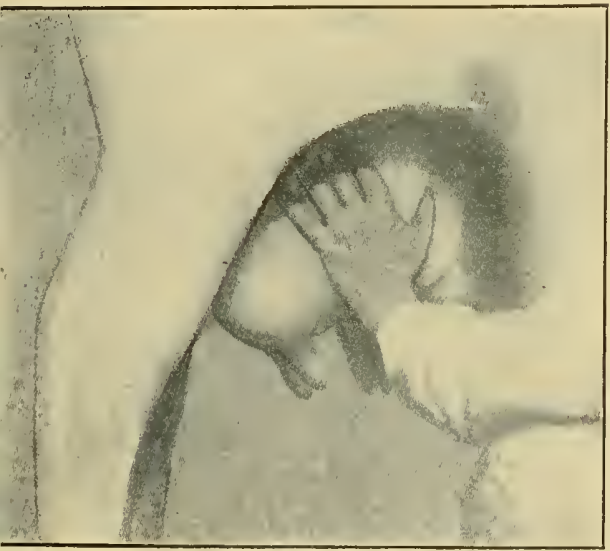

G. 3.-Second n11nipulation, right fore quarter.

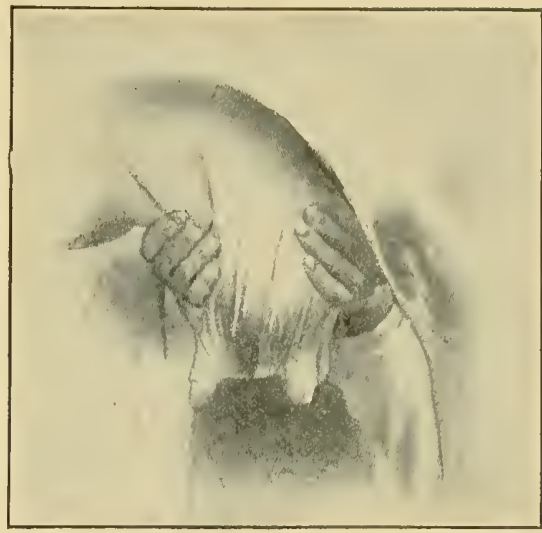

FIG. 2.-First manipulation, left quarters.

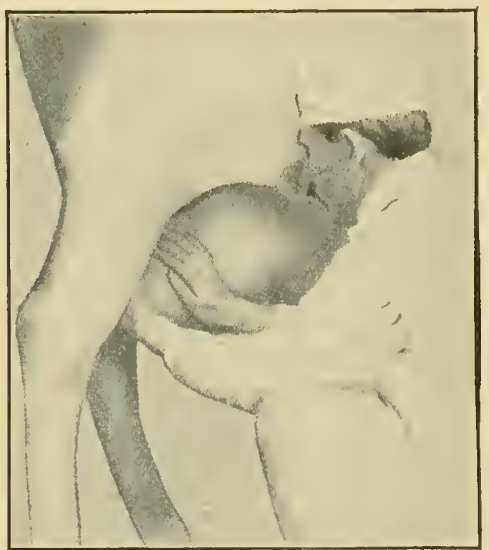

Fig 4--Second maripulation, right hind quarter.

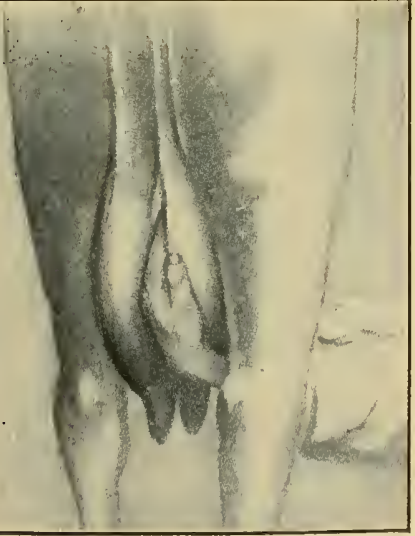

FIG. 5.-Second nuanipulation, right hind quarter, rear view.

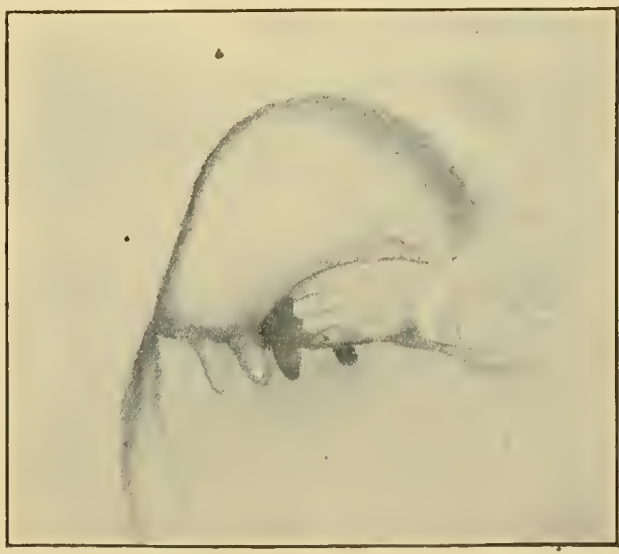

Fis. 6,-Third 111upipulation. 

As the method has been adopted by some of the most progressive farmers in Denmark, and this country it is well worthy of trial and is herewith described.

DESCRIPTION OF THE MANIPULATIONS IN THE HEGELUND MFTHOD OF MILKING.

First Manipulation.- The right quarters of the udder are pressed against each other (if the udder is very large, only one-quarter at a time is taken) with the left hand on the hind quarter and the right hand in front on the fore quarter, the thumbs being placed on the outside of the udder and the four fingers in the division between the two halves of the udder. The hands are now pressed toward each other and at the same time lifted toward the body of the cow. This pressing and lifting is repeated three times, the milk collected in the milk cistern is then milked out, and the manipulation repeated until no more milk is obtained in this way, when the left quarters are treated in the same manner. (See Plate XV, Figs. I and 2.)

Second Manipulation.-The glands are pressed together from the side. The fore quarters are milked each by itself by placing one hand, with fingers spread, on the outside of the quarter and the other hand in the division between the right and left fore quarters : the hands are pressed against each other and the teat then milked. When no more milk is obtained by this manipulation, the hind quarters are milked by placing a hand on the outside of each quarter, likewise with fingers spread and turned upward, but with the thumb just in front of the hind quarter. The hands are lifted and grasp into the gland from behind and from the side, after which they are lowered to draw the milk. The manipulation is repeated until no more milk is obtained. (See Plate XV, Figs. 3-5.)

Third Manipulation.-The fore teats are grasped with partly closed hands and lifted with a push toward the body of the cow, both at the same time, by which method the glands are pressed between the hands and the body; the milk is drawn after each three pushes. When the fore teats are emptied, the hind teats are milked in the same manner. (See Plate XV, Fig. 6.) 


\section{Standardizing Milk}

It may be desirable to produce a milk standardized to contain a fixed and constant percentage of fat. This is particularly important for infant feeding. Or one may wish to supply a milk of unusual and definite richness; or again one may want to combine two lots of cream of different fat percentages to obtain a cream of definite percentage.

A very simple method of determining what amount of any given two lots of milk or cream, varying in richness, is required for combination to obtain a milk or cream of definite fat percentage is given below. This method of standardizing milk was devised by Prof. R. A. Pearson, of Cornell University.

One should construct a figure like the accompanying cut, and in the

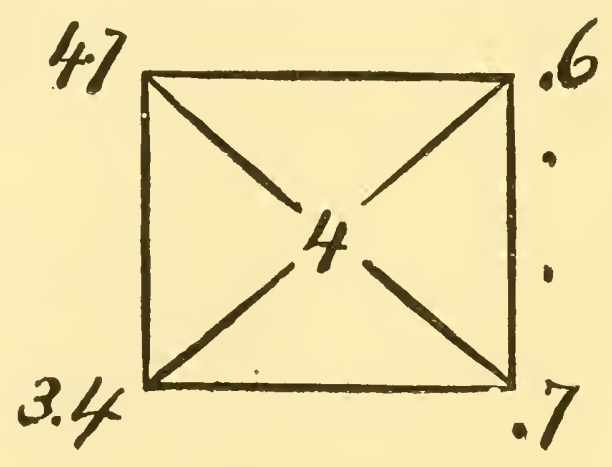

two left hand corners write the percentages of fat in the two lots of milk (or cream and milk, or two lots of cream, as the case may be).

In the centre, place the percentage of fat required. At the right hand corners write numbers which will be the differences between two numbers with which they stand in line.

Thus: If 4.7 and 3.4 are the percentages of fat in two lots of milk-and it is desired to make a mixture containing four per cent. of fat-subtract 4 from 4.7 and place the result $(.7)$ at the lower right hand corner. Subtract 3.4 from 4 and place the result (.6) at the upper right hand corner.

The result shows that it will take six parts of 4.7 per cent. milk, and seven parts of 3.4 per cent, milk, to make a standard four per cent. milk. 


\section{A New Method of Stable Ventilation.}

Quite recently there has come into existence a new system of ventilating barns by means of windows covered with cheap cotton cloth. No method could be simpler or less expensive and the results thus far reported have been very favorable.

Thus Ellis M. Santee, of the Dairy Department of Washington, D. C., writing in Hoard's Dairyman of May I 7 th, I907, records some couclusions from exhaustive experiments with cloth ventilation as compared with the King system. He affirms that even with the thermometer registering 43 degrees below (zero, presumably), water never froze in the barn with cloth-covered windows. Also that the difference in temperature in barns with cloth-covered windows and in those with all glass windows was but I to 3 degrees. Moreover, in the stables ventilated with cloth-covered windows, the humidity was 7 to Io per cent. lower than in the barns ventilated by the King system. Finally ho records the fact that many good dairymen have closed the outlets and inlets of their King system to give place to the cloth curtain method. Glass windows should be alternated with clothcoverech openings, the proportion being $3 \mathrm{sq}$. $\mathrm{ft}$. of glass and $2 \mathrm{sq}$. ft. of cloth-covered openings for each $\mathrm{I}, 000 \mathrm{lbs}$. of animal. The cloth slould be muslin of the first grade better than cheesecloth, costing 5 to 6 cents par yard.

\section{Method of Keeping Accounts of the Pure Milk Dairy}

(Sce the following three forms.)

MAPLEWOOD FARM

Daily Milk Report

Empty cases received last train.

Bottles sliort last train . . . ..........

Bottles broken when received . ..........

Bottles broken at farnir . . . .........

Cases milk shipped to-day. . , ,................. Qts. 
Explanation.-The foregoing report is signed by the manager at the farm. It shows the number of empty cases (holding 12 quart bottles) received from the city and the number of bottles broken and missing in them. Also the number of full cases shipped to the city.

Driver.

Route No.

\begin{tabular}{|c|c|}
\hline MILK RECEIVED & CASH ACCOUNT \\
\hline Received from ..........Ry & PaID on Account \\
\hline Cream & $\ldots \ldots \ldots \ldots \ldots \ldots \ldots$ \\
\hline Quarts Gals. Pints 1/2 Pints & 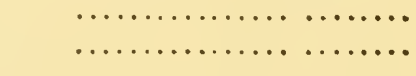 \\
\hline DELIVERED & 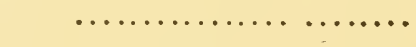 \\
\hline $\begin{array}{l}\text { Milk } \\
\qquad \text { Quarts............. }\end{array}$ & 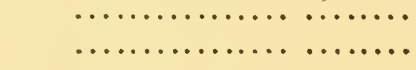 \\
\hline $\begin{array}{l}\text { Cream } \\
\quad \text { Pints............... }\end{array}$ & 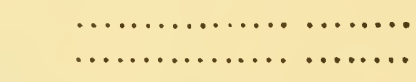 \\
\hline $\begin{array}{r}1 / 8 \text { Pints.......... } \\
\text { RETURNED }\end{array}$ & 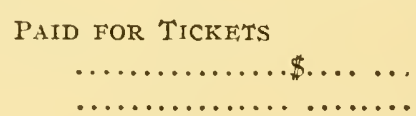 \\
\hline $\begin{array}{l}\text { Milk } \\
\quad \text { Quarts............ }\end{array}$ & ……… \\
\hline $\begin{array}{l}\text { Cream } \\
\quad \text { Pints.............. } \\
\quad 1 / 2 \text { Pints........... }\end{array}$ & $\begin{array}{l}\cdots \cdots \cdots \cdots \cdots \cdots \\
\cdots \cdots \cdots \cdots \cdots\end{array}$ \\
\hline $\begin{array}{l}\text { Bottles Delivered.... } \\
\text { Bottles Returned..... }\end{array}$ & $\begin{array}{l}\text { Cash Receipts..\$....... } \\
\text { Total,....\$...... }\end{array}$ \\
\hline
\end{tabular}

This blank is filled out daily by the driver of each delivery wagon . and represents, first, the amount of milk and cream received from..... railway; second, the amount of milk and cream delivered to customers; third, the amount of the same brought back to the store; fourth, the bottles delivered to and returned by customers; and fifth, the cash paid for accounts due or tickets, 
III.

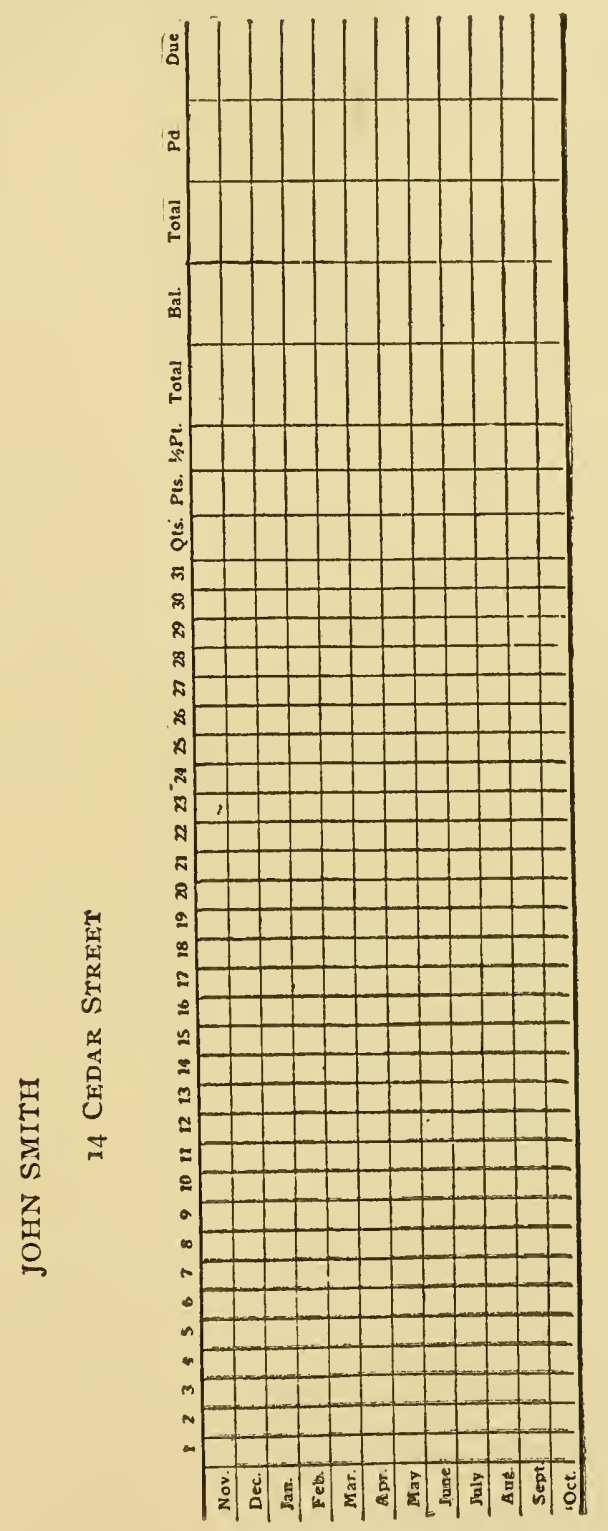

This form represents a loose card, one of which is devoted to each customer for a year. The day's sales of the drivers of the milk wagons are copied off their books each day and kept in the office of the city dairy in this form. 


\section{A General Outline of a Scheme for the Control, Supervision and Inspection of a City Milk Supply}

The legal control of a city milk supply is in the hands of the City Board of Health. The State Board of Health should, however, work in coöperation with the City Board through its jurisdiction orer the territory from which the milk is obtained. When the milk is drawn from several states this is, of course, of but slight value. Moreover, state supervision is not essential, since the city authorities can enforce sufficient influence over the producer of unsanitary nilk in the following ways: By condemning such when it arrives in the city; by warning or fines; by revoking the license of the dealer in the same in the city; and by requiring that the premises on which the milk is produced be inspected before the milk can be sold in the city.

Supervision of a milk supply must begin at the barn and be continued until the milk reaches the consumer. Thus milk nust be inspected at the following points :

I. At the farm.

2. During transportation from the farm to the R.R. or creamery.

3. At the creamery, when this is the shipping point.

4. On the cars during transportation to the city.

5. At the city R.R. or receiving station.

6. On the wagon in the city.

7. At the city dairy, hotel, restaurant, retail store and home of the consumer.

The country furnishing milk must be mapped, the farms and creameries from which milk is shipped must be plotted, and the territory divided into districts, each under the supervision of an inspector living in the region. It has been recommended that there be one inspector to each roo farms. At present New York City has about 100 inspectors ( 1907 ) to supervise some thirty to forty thousand farms in six states and shipping milk into the city from points four hundred miles distant. No milk slould be pernitted to enter a city until the seal of inspection lias been first placed upon it by an inspector in the country. 
When milk is shipped from creameries or country receiving stations these form convenient points for inspection and also serve as a base for investigation of the farms supplying the creameries. At the creaneries the following demand looking into: (I) The cleaning and sterilization of all utensils; (2) the water supply and drainage; (3) the temperature at which milk and cream are kept; (4) general cleanliness, requiring the absence of flies and dust.

The farms need inspection in regard to the ensuing matters: Cleanliness of the cows, milkers and other employees; of the barn, milk house, utensils and surroundings; the health of the employees and cows, with especial attention to infectious diseases in the former, and to tuberculosis and udder disease (garget) in the latter; the kind of food given to cows (avoidance of swill, fermented brewers' grains and distillery slops, etc.) and time of feeding; the purity of water and ice supply, ventilation of barus, removal of manure, drainage of premises, and methods of milking and handling and cooling milk. Also the method of storing and caring for milk and hauling it to the R.R. or creamery; and the care of the milk room, especially with regard to the absence of dust and flies.

Inspections of creameries and farms should be made once a month at least, and reports should be rendered in quadruplicate, one of which should be sent to the city office, one to the farmer, one to the retail dealer selling the milk, and one to be retained on file in the local office in the country. This suggestion was made by Dr. Goler, of Rochester, N. Y., who also recommends, in case the territory supplying a city is "large, the establishment of one or more laboratories in the country as sub-stations for the work of milk inspection. This might be conveniently carried out in connection with creameries.

Country inspectors should not only perform their police duties, but should act as teachers and should talk and distribute printed matter concerning everything which relates to the production and care of sanitary milk.

The plan adopted by the Massachusetts Board of Health, in publishing a monthly list of well conducted and cleanly farms, is to be commended. Goler urges the establishment of model dairy farms by the state in connection with the laboratory substations in the country, 
the scheme comprising the remodeling of some old and run-down farm, so that in its upbuilding the farmer could apply the same measures to his own premises.

In regard to the carriage of milk on the railroad, railways carrying milk to the large cities of the country now supply refrigerator cars for milk, with adequate icing facilities to cool milk below $50^{\circ} \mathrm{F}$, in most cases. When such refrigerating arrangements are not obtainable, milk and cream should be shipped as advised on p. 87.

Inspection on the cars is limited to taking the temperature of milk. At the receiving station in the city there must be daily inspection with reference to the temperature of milk, to the care of cans and bottles of milk while en route, and to the condition of empty bottles and cans which are being returned. The inspector shall here exanine milk by sight, smell and taste, and by lactometer and lactoscope (if such be the custom), and take samples for laboratory examination. According to the writer's views, the only accurate testing which should be done by the collectors of samples is that of temperature taking. Testing for the solids and fat and for adulteration and bacterial content can be done much more accurately at the laboratory.

During distribution of milk by wagon in the city, inspection is desirable to ascertain that the milk is properly iced in warm weather, that the temperature of the milk is kept below $50^{\circ} \mathrm{F}$., that bottling of milk is not done on the wagon, and that general cleanliness of utensils and wagon is observed. Samples of milk should be taken from each wagon at least once a month for laboratory examination.

A sample of milk should be taken from each retail store every month. Milk in the various stages of transportation from cow to consumer becomes more germ-laden through age and handling, especlally when poured from one utensil to another, and the case of the retail shop is the worst. This has been strikingly shown by Prof. J. O. Jordan, of Boston. The legal limit for bacterial content in Boston is 500,000 germs to the c.c. The milk during 1906, in respect to this standard, was found to be distributed as follows: On the cars, on arrival, 90 per cent. under germ standard (i.e., containing not less than 500,000 bacteria); on the wagons, 50 per cent. 
under germ standard; in the retail stores, is per cent. below germ standard. Such a difference between the quality of milk on arrival and subsequently does not occur in milk bottled at the farm, cooled immediately below $50^{\circ} \mathrm{F}$. and kept at that point all the time until it reaches the store customer. Only bottled nilk should be sold in stores, and the bottling should be done at the farm or, less favorably, at the creamery or city dairy. Inspection at stores must enforce requirements for a proper refrigerator and cooling of the 111ilk, and also that the store be apart from dwelling rooms.

In the inspection of city dairies, stores, hotels and restanrants, the proper cleaning of empty cans and bottles should receive special attention. In many cities an ordinance requires that milk cans and bottles must be thoroughly cleaned or sterilized before their return to the farm or creamery. Also an ordinance should forbid using utensils employed for transporting milk and cream as receptacles for any other material whatsoever. Jordan notes that broken eggs, coffee, oil, chocolate, molasses, blood, and, above all, kerosene, are not infrequently discovered in milk cans.

At each city dairy the cleanliness of premises and milk utensils, the purity of the water supply, and the facilities and method of cooling milk and cream should be the subjects of inspection. Samples of milk should be taken from the city dairy at least once monthly.

Inspection of milk at hotels and restaurants should be directed toward enforcing the ordinances as regards temperature of milk, cleanliness of utensils and the sale of skim milk. Samples should be taken once a month from hotels and restaurants.

The proper care of milk after it has reached the consumer is the most difficult matter of control and can only be managed by general education of the public. The Board of Health, through its monthly bulletins, and those selling clean milk may supply the public with information on the subject, and consumers should be fined for not returning empty milk bottles or cans properly cleaned.

Jordan points out another objection to the popular desire for the early arrival of milk we have noticed (p. I25): that milk left on the doorstep in the early morning hours of summer may be heated by the sun to an injurious degree. At this place it may not be out of 
orcler to note that the forms furnished by the City Board of Health to physicians for compulsory reports of infectious diseases should require the name of the milkmau supplying each infectious case reported. In Boston the wholesale milk dealers are exceptionally progressive. They assist the health aththorities by taking the temperature of milk consigned to them, by straining milk to discover dirt, by cleaning empty cans; while six dealers (I907) have actually installed bacteriological laboratories for their own use (Jordan).

A sufficient number of inspectors or collectors of sanples in cities may require one to each 50,000 of population. In addition to the duties described above, the city inspector should examine the premises of applicants for a city license to sell milk, before one may be issued.

The City Board of Health should publish in a monthly report the names of each dairyman, dividing them into four categories: those selling Certified, Inspected, Ordinary Market and Pasteurized milk; and should report the number of bacteria in each. Also notice of any dairyman who has been found guilty of infractions of any of the ordinances pertaining to milk should be thus publicly announced.

A. D. Melvin, Chief of the Bureau of Animal Industry, suggests that the following division be made of the milk composing a city supply : I. Certified milk. 2. Inspected milk from tuberculin-tested cows housed, fed and milked under good conditions with a maximum content of 100,000 germs per c.c. the year round, and shipped in sterilized containers at the farm at a temperature below $50^{\circ} \mathrm{F}$. 3. All other milk should be pastenrized (as soon as practicable after milking at $\mathrm{I} 54^{\circ} \mathrm{F}$. for twenty minutes), cooled immediately and sold in sterilized containers at a temperatıre below $50^{\circ} \mathrm{F}$. 


\section{INDEX}

Acidity of milk, test for ....... 138

of pasteurized milk... . ... ${ }_{13} \mathrm{~S}$

Air space in barn............. $5^{8}$

Analysis, quantitative, of bacteria I 49, I6 I

Anthrax affecting milk ........ 20

Albumin of milk ............. 24

Ayrshire cows............... 169

Babcock test for fat in milk... I4 I, I46 Bacteria, see Germs. analysis of milk for..... 149, 16r

Balanced rations, selection of.... 49 specimens of ............ 5 I

Barn dust................ 66

floors.................... $5^{8}$

plans of............. I78-r 87

ventilation of ........ 59,195

Barns.................. 57

Beasiings ............... 30

Bedding ................ 67

Bitter milk............... I8

Blue milk................ Is

Bookkeeping, city milk route... 195

Borax in milk.............. 136

Boric acid in milk........... I 36

Bottle boxes ............... 127

brushes............... 93

filler............... 89

washer............... 95

Bottled milk, cooling......... 84

Bottles, milk............... I04, 105 to prevent loss of.......... I 29

Bottling milk............... 96 96 utensils for............ 87

Brown milk............... Is

Brushes for cleaning milk utensils.................87.94

Burrell-Lawrence milking machine 189
Butter, action of gernis 0 Page composition of .........43, I IS fat, how to pay creamery pa-

trons for............. 120

flavor................ 37

from fresh cream.........3S, 4 I

skim milk............ 43

making, losses irs........ II 9-122

making, overrun in ...... I 19

milk, composition of...... 43

Budde's process of sterilizing milk IS8 Bye-products of milk......... 44

Caps for milk bottles.......... I30

Carriers for milk bottles....... 102

Cars for milk............... I0 3

Certified milk, circular describing I3 I cost of.............. II4 how to begin sa'e of....... II7 price of ............. II6 New York requirements .... 16I standard and origin of..... 16

Cheese, action of germs on..... 2 composition of .......... 43 hard............... $4 \mathrm{I}$ making............. $4 \mathrm{I}$ ripening $\ldots \ldots \ldots \ldots \ldots \ldots, 4 \pi$ soft............... 4 r

Clrolera, infecting milk....... 2I

Cleaning cows............. 70 utensils............. 85

Cloth ventilation of barns........ I95

Clothing for milk room........ 98

Colostrum................ 30, 135 as source of disease....... 3I

Commercial starters, Harrington's 39

Composite samples of milk..... I77

Composition of butter......... 43 butttermilk ............. 26 cheese............... $\varepsilon_{4}$ 


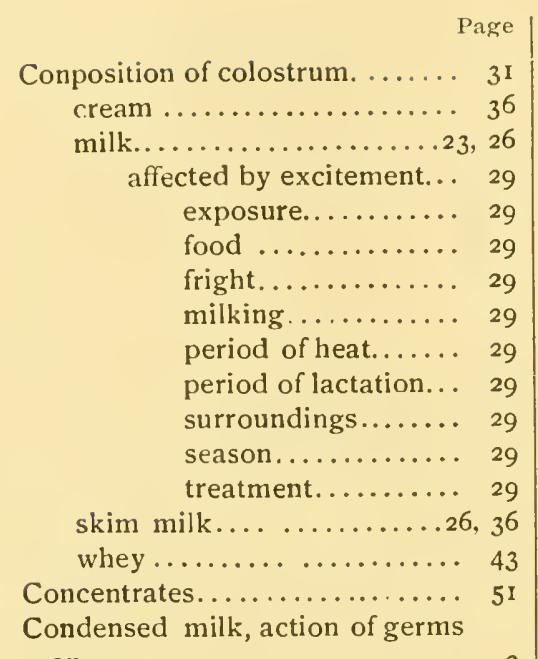

on .................... 2

Coolers, milk.............7I-83

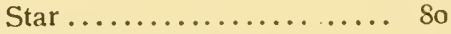

tubular............... 8o

Cooling bottled milk......... 84

of milk.............. 77

Cost of certified milk.......... I I4

Cow, annual cost of.......... II 3

Ayrshire............. 169

care of.............. 69

census ............. IIo, II I

for milk............. 169

dairy, characteristics of..... I 69

dehorning ............ I 74

grooming............. 70

Guernsey.............. I69

Holstein ............... I69

Jersey ................. 169

number of in barn........ 59

pox, affecting milk........ 20

profits................ I Io

rations............... I74

records............... I73

how to keep ......... I76

returns from........... I Io

standard for............ I 12

stall ................ I 77

value of.............. I 77

Cream, acidity of for butter..... I 139

bottling.............. 108

conditions favoring rising.... 33

dipper for removing........ I 32

set, germs in.......... 37
Page

Cream per cent. of solids in .... 36

ripening of ........... 37

separation of........... 107

starters.............. 39

thickeners........... I08, I40

whipping.............. Io9

Culture media for bacteriological

analysis................. I49

Curdling of milk ........... 25

Dairy, arrangement of. . . . . . 99-102 cows................ 169 routine................ 96

utensils, washing of. ...... $9^{9}$

Dehorning cows............. I74

Diarrhea of infants from milk.... 22

Diphtheria infecting milk...... 2 I

Drivers' uniform ............ I 3 I

Dust in barn ............. 66

milk room ............ 76

Dysentery infecting milk ...... 2 I

Ensilage affecting milk....... 54

Farrington's acidity test........ I $5^{8}$

Farrington on starters ........ 39

Fat of milk............... 25

Fat in milk and cream, test for, $14 \mathrm{I}-\mathrm{I} 46$

Feeding, balanced ration for.... 49 concentrates ............ 5 I

Haecker's rules for........ 50

for milk............... 46

of silage ............. 54

in relation to milking ...... 54

roughage .............. 5 I

specimen ration for........ 5 I

Fishy milk. ............85, 135

Flies in barn ............. 66

spray for on cows......... 66

Food, influence on lactation period 47 imparting flavor to milk .... 56 imparting taste to milk ..... 54

Foot and mouth disease affecting milk................ 20

Formaldehyde in milk........ I36

Freezine................ ro

Gelatine in milk............ I4I

Garget affecting milk.......... 20

Germs, acids and alkalies affecting 6 
Germs, action on butter, cream, cheese, milk, condensed milk. action of temperature on ... causing flavor of butter...... 38 characters of.............. 3 conditions of growth....5, I7-1S in barn................. 67 in filtered milk.......... 35 in cheese ripening, ....... 42 in market milk........... I7 in separated cream......... 35 influence on milk and products 12 lactic acid............... I3 action on man.......... I3 flavoring butter \& cheese I3 miscellaneous............. I5 flavoring butter......... 38 moisture affecting growth of. 6 multiplication of........... 4 number present in clean milk II of butyric acid............ Is of disease in milk.......... 15 of tuberculosis in milk...... I9 putrefactive............. I5 significance of, in milk ..... II numbers in milk....... I5 quantity and variety in milk............... I5 sunlight affecting.......... 6 standard for water supply.... 53 temperature affecting growth 5 test for................. $149-16 r$

Green milk ................ I8

Grooming cows............... 70

Guernsey cows.............. I69

Gutters for manure.......... 59

Haecker's rules for feeding..... 50

Heating water.............. 95 for dairy .............. $8_{5}$

Hegelund method of stripping cows.................... I92

Holstein cows.............. 169

Iceline..................... Iо

Infant mortality ............. 22

Inspected milk, New York requirements.................. I 65 Inspection of milk............ I 34 Jersey cows.............. I69
Keeping qualities of milk King system, ventilation. ........ 59

Lactation period of cows ....... 29 increased by feeding....... 47

Lactic acid germs............ I3 action on man............ 13 in fermentation of milk..... 24 flavoring butter and cheese, 13,38 killing other germs......... I3

Lactometer ............... I 46

Machine, milking........... 189 Manure, removal of from barn ... 66 trench ............... 59

Market milk, germs in ........ I7

Miscellaneous germs ........... I5

Modified milk, for infants....... I 137

Milk acidity, test for.......... 137 action of temperature on..... I4 adulterated with borax...... 136 adulteration, boric acid...... I 136 formaldehyde, or freezine 136 salicylic acid......... 137 sodium carbonate ....... 137 as a source of infant mortality 22 as a source of diarrhea...... 22 as a source of cholera infantum 22 bacteria, analysis of.....149-16I bad odor of............. I 35 bad taste of............. I35 bitter................. Is blue.................. 18 bookkeeping for city route... 195 bottle................. 104 caps.............. I30 carriers............. 102 cars ................. 103 shipping cases......... I03 to prevent loss of....... I 29 bottling of .............. 96 utensils for........... $8_{7}$ boxes, for bottles......... 127 brown ................ Is bye products in manufactures 44 certified................. I6 certified, cost of............ II 4

N. Y. requirements for .. 16I

price of.. ........... II 6 composite samples of...... I77 
Milk, composition of......... 23

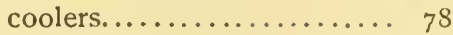
cooling of. .......... 77 condensed, action of germs on 2 curdling of............. 25

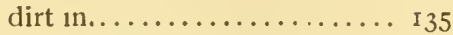
dirty, a source oftyrotoxicon 22 during tuberculin test....... 56 fat................... 25 test for............ I4 I-I46 feeding affecting composition of................ 46 feeding for ............. 46 fever, affecting milk........ 20 treatment of......... 69

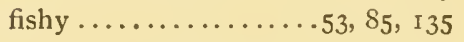
from silage............ 54 formation in udder ........ 46 green. ............... Is hints in delivery........... I29 house, arrangements of..... 99 plans of ........... I $78-187$ in anthrax............. 20 in cow $\operatorname{pox} . . . \ldots \ldots \ldots . . .20$ foot and mouth disease. . 20 garget.............. 20 milk fever............ 20 pleuropneumonia ...... 20 inspected, N. Y. requirements 165 inspection.............. I 34 keeping qualities of........ I4 modified for infants......... I3 [ pails...................73-74 pasteurized ..........7-I0, 187 preservatives............ Io tests for.......... 336 , I 37 proteids............... 24 pus in, test for............ I60 records.............. II 2,176 red $\ldots \ldots \ldots \ldots \ldots \ldots \ldots$ I8 returns from selling in various

forms ............. 123 room $\ldots \ldots \ldots \ldots \ldots \ldots \ldots \ldots, 75$

utensils for........... 76 samples............ I35, I 36 siphon for removing from bottle................ I 32 skim, food value of........ 43 test for............. I4I slimy ................ I8
Milk soapy................. Is solids, estimation of........ 146 souring of. ........... 24 standard for cow......... I 2 standardizing ............ I94 sterilizing, Budde's process.. I88 sterilizers for utensils. ...... 89 stirrer ............... 97 strainer.............. 84 stringy ............. 8 , I35 strippings............. 27 sugar............... 24 sweet................ Io time of delivery .......... I 26 utensils, washing......... 93 wagons.............. I 27 watered, test for ......... I 4 I yellow ............... Is Milkers, cleanliness of........ 7 I Milking............... 7 I as affecting composition of milk................ ${ }_{2} S$ in relation to feeding ...... 54 machine............. I89

Overrun ................ I 18 how to estimate.......... II9

Pails, milk...............73-74

Paper milk bottle ............ I05

Pasteurized milk..........

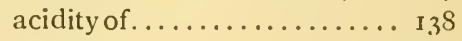
test for............... 137

Plans of barns............ I78-1 87 Pleuropneumonia affecting milk. . 20 Preservatives............... Io tests for............... I36 Price of certified milk ........ I 6 Proteids in milk............ 24 Putrefactive germs ........... I5

Records of cows............ 176 of milk............. 12,176 Red milk................. I8 Room, milk.............. 75 Roughage $\ldots \ldots \ldots \ldots \ldots \ldots \ldots$ I 5

Salicylic acid. ............. I 137 Scarlet fever infecting milk ..... 2 I Separation of cream.......... I07 
$\begin{array}{rr} & \text { Page } \\ \text { Separation, removing germs..... } & 35\end{array}$ removing dirt............ 35

Separator cream............. 34 slime ............... 34

Separators, management of..... 175

Shipping cases........... I0 $3-104$

Skim milk, food value of ...... 43 test for................ 14 I value of................ 124

Slimy milk................. Is

Smallpox infecting milk ....... 2 I

Soapy milk ................ is

Sodium carbonate in milk ...... I 137

Solids in milk............... I46

Souring of milk ............ 24

Stalls....................65, $5^{8}$

Stanchions ................ 65

Standardizing milk........... I94

Star cooler................. so

Startolene ................. 40

Starters, natural and commercial. 39

Sterilizers................. 89

Straining................., 84

Stringy milk............. I35, I8

Stripping cows, Hegelund method 192 Strippings of milk........... 27

Sugar of nilk.............. 24

Temperature affecting milk..... I4 Test, acidity of milk......... I 37 for gelatine $\ldots \ldots \ldots \ldots \ldots \ldots$ I4 $\mathrm{I}$
Test for preservatives in milk ... I $33^{6-7}$ for pus in milk ... ........ 160 for viscogen in milk ....... 140

Tie-ups.................. 65

Tuberculin test..........20, 56, 69

Tuberculosis. germs of in milk .. 19

Tubular coolers.............. so

Typhoid fever infecting milk.... 2 2 ז

Tyrotoxicon in milk........... 22

Utensils, cleaning ........... $8_{5}$ in milk room............ 76

Ventilation of barns......... 59, 195

King system of.......... 59

Viscogen in milk............ เo8, I40

Wagons, milk............. 27 I

Washing dairy utensils ......... 98 milk utensils............ 93 sink ................ 94

Water, germ standard for....... 53 for dairy use ........... $2 \mathrm{I}$ heating.............. 85,95

Watered milk, test for......... I4 I

Water supply............... 53

Water, stagnant, in pastures. ... 53

Whey, composition of........ 43

Whipping cream............ I09

Yellow milk .............. I8 



\title{
catalocue of
}

\section{William R. Jenkins Co.'s}

\author{
Works Concerning
}

\section{HORSES, CATTLE, SHEEP, SWIME, Ełc.} 1908

(*) Designates New Books.

(†) Designates Recent Publications.

ANDERSON. "Vice in the Horse" and ouler papers on Horses and Riding. By F. L. Anderson. Size, $6 \times 9$, cloth, illustrated.................. 75

ARMSTEAD. "The Artistic Anatomy of the Horse." A brief description of the varions Anatomical Structures which may be distinguished during Life through the Skin. By Hugh W. Armstead, MI.D., F.R.C.S. With illustrations from drawings by the author. Cloth oblong, $10 \times 12 \frac{1}{2} \ldots \ldots \ldots \ldots \ldots \ldots \ldots \ldots \ldots \ldots$

$\boldsymbol{B} \boldsymbol{A} \boldsymbol{C H}$. " How to Judge a Horse." A concise treatise as to its Qualities and Soundness; Including Bits and Bitting, Saddles and Saddling, Stable Drainage, DrivIng One Horse, a Palr, Four-in-hand, or Tandem, etc. By Capt. F.W. Bach. Size, $5 \times 7 \frac{1}{2}$, clo., fully illus. 100

BANHAM. "Tables of Veterinary Posology and Thera. peutics," with weights, measures, etc. By Geo. A. Banham, F. R. C. V.S. New edition. Cloth, size $4 \times 51-2,192$ pages..................... 00

BAUCHER. "Method of Horsemanship." Including the Breaking and Training of Horses. By F. Baucher..........................

BELL. (*)"The Veterinarian's Call Book (Perpetual)," By Roscoe R. Bell, D.V.S., editor of the American Veterinary Review. Completely revised 1907.

A visiting list, that can be commenced at any time and used until full, containing much useful information for the student and the busy practitioner. Among contents are items concerning: Prescription writing; Veterinary Drugs; Poisons; Solubility of Drugs; Composition of Milk,Bile, Blood, Gastric Julce, Urine, Saliva; Respiration; Dentition; Temperature, etc., etc. Bound in flexible leather, with flap and pocket.......................... 125 


\section{BITTING. "Cadiot's Exercises in Equine Surgery."}

See "Cadiot."

BRADLEY. "Outlines of' Yeterinary Anatomy." By O. Charnock Bradley, Member of the Royal College of Veterinary Surgeons; Professor of Anatomy in the New Veterinary College, Edinburgh.

The author presents the most important facts of veterinary anatomy in as condensed a form as possible, consistent with lucidity. $12 \mathrm{mo}$.

Complete in three parts.

PART I.: The Limbs (cloth)................ 125

PART II.: The Trunk (paper).............. 25

PART III,: The Head and Neck (paper).............. 125

The Set complete ...................... 325

CADIOT. "Exercises in Equine Surgery." By P. J. Cadiot. 'Translated by Prof. A. W. Bitting, D. V.M. Edited by Prof. A. Liautard, M.D.V.M. Size, $6 \times 9 \frac{1}{4}$. eloth, illustrated..................... 250

- "Roaring in Horses." Its Pathology and Treatment. This work represents the latest development in operative methods for the alleviation of roaring. Each step is most clearly defined by excellent full-page illustrations. By P. J. Cadiot, Professor at the Veterinary School, Alfort. Translated by Thos. J. Watt Dollar, M.R.C.V.S., etc. Cloth, size 5 1-4 x 7 1-8, 77 pages, illustrated........................ 75

- "Studies in Clinieal Veterinary Medicine and Surgery." By P. J. Cadiot. Translated, edited, and supplemented with 49 new articles ard 31 illustrations by Jno. A. W. Dollar, M.R.C.V.S. Cloth, size 7 × $93-4,619$ pages, 94 black and white illustrations..............5 25

-(*)" A Treatise on Surgical Therapentics of the Domestic Animals." By P. J. Cadiot and J. Almy. Translated by Prof. A. Liantard, MI,D., V.M.

I. General Surgery.-Means of restraint of animals, general anæsthesia, local anæthesia, surgical antisepsis and asepsis, hematosis, eauterization, firing,

II. Diseases Common to all Tissues.-Inflammation, abscess, gangrene, ulcers, fistula, foreign bodies, traumatic lesions, complications of traumatic lesions, granulations, cicatrices, mycosis, virulent diseases, tumors.

III. Diseases Special to all Tissues and Affections of the Extremities. -Diseases of skin and cellular tissue, of serous bursae, of muscles, of tendons, of tendinous svnovial sacs, of aponeurosis, of arteries, of veins. of lymplatics, of nerves, of bones, of articulations.

Cloth, size $6 \times 9,580$ pages, 118 illustrations.....450

CHAPMAN. "Manual of the Pathological Treatment of lameness in the Horse," treated solely by mechanical means. By George T. Chapman. Cloth, size $6 \times 9,124$ pages with portrait............200 
CLARKE. "('liart of the Feet and Teeth of Fossil IIorses." By W. H. Clarke. Card, size 9 1-2 x 12. 25

- "Horses" Teeth." Fourth elition, re-revised, with second appenclix. Cloth, size $51-4 \times 71-2,322$ pp., illus..2 50

CLEAVELAND. " "rononncing Medieal lexicon." Pocket mlition. By C H. Cleveland, M.D. Cloth, size $31.4 \times 41-2,302$ pages............... 75

CLIMINT. "Veterinary Post Mortem Examinations." By A. IV. Ciement, V.S. The absence in the English lantruage of any guide in making antopsies upon the lower animals, incluced Dr. Clement to write this book, trusting that it would prove of practical value to thes profession. Cloth, size $5 \times 71 \% 2,64$ pares, illustrated....................... 75

COURTENAI. (†) "Mammal of the Practice of Veterinary Medicine." By Erlward Courtenay, V.s. Revised by Frederick T. G. Hobday, F.R.C.V.S. Second edition. Cloth, size $51-4$ × $71-2,573$ pages ..........2 75

COX. "Horses : In Accilent and Disease." The sketches introduced embrace various attitudes which have been observed, such as in choking; the disorders and accidents occurring to the stomach and intestines; affection of the brain; and some special forms of lameness, etc. By J. Roalfe Cox, F.R.C.V.S. Cloth, size $6 \times 9,28$ full page illustrations. . . . . . . . 50

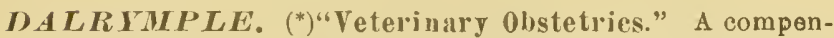
dium for the use of advanced students and Practitioners. By W. H. Dalrymple, M. R. C. V. S., principal of the Department of Veterinary Science in the Louisiana State University and A. \& M. College; Veterinarian to the Louisiana State Bureau of Agriculture, and Agricultural Experiment Stations. Second edition revised. Cloth, sire $6 x 91-4,162$ yages,

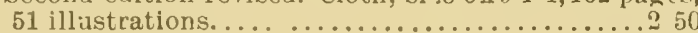

DALZIEL. "Brenking and Training Dogs." Part I, by Pathfinder. Part II, by Hugh Dalziel. Clnth,

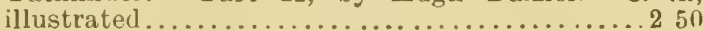

- "The Collic." By Hugh Dalziel. Paper, illustrated.... 50

— "The Diseases of Dogs." Causes, symptoms and treatment. By Hugh Dalziel. Illustrated. Paper, 50c. Cloth, 1 ro

- "Diseases of Horses." Paper .................... 50

— "The Fox Terrier." By Hugh Dalziel. Paper, 50; clo.100

_"The Greyhound." Cloth, 1llus.................100

— "The St. Bernarl." Cloth, illustrated....., ......100 
DANA. "Tables in Comparative Physiology." By Prof. C. L. Dana, M.D. Chart, 17 × $17 \ldots \ldots \ldots \ldots . .26$

DANCE. "Veterinary Tablet." By A. A. Dance. Chart, $17 \times 24$, mounted on linen, foldtd in a cloth case for the pocket, size $33-4 \times 6$ 1-2. Shows at a glance the Eynopsis of the diseases of horses, cattle and dogs: with their cause, symptoms and cure...........75

DE BRUIN. (*) "Bovine Obstetrics." By M. G. De Bruin Instructor of Obstetrics at the State Veterinary School in Utrecht. Translated by W. E. A. Wyman, formerly Professor of Veterinary Sclence at Clemson A. \& M. College, and Veterinarian to the South Carolina Experiment Station. Cloth, size $6 \times 9,382$ pages, 77 illustrations................... 00

\section{Synopsis of the Essential Fentures of the Work}

1. Authorized translation.

2. The only obstetrical work which is up to date.

3. Written by Europe's leading authority on the subject.

4. Written by a man who has practiced the art a lifetime.

5. Written by a man who, on account of his eminence as bovine practitioner and teacher of obstetrics, was selected by Prof. Dr. Frohner and Prof. Dr. Bayer (Berlin and Vienna), to discuss bovine obstetrics both practically and scientifically.

6. The only work containing a thorough differential djar:nosls of ante and post partum diseases.

7. The only work doing justice to modern obstetrical surgery and therapeutics.

8. Written by a man whose practical suggestions revolutionized the teaching of veterinary obstetrics even in the great schools of Europe.

9. The only work dealing fully with the now no longer obscure contagious and infectious diseases of calves.

10. Absolutely original and no compilation.

11. The only work dealing fully with the difficult problem of teaching obstetrics in the colleges.

12. The only work where the practical part is not overshadowed by theory.

A veterinarian, particularly if his location brings him in contact with obstetrical practice, who makes any pretence toward being scientific and in possession of modern knowledge upon this subject. will not be without this excellent work, as it is really a very valuable treatise.-Prof. Roscoe $R$. Bcll, in the American Veterinary Review.

In translating into English Professor De Brnin's excellent textbook on Bovine Obstetrics. Dr. Wyman has laid British and A merican veterinary surgeons and students under a debt of gratitude. The works represents the happy medium between the booklets which are adapted for cramming purposes by the student, and the ponderous tomes which, although useful to the teacher, are not exactly suited to the requirements of the everyday practitioner. . We can strongly recommend the work to veterinal'y students and practitioners. - The Journal of Comparative Pathology and Therapeutics.

DOLLAR. (*,6" Diseases of Cattle, Sheep, Goats and Nwine." By G. Moussu and Jno. A. W. Dollar, M.R.C.V.S. Size 6 × 9 1-2, 785 pages, 329 illustrations in the text and 4 full page plates............... 75

- $(\dagger)$ "A Hand-book of Horse-Shoeing," with Introductory chapters on the anatomy and physiology of the horse's font. By Jno. A. W. Dollar, M.R C.V.S., with the collaboration of Albert Wheatley, F.R.C.V.S. Cloth, size $6 \times 81-2,433$ pages, 406 illustrations .. 475 
DOLLAR (continued)

- $(\uparrow)$ "Operative Techuique." Volume 1 of "The Practice of Veterinary Surgery." Cloth, size 6 3-4 x 10, 264 pages, 272 1llustrations......................... 375

- "General Surgery." Volume 2 of "The Practice of Veter. inary Surgery." In preparation.

- $(\dagger)^{66}$ Regional Veteriuary Surgery." Volume 3 of "The Practice of Veterinary Surgery." By Drs. Jno. A. W. Dollar and H. Möller. Cloth, size 6 1-2 x 10853 and $x$ vi pages, 315 illustrations.............6 25

\section{- "Cadiot's Clinical Veterinary Medicine and Surgery."}

\section{- "Cadiot's Roaring in Horses." See "Cadiot."}

DUN. "Veterinary Melicines, their Actions and Uses." By Finlay Dun, V.s., late lecturer on Materia Medica and Dietetics at the Edinburgh Veterinary College, and Examiner in Chemistry to the Royal College of Veterinary Surgeons. Edited by James Macqueen, F.R.C.V.S. Tenth revised English editlon.

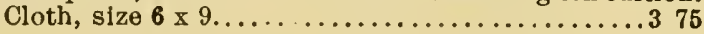

FLEMING. " The Contagious Diseases of Animals." Their Influence on the wealth and health of nations and how they are to be combated. Paper, size $5 \times 71-2$,

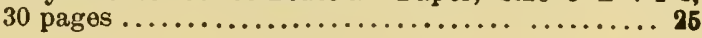

- "Human and Animal Variolse." A Study in Comparative Pathology. Paper, size $51-2 \times 81-2,61$ pages... 25

- "Parasites and Parasitic Diseases of the Domesticated Animals." By L. G. Neumann. Translated by Dr. Fleming. See "Neumann."

- "Operative Veterinary surgery." Vol. I, by Dr. Geo. Fleming, M.R.n.V.S. This valuable work, one of the most practical treatises yet issued on the subject in the English language, is devoted to the common operations of Veterinary Surgery; and the conclse descripfions and directions of the text are illustrated with numerous wood angravings. Cloth, size $6 \times 9$ 1-4, 285 and xviii pages, 343 illustrations............. .2 75 $\left({ }^{*}\right) \mathrm{Vol}$. II, edited and passed through the press by W. Owen Williams, F.R.C.V.S. Cloth, size $6 \times 91-4$. 430 and $x \times x$ vii pages, 344 illustrations........... 25

- "Roaring in Horses." By Dr. George Fleming, F.R C.V.S. Its hlstory, nature, causes, prevention and treatment. Cloth, size 5 1-2 $\times 83-4,160$ pages, 21 engravings, 1 colored plate................. 150

- "Veterinary Obstetrics." Including the Accidents and Diseases incident tu Pregnancy, Parturition. and the Farly Age in Domesticated Animals. By Geo. Fleming. F.R.C.V.S. Cloth, size $6 \times 83-4,758$ pages, lllus.6 25 
GOTTHIEL. (*) "6 A Mannal of General IIistology. By Win. S. Gottheil, M.D., Professor of Pathology in the American Veterinary College, New York; etc., etc.

Histology is the basis of the plyysician's art, as Anatomy is the foundation of the surgeon's science. Only by knowing the processes of life can we understand the changes of disease and the action of remedies; as the architect must know his buildiug materials, so must the practitioner of medicine know the intimate structure of the body. To present this knowledge in an accessible and simple form has been the author's task. Second edition revised. Cloth, size $51-2 \times 8,152$ pages, 68 illustrations...1 00

GIRESWELL. "The Borine Prescriber." For the use of Veterinarians and Veterinary Students. Second edition revised and enlarged, by James B, and Albert Gresswell, M.R.C.V.S. Cloth, size, $5 \times 71-2,102$ pages.............................. 75

- "The Equine Hospital Preseriber." For the use of Veterinary Practitioners and students. Third edition revised and enlarged, by Drs. James B. and Albert Gresswell, M.R.C.V.S. Cloth, size $5 \times 7$ 1-2, 165 pages............................ 75

- "Diseases and Disorlers of the Horse." A Treatise on Equine Medicine and Surcrery, being a contribution to the science of comparative pathology. By Albert, Jas. B. and Gen. Glesswell. Cloth, size 53.4 × 83.4 , 227 lages, illustrated................ 175

- Manual of "The Theory and Practice of Equine Medicine." By James B. Gresswell, F.R.C.V.S., and Albert Gresswell, M.R.C.V.S. Second edition revised. Cloth, size 5 1-4 × 7 1-2, 539 pages...........2 75

- (†) “Veterimary Pharmacopaia and Mamual of Comparative Therapy." By George and Charles Gresswell, with deseriptions and physiolngical actions of medicines, by Albert Gresswell. Second edition revised and ell largerl. Cloth, $6 \times 83-4,457$ pages......... 50

HASSLOCH. "A Compend of Veterinaly Materia Medica and Therapentics." By A. C. Hassloch, V.S., Lecturer on Materia Medica and Therapeutics, and Professor of Veterinary Dentistry at the New York College of Veterinary Surgeons and Schnol of Comparative Medicine, N. Y. Cloth, size 51.4 × $71.2,225$ pages........................... 150

HEATIEI. "The Stock Owner's (tuide." A handy Medical Treatise for every man who owns an ox or cow. By George S. Heatley, M.R.C.V.S. Cloth, size $51-4 \times 8,172$ pages..................... 25 
HILL. (t) The Diseases of the Cat." By J. Woodroffe Hill, F.R.C.V.S. Cloth, size $51.4 \times 71-2,123$ pages, illustrated.......................... 125

Written from the experience of many years' praetice and close pathological researeh into the maladies to which our domesticated feline friends are liablo-a subject which it must be admitted has not found the prominence in veterinary literature to which it is undoubtedly entitled.

- "The Management and Diseases of the Dog." By J. Woodroffe Hill, F.R.C.V.S. Cloth, size $5 \times 71-2$, extra fully illustrated.

HINEBAUCH. "Veterinary Dental Surgery." By T. D. Hinebauch, M.S.V.S. For the use of Students, Prae. titioners and Stockinen. Cloth, size $51-4 \times 8,256$ pages, illustrated..................... vu

HOARE. (*) "A Manual of Veterinary Therapentics and Pharmacology." By E. Wallis Hoare, F.R.C.V.S. Cloth, size $51-4$ × 7 1-t, xxvi plus 780 pages..... 475

HOBDAI. ( $)^{6 / T h e}$ Castration of Cryptorchid Horses and the Ovariotomy of Troublesome Mares." By Frederiek T. G. Hobday, F.R.C.V.S. Cloth, size $53-4$ × 83.4 , 116 pages, 34 illustrations,........ 175

HUNTING. (†) The Art of Horse-shoeing. A manual for Horseshoers. By William Hunting, F.R.C.V.S., ex-President of the Royal College of Veterinary Surgeons. Une of the most up-to-date, concise books of its kind in the English language. Cloth, size $6 \times 91-4$. 126 pages, 96 illustrations................ 100

JENKINS. (*) "Anatomical and Physiological Model of the Cow." Half life size. Composed of superposed plates, eolored to nature, showing internal organs, muscles, skeleton, ote., mounted on strong boards, - with explanatory text. Size of Model opened, $10 \mathrm{ft} . x 3 \mathrm{ft}$. , closed $3 \mathrm{ft} . \times 1 \frac{1}{2} \mathrm{ft} \ldots \ldots \ldots \ldots \ldots . . .1200$

- "Anatomical and Physiological Model of the Horse." Half llfe size. Size of Model $38 x+1$ in....... 12 (1) These models may also be obtained in smaller sizes together with Models of the Dog, Sheep and
Pig.

JONES. (*) "The Snrgical Anatomy of the Horse." By Jno. T. Share Jones, M.R C.V.S. Part I. To be completed in four parts. Each part-paper, $\$ t .25$; cloth, \$5.00. Subscriptions for the four parts, payable in advance, paper, $\$ 15.00$; cloth, $\$ 17.50$. 
KOBERT. "P'ractical Toxicology for Physicians and Students" By Professor Dr. Rudolph Kobert, Medical Director of Dr. Brehmer's Sanitarlum for Pulmonary Diseases at Goerbersderf in Silesia (Prussia), late Director of the Pharmacological Institute, Dorpat, Kussia Translated and edited by L. H. Friedburg, Ph.D. Authorized Edition. Practical knowledge by means of tables which occupy little space, but show at a glance similarities and differences between poisons of the same group. Also rules for the Spelling and Pronunciation of Chemical Terms, as adopted by the American Association for the Advancement of Science. Cloth, $61.2 \times 10,201 \mathrm{pp} . .250$

KOCH. "Etiology of Tuberculosis." By Dr. R. Koch. Trauslated by T. Saure. Cloth, size 6 × $91-4,97$ pages............................ 100

LAMBERT. "The Germ 'Theory of Disease." Bearing upon the health and welfare of man and the domesticated animals. By James Lambert, F.R.C.V.S. Paper, size 5 1-4 × 8 1-4, 26 pages, illustrated....25

LA W. "Farmers' Veterinary Adviser." A Guide to the Prevention and Treatment of Dlsease in Domestlc Animals. By Prof. James Law. Cloth, size $51-4 \times 71-2$, illustrated.................... 300

LIAUTARD. (†)"Animal Castration." A concise and practical Treatise on the Castration of the Domestic Animals. The only work on the subject in the English language. By Alexander Liautard, M.D., V.S. Having a fine portrait of the author. T'enth edition revised and enlarged. Cloth, size $51.4 \times 71-2,165$ pages. 45 illustrations.....................2 00 subject in English veterinary literature.-American Agriculturist.

- "Cadiot's Exercises in Equine Surgery." Translated by Prof. Bitting and edited by Dr. Liautard.

\section{See "Cadiot."}

- "A Treatise on Surgical Therapentirs of the Domestic Animals." By Prof. Dr. P. J. Cadiot and J. Almy. Translated by Prof. Liautard. See "Cadiot."

- "How to Tell the Age of the Domestic Animal." By Dr. A. Liautard, M.D., V.S. Standard work upon this subject, concise, helpful and containing many illustrations. Cloth, size $5 \times 71-2,35$ pages, 42 illustrations........................... 50

- "Lameness of Horses and Disenses of the Locomotory Apparatus." By A. Liautar., M.D.,V.S. This work is the result of Dr. Liautard's many years of experience. Cloth, size $51-4 \times 71-2,314$ pages......2 50 


\section{LIAUTARD (continued).}

- (") "Manual of Operative Veterinary Surgery" By A. Liautard, M.D., V.M. Engaged for year's in the work of teaching this special department of veterinary medicine, and having abundant opportunities of realizing the difficulties which the student who earnestly strives to perfect himself in his calling is obliged to encounter, the author formed the determination to facllitate his acquisition of knowledge, and began the accumulation of material by the sompilation of data and arrangement of memorandum, with the recorded notes of his own experience, the fruit of a long and extended practice and a careful study of the various authorities who have illustrated and organized veterinary literature. Revised edition, with complete index. Cloth, size $61.4 \times 9$, xxx and 803 pages, 563 illustrations.....................5 00

- "Pellerin's Median Neurotomy in the Treatment of Chronic 'Tendinitis and Periostosis of the Fetlock." Translated by Dr. A. Llautard. See "Pellerin."

- "Vade Mecum of Equine Anatomy." By A. Liautard, M.D.V.S. For the use of advanced stu lents and veterinary surgeons. Third edltion. Cloth, size $5 \times 71-2,30$ pages and 10 full page illustrations of the arteries. ............................2 00

- Zundel's “The Horse's Foot and Its Diseases."

See "Zundel."

LONG. "Book of the Pig." Its selection, Breeding, Feedling andManagement. Cloth..........4.00 LOWE. $\begin{gathered}(\dagger)^{66} \text { Breeding Racehorses by the Figure } \\ \text { System." Compiled by the late C. Bruce Lowe. }\end{gathered}$ Editerl by William Allison, "The Special Commlssioner," London Sportsman, Hon. Secretary Sporting League, and Manager of the International Horse Agency and Exchange. With numerous fine illustrations of celebrated horses. Cloth, size $8 \times 10,262$ pages................................ 750

LUDLOW. "Science in the Stable"; or How a Horse can be Kept in Perfect Health and be Used Without Shoes, in Harness or under the Saddle. With the Reason Why. Second Edition. By Jacob R. Ludlow, M.D. Late Staff Surgeon, U. S. Army. Paper, size $41-2$ x $53-4,166$ pages....................... 50

LUPTON. "Horses: Sound and Unsound," with Law relating to Sales and Warranty. By J Irvine Lupton. F.R.C.V S. Cloth, size 6 3-4 $\times 71.2,217$ pages, 28 illustrations..................... 125 
I'FADYEAN, (†) "Anatomy of the Horse." Second edition completely revised. A Dissection Guide. By John M'Fadyean, M.B., B.Sc., F.R.S.E. Cloth, size $6 \times 834,388$ pages, illustrated..........5 50

This book is intended for Veterinary students, and offers to them in its 48 full-page colored plates, 54 illustrations and excellent text, a valuable and practical aid in the study of Veterinary Anatomy, especially in the dissecting room.

- "Comparative Anatomy of the Domesticated Animals." By J. M'Fadyean. Prolusely illustrated, and to be issued in two parts.

Part I-Osteolog 5 , ready. Size $51-2 \times 81-2,166$ pages, 132 illustrations. Paper, 2 50; eloth....2 75 (Part II in preparation.)

MAGNER. "Standard Horse and Stock Book." By D. Magner. Comprising over 1,000 pages, illustrated with 1756 engravings. Leather binding. .......6 10

MILI.S. "How to Keep a Iog in the City." By Wesley Mills, M.D., D.V.S. It tells how to choose, manage, house, feed, educate the pup, how to keep him clean and teach him cleanliness. Paper, size $5 \times 71-2$,

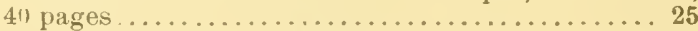

MOHLER. "Handbook of Meat Inspection." By Robert Ostertag, M.D. Transiated by Earley Vernon Wileox, A.M., Ph.D. With an introduction by John R. Mohler, V.M.D., A M. See "Ostertag."

MÖLLER - DOLLAR. (†) "Regional Veterinary surgery." See "Dollar."

MOSSELMAN-LIENAUX. " ${ }^{66}$ Manual of Veterinary Microbiology." By Professors Mosselman and Liénaux, Nat. Veterinary College, Cureghem, Belgium. Translated and edited by $R$. R. Dinwiddie, Professor of Veterinary Seience, College of Agriculture, Arkansas State University. Cloth, size $512 \times 8,342$ pages,

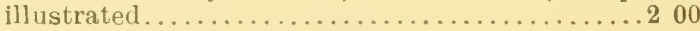

MOUSSO. (") "Diseases of Cattle, Sheep, Goats and Swine." See "Dollar."

NEUMANN. $\left({ }^{*}\right)$ "A Treatise on Parasites and Parasitic Diseases of the Domesticated Animals." A work to which the students of human or veterinary medicine, the sanitarian, agriculturist or breeder or rearer of animals, may refer for full information, regarding the external and internal Parasites-vegetable and animal-which attack various species of Domestic Animals. A Treatise by L. G. Neumaun, Professor at the National Veterinary School of Toulouse. Translated and edited by Geo. Fleming, C.B., LL. D.. F.R C.V.S. Second edition, revised and edited by James Macqueen, F.R.C.V.S., Professor at the Royal Veterinary College, Lonlon. Cloth, size $63.4 \times 10$, $\mathrm{xvi}+698$ pages, 365 illustrations .........6 75 
NOCARD. "The Animal Tuberculoses, and their Relation to IIuman 'Tuberculusis." By Ed. Nocard, Prof, of the Alfort Veterinary Collere. 'Translated by H. Scurfielı, M.D. Ed., Ph. Cimb. Clotl, $5 \times 71-2,143$ pages.. 100 Perhaps the chief interest to doctors of human mellicine in Professor Nocarl's book lies in the demonstration of the snall part played by heredity, and the great part played by contagion in the propagation of bovine tuberculosis.

VUNV. (" $)^{6}$ Veterinary Toxicology." By Joshua A. Nunn, F.R.C.V.S. The stuly of toxicology is intimately blended with other biological sciences, particularly physiology and chemistry, both of which it on many occasions overlaps. A carefully arranged and complete index is given in the front of the volume. Cloth, size $6 \times 53.4$, vii +191 pages........... 75

OSTERTAG. (") "Handbook of Meat Inspection." By Robert Ustertag, M D. Authorized Translation by Earley Vernon IVilcox, A.M., Ph.D. With an introduction by John R. Mohler, V.M.D., A.M. The work is exhaustive and authorative and has at once become the staudard authority upon the subject Second exlition, revised. Cloth, size $63-4$ × $93-4,920$ pages, 260 illustrations and 1 colored plate. ........ 50

PALLIN. (*) "A Treatise on Epizootic Lyuplangitis." By Capt. W. A. Pallin, F.R.C.V.S. In this work the author has endeavored to combine his own experience with that of other writers and so attempts to give a clear and complete account of a subject about which there is little at present in English veterinary lite:ature. Cloth, size $53-4 \times 81-2$, 90 pages, with 17 fine full page illustrations.................. 25

PEGLER. " Goat Keeping for Amatenrs." Paper, $5 \times 7 \frac{1}{2}$, 77 pages, illustrated................. 50

PELIERIN. "Median Neurotomy in the Treatment of Chronic T'endinitis and Periostosis of the Fetlock." By C. Pellerin, late repetitor of Clinic and Surgery to the Alfort Veterinary Selool. Translated, with Additional Facts Relating to It, by Prof. A. Liautard, M.D., V.M. Having rendered good results when performed by himself, the author believes the operation, which consists in dividing lie cubito-plantar nerve and in excising a portion of the peripherical end, the means of improving the conditions, and consequently the values of many apparently doomed animals. Agriculture in particular will be henefited.

The work is rliviled in' 1 wo parts. The first covers the study of Median Neurotomy itself; the second, the exact relations of the facts as observed by the author. Boards, $6 \times 91-2,61$ pages, illustrated..100 
"ETERS. "A Tuberculous Herd-Test with Tuber. culin." By Austin Peters, M. R. C. V.S., Chiof Inspector of Cattle for the New York State Board of Health during the winter of $1>92-93$. Pamphlet....25

REYNOLDS. "An Essay on the Breeding and Management of Jrauglit Horses." By $R$. S. Reynolds, M. K.C.V.S. Cloth, size $51-2 \times 83.4$, 104 pages.. 140

ROBEIGE. "The Foot of the Horse," or Lameness and all Diseases of the Feot traced to an Unbalanced Foot Bone, prevented or cured by balancing the foot. By David Roberge. Cloth, size $6 \times 9$ 1-4, 308 pages,

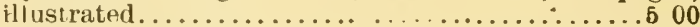

SESSI OVS. (*) "6 ('attle Tuberculosis," a Practical Guide to the Agriculturist and Inspector. By Harold Sessions, F.R.C.V.S., etc. Second edition. Size $5 \times 71-4$, vi + $1: 0$ pages............................. 00

The subject can be understood by those who have to deal palticularly with it, yet who, perhaps, have not had the necessary training to appreciate technical phruseology.

SEWEL1. "The Examination of Horses as to Sound. ness and selection as to Purchase." By Edward Sewell, M.R.U.V.S. Paper, size $51-2 \times 81.2$, 86 pages, lllustrated with 8 plates in color............ 150

.... It is a great advantage to the business man to know something of the elements of law, and nobody ought either to buy or own a horse who does not know something about the animal. That somethiug this book gives, and gives in a thoroughly excellent way....

SMITH. (") "A Manmal of Veterinary Physiology." By Vet. Capt. F. Smith, C.M.S., M K.C.V S., Examiner in Physiology, Royal College of Veterinary Surgeons, author of "A Manual of Veterinary Hygienษ." A completely reviser and enlarged edition just published. Cloth, $6 \times 83-4,720 \mathrm{pp}, 102$ illust'ns....4 25

The whole book has been carefully revised and brought up to date. All the important advances of the last few year's have been embodied. The chapter on the nervous system has been specially revised by Prof. Sherrington. whose remarkable work on the "spinal dog" has been introduced. A special point is made of the bearing of physiology on pacbology, and the utilization of physiology to the better understanding of every-day practice. The book is written by a veterinary surgeon for veterinary practitioners and students, and is the only work in the Enghish language which can clam to be purely veterinary.

- (") ${ }^{66}$ Manual of Veterinary Hygiene." Third edition revlsed. Cloth, size 5 1-4 x $71-2$, xx + 1036 pages, with 255 illustrations ........................ 75

Recognizing the rapid advance and extended field of the subject since the previous issue, the author has entirely re-written the work and enlarged its scope, whieh is brought thoroughly up to date. Contains over 500 more pages than the second edition. 
STRANGEWAX. (†) "Veterinary Anatomy." Edited by I. Vaughan, F.L.S., M.R.C V.S. New edition revised. Cloth, size $61-4$ × 9 1-2, 625 pages, 224 illus.....5 00

SUSSDORF. "Six Large Colored Wall Diagrams." By Prof. Sussdorf, M.D. (of Göttingeu). Text translated by Prof. W. Owen Williams, of the New Veterinary College, Edinburgh. Size, 44 inches by 30 inches.

$$
\begin{array}{ll}
\text { 1.- Horse. } & 4 .-0 x . \\
\text { 2. - Mare. } & 5 .- \text { Boar and Sow. } \\
\text { 3.-Cow. } & 6 .- \text { Dog and Bitch. }
\end{array}
$$

The above are printed in eight or nine colors.

Showing the position of the viscera in the large cavities of the body.

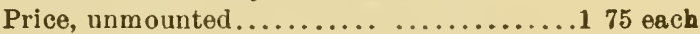

" mounted on linen, with roller........ 50 "6

THOMIPSON. †" Elementary Lectures on Veterinary Science." For agricultural students, farmers and stock keepers. By Heury Thompson, M.R.C.V.S., lecturer on Veterinary Science at the Aspatria Agricultural College. England. It is complete yet concise and an up-to-date book. Cloth, 397 pp., 51 illus..3 75

VAN MATER. " "A Text Book of Veterinary ophthahmology." By George G. Van Mater, M.D., D.V.S., Professor of Ophthalmology in the American Veterinary College; Oculist and Aurist to St. Martha's Sanitarium and Dispensary; Consulting Eye and Ear Surieon to the Twenty-sixth Ward Dispensary; Eye and Ear Surgeon, Brooklyn Eastern District Dispensary, etc. Illustrated by one chromo lithograph plate and 71 engravings. Clnth, 6 × $91-4,151$ pages...3 00 . . We intend to adopt this valuable work as a text book. $-E$. J. Creely, D. V.S., Dean of the San Francisco Veterinary College.

VETERINARY DIAGRAMS in Tabular Form. Size, $28 \frac{1}{2}$ in. $\times 22$ inches. Price per set of five...4 00 Inunted and folded in case ............... n Mounted on roller and varnished............ 1000

No. 1. "The External Form and Elementary Anatolluy of the Horse." Eight colored illustrations1. External regions; 2. Skeleton : 3. Muscles (Superior Layer); 4. Muscles (Deep Layer); 5. Respiratory Apparatus; 6. Digestive Apparatus; 7. Circulatory Apparatus : 8. Nerve Apparatus; with description....125 Mounted on roller and varnished............2 25

No. 2. "The Age of Domestic Animals." Forty-two figures illustrating the structure of the teeth, indicating the Age of the Horse, Ox, Sheep, and Dog, with full description ....................... 75 Mounted on roller and varnished..........2 00 
VETERINARY DIAGRAMS (continued).

No. 3. "The Unsommlness and befects of the Horse." Fifty figures illustrating-1. The Defects of Conformation; 2. Defects of Position; 3. Infirmities or Signs of Disease; 4. Unsoundnesses; 5 . Defects of the Foot; with full description.................... 75 Ilounted on roller und rarnished............2 00

No. 4. "The Shoeing of the Horse, Mule and 0x." Fifty figures descriptive of the Anatomy and PhysioIngy of the Foot and of Horse-shoeing. . . . . . . . . . 75 Mounted on roller and varnished............200

No. 5. "The Elementary Auatomy, Points, and Butclier"s Joints of the Ux." Ten colored illustrations -1. Skeleton; 2. Nervous System; 3. Digestive System (Right Side); 4. Respiratory System ; 5 . Points of a Fat Ox; 6. Muscular System; 7. Vascular System; 8. Digestive System (Left Side); 9. Butcher's Sections of a Calf : 10. Butcher's Sections of an Ox; with full

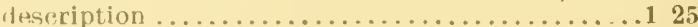
Monnted on roller and varnished...........2 25

"ILLEY. "A Practical Guide to Meat Inspection." By Thomas Walley, M.R.C.V.S., late principal of the Edlinburgh Royill (Dick) Veterinaly College; Profrassor of Veterinary Medicine and Surgery, etc. Fourth Ellition, thoroughly revised and enlarged hy Stewart Stockman, M.R.C.V.S., Professor of Pathology, Lecturer on Hygiene and Meat Inspection at Dick Veterinary College, Edinburgh. Cloth, size 5 I-2 $\times 8$ I-4, with 45 colored illus., 295 pages.....3 00

An experience of over 31$)$ years in his profession and a long official connection (some sixteen years) with Ediuburgh Abattoirs have enabled the author to gather a large store of information on the subject, which he has embodied in his book.

While Dr. Stockman is indeed indebted to the old for much useful information, this up-todate work will hardly be recognized as the old "Walley's Meat Inspection."

WILCO.Y. $\left(^{*}\right)^{66}$ Hanlbook of Meat Inspection." By Robert Ustertag, M.D. See "Ostertag."

WILLIAMS. "Priuciples and Practice of Veterinary Molicine." Author's edition, entirely revised and illu=lrater with numerous plain and colorar plates. Rv W. Williams, MI.R.C.V.S. Cloth, size $5 \ddot{\jmath}-4$ × 83.4 , 863 pages.......................... 50

- "Priuciples and Practice of Veteriuary Surgery." Author's edition, entirely revised and illustrated with numerous plain and colored plates. By W Williams, M.R.C.V.S. Cloth, size 61.2 × $91.4,756$

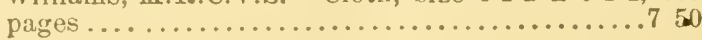


THE MOST COMPLETE, PROGRESSITE AND

SCIENTIFIC BOOK ON THE SUBJECT IN

THE ENGLISII LANGUAGE

(") WINSLOW. "Veterinary Materia Medien and Therapeuties." By Kenelm Winslow. J.A.S., MI.D.V., M.D., (Harv.); formerly Assistant Profensor of Therapeutics in the Veterinary School of Harvard University; Fellow of tie Massach usetts Medical Society; Surgeon to the Nerton Ilospital, ete.

\section{Fifth Edition, Revised and Enlarged}

Cloth, siz $61.4 \times 91-1, x+804$ pages........6 00

In accoldance with the litherto expressed rlesire of the author and mblisher's $t$ ( keep this work at its lighest point of efficiency, it has been deemed incumbent upon them to again present a new and revised edition - the fourth edition of 1906 being exhausted.

In the present revision the most notable feature is the substitution of it section on Condensed Treatment of Uiseases of the Domestic Animals tor the lnde $x$ of Diseases and Remedial Neasures, at the end if the book. In the prepration of this matter. verr considerable time and pain. have been taken to render this section a reflection and epitome of all that is most modern and progressive in veterinary therapentics.

iperial indications for treatment, including drugs and therapeutic agents other than drugs, in the different phases and stages of all the important diseases of the domestic animals are to be found. These diseases embrace not only medical and surgical disonders, but those of the EYF, SKIN and E.IR. If the attempt has been in any degree successful, this new edition to the book should prove one of its most valuable teatures both to practitioner's and students.

IIoreover, many changes have been made in the text in consonance with recent advances in our knowledge of the action of drugs.

WTMAN. $\left({ }^{*}\right)^{66}$ Bovine Obstetries," By M. G. De Bruin. Translated by W. E. A. Wyman, II.D.V., V.S. See also "De Bruin."

- (") "Catechisu of the Principles of Veterinary Surgery." Bv W. E. A. Wyman, II.D.V.,V.S. Cloth, size 6 × 9 ,

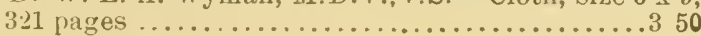

Concerning this new work altention is called to the following points:

1.-It discusses the subject upon the basis of veterinary investigations. 2.-It does away with works on human pathology, histolog $y$, etc.

3.-It explains each question thoroughly both from a scientific as well as a practical point of view

4.-It is writen by one knowing the needs of the student.

5.-It deals exhaustively with a chapter on tumors, heretofore utterly neglected in veterinary pathology.

6.-T'he only work in English specializing the snbject.

7.-The only work thoroughly taking into cousideration American as well as European investigations.

8.- Offering practical hints which have not appeared in print, the result of large city and country practice. 
WYMAN (Continued)

- $(\uparrow)$ "The Clinical Diagnosis of Lameness in the Horse." ky W. E. A. Wyman, D.V.S., formerly Professor of Veterinary science, Clemson A. \& M. College, and Veterinarian to the South Carollna Experiment Station. Cloth, size $6 \times 9$ 1-2, 182 pp., 32 illus....2 50

- $(t)^{66}$ Tibio-peroneal Neurectomy for the Relief of Sparin Lameness." By W. E. A. Wyman, M.D.V., V.S. Buards, size $6 \times 9,30$ pages, illustrated......... 50 Anyone wanting to perform this operation should procure this little treatise; he will find it of considerable help.-The Veterinary Journal.

ZUILL. "Typhoid Fever; or Contagious Influenza in the Horse." By Prof. W. L. Zuill, M.D.,D.V.S. Pamphlet, size 6 × 9 1-4, 29 pages............ 25

ZUNDEL. "The Horse's Foot and Its Diseases." By A. Zundel, Principal Veterinarian of Alsace Lorralne. Translated by Dr. A. Liautard, V.S. Cloth, size $5 \times 73-4,248$ pages, illustrated..............2 00

Auy book sent prepaid for the price

WILLIAM R. JEHKINS CO.

851 and 853 Sixth Avenue,

NEW YORK. 

DEC $12190 \%$ 



\section{LIBRARY OF CONGRESS}

III I I I I I

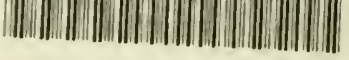

00008951,379 